UNIVERSIDADE DE SÃO PAULO

ESCOLA DE ENGENHARIA DE SÃO CARLOS

DEPARTAMENTO DE ENGENHARIA DE TRANSPORTES

ELAINE RODRIGUES RIBEIRO

Análise exploratória de método utilizando

Wavelet para detecção de padrões e anomalias

em dados históricos do tráfego veicular 



\title{
Análise exploratória de método utilizando Wavelet para detecção de padrões e anomalias em dados históricos do tráfego veicular
}

\author{
Dissertação apresentada à Escola de \\ Engenharia de São Carlos da Universidade \\ de São Paulo, como parte dos requisitos para \\ a obtenção do título de Mestre em Ciências \\ no Programa de Pós-Graduação em \\ Engenharia de Transportes.
}

Área de concentração: Planejamento e Operação de Sistemas de Transporte.

Orientador:

Prof. Doutor André Luiz Barbosa Nunes da Cunha

São Carlos 
AUTORIZO A REPRODUÇÃO TOTAL OU PARCIAL DESTE TRABALHO, POR QUALQUER MEIO CONVENCIONAL OU ELETRÔNICO, PARA FINS DE ESTUDO E PESQUISA, DESDE QUE CITADA A FONTE.

Ribeiro, Elaine Rodrigues

R484a Análise exploratória de método utilizando Wavelet para detecção de padrões e anomalias em dados

históricos do tráfego veicular/ Elaine Rodrigues

Ribeiro; orientador André Luiz Barbosa Nunes da Cunha. São Carlos, 2017.

Dissertação (Mestrado) - Programa de Pós-Graduação em Engenharia de Transportes e Área de Concentração em Planejamento e Operação de Sistemas de Transporte -Escola de Engenharia de São Carlos da Universidade de São Paulo, 2017.

1. Wavelet. 2. Reconhecimento de padrões. 3. Detecção de anomalias. I. Título. 
Dedico este trabalho aos meus pais, Nilton e Zilda, por todo apoio, confiança e esforço para que eu pudesse alcançar os meus sonhos. 



\section{AGRADECIMENTOS}

A Deus, por tudo e a todo instante.

Aos meus pais, Nilton e Zilda, por terem confiado em mim, acreditado nos meus objetivos e apoiado para que eu concluísse essa etapa da minha vida. Sei o esforço e sacrifícios que sempre fizeram por mim. Devo esta conquista a vocês e saibam que tenho muito orgulho dos pais que tenho.

Aos meus irmãos Rafael e Vinícius, por toda torcida e incentivo, mesmo distantes, nossa família sempre foi o meu alicerce. A minha irmã Eliane, meu cunhado Binho, meu sobrinho Luiz Eduardo e meu afilhado Diogo pelo carinho e a alegria em cada momento compartilhado e a compreensão da minha ausência nesta etapa.

Ao Júlio Bartolo, sempre presente com muito carinho e companheirismo e nos momentos difíceis ao longo desse trabalho, manteve a paciência e me incentivou com seus gestos e palavras. Agradeço também a família Bartolo.

Ao professor Dr. André Luiz B. N. da Cunha, por ter me aceitado como sua primeira orientada. Agradeço imensamente pela confiança investida desde o primeiro momento, pelo apoio, atenção e paciência em todas as vezes que precisei. Sinto-me privilegiada por ser sua orientada, pois sei que, academicamente, não teria amadurecido tanto ao longo do mestrado sem o seu apoio e exigência, na medida e hora certa.

Ao professor Manoel Castro Neto por participar da banca de qualificação e defesa, ao professor Cassiano Isler por participar da banca de defesa e a professora Cira Pitombo por participar da banca de qualificação. Todas as contribuições foram muito importantes para o desenvolvimento desta pesquisa.

Aos professores e funcionários do Departamento de Transportes (STT) da EESC-USP pelo convívio e amizade. Em especial aos funcionários Ana, Sabrina, Beth, Benê, Paulinho, João e Paulo Toyama pela atenção e pelos inúmeros serviços prestados.

A quatro professores em especial que a cada etapa da minha vida me direcionaram e apoiaram em um novo rumo da minha estrada: Lucia Montovani, Jalmira Fiuza, Rodrigo 
Barros e Marcos Silva (Marquinho). Agradeço também aos meus amigos Marly Leite, Gustavo Lima e Mariana do Vale, que independente da distância e do tempo, me apoiaram em cada passo.

Ao meu amigo Helder Oliveira do Departamento de Engenharia Elétrica e de Computação da EESC-USP pela amizade e diretrizes no desafio chamado Wavelet. Todas as conversas, estudos, sugestões e discussões acirradas foram essenciais para o desenvolvimento deste trabalho.

Aos amigos do grupo de pesquisa: Adriano Felicio, Bruna Kuramoto, Gabriel Oliveira, Leandro Marcomini, Mariana Thebit e Natália Panice pela amizade, momentos de descontração, discussões produtivas e incentivo nos momentos críticos da pesquisa.

Por fim, a todos os pós-graduandos do STT pela amizade, risadas e ótimo convívio. Em especial aqueles que acompanharam de perto essa jornada e que tenho muito carinho: Alisson Medeiros, Anabele Lindner, Andreza Dornelas, Andrise Buchweitz, Angélica Oliveira, Anthony Gomes, Bruno Brandimarte, Diego Camargo, Fábio Vieira, Felipe Bethonico, Fernando Piva, Francisco Moraes, José Venâncio, Luan Carvalho, Maria Cristina Miranda, Maria José Zagatto, Murilo Santos, Thaís Guerreiro, Tiago Torquato, Ramane Souza, Renaude Carneiro, Rosuel Krum, Samille Rocha e Sérgio Oliveira. 


\section{RESUMO}

RIBEIRO, E. R. Análise exploratória de método utilizando Wavelet para detecção de padrões e anomalias em dados históricos do tráfego veicular. 2017. 207 p. Dissertação (Mestrado). Escola de Engenharia de São Carlos, Universidade de São Paulo, São Carlos, 2017.

Este trabalho visa realizar uma análise exploratória de método utilizando Wavelet para analisar as variações na corrente de tráfego verificando simultaneamente os padrões no comportamento do tráfego e momentos atípicos, em diferentes escalas de tempo, através da Transformada Wavelet e métodos complementares em dados históricos do tráfego veicular. Os dados empíricos utilizados foram coletados separadamente para cada faixa de tráfego, em intervalos de curta duração (5 ou 6 minutos), em rodovias do estado de São Paulo. A partir desses dados, foram gerados os componentes de aproximação e detalhe da Transformada Wavelet Discreta de Haar. Os componentes gerados foram analisados e caracterizados antes de aplicar os métodos complementares. Para o reconhecimento de padrões no comportamento do tráfego foram utilizados os componentes de aproximação e a análise de agrupamento. Os resultados indicaram: (1) que existe grande tendência de classificar dias úteis típicos com terças, quartas e quintas-feiras, (2) a influência dos feriados na quantidade de agrupamentos, (3) a existência de diferentes efeitos para cada feriado e (4) influência do feriado de forma distinta a cada sentido da rodovia. Para detecção de momentos atípicos foram utilizados os coeficientes de detalhe e determinado um threshold em função do desvio padrão do coeficiente para determinar o que foi considerado como anomalia. Os resultados indicaram: (1) os primeiros níveis de decomposição apresentaram maior número de anomalias, (2) análises em sinais de período mensal concentraram mais anomalias do que a análise em um sinal de período anual, (3) a concentração de anomalias por tipo de dia está diretamente relacionada com o fluxo direcional e (4) identificou falhas no sensor.

Palavras-chave: Wavelet, comportamento do tráfego veicular, detecção de anomalias. 



\section{ABSTRACT}

RIBEIRO, E. R. Exploratory method analysis using Wavelet to detect patterns and anomalies in traffic history data. 2017. 207 p. Thesis (Master of Science). São Carlos School of Engineering, University of São Paulo, São Carlos, 2017.

This work aims to achieve an exploratory method analysis using Wavelet to analyze of traffic flow variations, evaluating both traffic behavior patterns and atypical moments, in different time scales, using Wavelet Transform and complementary traffic history data. Empirical data was collected separately for each traffic lane, in short intervals (5 or 6 minutes), in São Paulo state highways. The Haar's Discrete Wavelet Transform approximation and detail components were generated from this collected data. These components were analyzed and characterized before using complementary methods. For pattern recognition in traffic behavior, approximation components were used, with cluster analysis. Results indicate that: (1) there is a great tendency in classifying work days in Tuesdays, Wednesdays and Thursdays, (2) holydays have influence in number of clusters, (3) each holyday have different effects and (4) holydays have different influences in each traffic direction. For the detection of atypical moments, detail coefficients were used with a determined threshold based on the standard deviation of said coefficient to define what was considered as an anomaly. Results indicate that: (1) the first levels of decomposition show a bigger number of anomalies, (2) monthly period signal analysis concentrate more anomalies than annual signals, (3) the anomaly concentration by each kind of day is directly related to traffic direction and (4) sensor flaws are identified.

Keywords: Wavelet, vehicle traffic behavior, anomalies detection. 



\section{LISTA DE FIGURAS}

Figura 2-1 - Variação do fluxo de tráfego ao longo do dia 14/09/2011 na rodovia SP-280 km 51,9. 35

Figura 2-2 - Variação do fluxo de tráfego ao longo da semana na rodovia SP-280 km 51,9

Figura 2-3 - Variação do fluxo de tráfego ao longo de um ano entre 2011 e 2012 na rodovia SP-280 km 51,9 . .36

Figura 2-4 - Exemplo de análise de frequência com a Transformada de Fourier. . .47

Figura 2-5 - Processo de deslocamento e dilatação da Wavelet. . .49

Figura 2-6 - Representação de decomposição da Transformada Wavelet Discreta...........52

Figura 2-7 - Formas de diferentes tipos de Wavelets.................................................................55

Figura 3-1 - Rodovias em que os dados foram coletados. 59

Figura 3-2 - Fluxo de tráfego no sentido Leste no período de um ano completo na rodovia SP-280 km 51,9

Figura 3-3 - Velocidade veicular no sentido Leste no período de um ano completo na rodovia SP-280 $\mathrm{km} \mathrm{51,9.....}$ . .62

Figura 3-4 - Componentes de Aproximação e de Detalhe - Período de 24 horas .65

Figura 3-5 - Componentes de Aproximação e de Detalhe - Período de 21 horas e 20 minutos.

Figura 4-1 - Etapas do método proposto para reconhecimento de padrões no comportamento do tráfego 71

Figura 4-2 - Coeficiente de Aproximação e Detalhe no nível para um sinal no período de uma semana . .72

Figura 4-3- Resultado da análise de agrupamento com 7 clusters para o período de um ano .76

Figura 4-4 - Grupos formados para 7 agrupamentos com o $C A 4$ para o período de um ano .78

Figura 4-5 - Resultado das análises de agrupamento para o $C A_{4}$ de setembro - Leste.....79

Figura 4-6 - Grupos formados para 5 agrupamentos com o $C A_{4}$ de setembro - Leste .......80 
Figura 4-7 - Resultado das análises de agrupamento para o $C A_{4}$ de dezembro - Leste .. 80 Figura 4-8 - Grupos formados para 5 agrupamentos com o $C A_{4}$ de dezembro - Leste.... 81 Figura 4-9 - Resultado das análises de agrupamento para o $C A_{4}$ de março - Leste.......... 82

Figura 4-10 - Grupos formados para 5 agrupamentos com o $C A_{4}$ de março - Leste......... 82 Figura 4-11 - Resultados das análises de agrupamento para o $C A_{4}$ de setembro - Oeste 83

Figura 4-12 - Grupos formados para 5 agrupamentos com o $C A_{4}$ de setembro - Oeste.. 84 Figura 4-13 - Resultados das análises de agrupamento para o CA4 de dezembro - Oeste 84

Figura 4-14 - Grupos formados para 5 agrupamentos com o $C A_{4}$ de dezembro - Oeste 85 Figura 4-15 - Resultados das análises de agrupamento para o $C A 4$ de março - Oeste..... 85 Figura 4-16 - Grupos formados para 5 agrupamentos com o $C A_{4}$ de março - Oeste ......... 86 Figura 4-17 - Volume Horário Médio (VHM), Volume Horário Médio em Dias Úteis (VHMDU) e Médias dos $C A 4$ para o ano analisado ............................................... 88

Figura 4-18 - Volume Horário Médio (VHM), Volume Horário Médio em Dias Úteis (VHMDU) e Médias dos $C A_{4}$ para os meses analisados 88

Figura 4-19 - Resultados das análises de agrupamento baseado no método de Weijermars e Berkum (2005) de setembro no sentido Leste. 91

Figura 4-20 - Resultados das análises de agrupamento baseado no método de Weijermars e Berkum (2005) de dezembro no sentido Leste 91

Figura 4-21 - Resultados das análises de agrupamento baseado no método de Weijermars e Berkum (2005) de março no sentido Leste. 91

Figura 4-22 - Grupos formados para 4 agrupamentos baseado no método de Weijermars e Berkum (2005) de setembro no sentido Leste. 92

Figura 4-23 - Grupos formados para 5 agrupamentos baseado no método de Weijermars e Berkum (2005) de dezembro no sentido Leste 93

Figura 4-24 - Grupos formados para 3 agrupamentos baseado no método de Weijermars e Berkum (2005) de março no sentido Leste 93

Figura 4-25 - Volume Horário Médio para terças, quartas e quintas-feiras e Médias dos $\mathrm{CA}_{4}$ 94

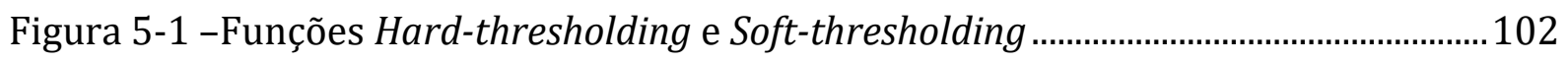

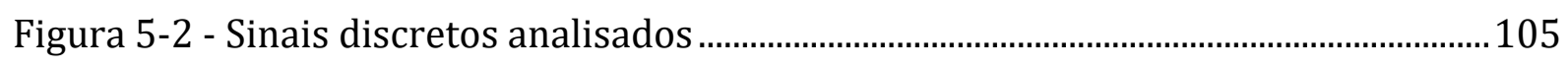

Figura 5-3 - Coeficientes de detalhe em 11 níveis......................................................................106 
Figura 5-4 - Coeficientes de detalhe gerados pelos dados de Fluxo Leste Anual de set/2011 a ago/2012 ..................................................................................... 106

Figura 5-5 - Volume Horário para as 1.000 horas mais carregadas..................................... 118

Figura 6-1 - Resultado das análises de agrupamento para o $C A 4$ - Fluxo Leste - Mesmo local em época diferente 123

Figura 6-2 - Grupos formados para 5 agrupamentos com o $C A_{4}$ - Fluxo Leste - Mesmo local em época diferente 124

Figura 6-3 - Resultado das análises de agrupamento para o $C A_{4}$ - Fluxo Oeste - Mesmo local em época diferente 125

Figura 6-4 - Grupos formados para 5 agrupamentos com o $C A_{4}$ - Fluxo Oeste - Mesmo local em época diferente 126

Figura 6-5 - Resultado das análises de agrupamento para o $C A_{4}$ - Fluxo Leste - Mesma época em locais diferentes. 128

Figura 6-6 - Grupos formados para 5 agrupamentos com o $C A_{4}$ - Fluxo Leste - Mesma época em locais diferentes.

Figura 6-7 - Resultado das análises de agrupamento para o $C A_{4}$ - Fluxo Oeste - Mesma época em locais diferentes. 131

Figura 6-8 - Grupos formados para 5 agrupamentos com o $C A_{4}$ - Fluxo Oeste - Mesma época em locais diferentes. 132

Figura 6-9 - Resultado das análises de agrupamento para o $C A_{4}$ - Fluxo Leste - Mesma época e local, via Marginal

Figura 6-10 - Grupos formados para 5 agrupamentos com o $C A_{4}$ - Fluxo Leste - Mesma época e local, via Marginal

Figura 6-11 - Resultado das análises de agrupamento para o $C A_{4}$ - Fluxo Oeste - Mesma época e local, via Marginal

Figura 6-12 - Grupos formados para 5 agrupamentos com o $C A_{4}$ - Fluxo Oeste - Mesma época e local, via Marginal 138

Figura 6-13 - Resultado das análises de agrupamento para o $C A 4$ - Fluxo Leste - Mesma época e local, Via Expressa 140

Figura 6-14 - Grupos formados para 5 agrupamentos com o $C A_{4}$ - Fluxo Leste - Mesma época e local, Via Expressa.

Figura 6-15 - Resultado das análises de agrupamento para o $C A_{4}$ - Fluxo Oeste - Mesma época e local, Via Expressa..... 
Figura 6-16 - Grupos formados para 5 agrupamentos com o $C A_{4}$ - Fluxo Oeste - Mesma época e local, Via Expressa

Figura 6-17 -- Resultado das análises de agrupamento para o $C A_{4}$ - Fluxo Leste Automóvel 145

Figura 6-18 - Grupos formados para 5 agrupamentos com o $C A_{4}$ - Fluxo Leste - Automóvel 146

Figura 6-19 - Resultado das análises de agrupamento para o $C A_{4}$ - Fluxo Oeste Automóvel 148

Figura 6-20 - Grupos formados para 5 agrupamentos com o $C A_{4}$ - Fluxo Oeste Automóvel 148

Figura 6-21 - Resultado das análises de agrupamento para o $C A_{4}$ - Fluxo Leste - Caminhão .150

Figura 6-22 - Grupos formados para 6 agrupamentos com o $C A_{4}$ - Fluxo Leste - Caminhão 151

Figura 6-23 - Resultado das análises de agrupamento para o $C A_{4}$ - Fluxo Oeste - Caminhão 153

Figura 6-24 - Grupos formados para 6 agrupamentos com o $C A_{4}$ - Fluxo Oeste - Caminhão 153

Figura 6-25 - Resultado das análises de agrupamento para o $C A_{4}$ - Fluxo Leste - Moto 155

Figura 6-26 - Grupos formados para 5 agrupamentos com o $C A_{4}$ - Fluxo Leste - Moto156 Figura 6-27 - $C D_{1}$ gerado pelos dados de velocidade das motos no sentido Leste Threshold de 169,414. 157

Figura 6-28 - Resultado das análises de agrupamento para o $C A_{4}$ - Fluxo Oeste - Moto 158

Figura 6-29 - Grupos formados para 5 agrupamentos com o $C A_{4}$ - Fluxo Oeste - Moto 158

Figura 6-30 - $C D_{1}$ gerado pelos dados de velocidade das motos no sentido Leste Threshold de 146,924. 160

Figura 6-31 - Resultado das análises de agrupamento para o $C A_{3}$ - Fluxo Norte .............162

Figura 6-32 - Grupos formados para 5 agrupamentos com o $C A_{3}$ - Fluxo Norte .............163

Figura 6-33 - Resultado das análises de agrupamento para o $C A_{3}$ - Fluxo Sul .................164

Figura 6-34 - Grupos formados para 5 agrupamentos com o $C A_{3}$ - Fluxo Sul...................165 


\section{LISTA DE TABELAS}

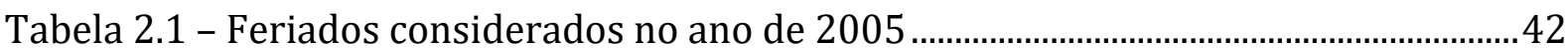

Tabela 2.2 - Critérios de dias influenciados por feriados ............................................................43

Tabela 3.1 - Sensores com porcentagem inferior a 0,0436\% de dados faltantes ..............60

Tabela 3.2 - 6 primeiros pontos do banco de dados estruturado ..........................................61

Tabela 3.3 - Quantidades de pontos em cada vetor ...................................................................63

Tabela 3.4 - Escala da janela em cada nível para os dados analisados....................................64

Tabela 3.5 - Quantidade de pontos por nível de decomposição ..................................................64

Tabela 5.1 - Feriados no período de setembro/2011 a agosto/2012 …..............................104

Tabela 5.2 - Frequência de anomalias encontradas por dia em cada nível investigado -

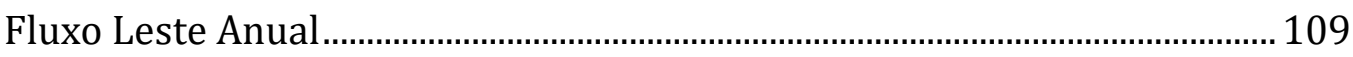

Tabela 5.3 - Anomalias que se mantiveram em no mínimo 3 níveis no Fluxo Leste Anual 110

Tabela 5.4 - Porcentagem de anomalias por tipo de dia a cada nível - Fluxo Leste Mensal

Tabela 5.5 - Anomalias no nível 11 - Fluxo Leste Mensal

Tabela 5.6 - Porcentagem de anomalias por tipo de dia a cada nível - Fluxo Oeste Mensal

Tabela 5.7 - Porcentagem de anomalias por tipo de dia a cada nível - Velocidade Leste Mensal

Tabela 5.8 - Anomalias no nível 8 - Velocidade Leste Mensal.............................................. 115

Tabela 5.9 - Anomalias no nível 11 - Velocidade Leste Mensal............................................ 115

Tabela 5.10 - Porcentagem de anomalias por tipo de dia a cada nível - Velocidade Oeste Mensal.

Tabela 5.11 - Anomalias no nível 8 - Velocidade Leste Mensal ............................................. 116

Tabela 5.12 - Anomalias no nível 11 - Velocidade Oeste Mensal.......................................... 117

Tabela 5.13 - Falhas no sensor detectadas.................................................................................. 117

Tabela 5.14 - Volume Horário para as 30 horas mais carregadas ........................................ 119

Tabela 6.1 - Frequência de anomalias encontradas por dia em cada nível investigado - 
Fluxo Leste - Mesmo local em época diferente

Tabela 6.2 - Frequência de anomalias encontradas por dia em cada nível investigado Velocidade Leste - Mesmo local em época diferente. 124

Tabela 6.3 - Frequência de anomalias encontradas por dia em cada nível investigado Fluxo Oeste - Mesmo local em época diferente. 127

Tabela 6.4 - Frequência de anomalias encontradas por dia em cada nível investigado Velocidade Oeste - Mesmo local em época diferente.

Tabela 6.5 - Frequência de anomalias encontradas por dia em cada nível investigado Fluxo Leste - Mesma época em locais diferentes 129

Tabela 6.6 - Frequência de anomalias encontradas por dia em cada nível investigado Velocidade Leste - Mesma época em locais diferentes 130

Tabela 6.7 - Frequência de anomalias encontradas por dia em cada nível investigado Fluxo Oeste - Mesma época em locais diferentes 133

Tabela 6.8 - Frequência de anomalias encontradas por dia em cada nível investigado Velocidade Oeste - Mesma época em locais diferentes 133

Tabela 6.9 - Frequência de anomalias encontradas por dia em cada nível investigado Fluxo Leste - Mesma época e local, via Marginal. 136

Tabela 6.10 - Frequência de anomalias encontradas por dia em cada nível investigado Velocidade Leste - Mesma época e local, via Marginal 136

Tabela 6.11 - Frequência de anomalias encontradas por dia em cada nível investigado Fluxo Oeste - Mesma época e local, via Marginal 138

Tabela 6.12 - Frequência de anomalias encontradas por dia em cada nível investigado Velocidade Oeste - Mesma época e local, via Marginal 139

Tabela 6.13 - Frequência de anomalias encontradas por dia em cada nível investigado Fluxo Leste - Mesma época e local, via Expressa. 141

Tabela 6.14 - Frequência de anomalias encontradas por dia em cada nível investigado Velocidade Leste - Mesma época e local, via Expressa 142

Tabela 6.15 - Frequência de anomalias encontradas por dia em cada nível investigado Fluxo Oeste - Mesma época e local, via Expressa 144

Tabela 6.16 - Frequência de anomalias encontradas por dia em cada nível investigado Velocidade Oeste - Mesma época e local, via Expressa 144

Tabela 6.17 - Frequência de anomalias encontradas por dia em cada nível investigado Fluxo Leste - Automóvel 146 
Tabela 6.18 - Frequência de anomalias encontradas por dia em cada nível investigado Velocidade Leste - Automóvel

Tabela 6.19 - Frequência de anomalias encontradas por dia em cada nível investigado Fluxo Oeste - Automóvel

Tabela 6.20 - Frequência de anomalias encontradas por dia em cada nível investigado Velocidade Oeste - Automóvel

Tabela 6.21 - Frequência de anomalias encontradas por dia em cada nível investigado Fluxo Leste - Caminhão

Tabela 6.22 - Frequência de anomalias encontradas por dia em cada nível investigado Fluxo Leste -Caminhão

Tabela 6.23 - Frequência de anomalias encontradas por dia em cada nível investigado Fluxo Oeste - Caminhão

Tabela 6.24 - Frequência de anomalias encontradas por dia em cada nível investigado Velocidade Oeste - Caminhão 154

Tabela 6.25 - Frequência de anomalias encontradas por dia em cada nível investigado Fluxo Leste - Moto. 156

Tabela 6.26 - Frequência de anomalias encontradas por dia em cada nível investigado Velocidade Leste - Moto 156

Tabela 6.27 - Frequência de anomalias encontradas por dia em cada nível investigado Fluxo Oeste - Moto 159

Tabela 6.28 - Frequência de anomalias encontradas por dia em cada nível investigado Velocidade Oeste - Moto 159

Tabela 6.29 - Escala da janela em cada nível para os dados com 5 e 6 minutos de intervalo 161

Tabela 6.30 - Frequência de anomalias encontradas por dia em cada nível investigado Fluxo Norte

Tabela 6.31 - Frequência de anomalias encontradas por dia em cada nível investigado Velocidade Norte 164

Tabela 6.32 - Frequência de anomalias encontradas por dia em cada nível investigado Fluxo Sul 166

Tabela 6.33 - Frequência de anomalias encontradas por dia em cada nível investigado Velocidade Sul 166 



\section{SUMÁRIO}

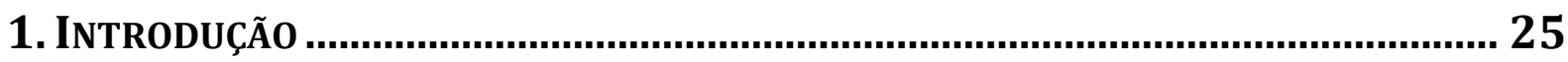

1.1. OBJETIVOS.................................................................................................................2

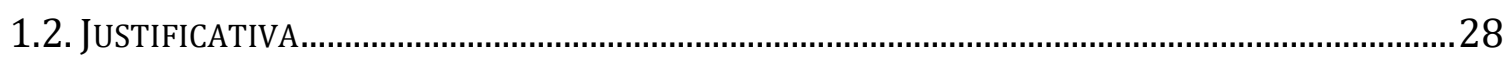

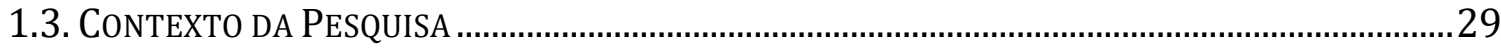

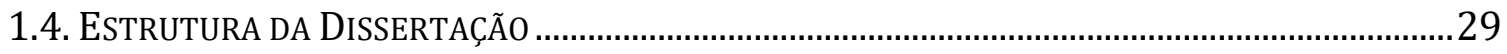

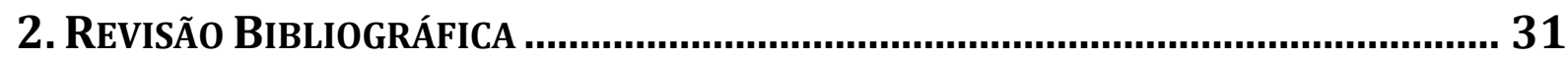

2.1. CARACTERIZAÇÃO DOS PARÂMETROS FUNDAMENTAIS DA CORRENTE DE TRÁFEGO ...................31

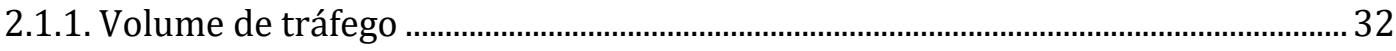

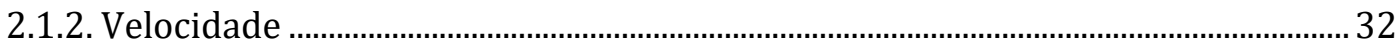

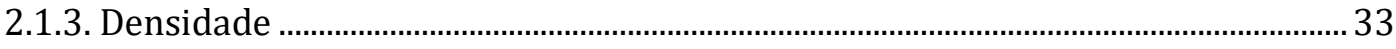

2.1.4. Variação do fluxo de tráfego.......................................................................................... 34

2.1.5. Métodos de análise da variação do fluxo de tráfego ................................................... 37

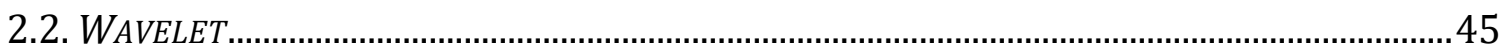

2.2.1. Apresentação da teoria Wavelet ................................................................................... 45

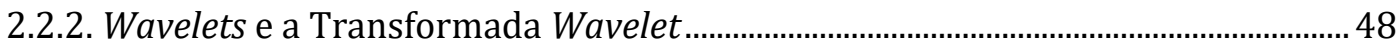

2.2.3. Transformada Wavelet Discreta - análise de multiresolução ................................. 50

2.2.4. Tipos de Wavelets ................................................................................................... 53

2.2.5. Wavelets na Engenharia de Transportes................................................................... 55

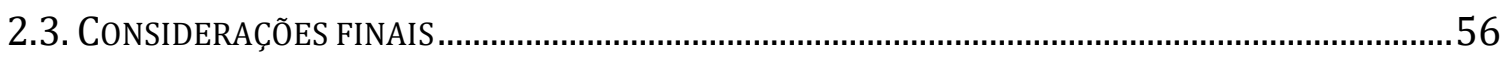

3. CARACTERIZAÇÃo do SinAl DE EnTRAdA........................................................ 57

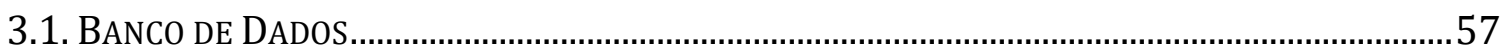

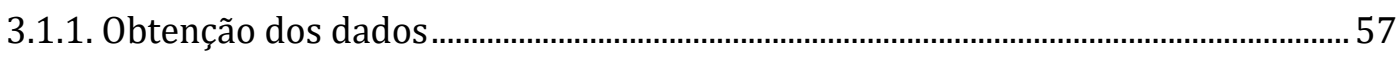

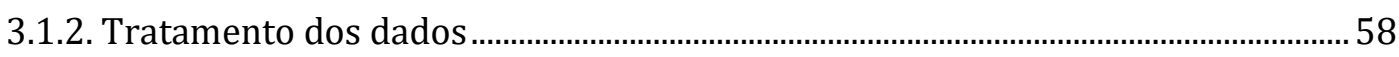

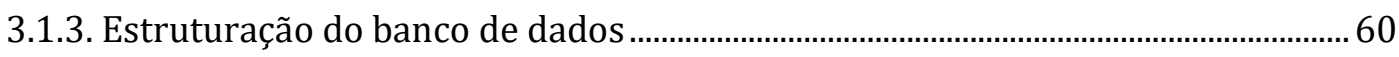

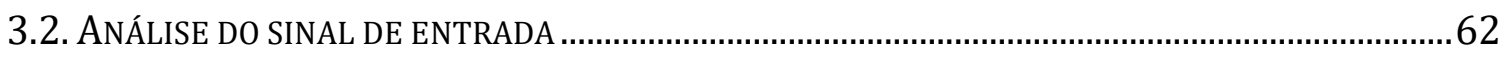

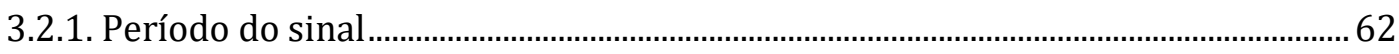

3.2.2. Definição da Wavelet e nível de decomposição ........................................................... 63 
4. ReConhecimento de PadRõES EM Dados de TRÁfEgo .....................................69

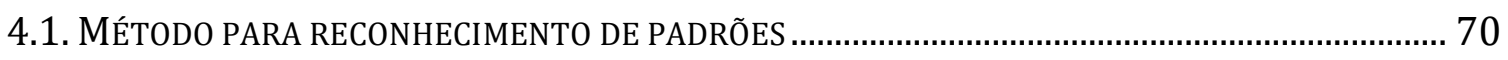

4.1.1. Escolha do coeficiente analisado …………...............................................................

4.1.2. Análise de agrupamento .................................................................................................

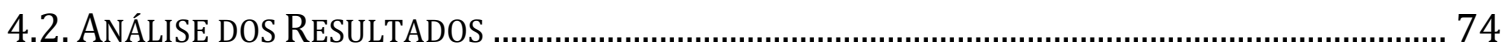

4.2.1. Análise por período ………………………………………………………………..... 75

4.2.2. Análise por fluxo direcional ......................................................................................

4.2.3. Análise comparativa com outros estudos ………………………………………........

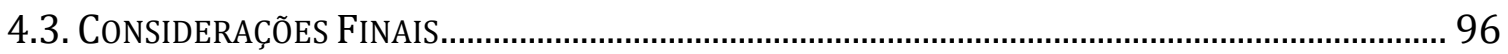

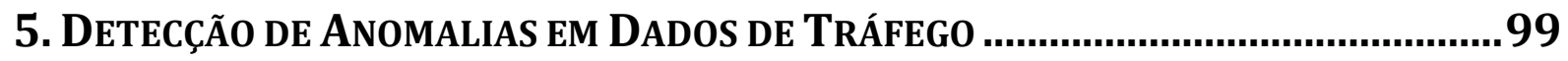

5.1. Definição de Anomalia Em Sinais de TráfEgo Veicular Utilizando a Transformada

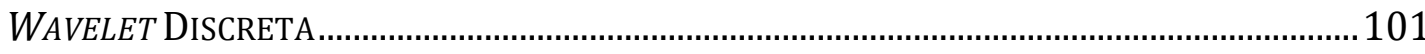

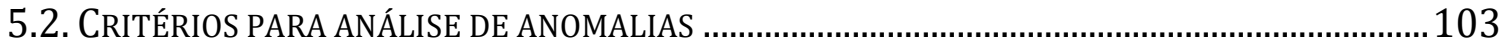

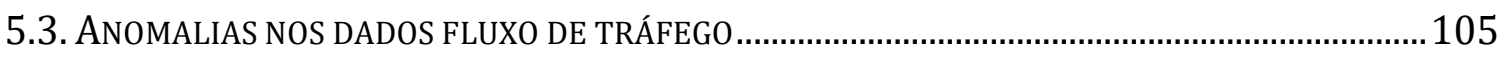

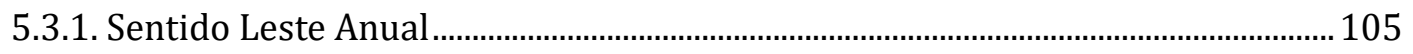

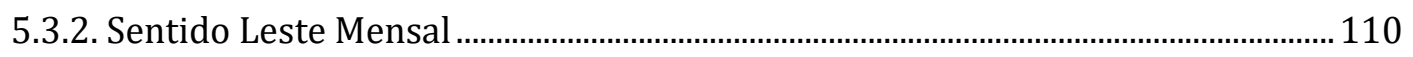

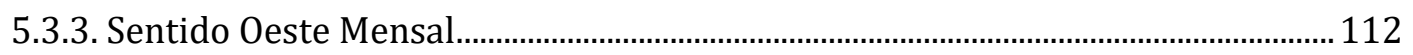

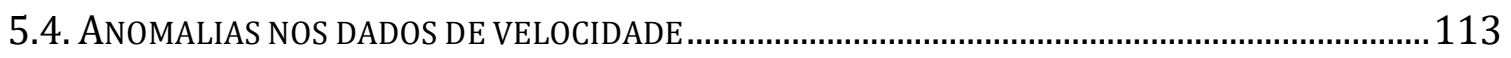

5.4.1. Sentido Leste Mensal ............................................................................................. 114

5.4.2. Sentido Oeste Mensal............................................................................................... 115

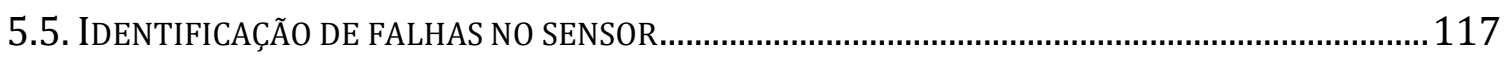

5.6. AnÁlise Comparativa Com o Volume HorÁRIo PERCENTUAL............................................118

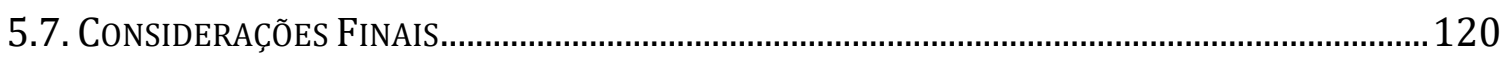

\section{APliCaÇão do MÉTodo em DifEREnTES Condições de TrÁFEgo ................... 121}

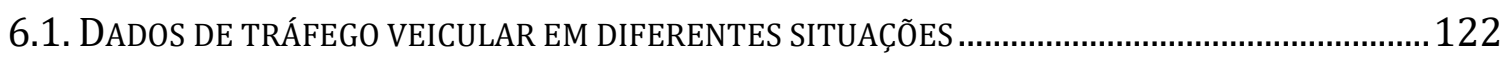

6.1.1. Mesmo local em época diferente ………………................................................... 122

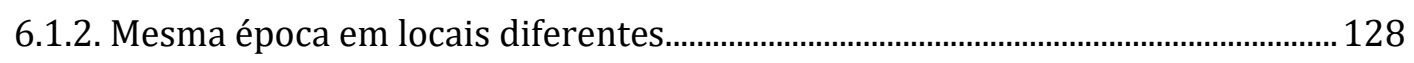

6.1.3. Mesma época e local, vias diferentes ..................................................................... 134

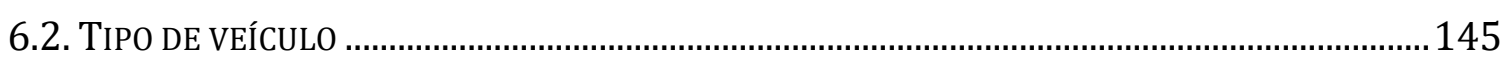

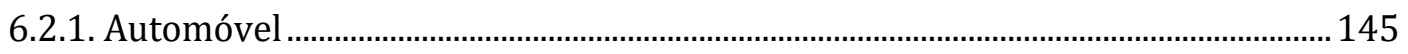




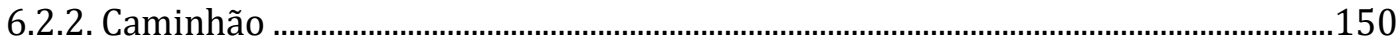

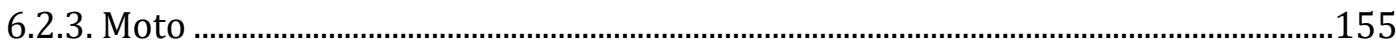

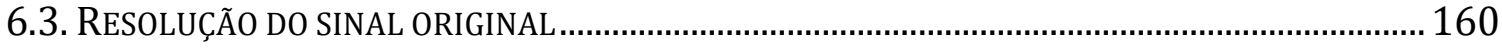

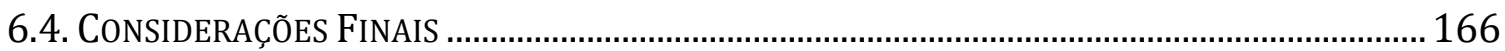

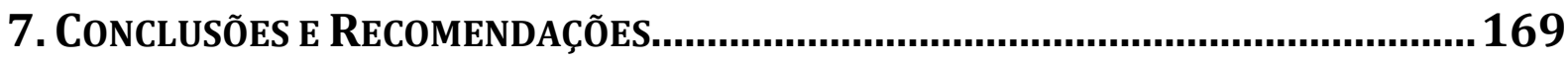

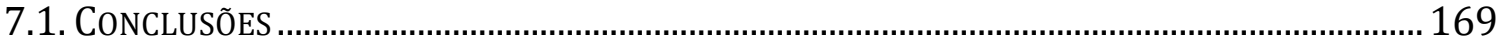

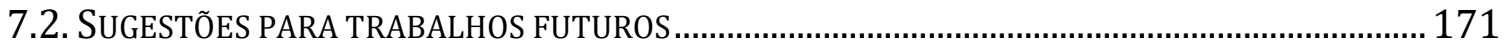

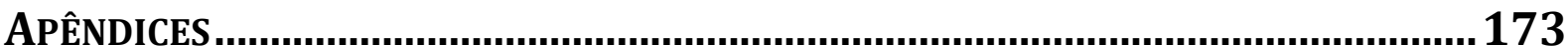

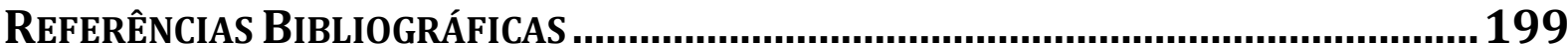





\section{INTRODUÇÃO}

O estudo de tráfego é etapa essencial na Engenharia de Transportes, tendo como propósito obter parâmetros que descrevam o comportamento do tráfego e a composição da frota de veículos. Três variáveis básicas podem ser usadas para descrever o tráfego em qualquer via: fluxo de tráfego, velocidade veicular e densidade (TRB, 2010).

O fluxo ou volume de tráfego representa a quantidade, o sentido e a composição da quantidade de veículos que passam por um ou vários pontos durante determinado período de tempo. As informações do volume de tráfego podem ser usadas na análise de capacidade, na avaliação das causas de congestionamento e de elevados índices de acidentes, no dimensionamento do pavimento, nos projetos de canalização do tráfego e outras melhorias (DNIT, 2006). Uma característica marcante e inerente do fluxo de tráfego é a sua variação, tanto temporal - minuto, hora, dia, semana, mês e no ano - quanto espacial - em diferentes locais, sentido de tráfego e segundo a faixa de tráfego analisada.

A velocidade é uma das características essenciais do tráfego e uma das mais complexas de se determinar (DNIT, 2006). A velocidade média apresenta dois conceitos bem distintos: velocidade média no tempo (Time Mean Speed - TMS) e velocidade média no espaço (Space Mean Speed -SMS), que podem produzir valores diferentes. Basicamente, a TMS é uma medida pontual, enquanto a SMS é uma medida relativa a um comprimento da estrada ao longo de um determinado período de tempo (ROESS; MCSHANE; PRASSAS, 1998). O levantamento da velocidade em campo pontualmente, determina as velocidades dos veículos no instante em que eles passam por um determinado ponto ou seção da via. Este tipo de velocidade é fundamental na engenharia de tráfego para a análise das condições de segurança na circulação, pois reflete o desejo dos motoristas em trafegar com as velocidades que julgam adequadas para as condições geométricas, ambientais e de tráfego existentes no local (DNIT, 2006).

Segundo o Highway Capacity Manual (HCM) (TRB, 2010), a densidade é um parâmetro crítico para instalações de fluxo ininterrupto, pois caracteriza a qualidade das operações de trânsito, descrevendo a proximidade que os veículos estão um dos outros, o 
que reflete na liberdade de manobra dentro do fluxo de tráfego.

A análise dessas três variáveis permite obter um panorama global da fluidez do tráfego, mesmo que o comportamento do tráfego seja dinâmico no tempo. De modo geral, pode-se afirmar que o comportamento do tráfego em dias típicos ocorre na maior parte do tempo, enquanto que os dias de pico podem ser considerados eventos anômalos. No entanto, as definições encontradas na literatura remetem às horas de pico (TRB, 2010; DNIT, 2006) e o comportamento de dias típicos deve ser realizado por métodos empíricos.

Na literatura, métodos empíricos são raros de serem encontrados, dentre esses o de Weijermars e Berkum (2005) e de Cunha (2007) propuseram o conceito de dia típico de tráfego e apresentaram resultados satisfatórios para as pesquisas em que foram empregados. Porém, algumas restrições podem ser citadas: (1) os métodos são altamente dependentes da experiência do pesquisador para a definição dos eventos regionais que interferem no tráfego veicular da região estudada; (2) a escolha da unidade de representação do fluxo, tal como o volume horário médio (VHM), pode suavizar o impacto de anomalias ocorridas em intervalos menores (dentro da hora), distorcendo ou perdendo totalmente a informação original, tais como gargalos, falhas em sensores, acidentes ou incidentes (ZHENG; WHASHINGTON, 2012; ZHENG et al., 2011).

Outra forma de analisar os parâmetros do tráfego é a partir do processamento digital de sinais. Para utilizar essa análise, os dados de tráfego devem ser coletados continuamente no tempo (sinal contínuo) e então convertidos por amostragem em uma sequência numérica em função do tempo (sinal discreto). Portanto, um banco de dados contendo parâmetros de tráfego amostrados em intervalos determinados de tempo é um sinal discreto.

Para o processamento digital de sinais há diversas técnicas computacionais que podem analisar o sinal no domínio da frequência ou no domínio do tempo. No domínio da frequência são estudadas quais frequências estão presentes no sinal, e no domínio do tempo estuda-se a amplitude do sinal a cada instante de tempo. Para analisar sinais estacionários (sinal que não possui sempre a mesma frequência ao longo de todo o período de tempo) é comum utilizar a Transformada de Fourier. Essa técnica contém o maior número de aplicações práticas, utilizada nas mais diversas áreas das ciências aplicadas, inclusive engenharia, tendo um papel central nas telecomunicações modernas e também no processamento digital de imagens (BARBOSA; BLITZKOW, 2008). A 
vantagem da Transformada Discreta de Fourier (do inglês DFT - Discrete Fourier Transform) é que permite, a partir de um sinal no domínio do tempo, obter o sinal correspondente no domínio da frequência. Entretanto, a desvantagem da DFT é que nada se conhece da localização dessas frequências, o que pode ser um problema quando analisamos um sinal não estacionário, ou seja, um sinal que não possui sempre a mesma frequência ao longo de todo o período de tempo para o qual foi definido (GUIDO; SLAETS; ALMEIDA, 2012).

Para suprir as limitações da DFT, uma nova técnica de processamento de sinais foi desenvolvida, a Transformada Wavelet (TW) (BARBOSA; BLITZKOW, 2008). As Wavelets são funções capazes de decompor e descrever uma série de dados no domínio do tempo, as quais permitem analisar esses dados em diferentes escalas de frequência e de tempo. Para a área de engenharia de transportes, isso representa analisar todas as características do tráfego sem implicar em distorções ou perda de informações do sinal original, pois extrai informações locais no domínio do tempo em sinais não estacionários (ZHENG; WHASHINGTON, 2012).

Zheng e Washington (2012) afirmam que com outras técnicas de mineração de dados - análise de agrupamento, lógica fuzzy e redes neurais - a Transformada Wavelet pode ser usada para identificar questões relacionadas ao trânsito, demonstrando o potencial das Wavelets na análise de dados de tráfego não estacionários ou ruidosos. Entre as aplicações da TW na Engenharia de Transportes, encontram-se: detecção automática de incidentes de autoestrada, características do tráfego em torno de autoestrada em zonas de trabalho, previsão do fluxo de tráfego, reconhecimento de padrões de tráfego e detecção de oscilações do tráfego.

\subsection{OBJETIVOS}

A meta desta pesquisa é realizar uma análise exploratória da aplicação da Transformada Wavelet em dados históricos de tráfego veicular para identificação e representação automática das variações do comportamento da corrente de tráfego Para tanto, foram propostos os seguintes objetivos específicos:

a) Definir a família Wavelet e a escala de tempo a ser usada nos dados da corrente de tráfego; 
b) Reconhecer padrões no comportamento do tráfego veicular em rodovias;

c) Detectar anomalias do tráfego veicular em rodovias.

\subsection{JUSTIFICATIVA}

Os métodos empíricos comumente utilizados para análise dos parâmetros básicos da corrente de tráfego apresentam limitações que podem ocasionar suavizações, distorções ou perdas das características originais do tráfego, seja pela técnica utilizada ou pela pré-classificação dos dados. Com base nisso, a justificativa deste trabalho se dá pelos seguintes fatores:

a) Ausência de um consenso para definir dias úteis típicos: na literatura é encontrada a conceptualização de volume médio diário em dias úteis, o qual excluem os finais de semana (ROESS; MCSHANE; PRASSAS, 1998) mas não analisam as variações do comportamento de tráfego durante os dias úteis da semana. Pode ser encontrado também métodos empíricos que pré-classificam o banco de dados em dias úteis ou fins de semana (WEIJERMARS; BERKUM, 2005) ou excluem os fins de semanas, feriados e dias influenciados pelo mesmo (CUNHA, 2007), mas esses métodos variam conforme o objetivo da pesquisa e banco de dados utilizados, assim como dependem da experiência do pesquisador para definir quais dados serão utilizados e quais dados serão excluídos;

b) Falta de um método de análise do comportamento do fluxo de tráfego em diferentes períodos: $\mathrm{Na}$ literatura referente a análise de comportamento padrão do fluxo de tráfego, os dados atípicos que podem perturbar esse comportamento geralmente são excluídos ou ignorados, no entanto, uma análise conjunta do comportamento padrão e momentos atípicos pode proporcionar melhores avaliações dessas variações;

c) Análise exploratória da teoria Wavelet aplicada em Engenharia de Transportes. Apesar de ser uma técnica relativamente nova, estudos pioneiros têm demonstrado o potencial das Wavelets na análise de dados de tráfego. No entanto ainda faltam alguns fundamentos teóricos e orientações do 
seu uso (ZHENG; WHASHINGTON, 2012). Em especial, na aplicação dessa ferramenta em dados de tráfego, possibilitando que o engenheiro de transportes possa utilizar na prática.

\subsection{CONTEXTO DA PESQUISA}

Este trabalho faz parte de uma linha de pesquisa desenvolvida no Departamento de Transportes da Escola de Engenharia de São Carlos, pelo Prof. Dr. André Luiz B. N. da Cunha, visando o tratamento de dados com técnicas de processamento digital de sinais. Introduzindo essa linha de pesquisa, esse trabalho pretender realizar uma primeira análise exploratória da Transformada Wavelet e sua aplicação em dados do tráfego veicular.

De modo geral, esta pesquisa propõe um novo método que auxilie nas análises de variações do fluxo de tráfego em diferentes escalas e na classificação de dias típicos de tráfego, devido à importância desse comportamento em diversas áreas da Engenharia de Transportes. Nesse contexto, a teoria Wavelet é uma ferramenta útil e a proposta deste trabalho é apresentar de forma clara a sua aplicação e utilização em dados de tráfego veicular. No entanto, outros dados de séries temporais dentro da Engenharia de Transportes podem receber o tratamento de Wavelets, como por exemplo, no monitoramento de estruturas de pontes de concreto, que utiliza a Transformada Wavelet como filtro para avaliar as frequências da ponte que são geradas pelos resíduos da dupla diferença de fase do sinal GPS (Global Position System) (LAROCCA et al., 2014).

\subsection{ESTRUTURA DA DISSERTAÇÃO}

Esta dissertação é dividida em sete capítulos, incluindo este primeiro capítulo introdutório o qual apresenta a justificativa, objetivo e contexto da pesquisa. No Capítulo 2 é realizada uma revisão bibliográfica contendo os fundamentos básicos da Engenharia de Tráfego e da Transformada Wavelet, assim como trabalhos aplicados em Engenharia de Transportes que utilizaram a Transformada Wavelet.

O Capítulo 3 descreve como foi realizada a coleta dos dados e a amostragem para 
um sinal discreto. Em seguida, são apresentados os coeficientes gerados pela Transformada Wavelet a partir desse sinal de entrada.

O Capítulo 4 apresenta o procedimento para reconhecimento de padrões descrevendo o coeficiente utilizado, o método complementar a Transformada Wavelet e uma análise dos resultados obtidos. 0 Capítulo 5 por sua vez relata o procedimento utilizado para detecção de anomalia, também descrevendo o coeficiente utilizado, o método auxiliar a Transformada Wavelet e uma análise dos resultados obtidos.

O Capítulo 6 traz a aplicação da análise exploratória dos procedimentos utilizados nesta pesquisa para o reconhecimento de padrões e detecção de anomalias em diferentes situações de tráfego veicular. Por fim, o Capítulo 7 apresenta as conclusões desta pesquisa e sugestões para pesquisas futuras. 


\section{REVISÃO BIBLIOGRÁFICA}

Este capítulo descreve a revisão da literatura sobre a caracterização dos parâmetros básicos do fluxo de tráfego e a Wavelet, objetos de estudo desta pesquisa de dissertação de mestrado. Na primeira seção são sintetizados os principais conceitos encontrados na literatura em relação aos parâmetros básicos do fluxo de tráfego - volume de tráfego, velocidade veicular e densidade - e seu uso em diferentes áreas da Engenharia de Transportes. Em seguida, são apresentados e discutidos a variação do fluxo de tráfego e os métodos para análise dessas variações.

Na segunda seção são introduzidos os conceitos básicos relacionados à Wavelet. Inicia-se com uma referência em ordem histórica dos métodos de Processamento de Sinais, seguido de maior detalhamento da Transformada Wavelet, método escolhido para desenvolvimento deste trabalho. Como esta pesquisa é multidisciplinar, esses conceitos são essenciais para seu desenvolvimento e compreensão. Por fim, são apresentadas as aplicações da Transformada Wavelet em diferentes áreas da Engenharia de Transportes.

As principais conclusões desta pesquisa estão resumidas nas considerações finais deste capítulo, a fim de embasar os procedimentos metodológicos propostos nos capítulos seguintes para definir padrões no comportamento de tráfego e detectar anomalias.

\subsection{CARACTERIZAÇÃO DOS PARÂMETROS FUNDAMENTAIS DA CORRENTE DE TRÁFEGO}

Esta seção apresenta os três parâmetros fundamentais da corrente de tráfego e suas aplicações na Engenharia de Transportes. Em seguida, são indicadas as variações espacial e temporal do volume de tráfego. Por fim, é apresentado e discutido alguns dos métodos de análise dessas variações. 


\subsubsection{Volume de tráfego}

O volume de tráfego representa o número total de veículos que passam em uma determinada seção da via durante um intervalo específico de tempo (ROESS; MCSHANE; PRASSAS, 1998). Os intervalos de tempo usados podem ser em termos de período anual, mensal, diário, horário e até sub-horário. Volume é uma variável que quantifica a demanda, ou seja, o número de veículos que passam por um determinado ponto ou instalação durante um período de tempo específico (TRB, 2010). May (1990) ressalta que por isso, as medições de tráfego têm diversos usos no planejamento, projeto e operação do sistema viário.

No planejamento, os dados de volume de tráfego são usados principalmente como suporte para tomada de decisões em um nível tático-estratégico, fornecendo informações para classificação funcional das vias, identificação de tendências de tráfego, alimentação e calibração de simuladores e modelos de previsão de demandas, avaliação de políticas públicas, previsão de impostos, dimensionamento de recursos de gestão do tráfego, entre outras atividades. Sendo assim, o volume de tráfego desempenha uma função crucial, considerando que, na prática, as avaliações econômicas de políticas de transportes são baseadas na projeção de volumes de tráfego providos por modelos de planejamento. É importante assegurar que esses modelos estejam devidamente calibrados e validados para as condições locais (OLIVEIRA, 2004).

Na etapa de projeto, no entanto, é preferível quantificar o volume de tráfego com a finalidade de dimensionamento e manutenção de vias (WRIGHT et al., 1997), capacidade e segurança viária (SPINDOLA; GRISALES, 1995) e no suporte a diretrizes de projetos de novos empreendimentos em função do seu impacto na circulação viária (BONNESON, 1987). A análise operacional requer medidas de volume para o controle semafórico, análises de acidente, nível de serviço atual, na avaliação de melhorias operacionais, avaliação da qualidade do ar e auxílio a sistemas de informação ao usuário (OLIVEIRA, 2004).

\subsubsection{Velocidade}

Outro parâmetro que descreve o comportamento do tráfego veicular é a velocidade. A velocidade representa uma taxa de movimento, expressa geralmente em quilômetros 
por hora $(\mathrm{km} / \mathrm{h})$, definida pela razão da distância pelo tempo (TRB, 2010). Em um fluxo de tráfego em movimento, cada veículo viaja a uma velocidade diferente. Portanto o fluxo de tráfego não possui somente uma velocidade característica, mas sim uma distribuição da velocidade individual do veículo (ROESS; MCSHANE; PRASSAS, 1998).

A velocidade média pode ser estimada de dois modos: velocidade média no tempo (Time Mean Speed - TMS) e velocidade média no espaço (Space Mean Speed -SMS). Os conceitos são bem distintos e, basicamente, a TMS é uma medida pontual, enquanto a SMS é uma medida relativa a um comprimento da estrada ao longo de um determinado período de tempo. Matematicamente, a TMS é uma média direta de velocidades individuais do veículo, enquanto a SMS é uma média harmônica (ROESS; MCSHANE; PRASSAS, 1998).

O levantamento da velocidade em campo pontualmente determina as velocidades dos veículos no instante em que eles passam por um determinado ponto ou seção da via. Este tipo de velocidade é fundamental na engenharia de tráfego para a análise das condições de segurança na circulação, pois reflete o desejo dos motoristas em trafegar com as velocidades que julgam adequadas para as condições geométricas, ambientais e de tráfego existentes no local (DNIT, 2006). A velocidade é de fundamental importância na engenharia de tráfego para definições de condições de segurança em projetos viários, como velocidade de tráfego e geometria da via (rampas e curvas).

\subsubsection{Densidade}

Por fim, a densidade também é um parâmetro fundamental da corrente de tráfego. Densidade representa o número de veículos que ocupa um dado comprimento da via em um instante particular. Geralmente é expressa como veículos por quilômetro (veic/km) ou carro de passeio por quilômetro ( $\mathrm{pc} / \mathrm{km}$, do inglês passenger car). Ao contrário das duas medidas anteriores, a densidade é uma variável difícil de obter diretamente no campo. Uma forma de obtê-la é através de imagens sucessivas de trechos da rodovia. Por outro lado, a forma indireta de determinação da densidade é utilizando a relação da taxa de fluxo pela velocidade média, expressa geralmente em veículo por quilômetro (veic/km). A densidade é um parâmetro crítico para instalações de fluxo não interrompido porque caracteriza a qualidade das operações de trânsito (TRB, 2010). 


\subsubsection{Variação do fluxo de tráfego}

Uma característica marcante e inerente do fluxo de tráfego é a sua variação temporal - minuto, hora, dia, semana, mês e no ano - e espacial - em diferentes locais, sentido de tráfego e segundo a faixa de tráfego analisada. Essas variações podem ocorrer devido a efeitos conhecidos e predeterminados, por exemplo, o período do dia, o dia da semana, feriados ou segundo as características geométricas e funcionais da via. Outro conjunto de fatores que pode influenciar nessa variação, não são predeterminadas, mas as causas são conhecidas, incluem por exemplo, as condições de tempo ou a ocorrência de incidentes em vias próximas (OLIVEIRA, 2004).

Essas variações estão diretamente relacionadas com o comportamento da corrente de tráfego, objeto de estudo dessa dissertação, por isso, nesta seção são apresentados e discutidos os principais aspectos das diferentes formas de variação do volume de tráfego, de modo a auxiliar a compreensão das discussões e do contexto em que se insere essa pesquisa, assim como as análises propostas nos próximos capítulos.

\subsubsection{Variação temporal}

O volume de tráfego pode variar em diversas escalas de tempo desde variação horária até a variação anual, passando por uma variação semanal e mensal. É importante analisar e compreender os padrões dessas variações para possibilitar a estimativa do fluxo de tráfego em determinados períodos do tempo baseado no conhecimento e expansão do fluxo de tráfego em outros períodos (MAY, 1990). A seguir, são indicados as diferentes formas de variação temporal e os principais fatores que influenciam o seu comportamento.

a) Variação horária: é a principal variação para o analista de tráfego, pois reflete diretamente as variações dos sistemas de atividade humana (CET, 1982). Existem muitos fatores que afetam as distribuições horárias do volume de tráfego, tais como as características geométricas e operacionais da via, e os padrões de uso do solo associado com a rede viária. Quaisquer mudanças destes fatores podem afetar as distribuições horárias com o passar do tempo (OLIVEIRA, 2004). Como exemplo, a Figura 2-1 ilustra o fluxo de tráfego a cada 5 minutos do dia 14/09/2011 no km 51,9 da rodovia Presidente Castelo Branco (SP-280) no estado de São Paulo. Nota-se que o comportamento do tráfego varia dentro do 
intervalo de uma hora e a cada hora ao longo do dia.

Figura 2-1 - Variação do fluxo de tráfego ao longo do dia 14/09/2011 na rodovia SP-280 km 51,9

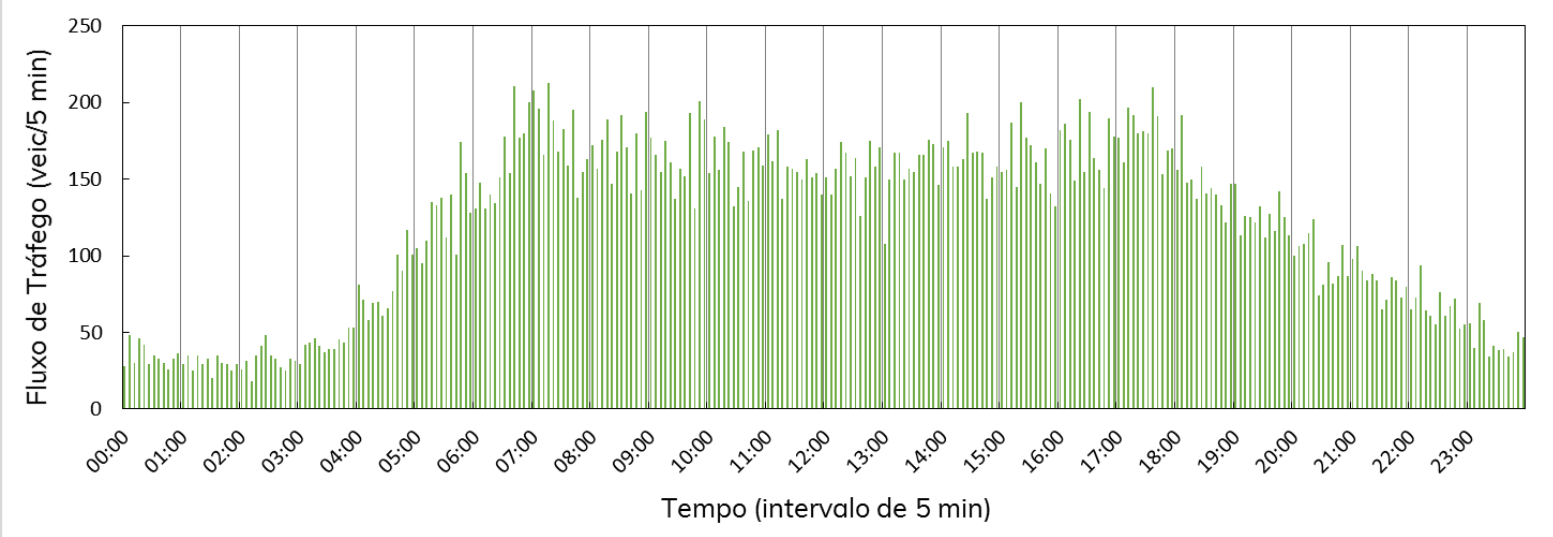

Fonte: Elaborada pelo autor

b) Variação diária: é a variação do volume de tráfego entre os diferentes dias da semana. Oliveira (2004) alega que embora essa característica varie geograficamente, o volume diário médio entre os dias úteis e finais de semana diferem entre si. Para ilustração, a Figura 2-2 apresenta um exemplo de variação do fluxo de tráfego durante uma semana, com início no domingo (11/09/2011 00:00) e fim no sábado (17/09/2011 23:59). Visualmente, é possível notar uma diferença no comportamento do fluxo de tráfego no domingo perante o restante dos dias da semana, pois o domingo apresentou a maior concentração do fluxo de tráfego. 0 sábado também apresentou uma curva dissemelhante ao restante da semana, mas não se sobressaiu com um valor alto no fluxo de tráfego. Nota-se também uma diferença sutil na variação do fluxo de tráfego nos dias 12 (segundafeira) e dia 16 (sexta-feira), enquanto os dias 13,14 e 15 (terça, quarta e quintafeira, respectivamente) não apresentaram grandes variações entre si. 
Figura 2-2 - Variação do fluxo de tráfego ao longo da semana na rodovia SP-280 km 51,9

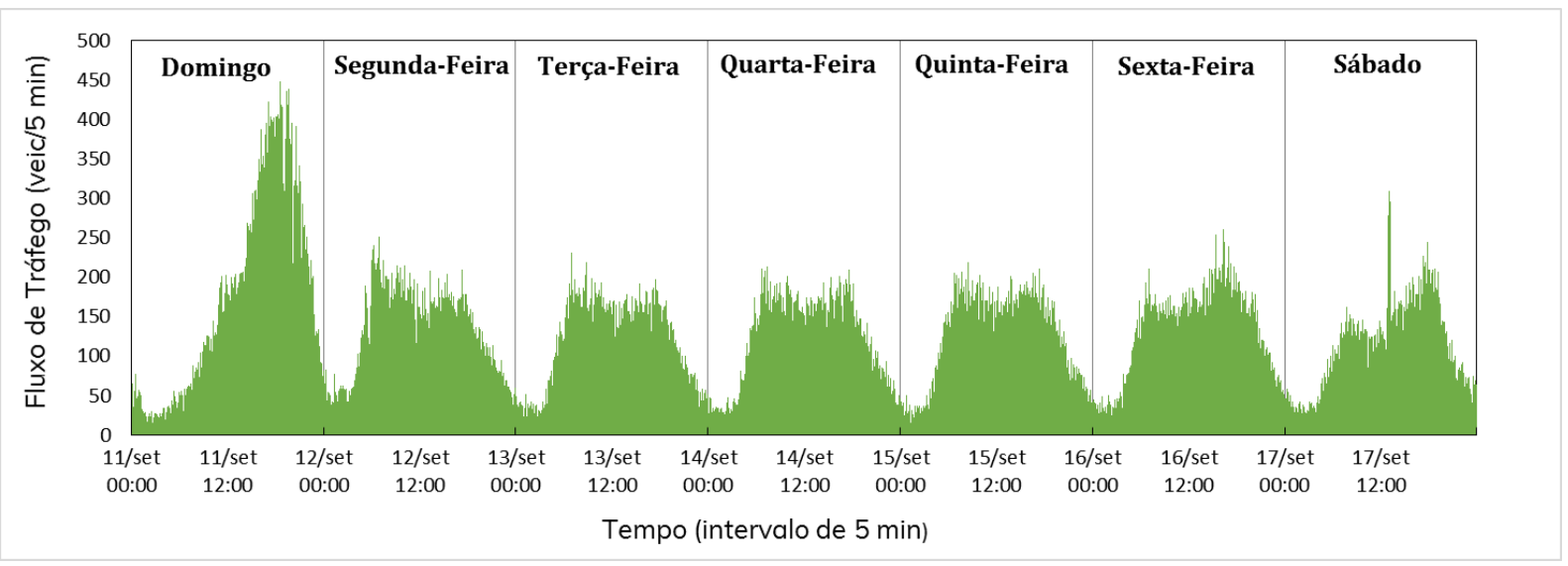

Fonte: Elaborada pelo autor

c) Variação mensal: cada mês do ano apresenta volumes de tráfego diferentes. As variações mensais estão relacionadas basicamente pelo tipo de rota (residencial, comercial, recreacional, etc.) e pela natureza das atividades presentes nos entornos (ROESS; MCSHANE; PRASSAS, 1998). Como exemplo, a Figura 2-3 ilustra o volume diário ao longo de um ano completo. Novamente, é possível notar certo padrão no comportamento dos dias ao longo do ano, no entanto, alguns períodos tem uma oscilação maior, como no exemplo, os dias 30 e 31 de dezembro (véspera de Ano Novo - A), a última semana de fevereiro (Carnaval B), a primeira semana de abril (Páscoa - C) e primeira semana de junho (Corpus Christi - D) e cada mês acaba se destoando uns dos outros.

Figura 2-3 - Variação do fluxo de tráfego ao longo de um ano entre 2011 e 2012 na rodovia SP-280 km 51,9

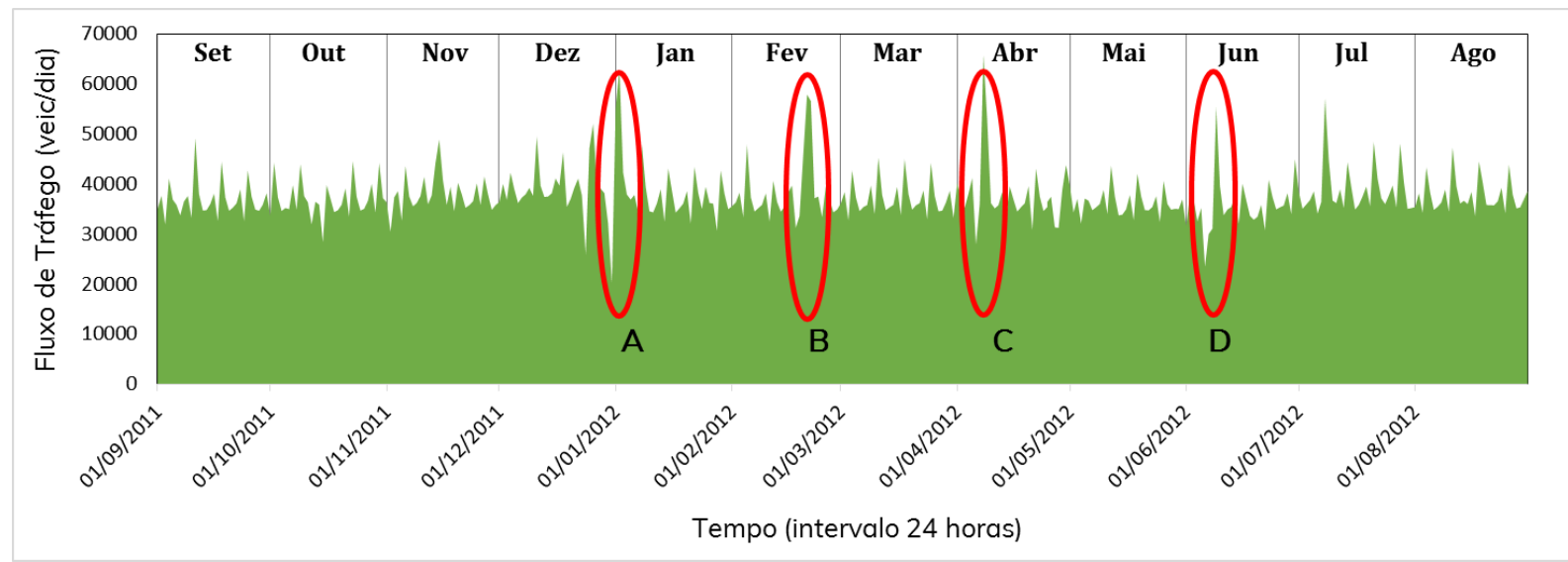

Fonte: Elaborada pelo autor 
d) Variação anual: o volume de tráfego normalmente apresenta variações anuais que refletem as mudanças econômicas e sociais da região. Essa variação indica a tendência a longo prazo, sendo uma importante estratégia para o analista na alimentação de modelos de projeção de demanda, como também para gestores públicos em relação à previsão a destinação de recursos em infraestrutura (OLIVEIRA, 2004).

\subsubsection{Variação espacial}

A variação espacial do volume de tráfego depende principalmente das diferentes funções da via e características da região a que atende. Uma das formas da variação espacial é o padrão direcional ao longo de rotas específicas (MAY, 1990). Ou seja, no período da manhã o fluxo pode ser predominante em um sentido e no sentido inverso no período da tarde. Wright et al. (1997) corrobora com essa característica e ressalta que é necessário a monitoração do tráfego em ambos os sentidos de direção.

Existem outras formas de variação espacial, entre elas as proporções de movimentos de conversão e a distribuição do volume entre as faixas de tráfego da via (OLIVEIRA, 2004).

Além da variação espacial, há variações especiais que interferem diretamente no tráfego como eventos esportivos, culturais e religiosos, os quais provocam alterações previsíveis, permitindo que o engenheiro de tráfego determine e aplique as medidas cabíveis para solução ou minimização dos problemas. Acidentes, incêndios, inundações, alterações da ordem pública podem ser estudados de antemão, para se dispor de medidas para adaptação e aplicação a esses casos (DNIT, 2006).

\subsubsection{Métodos de análise da variação do fluxo de tráfego}

0 volume de tráfego pode ser classificado de diferentes formas, devido às suas características dependerem basicamente de suas dimensões temporal e espacial, ligado ao sistema de atividades humanas e socioeconômicas em que a via está inserida (REIS, 2001, apud OLIVEIRA, 2004).

Geralmente, as aplicações do volume de tráfego seguem as seguintes representações: Volume Horário, Taxa de Fluxo e Volume Médio Diário. No entanto, a 
literatura conceitual se refere a várias representações para volumes diários, volumes horários e volumes sub-horários. Essas variações estão diretamente relacionadas ao comportamento da corrente de tráfego, por isso, nesta seção são apresentados e discutidos os principais aspectos das diferentes formas de variação do volume de tráfego, de modo a auxiliar a compreensão das discussões e do contexto em que se insere essa pesquisa, assim como as análises propostas nos próximos capítulos.

\section{Volumes Diários}

Os Volumes Diários são frequentemente utilizados como base para o planejamento de estradas e observações gerais de tendências. Segundo Aunet (2000), o Volume Médio Diário Anual representa a estatística de dados de tráfego mais utilizada. Quatro parâmetros de volume diário principais foram difundidos (ROESS; MCSHANE; PRASSAS, 1998):

a) Volume Diário Médio Anual (do inglês Average Annual Daily Traffic - AADT): é a quantidade total de veículos que passam por um determinado local durante um ano completo dividido por 365, obtendo assim uma média de tráfego de 24 horas para aquele ano.

b) Volume Diário Médio Anual em Dias Úteis (do inglês Average Annual Weekday Traffic - AAWT): é o volume total em dias úteis dividido por 260. Este volume é de interesse considerável, pois representa o impacto do tráfego apenas nos dias úteis.

c) Volume Diário Médio (do inglês Average Daily Traffic - ADT): é o volume de tráfego médio de 24 horas em um determinado local durante um período de tempo inferior a um ano. Pode ser medido por exemplo em: meses, semanas ou dias.

d) Volume Diário Médio em Dias Úteis (do inglês Average Weekday Traffic - AWT): é o volume de tráfego médio que ocorre nos dias úteis durante um período de tempo inferior a um ano. Assim como o Tráfego Diário Médio, pode ser medido por qualquer período de tempo, inferior a um ano. 


\section{Volumes Horários}

O volume de tráfego varia ao longo do dia. Analisando a variação horária, é de interesse a hora em que ocorre o maior volume de tráfego, referida como "hora de pico". No entanto, o volume da hora de pico não ocorre em todos os sentidos da rodovia simultaneamente, sendo um volume direcional, ou seja, em apenas um sentido da rodovia (ROESS; MCSHANE; PRASSAS, 1998).

Essa hora é fundamental para engenheiros de tráfego seja para projetos ou análises operacionais. 0 volume da hora de pico é utilizado para o projeto de rodovias, pois devem ser projetadas para suportar o volume de tráfego da hora de pico na direção em que ocorrer. Por conseguinte, na análise operacional, o volume de pico é importante para medidas de controle, de segurança e de capacidade, pois deve-se considerar as condições da via durante o horário de pico, assim como os volumes sub-horários (ROESS; MCSHANE; PRASSAS, 1998).

Roess, McShane e Prassas (1998) apresentam ainda uma estimativa do volume de tráfego na hora de pico a partir de uma projeção diária de volume, conforme a equação a seguir:

$$
D D H V=A A D T \cdot K \cdot D
$$

Sendo: $D D H V$ : Volume Horário de Projeto Direcional (do inglês Directional Design Hour Volume), expresso em veículo por hora (veic/h);

AADT: Tráfego Diário Médio Anual (do inglês Average Annual Daily Traffic), expresso em veículo por dia (veic/dia);

K: $\quad$ proporção do tráfego diário durante a hora de pico;

D: $\quad$ proporção do tráfego que se desloca na direção do pico.

0 valor $K$ representa, para fins de projeto, a proporção de AADT que ocorre durante a i-ésima hora mais carregada do ano. No Brasil, o DNIT (2006) indica utilizar a 30 a (trigésima) e a 50a (quinquagésima) hora para análise de projeto. As horas de pico variam para cada dia e podem ser classificadas em ordem decrescente de volume. Os fatores $K \mathrm{e}$ $D$ são geralmente baseados em características locais ou regionais (ROESS; MCSHANE; PRASSAS, 1998).

Como o volume e as características básicas da variação do volume podem sofrer 
alterações com o passar do tempo, essa projeção tem limitações para projetar futuras demandas de tráfego (ROESS; MCSHANE; PRASSAS, 1998).

\section{Volumes sub-horários}

Apesar do volume diário e horário atenderem as várias funções nas análises de tráfego, existe ainda a variação dentro da hora. A qualidade do fluxo de tráfego é muitas vezes relacionada à flutuação da demanda do fluxo de tráfego a curto prazo. Uma rodovia pode ter capacidade para atender a demanda na hora de pico, mas pode não atender os picos do fluxo de tráfego dentro da hora de pico (ROESS; MCSHANE; PRASSAS, 1998).

O HCM - Highway Capacity Manual - (TRB 2010) apresenta a definição de taxa de fluxo de tráfego e o Fator de Hora Pico (FHP, do inglês peak hour fator - PHF). A taxa de fluxo de tráfego descreve o número de veículos observados em um ponto durante um intervalo de tempo menor que uma hora, normalmente em 15 minutos, mas expresso como uma taxa horária equivalente. 0 conceito de Fator de Hora Pico (FHP) expressa a flutuação dentro da hora de pico, é calculado pela relação entre o Volume Horário de Pico (VHP) pela taxa de fluxo equivalente nos 15 minutos mais congestionado da hora pico, conforme Equação 2.2.

$$
F H P=\frac{V H P}{T_{M A X}\left(\text { normalmente } 4 \cdot V_{15}\right)}
$$

Sendo, FHP: Fator de Hora de Pico;

VHP: Volume Horário de Pico;

TMAX: Taxa de fluxo máxima;

V15: $\quad$ Volume de tráfego máximo de 15 minuto dentre os intervalos da hora de pico

O FHP pode ser aplicado a uma área ou parte de um sistema viário e geralmente descreve as características de geração de viagem. Conhecendo o FHP, pode-se converter um volume de horas de pico para uma taxa de fluxo pico estimada dentro da hora.

Conforme foi apresentado, há diversas formas de analisar as variações do volume de tráfego e cada forma cumpre uma função dentro das análises de variação do tráfego veicular. Apesar dessas representações atenderem a diversas funções, ainda não atendem 
a todos os objetivos de pesquisa na Engenharia de Transportes, surgindo assim, novos métodos empíricos que analisam a variação do volume de tráfego conforme o objetivo da pesquisa. A seguir, são apresentados dois desses métodos.

\subsubsection{Análise de comportamento de tráfego de Weijermars e Berkum}

Um dos poucos trabalhos na literatura que propõe a análise de comportamento de tráfego é o de Weijermars e Berkum (2005). Os autores descreveram um método para definir padrões no comportamento do tráfego veicular através de dados de fluxo de tráfego utilizando análise de agrupamento. Os dados utilizados pelos autores foram coletados em uma rodovia na Holanda, no ano de 2003.

Inicialmente, os autores eliminaram do banco de dados os dias de congestionamento e os dias com dados ausentes. Em seguida foi apresentada uma pré-classificação dos dados em dias úteis (segunda a sexta-feira) e não úteis (sábado e domingo). No entanto, os autores perceberam que essa pré-classificação poderia perturbar alguns dos padrões existentes. Por isso, resolveram avaliar o impacto antes e depois da pré-classificação.

Antes da pré-classificação foi aplicada uma análise de agrupamentos em duas etapas. Na primeira etapa, os dias são agrupados com base nas diferentes características separadamente (fluxo de tráfego diário, fluxos de pico, períodos de pico e a relação entre os fluxos de pico e o fluxo fora do pico) e, assim, todos os dias foram classificados em múltiplos clusters. Na segunda etapa, os dias foram classificados em clusters finais com base nas combinações dos agrupamentos resultantes da primeira etapa.

Sendo assim, os autores avaliaram dois perfis de tráfego: dias úteis e não úteis, utilizando três conjuntos de dados: (i) todos os dados sem a pré-classificação, mas com análise de agrupamento em duas etapas; (ii) os dados pré-classificados em dias úteis e (iii) os dados pré-classificados como dias não úteis.

Os resultados dos clusters indicaram que os dados pré-classificados obtiveram melhores definições do que os dados analisados em duas etapas, pois no agrupamento do banco de dados ( $i$ ) houve variação entre os perfis dos grupos, impossibilitando uma definição de padrões. Os resultados encontrados pelos autores indicaram também que os dias úteis são mais fáceis de classificar do que os dias não úteis, além disso o perfil dos dias úteis foi melhor definido para os dados pré-classificados do que os resultantes da análise de agrupamento em duas etapas. Para o conjunto de dados (ii) foi obtido quatro 
grupos de dias úteis: (1) segunda-feira, (2) terça, quarta e quinta-feira, (3) sexta-feira e (4) dias em período de férias.

\subsubsection{Critério de dias influenciados por feriados de Cunha (2007)}

Cunha (2007) avaliou o efeito do uso de uma medida de desempenho alternativa à densidade no cálculo dos fatores de equivalência para caminhões típicos em rodovias de pista dupla no estado de São Paulo. Uma das etapas do trabalho de Cunha (2007) foi caracterizar a composição típica do tráfego veicular e do desempenho dos caminhões em rodovias paulistas. No entanto, a análise de comportamento do tráfego a partir do Volume Diário Médio Anual e do volume de tráfego na 30a e 50 ineficiente para caracterizar o fluxo de caminhões tipicamente observados nas rodovias. Portanto, foi proposto um método de determinação do fluxo de tráfego em dias úteis típicos, sem a influência dos feriados.

A proposta de Cunha (2007) foi baseada em três critérios, de acordo com os dados de tráfego entre 1999 a 2005. A primeira etapa consistiu em definir os feriados nacionais e estaduais de São Paulo que foram eliminados do banco de dados por causarem maior variação do fluxo de tráfego. A Tabela 2.1 ilustra os feriados considerados por Cunha (2007) no ano de 2005.

Tabela 2.1 - Feriados considerados no ano de 2005

\begin{tabular}{ll}
\hline Mês & Feriados em 2005 \\
\hline Janeiro & 1 (Ano Novo) \\
Fevereiro & 8 (terça de Carnaval*) \\
Março & 27 (Páscoa) \\
Abril & 21 (Tiradentes) \\
Maio & 1 (Dia do Trabalho) \\
& 26 (Corpus Christi*) \\
Julho & 9 (Revolução Constitucional) \\
Setembro & 7 (Dia da Independência) \\
Outubro & 12 (N. S. Aparecida) \\
Novembro & 2 (Finados) \\
& 15 (Proclamação da República) \\
Dezembro & $24-25$ (Natal) \\
& 31 (Ano Novo) \\
\hline
\end{tabular}

* Feriado Móvel

Fonte: Adaptado de Cunha (2007)

A segunda etapa do método definiu os demais dias da semana influenciados por cada feriado, de acordo com o dia da semana em que o mesmo ocorreu. A Tabela 2.2 apresenta 
esse critério.

Tabela 2.2 - Critérios de dias influenciados por feriados

\begin{tabular}{ll}
\hline Dia do feriado & Dias da semana influenciados \\
\hline Domingo (dom) & sáb - dom - seg \\
Segunda-feira (seg) & sex - sáb - dom - seg - ter \\
Terça-feira (ter) & sex - sáb - dom - seg - ter - qua \\
Quarta-feira (qua) & ter - qua - qui \\
Quinta-feira (qui) & qua - qui - sex - sáb - dom \\
Sexta-feira (sex) & qui - sex - sáb - dom \\
Sábado (sáb) & sex - sáb - dom \\
\hline
\end{tabular}

Fonte: Adaptado de Cunha (2007)

Ao aplicar esses dois critérios, Cunha (2007) obteve os dias do ano em que a interferência dos feriados foi mínima. Depois de analisar o fluxo de tráfego médio em cada dia da semana, o autor notou que as terças, quartas e quintas-feiras apresentaram o comportamento do tráfego semelhante durante o dia inteiro, o que não ocorreu nos demais dias da semana. Baseado nessa semelhança, o terceiro e último critério de Cunha (2007) para determinar o dia típico útil foi determinar a média dos volumes horários somente nas terças, quartas e quintas-feiras.

Note que Cunha (2007) não eliminou feriados locais, festas religiosas e eventos culturais que também alteram o fluxo veicular em cada região, pois isso implicaria em uma análise de cada local do banco de dados isoladamente e o propósito maior do método era considerar datas mais significativas do ano de modo que possa ser aplicado em qualquer região, conforme justifica o autor. Além disso, outra ressalva é quanto aos feriados móveis que devem ser observados a cada ano de análise.

Bethonico (2016) utilizou o método de Cunha (2007) para propor um novo método de calibração automática de simuladores microscópicos de tráfego utilizando medidas macroscópicas. Porém, Bethonico (2016) ressalta que seria interessante um método automático para o tratamento dos dados, especialmente para a definição do dia típico de tráfego.

Em resumo, há diversas formas de analisar as variações no volume de tráfego, seja por definições na literatura referencial ou método do dia típico de tráfego. No entanto, algumas limitações foram encontradas nesses métodos.

Primeiramente, não existe um consenso na definição de dia útil típico, 
representação da variação do volume de tráfego de grande interesse na área de planejamento por representar o comportamento padrão do fluxo de tráfego durante um dia útil. Roess, McShane e Prassas (1998) indicam uma média diária que exclui os fins de semana e trabalha com um média diária apenas dos dias úteis, no entanto não desconsidera os feriados e os dias que podem ser influenciados pelos mesmos, assim como também não analisa se há distinção entre os dias da semana, por exemplo, se o comportamento do tráfego de uma segunda-feira é o mesmo comportamento do tráfego de uma sexta-feira.

Weijermars e Berkum (2005) em seu método compararam os resultados com e sem uma pré-classificação dos dados e concluíram que pré-classificar os dados em dias úteis e não úteis geravam melhores agrupamentos. E nos agrupamentos de dias úteis, resultou em quatro grupos: (1) segundas-feiras, (2) terças, quartas e quintas-feiras, (3) sextasfeiras e (4) dias em período de férias. Esses resultados indicam que há dissimilaridade entre esses quatro grupos.

Por fim, Cunha (2007) em seu método, excluiu os feriados e os dias influenciados pelo mesmo e analisando o fluxo de tráfego médio em cada semana, notou que as terças, quartas e quintas-feiras apresentaram comportamento semelhante durante todo o dia, o que não aconteceu com os outros dias da semana e assim, utilizou esse grupo como sendo os dias úteis típicos. Esses trabalhos apontam que há uma diferença do comportamento do tráfego entre os dias úteis da semana, seja em rodovias do estado de São Paulo, Brasil (CUNHA, 2007) ou Holanda (WEIJERMARS; BERKUM, 2005), mas ainda falta um consenso do que é dia útil típico e como defini-lo.

Um ponto de destaque a ser considerado é que os métodos apresentados excluíram os dados atípicos de tráfego para se determinar o comportamento do tráfego. No entanto, uma análise desses dados excluídos poderia fornecer informações relevantes do comportamento do tráfego de forma geral, indicando diversas situações e perturbações na corrente de tráfego.

Vale ressaltar que os métodos do dia típico são dependentes da experiência do analista para definir os feriados de maior impacto. Além disso, feriados locais, festas religiosas e eventos culturais também podem alterar o fluxo veicular em cada região devem ser incorporados na análise. Quanto maior o banco de dados e mais locais forem analisados, mas propenso a erros o método se torna. Por exemplo, em uma análise de uma 
rodovia que liga dois estados, será influenciada não só por feriados nacionais, mas também por feriados estaduais distintos, sem contabilizar os feriados municipais e eventos locais.

Tanto a forma de representação indicada na literatura de referência quanto o método de Cunha (2007) utilizam volumes médios para definir o comportamento do tráfego e isso pode ocasionar dois problemas: (1) a suavização ou distorção das características do fluxo de tráfego dentro da escala medida, perdendo informações importantes para a definição do comportamento de tráfego e dias atípicos (ZHENG et al., 2011; ZHENG; WASHINGTON, 2012); e (2) a cada nova variação analisada (diária, horária ou sub-horária) o pesquisador precisa sempre voltar aos dados originais e recalcular a média, pois uma vez que se tem os volumes médios, não é possível retornar aos dados originais. Por exemplo, caso o pesquisador deseje utilizar a média diária e em seguida utilizar a média horária, se dividir por 24 horas, terá um valor médio para todo o dia, mas não representará a variação horária ao longo do dia. No entanto, para encontrar o volume médio diário, poder-se-ia partir do volume horário, conforme visto na seção 2.1.5.1.

Outras pesquisas vêm sendo desenvolvidas com o objetivo de analisar o comportamento do tráfego. Rakha e Aerde (1995) fizeram uma análise estatística das variações do dia a dia nos dados de fluxo de tráfego e concluíram que utilizar o tráfego diário pode ocasionar erros de projeto ou estimativas que não condizem com o comportamento real do tráfego. Stathoupoulos e Karlaftis (2001) analisaram as variações dentro do dia em uma área urbana da Grécia e concluíram que o comportamento de tráfego varia de acordo com a direção e a hora do dia. Ivan (2002) analisou se a hora, dia da semana e mês tinham efeitos na proporção do volume horário em rodovias, já Thomas, Weijermars e Berkum (2008) analisaram a variação no comportamento do tráfego na cidade de Almelo, Holanda.

\subsection{WAVELET}

\subsubsection{Apresentação da teoria Wavelet}

A maior parte das observações e simulações não lineares é registrada a partir de 
uma série temporal. Em contrapartida nas análises estatísticas clássicas de sinais, atualmente encontra-se uma vasta gama de técnicas de análise espectral desenvolvidas e introduzidas na literatura com a finalidade de fornecer ferramentas para a caracterização de regime não-lineares que estão associados à complexa variabilidade observada das mais diferentes variáveis (BARBOSA; BLITZKOW, 2008).

Entre as análises espectrais, a análise de Fourier é considerada uma das principais ferramentas (SÁBLON; MENDEZ; IANO) e é um instrumento bastante difundido (GUIDO; SLAETS; AMEIDA, 2012). Além disso, contém o maior número de aplicações práticas, utilizada nas mais diversas áreas das ciências aplicadas, inclusive engenharia, tendo um papel central nas telecomunicações modernas e também no processamento digital de imagens (BARBOSA; BLITZKOW, 2008).

Criada pelo matemático Jean Baptiste Fourier, a Transformada de Fourier (TF) é uma ferramenta útil que possibilita determinar a contribuição que cada função de base sinusoidal apresenta para a energia total presente na série temporal (BARBOSA; BLITZKOW, 2008). A TF é definida pela seguinte equação:

$$
F(\omega)=\int_{-\infty}^{\infty} f(t) e^{-i \omega t} d t
$$

Sendo, $f(t)$ a série temporal ou sinal analisado, $\omega$ é a frequência que cada componente oscilatória inerente ao sinal apresenta e a exponencial transforma para o domínio da frequência. Essa representação do sinal no domínio da frequência permite distinguir quais frequências estão presentes no sinal. Para um sinal estacionário (sinal que possui frequência constante), a frequência apontada pela TF está presente em todo o sinal. No entanto, um sinal não-estacionário, a TF aponta somente as frequências presentes no sinal, mas não determina a localização das mesmas, ou seja, não determina em qual instante de tempo certa frequência aparece (GUIDO; SLAETS; AMEIDA, 2012). A Figura 2-4 ilustra um exemplo da aplicação da Transformada de Fourier em um sinal. 
Figura 2-4 - Exemplo de análise de frequência com a Transformada de Fourier

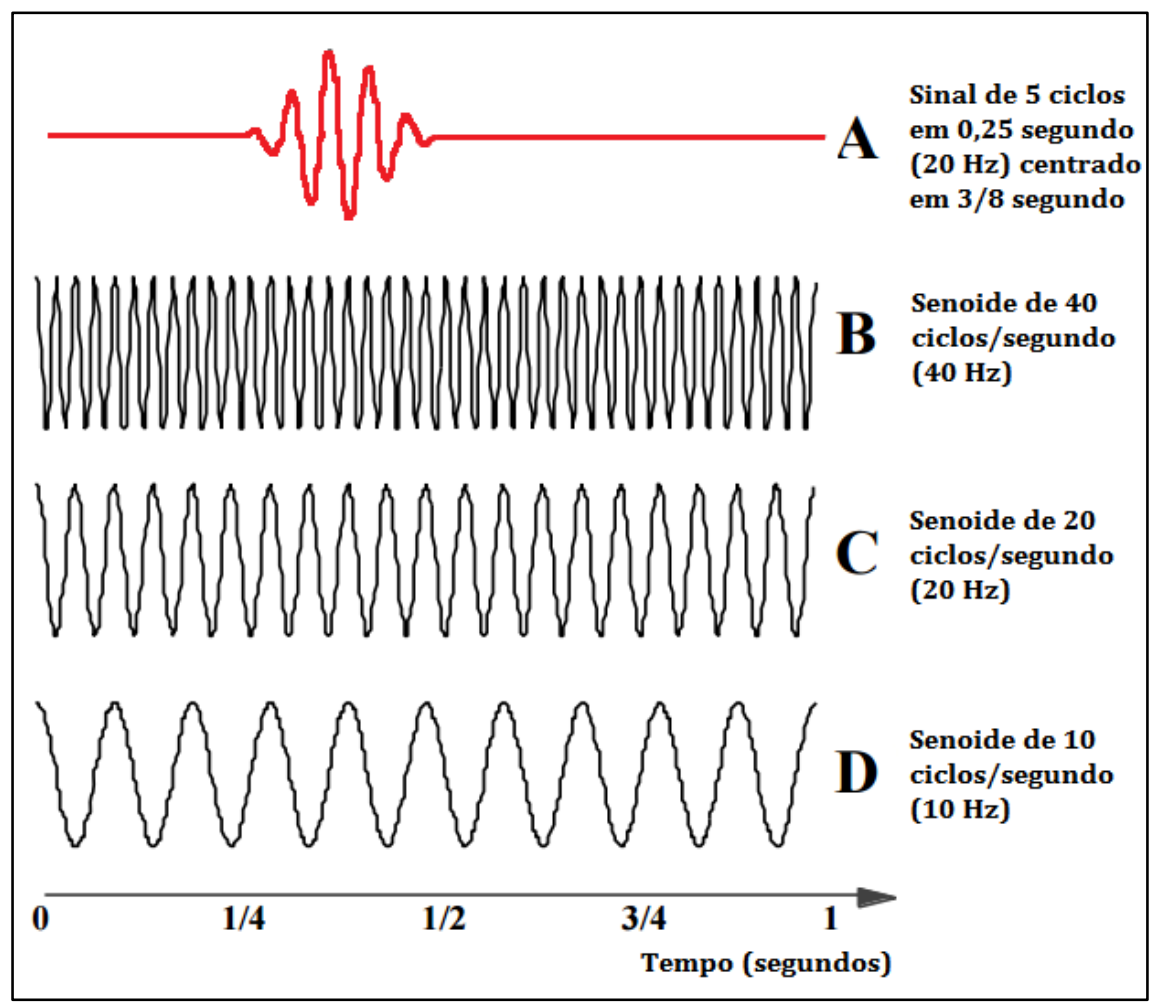

Fonte: Adaptada de Fugal (2009)

Inicialmente foi suposto um sinal de $20 \mathrm{~Hz}$ (A) e em seguida, esse sinal foi comparado ponto a ponto com senoides que representavam a Transformada de Fourier (B, C e D). 0 sinal $A$ contém cinco ciclos em 0,25 segundo $(20 \mathrm{~Hz})$, centrado em 3/8 segundo, totalizando 5 picos (máximos locais) e 5 vales (mínimos locais). Na primeira senoide de $40 \mathrm{~Hz}$ (B) a ser comparada com o sinal $A$, observou-se que os picos e vales da mesma não se enquadrava aos picos e vales do sinal, ilustrando assim, baixa correlação entre o sinal A e a senoide B. Dilatando essa senoide de $40 \mathrm{~Hz}$ para $20 \mathrm{~Hz}$ (C), mesma frequência do sinal, os picos e vales se alinharam e tiveram uma correlação maior entre o sinal e a senoide $C$ do que a senoide B. Porém, se continuar alongando a senoide para uma frequência de $10 \mathrm{~Hz}$ (D), a correlação diminui novamente pois os picos e vales novamente não se alinham. Analisando então apenas a frequência do sinal e das senoides, conclui-se que o sinal A e a senoide C são os que tem maior correlação de frequência. No entanto, em nenhuma das senoides foi possível diferenciar o instante em que o sinal apresentava a frequência de $20 \mathrm{~Hz}$ e o instante em que a frequência era zero (FUGAL, 2009).

Gabor (1946) percebeu esta deficiência na aplicabilidade da TF em séries temporais não-estacionárias (caso da maioria dos fenômenos encontrados na natureza) e visando 
melhorar a representatividade desse tipo de séries temporais, ele propôs um novo método. Nesse método a série temporal é dividida em intervalos iguais e em seguida a TF é aplicada em cada um desses intervalos. Esse método ficou conhecido como Transformada Janelada de Fourier (TJF, também conhecido como Transformada de Fourier de Tempo-Curto ou Short-Time Fourier Transform - STFT) e contribuiu substancialmente para o estudo e análise de séries temporais não-estacionárias. No entanto, permanecia dois problemas a serem resolvidos: (1) a janela temporal permanecia fixa, não possibilitando modificar o tamanho da mesma após o início da aplicação da TJF na série temporal analisada; e (2) as funções trigonométricas possuem energia infinita, ou seja, as mesmas são limitadas entre - $\infty$ e $\infty$ (BARBOSA; BLITZKOW, 2008).

A ideia de realçar um sinal sob várias escalas diferentes e analisá-lo com várias resoluções surgiu de forma independente em diversas áreas da matemática, física e engenharia (FARIA, 1997). Em 1960, Calderón abordou em seus trabalhos a decomposição atômica, introduzindo a identidade de Calderón, uma decomposição de um operador de identidade (MEYER, 1993). Sob uma perspectiva histórica, foi relacionado entre si várias teorias, desde a decomposição de Littlewood-Paley (1930) à identidade de Calderón e a primeira síntese que empregava o termo Wavelet surge com o trabalho de Grossman e Morlet em 1984. No entanto, ainda em 1910, enquanto trabalhava na construção de bases para representar funções integráveis quadraticamente, Alfred Haar construiu a primeira família Wavelet de que se tem notícia e que leva seu nome (FARIA, 1997).

\subsubsection{Wavelets e a Transformada Wavelet}

Wavelets ou ondaletas são "pequenas ondas" obtidas a partir de uma função modelo, conhecida como Mother Wavelet $-\psi(t) \in L^{2}(R)$-, por meio de dilatações (contrações ou escalamento) e translações (deslocamentos). 0 objetivo em realizar essas operações é obter uma família de funções base para descrever outras funções $\in L^{2}(R)$ (FARIA, 1997). Em linhas gerais, Wavelets são funções capazes de decompor e descrever uma série histórica de dados no domínio do tempo para o domínio da frequência, permitindo analisar estes dados em diferentes escalas e níveis.

Um exemplo de aplicação da Wavelet é ilustrado na Figura 2-5, supondo o mesmo 
sinal de $20 \mathrm{~Hz}$ centrado em 3/8 segundo. Comparado com uma Mother Wavelet, a Wavelet Daubechies 20 (Db20), em diferentes situações. $\operatorname{Em~} B$, ao aplicar a $D b 20$ não existe nenhuma correlação com o sinal $A$, pois no instante em que a $D b 20$ é aplicada, a frequência do sinal é zero. Já em $\mathrm{C}$, a $D b 20$ se deslocou para alinhar ao pulso no sinal $A$, porém a correlação é baixa, pois a $D b 20$ ainda está com a frequência de $40 \mathrm{~Hz}$ e o sinal de $20 \mathrm{~Hz}$. No entanto, em $D$ a $D b 20$ já deslocada, se dilata para $20 \mathrm{~Hz}$ e assim tem uma ótima correlação com o sinal A, pois além de estar na mesma frequência, detecta o instante em que o pulso ocorre (FUGAL, 2009).

Figura 2-5 - Processo de deslocamento e dilatação da Wavelet

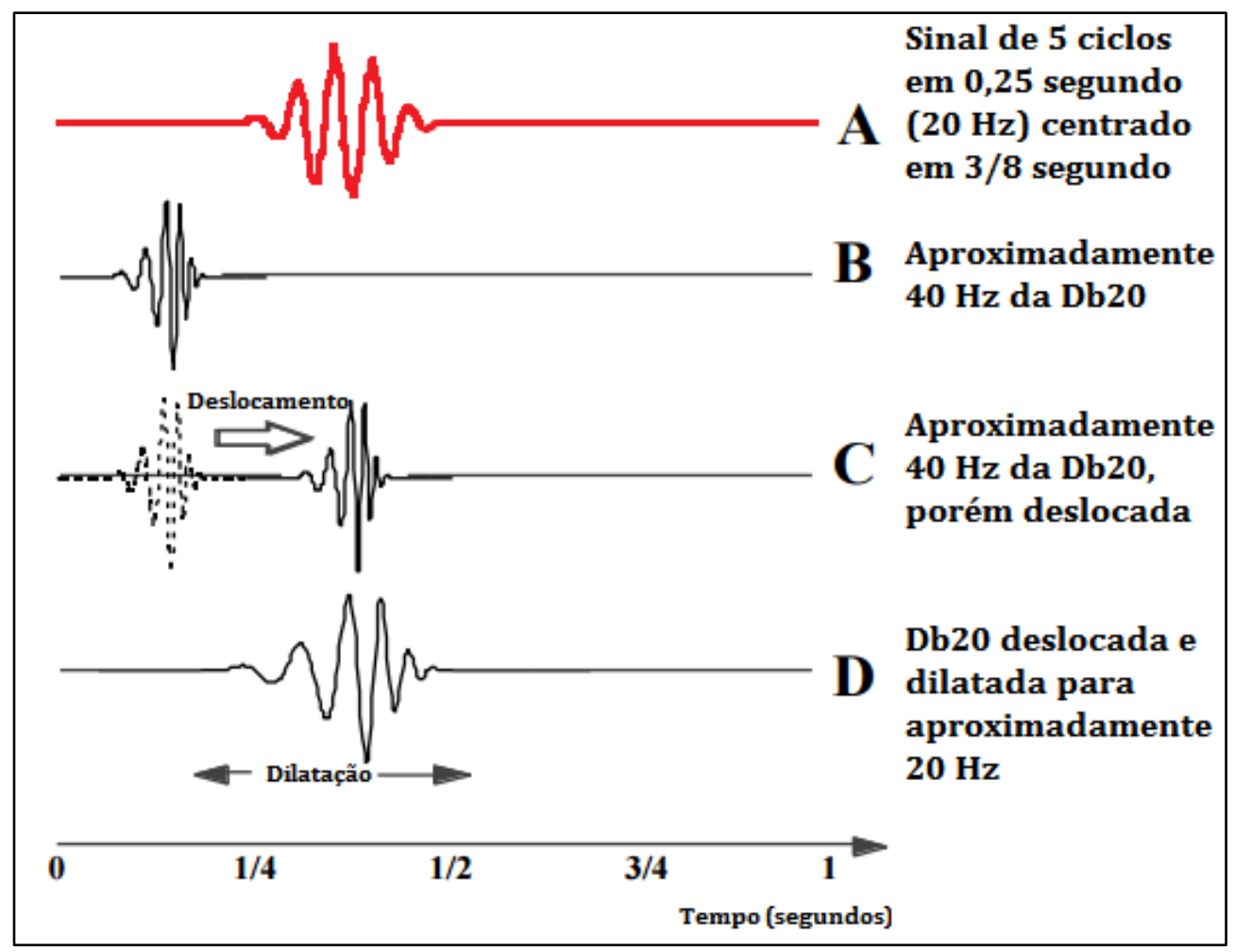

Fonte: Adaptada de Fugal (2009)

Para que uma função seja denominada de função Wavelet, ela deve atender a duas propriedades distintas:

a) A integral da Mother Wavelet deve ser igual a zero;

$$
\int_{-\infty}^{+\infty} \psi(t) d t=0
$$


b) A função Wavelet deve possuir energia unitária;

$$
\int_{-\infty}^{+\infty}|\psi(t)|^{2}=1
$$

As propriedades citadas acima expressam que $\psi(t)$ é quadraticamente integrável, ou seja, a função Mother Wavelet pertence ao conjunto das funções de quadrado integrável $L^{2}(\mathbb{R})$ dentro do conjunto de números reais $\mathbb{R}$. As propriedades acima, sugerem também que $\psi(t)$ tende a oscilar acima e abaixo do eixo $t$ e que tem sua energia localizada em uma certa região, pois ela é finita. A maior parte de sinais reais de importância na aplicação de processamento de sinais são encontrados nessa classe das funções finitas (BARBOSA; BLITZKOW, 2008).

Essa característica de energia concentrada em uma região finita é o que diferencia a análise de sinais quando se utiliza Wavelet e Fourier, sendo que ao utilizar a Transformada de Fourier, usa-se funções trigonométricas (seno e cosseno) que são periódicas, portanto possuem energia infinita. De modo geral, as funções denominadas Wavelets possuem a propriedade básica de dupla localização: frequência e tempo, enquanto Fourier é apenas na frequência (BARBOSA; BLITZKOW, 2008).

A aplicação das funções Wavelets inclui a Transformada Wavelet Contínua (TWC) e Transformada Wavelet Discreta (TWD), além de suas respectivas Transformadas Inversas. A TWC traz muitas repetições de informações do sinal analisado, tornando-a desinteressante computacionalmente, no entanto a TWD é utilizada seja em sua versão mais simples, na chamada "análise de multiresolução" ou em uma versão mais completa que permite um detalhamento personalizado do espectro, chamada de "análise por pacotes" (DIAS, 2003).

\subsubsection{Transformada Wavelet Discreta - análise de multiresolução}

Uma das estruturas de Transformação Discreta mais utilizadas entre as disponíveis na literatura é as "diádicas", que opera com escalas e posições baseadas em potências de 2 (dois). Esse esquema foi disposto da forma que é conhecido hoje por Mallat, em 1989, que percebeu uma semelhança apropriada entre o algoritmo de decomposição diádico (análise de multiresolução) e o uso de um banco de filtros, conceito este procedente a teoria geral de processamento de sinais. Por ser o esquema de decomposição mais empregado, o termo "Transformada Wavelet Discreta (TWD, do inglês Discrete Wavelet 
Transform - DWT) se refere especificamente ao algoritmo de Mallat, embora outros esquemas de Transformação Discreta existam (DIAS,2003).

A TDW decompõe o sinal analisado em componentes de alta escala, nomeados de "Aproximações" e de baixa escala, nomeados de "Detalhes", em cada resolução. 0 componente de Aproximação, corresponde ao conteúdo de baixa frequência do sinal, gerado pelo filtro passa-baixa e o componente de Detalhe corresponde ao conteúdo de alta frequência do sinal, gerado pelo filtro passa-alta (GUIDO; SLAETS; ALMEIDA, 2012).

Se cada sinal analisado gera duas novas componentes, o resultado de um TDW apresentaria, portanto, duas vezes mais dados do que o sinal original e assim sucessivamente a cada nível, o que seria um retrocesso em termos de eficiência computacional. No entanto, para compensar o esforço extra indesejável, a decomposição é realizada reduzindo-se a taxa de amostragem (downsamlpling) na mesma proporção que o número de decomposições (DIAS, 2003).

Como exemplo, considere um sinal discreto $(S)$ de tamanho $N$. Ao aplicar a Transformada Wavelet Discreta pela primeira vez, decomposição no nível 1, dois novos sinais de tamanho $N / 2$ são gerados, representados por um par de componentes, sendo um denominado de Detalhe $\left(D_{1}\right)$ e o outro de aproximação $\left(A_{1}\right)$. Em linhas gerais, os componentes de Detalhe 1 carregam informações das grandes variações do sinal $S$, devido à filtragem passa-alta, enquanto os componentes de Aproximação 1 descrevem um sinal suavizado pelo filtro passa-baixa. A decomposição do nível 2 ocorre se aplicar a TDW no componente de Aproximação $A_{1}$, o que resulta em dois outros sinais de tamanho $N / 4$, descritos pelos componentes de Detalhe $D_{2}$ e de Aproximação $A_{2}$. 0 detalhamento hierárquico ocorre na aplicação sucessiva da Transformada Wavelet Discreta nos Componentes de Aproximações, reduzindo pela metade a representação do sinal anterior. Este processo está representado na Figura 2-6 podendo se repetir por $\log _{2}(N)$. 
Figura 2-6 - Representação de decomposição da Transformada Wavelet Discreta

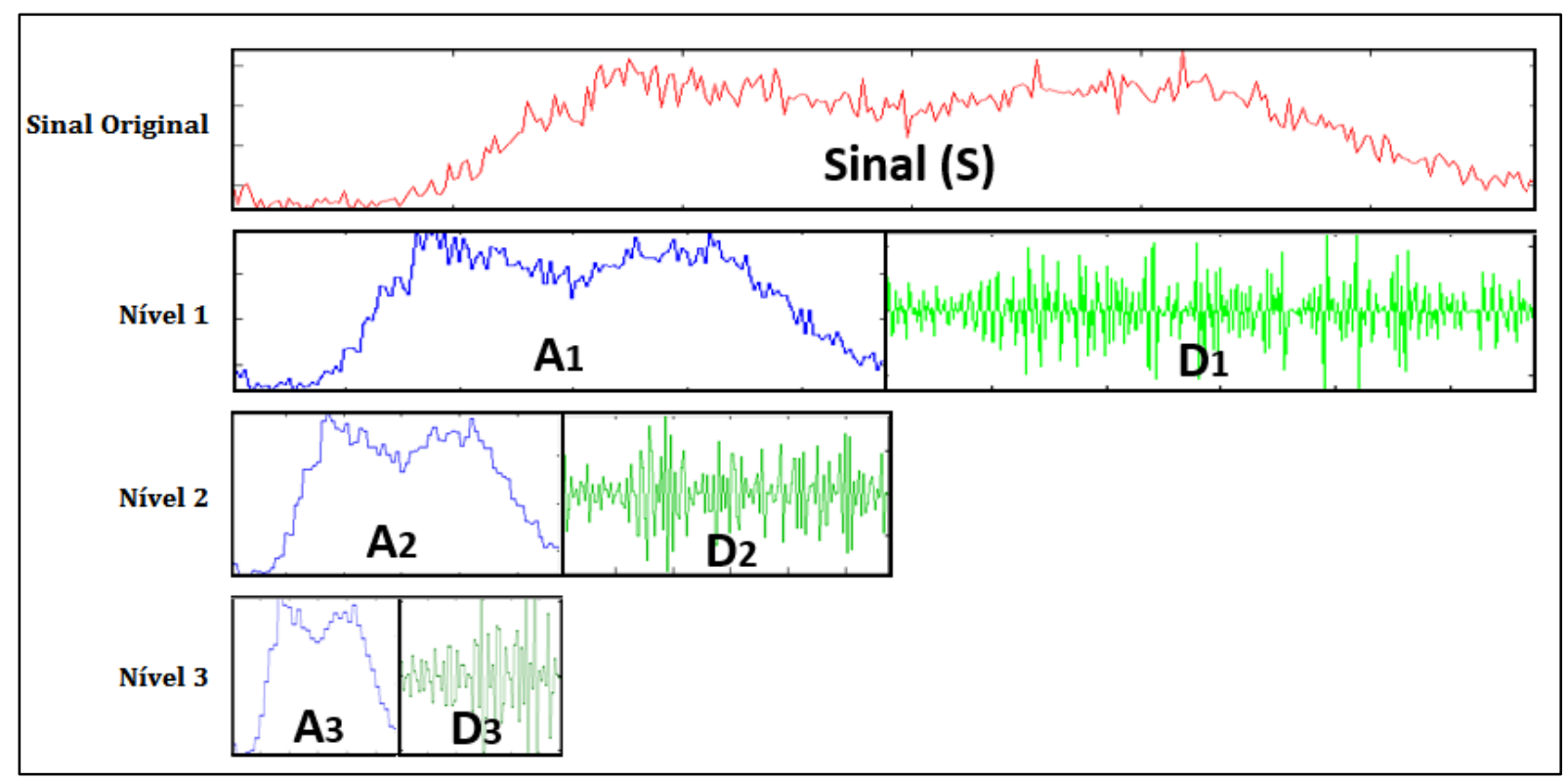

Fonte: Adaptado de Ribeiro e Cunha (2016)

É importante ressaltar na Figura 2-6 que a aplicação da Transformada Wavelet Discreta em $k$ níveis resulta sempre em um sinal de tamanho $N$, composto de uma aproximação no nível $k\left(A_{k}\right)$ e $k$ detalhes $\left(D_{k}, D_{k-1}, \ldots, D_{1}\right)$. A decomposição no nível 1 , resulta nos componentes $A_{1}$ e $D_{1}$; no nível 2, o resultado é composto pelos componentes $A_{2}, D_{2}$ e $D_{1}$; no nível 3, os componentes são definidos por $A_{3}, D_{3}, D_{2}$ e $D_{1}$. Essa estrutura hierárquica da Transformada Wavelet Discreta tem como característica fundamental a sua propriedade de decomposição e reconstrução do sinal.

A reconstrução do sinal é feita pela Transformada Wavelet Discreta Inversa (TWDI). Independentemente do nível de decomposição adotado, a aplicação da TWDI em componentes de Aproximação e Detalhe de um mesmo nível resulta no sinal do nível anterior. Como exemplo, a TWDI dos coeficientes $A_{3}$ e $D_{3}$, resulta em $A_{2}$; assim como a inversa de $A_{2}$ e $D_{2}$ retorna à $A_{1}$; e a Transformada Inversa de $A_{1}$ e $D_{1}$ reconstrói o sinal $S$.

A Transformada Wavelet Discreta (Equação 2.6) e a Transformada Wavelet Discreta Inversa (Equação 2.7) podem ser expressas da seguinte forma: 


$$
\begin{array}{r}
d_{j, k}=\left\langle\psi_{j, k}(t), f(t)\right\rangle=\int f(t) \psi_{j, k}(t) d t \\
f(t)=\sum_{j=-\infty}^{\infty} \sum_{k=-\infty}^{\infty} \psi_{j, k}(t) \cdot d_{j, k}
\end{array}
$$

Sendo $d_{j, k}$ os Componentes da Wavelet, correspondentes ao sinal transformado $\mathrm{F}(a, b)$ em que $a$ é a escala e $b$, o deslocamento (FARIA, 1997).

\subsubsection{Tipos de Wavelets}

Existem vários tipos de Wavelets apresentados na literatura. Um dos primeiros questionamentos ao iniciar sua aplicação é qual entre tantas será utilizada? A resposta está diretamente relacionada à aplicação, principalmente ao sinal que será analisado.

Vários pesquisadores vêm propondo regras de construção de Wavelets de acordo com as restrições e necessidades que cada aplicação específica determina. Portanto, é possível gerar uma infinidade de Wavelets diferentes e construir um conjunto de Wavelets adequado ao processamento de um tipo de sinal ou aplicação específica, em busca de melhores resultados (FARIA, 1997).

Fugal (2009) reuniu as principais famílias Wavelets e as classificou de acordo com as suas propriedades. Nesta Revisão Bibliográfica são citadas essas classificações e as principais famílias Wavelets de cada uma. Mais detalhes dessa classificação e detalhamento completo de cada família Wavelet é encontrado no livro de Fugal (2009).

\subsubsection{Crude Wavelets}

Este tipo de Wavelet não tem ortogonalidade, momento de fuga e filtros adicionais. São derivadas de uma equação explícita, portanto são regulares e de design simétrico. Podem ser utilizadas em um TWC mas não em uma TWD em um sinal real. Alguns exemplos mais conhecidos dessa Wavelet são:
a) Mexican Hat Wavelet;
b) Morlet Wavelet;
c) Gaussian Wavelet;
d) Meyer Wavelets. 


\subsubsection{Complex Crude Wavelets}

São funções Wavelet complexas que devem ser aplicadas em duas situações. Na primeira, para aplicação em sinais complexos. Na segunda, é que algumas formas de onda dever ser complexas para funcionar como Wavelets. Essas Wavelets só podem ser utilizadas em TWC. Exemplo desse tipo de Wavelet são:
a) Shannon ("Sinc") Wavelet
b) Complex Frequency B-Spline Wavelets
c) Complex Morlet Wavelet
d) Complex Gaussian Wavelets

\subsubsection{Orthogonal Wavelets}

São funções Wavelets que podem ser usadas em uma TWD e TWDI devido à sua capacidade de reconstrução perfeita, permitindo assim não apenas a identificação dos ruídos, mas também seu tratamento e compressão. Os filtros ortogonais básicos têm suporte compacto, ou seja, começam e terminam. Alguma das principais famílias Wavelets desse filtro inclui:
a) Haar Wavelets
b) Daubechies Wavelets
c) Symlets
d) Coiflets
e) Discrete Meyer Wavelets

\subsubsection{Biorthogonal and Reverse Biorthogonal Wavelets}

As Wavelets Biorthogonal e Reverse Biorthogonal estão disponíveis em filtros de diferentes comprimentos e relação de ortogonalidade, o que permite conseguir uma simetria e reconstrução perfeita. Unindo essa flexibilidade com a habilidade inata das Wavelets para atuar como um "Microscópio Matemático" por alongamento e deslocamento obtém-se uma ferramenta muito versátil e poderosa.

a) Biorthogonal Wavelets 


\section{b) Reverse Biorthogonal Wavelets}

Essas são algumas das várias Wavelets disponíveis na literatura, na Figura 2-7 são apresentadas as formas de oito dessas Wavelets.

Figura 2-7 - Formas de diferentes tipos de Wavelets

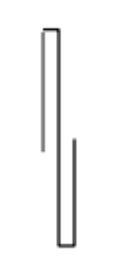

Haar

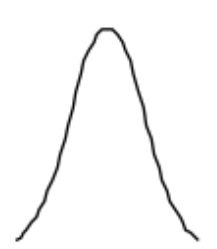

Gaussian or Spline

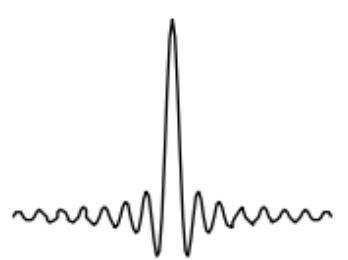

Shannon or Sinc

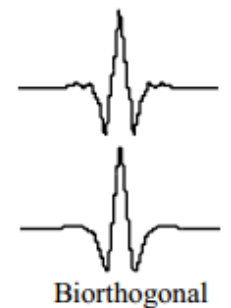

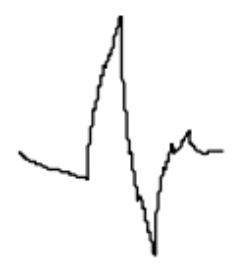

Daubechies 4

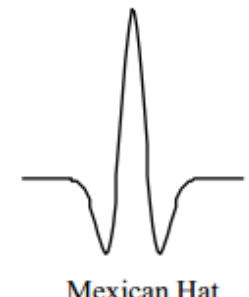

Mexican Hat

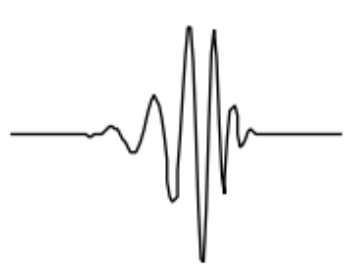

Daubechies 20

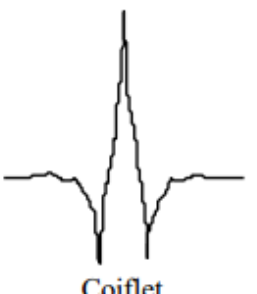

Fonte: Adaptada de Fugal (2009)

\subsubsection{Wavelets na Engenharia de Transportes}

Nos últimos anos houve grande desenvolvimento matemático das Wavelets e suas aplicações para diversas áreas. Devido à variação temporal do comportamento do tráfego, a Transforma Wavelet tornou-se uma ferramenta eficaz de decomposição tempofrequência em séries não-estacionárias (ZHENG; WHASHINGTON, 2012). Na área de Engenharia de Transportes a aplicação das Wavelets, combinadas com técnicas de mineração de dados - tais como, análise de agrupamento, lógica fuzzy, redes neurais - tem se concentrado para investigar questões relacionadas como:

a) Detecção automática de incidentes de autoestrada (ADELI; SAMANT, 2000; GHOSH-DASTIDAR; ADELI, 2003; KARIM; ADELI, 2002; JEONG et al. 2009; KARIM; ADELI, 2003; SAMANT; ADELI, 2000; SAMANT; ADELI, 2001; TENG; QI, 2003);

b) Característica do tráfego em torno de autoestrada em zonas de trabalho (ADELI; GHOSH-DASTIDAR, 2004; GHOSH-DASTIDAR; ADELI, 2006; GHOSH; BASU; O’MAHONY, 2010); 
c) Previsão do fluxo de tráfego (BOTO-GIRALDA et al. 2010, JIANG; ADELI, 2005; XIE; ZHANG; YE, 2007, ZHANG, 2016);

d) Reconhecimento de padrões de tráfego (CHUNG, 2003; GHOSH; BASU; O’MAHONY, 2006; JIANG; ADELI, 2004);

e) Detecção de oscilações do tráfego (ZHENG et al., 2011; ZHENG; WHASHINGTON, 2012; MOHAN et al., 2014).

Esses estudos pioneiros têm demonstrado o potencial das Wavelets na análise de dados de tráfego. No entanto, faltam alguns fundamentos teóricos e orientações do seu uso em dados de tráfego (ZHENG; WHASHINGTON, 2012). Em especial, na aplicação dessa ferramenta em dados de tráfego, possibilitando que o engenheiro de transportes possa utilizar na prática.

\subsection{CONSIDERAÇÕES FINAIS}

Este capítulo apresentou o levantamento da literatura necessário para produção desta seção em duas partes. A seção 2.1 sintetizou os parâmetros básicos do fluxo de tráfego e seu uso em diversas áreas da Engenharia de Transportes. Descreveu as principais variações do fluxo de tráfego, apresentou e discutiu as principais representações da variação do volume de tráfego consagrado na literatura e dois métodos empíricos adicionais.

A seção 2.2 apresentou em linhas gerais os conceitos básicos da Teoria Wavelet e discorreu uma breve introdução da teoria e da descrição histórica. Também foi apresentada as formas de aplicação e a Transformada Wavelet Discreta para análise de multiresolução. 


\section{CARACTERIZAÇÃo do SinAL DE ENTRADA}

Parte relevante da malha rodoviária do estado de São Paulo é operada por concessionárias privadas. Segundo dados da Secretaria dos Transportes do Estado de São Paulo (2016), a malha rodoviária sob regime de concessão representa mais de 5,6 mil km de extensão. Ao todo, são 19 concessionárias atuando nas rodovias paulistas. Um dos papéis das concessionárias é a obtenção dos dados de tráfego através de sensores implantados nos trechos homogêneos (trechos com características físicas e operacionais semelhantes) das vias integrantes do Sistema Rodoviário de modo que essas informações possam ser auditadas pelo Poder Concedente em qualquer época do ano ou período do dia (ARTESP, 2014).

O objetivo deste capítulo é especificar os procedimentos para fornecer o sinal de entrada, com a obtenção, tratamento e estruturação do banco de dados e em seguida, decompor o sinal de entrada gerado pela TWD e analisar os Componentes de Detalhe e Aproximações resultantes. Este capítulo é de suma importância para a continuação desta pesquisa pois, além de constituir os sinais que serão analisados posteriormente pelos métodos complementares, serve como base para análise dos mesmos.

\subsection{BANCO DE DADOS}

Para o desenvolvimento desta pesquisa foram utilizados dados de fluxo de tráfego e velocidade veicular, obtidos por estações de monitoramento de tráfego, fornecidos por concessionárias rodoviárias do estado de São Paulo. Esses dados foram tratados e consolidados em único banco de dados como apresentado na seguinte seção.

\subsubsection{Obtenção dos dados}

Por meio de sensores do tipo laço indutivo ou outra tecnologia equivalente, os sensores das rodovias do estado de São Paulo fornecem dados agregados de fluxo e velocidade média. No entanto cada concessionária disponibiliza seus relatórios em um 
formato distinto. Os dados disponibilizados pela ARTESP continham relatórios mensais ou bimestrais das concessionárias AutoBan e CCR ViaOeste, entre o período de setembro/2011 a maio/2014.

O banco de dados disponibilizado pela CCR ViaOeste era composto de planilhas que forneciam informações de data, hora, volume total, volume de automóveis, volume de comerciais e volume de motos, assim como as respectivas velocidades médias dessas categorias veiculares. Cada planilha eletrônica continha dois meses de dados desagregados em intervalos de 5 minutos. Já o banco de dados disponibilizados pela AutoBan continha planilhas que forneciam informações de data e hora, volume total, volume de automóveis e veículos comerciais, taxa de ocupação e velocidade média de todos os veículos. Cada planilha continha um mês de dados em intervalos de 6 minutos e apresentava uma faixa da rodovia em um sentido.

As diferenças entre os formatos das planilhas podem ser explicadas por dois motivos: (1) tecnologia empregada para a coleta de dados, alguns aparelhos registram as informações em intervalos de 5 minutos e outros em 6 minutos e (2) pelo país de origem da empresa que administra a concessionária, pois essas empresas adotavam o modelo aplicado nos seus países sede.

\subsubsection{Tratamento dos dados}

Como qualquer dispositivo eletrônico, os sensores estão sujeitos à falha de funcionamento. Assim sendo, independentemente do formato das planilhas, é necessário analisá-las em busca de dados inconsistentes captados pelo sensor de tráfego, pois essas falhas podem interferir nas informações que deveriam refletir as condições de tráfego do local, seja com ausência de informações (dados faltantes) ou dados de tráfego repetidos erroneamente.

Para o tratamento dos dados foram realizadas as seguintes etapas: (1) organização, os dados foram separados por sensor, por sentido da via e por ano. (2) filtragem, foi necessário filtrar todas as planilhas em busca de dados faltantes; erros do sensor; e períodos de manutenção. 0 Apêndice 3.1 consiste em uma tabela que apresenta a localização de cada sensor das duas concessionárias e a quantidade de dados faltantes em cada mês de coleta. 
Como a meta desta pesquisa é realizar uma análise exploratória para o tratamento de dados, foi buscado trabalhar com no mínimo o período de um ano de dados completos e analisá-los por períodos: diário, mensal e anual. Devido à ausência de informações por falhas na coleta de dados, foi priorizado o conjunto de dados no período de um ano com a menor quantidade de falhas.

Os sensores investigados estão situados nas rodovias: SP-280 (Rodovia Presidente Castelo Branco), SP-270 (Rodovia Raposo Tavares), SP-021 (Rodoanel Mário Covas) e SP348 (Rodovia dos Bandeirantes), ilustradas na Figura 3-1.

Figura 3-1 - Rodovias em que os dados foram coletados

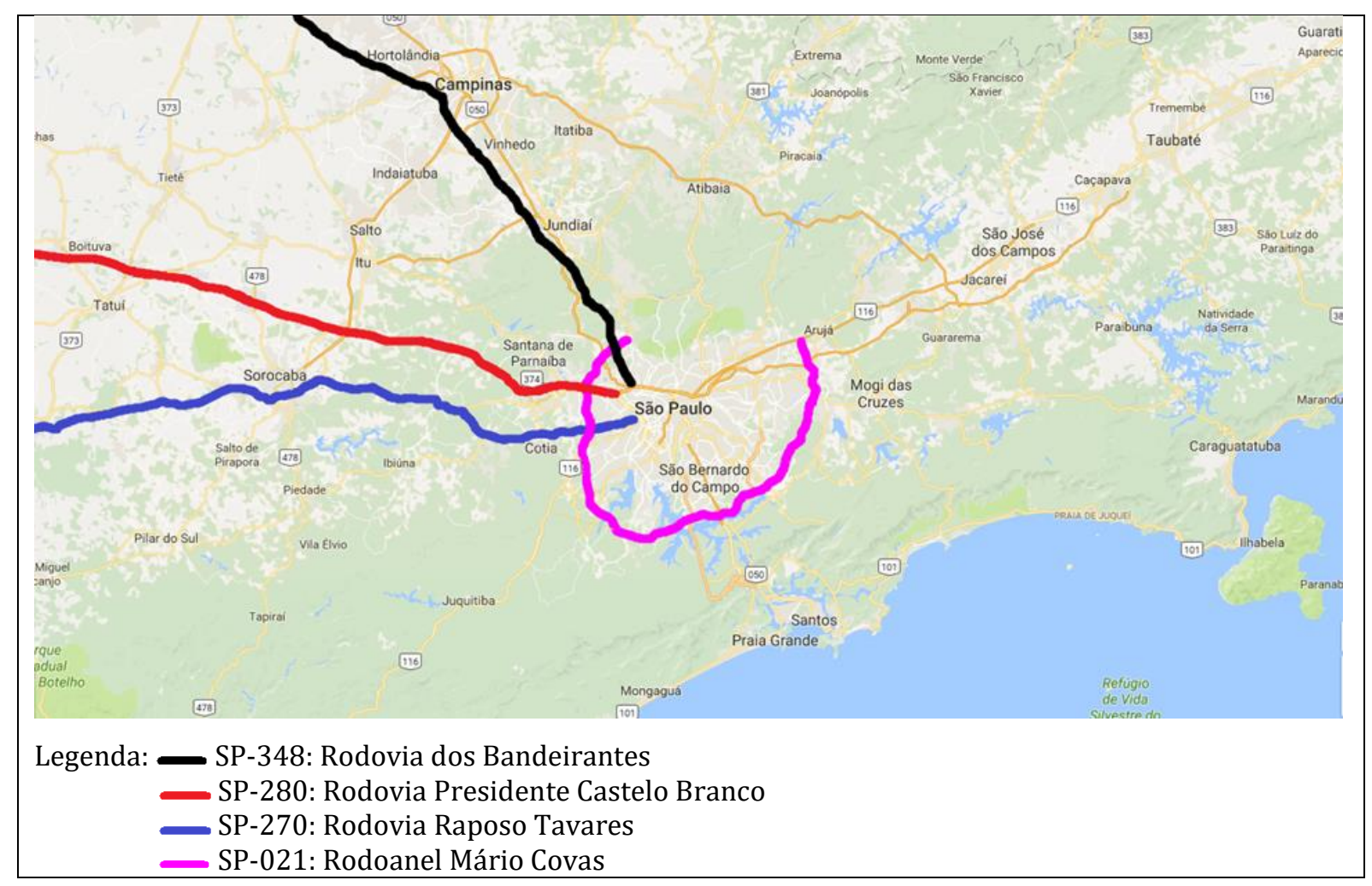

Fonte: Elaborada pelo autor

Como descrito anteriormente na obtenção de dados, o intervalo de amostragem da concessionária CCR ViaOeste é de 5 minutos e da AutoBan, de 6 minutos. Portanto, é importante analisar não só a quantidade de dados faltantes, mas também, quanto tempo esses dados representam. Ao todo foram verificados 20 sensores contendo os dados de tráfego de ambos sentidos da via, totalizando 685 planilhas que foram organizadas e filtradas em busca de ausência de informação. Com base nessa filtragem, uma planilha indica todos os sensores analisados e seu intervalo de ausência de informação no período 
de um ano está no Apêndice 3.2. Em resumo, os sensores com as menores quantidades de falhas foram da ordem de 4 horas em um ano. A Tabela 3.1 descreve os cinco locais e períodos com menores falhas observadas em relação aos demais.

Tabela 3.1 - Sensores com porcentagem inferior a 0,0436\% de dados faltantes

\begin{tabular}{lllllll}
\hline Rodovia & Km & Sentido & Período & Dados Faltantes & Equivalente em horas & \% \\
\hline SP-280 & 51,9 & L/OE & $09 / 2011$ a 08/2012 & 24 & 2 horas & 0,0228 \\
SP-280 & 51,9 & L/OE & $10 / 2011$ a 09/2012 & 27 & $2 \mathrm{~h} 15 \mathrm{~min}$ & 0,0256 \\
SP-280 & 51,9 & L/OE & $11 / 2011$ a 10/2012 & 32 & $2 \mathrm{~h} 40 \mathrm{~min}$ & 0,0304 \\
SP-280 & 22,3 & OM & 09/2012 a 08/2013 & 46 & $3 \mathrm{~h} 50 \mathrm{~min}$ & 0,0436 \\
SP-280 & 22,3 & OM & $10 / 2012$ a 09/2013 & 46 & $3 \mathrm{~h} 50 \mathrm{~min}$ & 0,0436 \\
\hline
\end{tabular}

Fonte: Elaborada pelo autor

Nota-se na Tabela 3.1 que os dados mais completos estão localizados na Rodovia Presidente Castelo Branco (SP-280) em dois sensores, km 51,9 e km 22,3. 0 km 51,9 no período de setembro/2011 a outubro/2012 foi o período com menor tempo total de falhas. Devido ao menor número de falhas (0,0228\%) observadas em um ano completo, foi escolhido o $\mathrm{km} \mathrm{51,9} \mathrm{no} \mathrm{período} \mathrm{de} \mathrm{setembro/2011} \mathrm{a} \mathrm{agosto/2012,} \mathrm{para} \mathrm{realizar} \mathrm{as}$ análises diárias, semanais, mensais e anuais.

\subsubsection{Estruturação do banco de dados}

A estruturação do banco de dados consiste em padronizar os dados para que os mesmos mantenham quantidade de dados por determinado período e não propague nenhum erro no sinal de entrada analisado.

Como a aplicação da Transformada Wavelet é realizada em séries temporais, as mesmas não podem apresentar falhas no sinal. Ou seja, ao se trabalhar com qualquer período de tempo ou escala, é necessário levar em consideração que não pode ocorrer saltos nos dados, pois ao aplicar a Transformada Wavelet ela decompõe o sinal por inteiro e não por partes.

Para estruturar o banco de dados escolhido em um sinal discreto de um ano de dados completo foram necessários resolver dois problemas. 0 primeiro com relação aos dados de fato faltantes e para isso optou-se por preencher com zero esse intervalo de duas horas, tanto para o fluxo como a velocidade. Os dois períodos de uma hora que foram 
alterados foram: (1) 16/10/2011 de 01:55 às 02:50 e (2) 17/02/2012 de 08:15 às 09:10.

O segundo problema foi com relação ao horário de verão para o período de um ano completo. Para o período avaliado, o início do horário de verão ocorreu no dia 16/10/2011, o que apresentou uma hora a menos de registro de informações para esse dia, ou seja, os dados iniciavam à 1:00 hora, ao invés de 0:00 hora. De forma semelhante, foi decidido preencher com valor zero tanto para o fluxo, como para a velocidade para o horário faltante. Por outro lado, o horário de verão encerrou no dia 25/02/2012, resultando em um período com 25 horas de registro, ao invés de 24 horas. Dessa forma, foi necessário excluir o intervalo que estava repetido para que todos os dias do ano tivessem o mesmo tamanho.

Conforme visto na seção 3.1.1, os dados disponibilizados são separados por tipo de veículo (automóveis, motos e comerciais) e faixa de tráfego. No entanto, no primeiro momento da pesquisa, o objetivo é analisar a variação global do comportamento do tráfego, por isso, os dados foram agregados por todos os tipos de veículo e todas as faixas para cada sentido da via (Leste e Oeste) e mantendo o intervalo de tempo original (5 minutos). A Tabela 3.2 apresenta as seis primeiras linhas do banco de dados analisado. A partir desses dados, é possível gerar os sinais de entrada. Como exemplo, a Figura 3-2 apresenta o sinal discreto do fluxo de tráfego para o período de um ano e a Figura 3-3 apresenta o sinal discreto da velocidade veicular para esse mesmo período.

Tabela 3.2 - 6 primeiros pontos do banco de dados estruturado

\begin{tabular}{rrrrr}
\hline & ID & Data & Fluxo & Velocidade \\
\hline $\mathbf{1}$ & $01 / 09 / 201100: 05$ & 37 & 89 \\
$\mathbf{2}$ & $01 / 09 / 201100: 10$ & 48 & 82 \\
$\mathbf{3}$ & $01 / 09 / 201100: 15$ & 26 & 85 \\
$\mathbf{4}$ & $01 / 09 / 201100: 20$ & 47 & 81 \\
$\mathbf{5}$ & $01 / 09 / 201100: 25$ & 52 & 82 \\
$\mathbf{6}$ & $01 / 09 / 201100: 30$ & 37 & 90 \\
\hline
\end{tabular}

Fonte: Elaborada pelo autor 
Figura 3-2 - Fluxo de tráfego no sentido Leste no período de um ano completo na rodovia SP-280 km 51,9

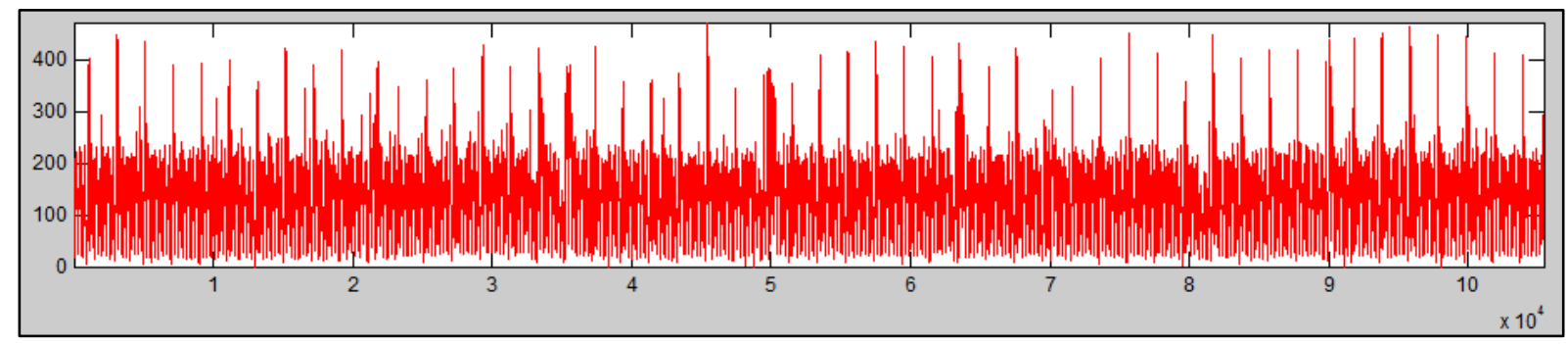

Fonte: Elaborada pelo autor

Figura 3-3 - Velocidade veicular no sentido Leste no período de um ano completo na rodovia SP-280 km 51,9

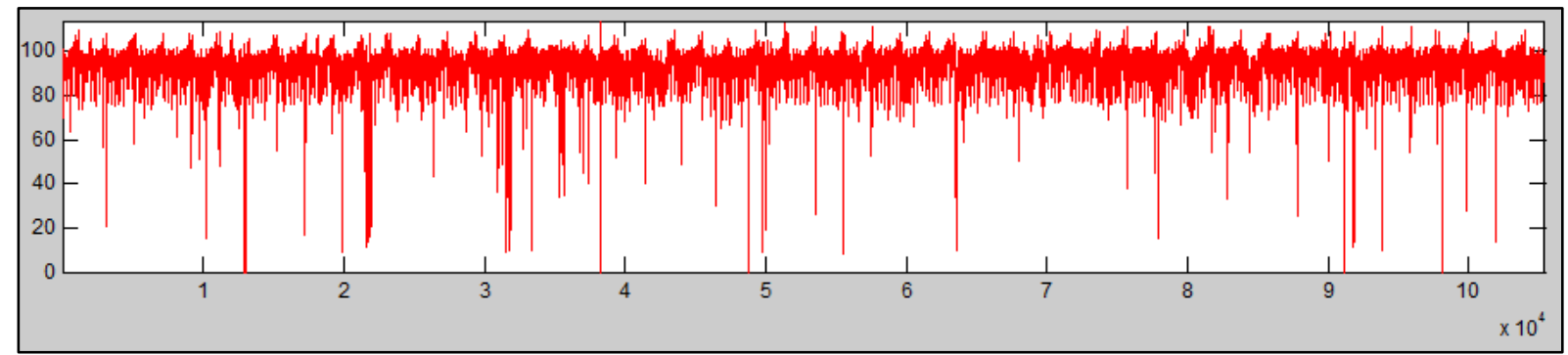

Fonte: Elaborada pelo autor

\subsection{ANÁLISE DO SINAL DE ENTRADA}

Com o banco de dados estruturado e os sinais discretos formados, é possível aplicar a Transformada Wavelet Discreta. A TWD gera dois componentes em cada nível, o Componente de Detalhe e de Aproximação. Nesta pesquisa, foram utilizados os Componentes de Detalhe para detecção de anomalias e os Componentes de Aproximação para identificar comportamentos no tráfego veicular

Nesta seção são abordadas as especificações necessárias para aplicação da Transformada Wavelet e, em seguida, uma caracterização dos coeficientes gerados.

\subsubsection{Período do sinal}

Antes de aplicar a Transformada Wavelet foi necessário determinar o período do sinal de entrada, ou seja, quanto tempo de fluxo e velocidade seriam analisados. Como visto anteriormente, o banco de dados foi estruturado para um ano completo. Os sinais gerados por esses dados são vetores com uma quantidade $(x)$ de pontos. Como o intervalo 
de entrada $(t)$ era conhecido (5 minutos), foi calculado quantos pontos cada vetor continha, dividindo o tempo total do vetor (T) em minutos por $t$. A Tabela 3.3 apresenta a quantidade de pontos nos vetores mais utilizados nesta pesquisa: uma hora, um dia, uma semana, um mês (29, 30 e 31 dias) e um ano bissexto (366 dias).

Tabela 3.3 - Quantidades de pontos em cada vetor

\begin{tabular}{rc} 
Vetor & $\begin{array}{c}\text { Quantidade de pontos } \\
(\mathrm{x}=\mathrm{T} / \mathrm{t})\end{array}$ \\
\hline 1 hora & 12 \\
$\mathbf{1}$ dia & 288 \\
$\mathbf{7}$ dias & 2.016 \\
$\mathbf{2 9}$ dias & 8.352 \\
$\mathbf{3 0}$ dias & 8.640 \\
$\mathbf{3 1}$ dias & 8.928 \\
$\mathbf{3 6 6}$ dias & 105.480 \\
\hline
\end{tabular}

Fonte: Elaborada pelo autor

\subsubsection{Definição da Wavelet e nível de decomposição}

Os dados analisados nesta pesquisa são séries temporais com variações bruscas na frequência e em forma de degraus. Há uma variação a cada ponto do sinal original, seja no fluxo veicular ou velocidade média. Segundo Barbosa e Blitzkow (2008) para este tipo de sinal, a Wavelet de Haar é a mais indicada.

A Transformação nível 1 ocorre quando é aplicada a Transformada Wavelet em um sinal. 0 nível 2 ocorre quando é aplicada a Transformada Wavelet no primeiro componente (Componente de Aproximação) desse sinal já transformado, e assim por diante (GUIDO, SLAETS e ALMEIDA, 2012). Para definir o nível de decomposição a ser analisado, foi necessário compreender o resultado do sinal a cada nível de decomposição $(n)$, pois a partir desse nível seria possível saber a localização da frequência analisada. Como o sinal original tinha intervalos $t$ de 5 minutos, cada nível de decomposição $(n)$ redimensionava o sinal para uma nova janela de intervalo $t \cdot 2^{n}$. A Tabela 3.4 apresenta as janelas de tempo para cada nível. 
Tabela 3.4 - Escala da janela em cada nível para os dados analisados

\begin{tabular}{|c|c|c|}
\hline Nível (n) & \multicolumn{2}{|c|}{ Janela de tempo $\left(5 \times 2^{n}\right)$} \\
\hline 1 & $10 \mathrm{~min}$ & \\
\hline 2 & $20 \mathrm{~min}$ & \\
\hline 3 & $40 \mathrm{~min}$ & \\
\hline 4 & $80 \mathrm{~min}$ & $(1 \mathrm{~h} 20 \mathrm{~min})$ \\
\hline 5 & $160 \mathrm{~min}$ & $(2 \mathrm{~h} 40 \mathrm{~min})$ \\
\hline 6 & $320 \mathrm{~min}$ & $(5 \mathrm{~h} 20 \mathrm{~min})$ \\
\hline 7 & $640 \mathrm{~min}$ & (10h 40min) \\
\hline 8 & $1.280 \mathrm{~min}$ & $(21 \mathrm{~h} 20 \mathrm{~min})$ \\
\hline 9 & $2.560 \mathrm{~min}$ & (1 dia $18 \mathrm{~h} 40 \mathrm{~min})$ \\
\hline 10 & $5.120 \mathrm{~min}$ & (3 dias $13 \mathrm{~h} 20 \mathrm{~min}$ ) \\
\hline 11 & $10.240 \mathrm{~min}$ & (7 dias 2 h $40 \mathrm{~min}$ ) \\
\hline 12 & $20.480 \mathrm{~min}$ & (14 dias 5 h $20 \mathrm{~min}$ ) \\
\hline 13 & $40.960 \mathrm{~min}$ & (28 dias 10 h $40 \mathrm{~min}$ ) \\
\hline 14 & $81.920 \mathrm{~min}$ & (56 dias 21 h $20 \mathrm{~min}$ ) \\
\hline 15 & $163.840 \mathrm{~min}$ & (113 dias $18 \mathrm{~h} 40 \mathrm{~min}$ ) \\
\hline 16 & $327.680 \mathrm{~min}$ & (227 dias 13 h $20 \mathrm{~min})$ \\
\hline
\end{tabular}

Fonte: Elaborada pelo autor

Outra forma de compreender a decomposição a cada nível é pela quantidade de pontos fornecida para cada novo coeficiente. Pela teoria da Transformada Wavelet Discreta em análise de multirresolução, sabe-se que a cada novo nível o sinal diminui pela metade. A Tabela 3.5 apresenta a quantidade de pontos dos coeficientes para cada nível dos vetores mais utilizados nesta pesquisa.

Tabela 3.5 - Quantidade de pontos por nível de decomposição

\begin{tabular}{|c|c|c|c|c|c|c|}
\hline Nível & $1 \mathrm{dia}$ & 7 dias & 29 dias & 30 dias & 31 dias & 366 dias \\
\hline 1 & 144 & 1.008 & 4.176 & 4.320 & 4.464 & 52.704 \\
\hline 2 & 72 & 504 & 2.088 & 2.160 & 2.232 & 26.352 \\
\hline 3 & 36 & 252 & 1.044 & 1.080 & 1.116 & 13.176 \\
\hline 4 & 18 & 126 & 522 & 540 & 558 & 6.588 \\
\hline 5 & 9 & 63 & 261 & 270 & 279 & 3.294 \\
\hline 6 & 5 & 32 & 131 & 135 & 140 & 1.647 \\
\hline 7 & 3 & 16 & 66 & 68 & 70 & 824 \\
\hline 8 & 2 & 8 & 33 & 34 & 35 & 412 \\
\hline 9 & - & 4 & 17 & 17 & 18 & 206 \\
\hline 10 & - & 2 & 9 & 9 & 9 & 103 \\
\hline 11 & - & - & 5 & 5 & 5 & 52 \\
\hline 12 & - & - & 3 & 3 & 3 & 26 \\
\hline 13 & - & - & 2 & 2 & 2 & 13 \\
\hline 14 & - & - & - & - & - & 7 \\
\hline 15 & - & - & - & - & - & 4 \\
\hline 16 & - & - & - & - & - & 2 \\
\hline
\end{tabular}

Fonte: Elaborada pelo autor

Ao analisar a Tabela 3.5, foi observado que a quantidade de pontos a cada nível de decomposição reflete uma escala de tempo. Por exemplo, no nível 11 são 52 pontos e sabe- 
se que em um ano são 52 semanas, portanto cada ponto desse nível representa aproximadamente uma semana, o que pode ser conferido na Tabela 3.4 que apresenta a escala de tempo para o nível 11 (7 dias 2 horas e 40 minutos). Portanto, para as análises de variação temporal, basta escolher o nível de decomposição correspondente à escala de tempo que se deseja analisar. Porém, deve-se tomar cuidado com o tamanho da escala de tempo usada, pois pode não refletir o intervalo desejado, conforme explicado a seguir.

Como visto, é possível calcular a quantidade de pontos para cada nível e a distância entre esses pontos. Porém, quando a quantidade de pontos do sinal original não for potência de base dois, a partir de um certo nível, a janela de decomposição é maior do que a última janela do sinal a ser decomposto, impossibilitando assim, a sua decomposição e, consequentemente, essa última janela do sinal é mantida até o último nível de decomposição possível. Por exemplo, a Figura 3-4 apresenta o sinal ( $s$ ) do fluxo de tráfego veicular do dia 04/09/2011 (Domingo, 24 horas, 288 intervalos de 5 minutos) e a sua decomposição pela Transformada Wavelet em até 8 níveis, representados pelos Componentes de Aproximação $\left(a_{i}\right)$ e de Detalhe $\left(d_{i}\right)$.

Figura 3-4 - Componentes de Aproximação e de Detalhe - Período de 24 horas

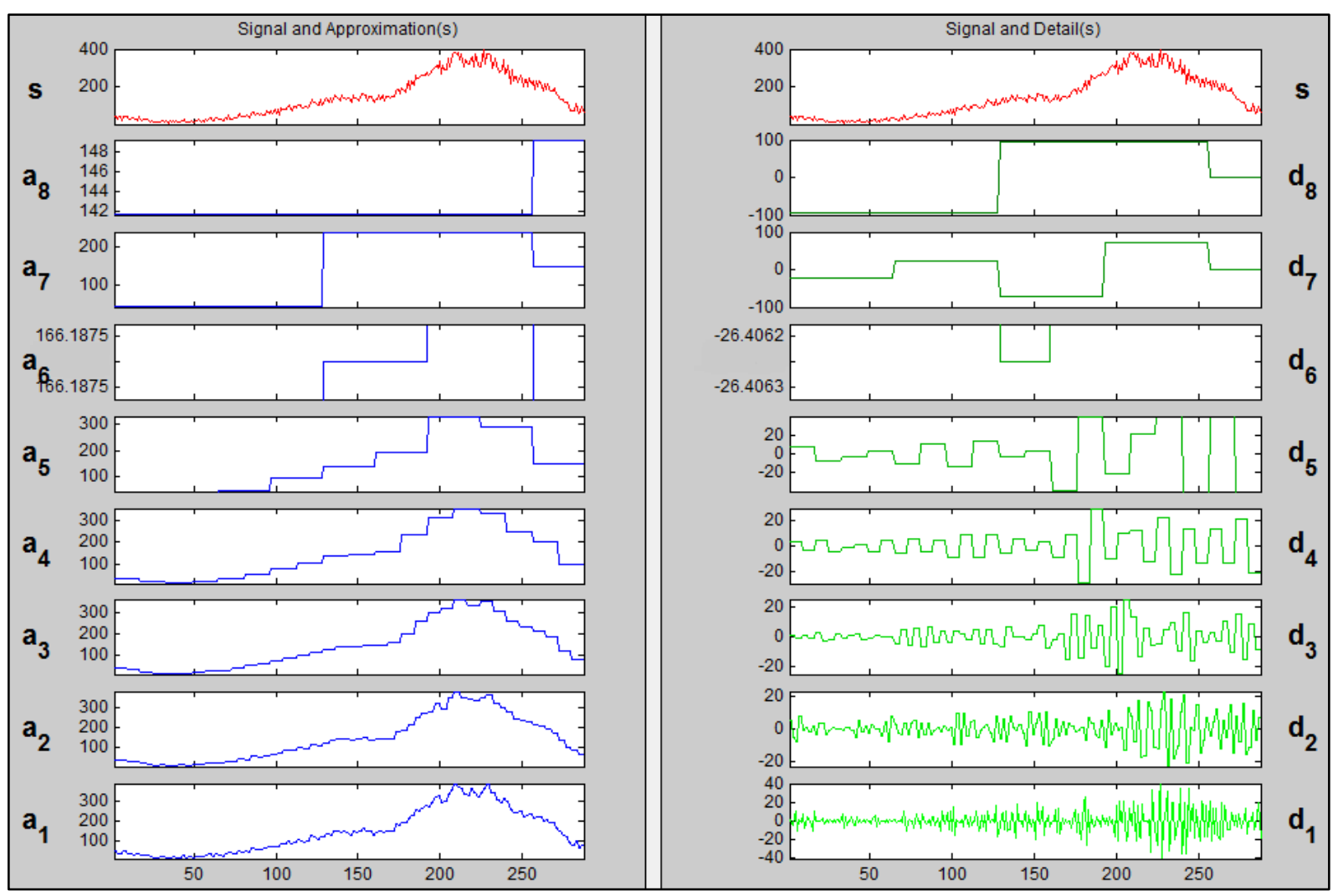

Fonte: Elaborada pelo autor 
Como a quantidade de pontos do sinal original não corresponde a potência de base dois, nota-se que nos níveis 6, 7 e 8 os pontos de 257 a 288 não foram decompostos. No nível 8 o Componentes de Aproximação $\left(a_{8}\right)$ evidencia essa diferença entre janelas. A primeira janela abrange os pontos de 0 a 256 correspondente ao período das 00:00 às 21:20 horas, enquanto a segunda janela abrange os pontos de 257 a 288 correspondendo das 21:21 às 23:59 horas. A potência de base dois mais próxima ao período de um dia seria de 256 pontos (21 horas e 20 minutos).

Apenas para ilustrar uma decomposição com uma quantidade de pontos igual a uma potência de base dois, foram excluídos os dados que não foram decompostos a partir do nível 5 da Figura 3-4, e mantidos os 256 pontos iniciais, conforme apresenta a Figura 3-5. No entanto, esse novo conjunto não reflete a situação real ao longo do dia e para o caso do exemplo de domingo, a situação se torna mais grave, pois mantem informações no período de baixo fluxo de tráfego e elimina quando o fluxo de tráfego é alto.

Para evitar que isso ocorra e comprometa a aplicação da Transformada Wavelet nos dados de tráfego veicular, o período de análise foi mensal e anual e não foram utilizados níveis de decomposição com grandes janelas, pois nenhum sinal de entrada era potência de base dois.

Considerando essas análises para a detecção de anomalias nos dados anual e mensais foram utilizados os níveis:

a) 1 e 2: por serem as primeiras decomposições e próximo ao intervalo de 15 minutos;

b) 3 e 4: por serem os dois níveis mais próximos a uma hora;

c) 8: por ser a janela mais próxima a um dia (21 horas e 20 minutos);

d) 11: por ser mais próximo a uma semana (7 dias 2 horas e 40 minutos).

Para a análise do comportamento do tráfego veicular utilizou o nível de decomposição 4. Nesse nível o Componente de Aproximação contém 18 pontos que representam as características do sinal original com 288 pontos. 
Figura 3-5 - Componentes de Aproximação e de Detalhe - Período de 21 horas e 20 minutos

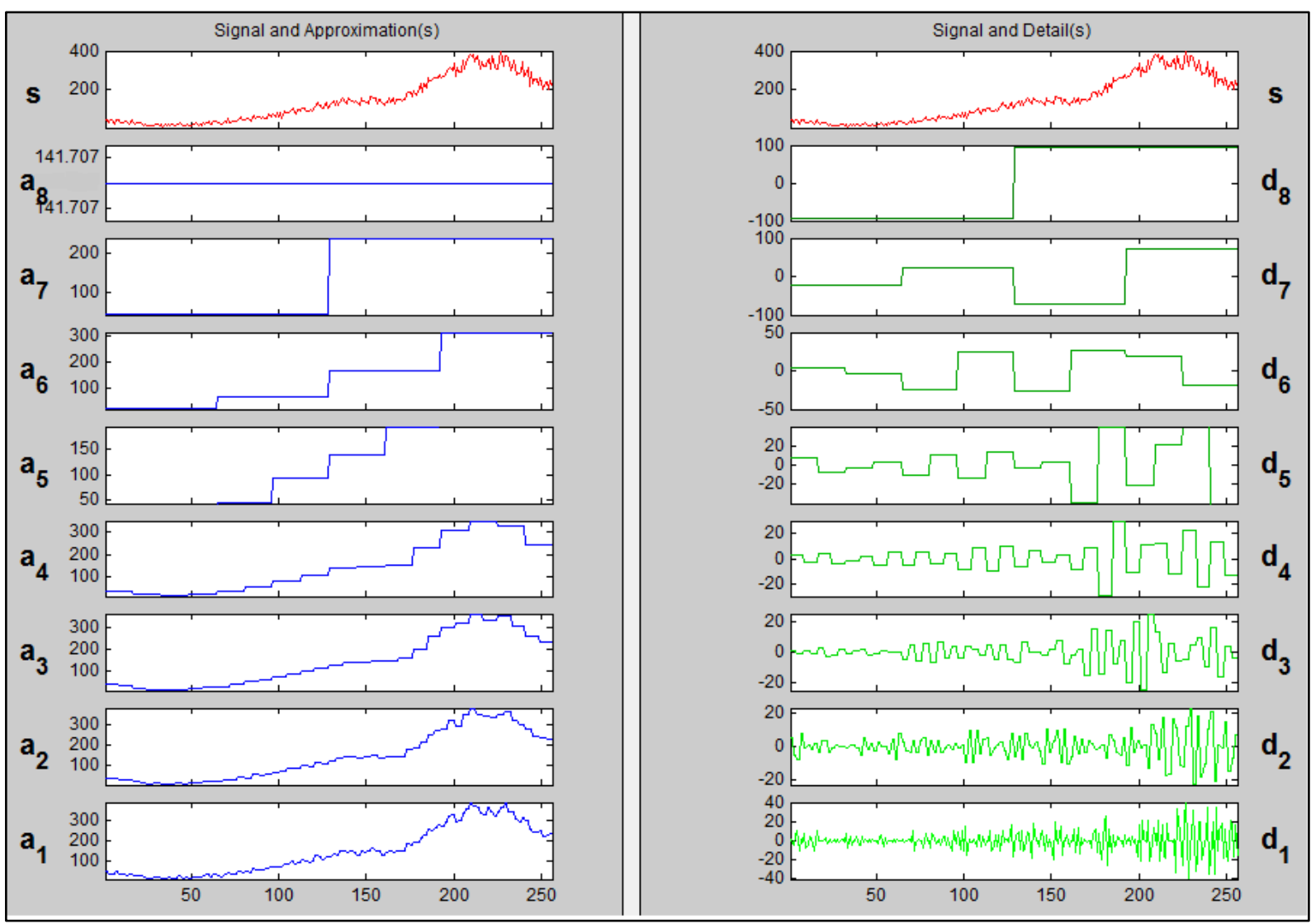

Fonte: Elaborada pelo autor

Vale ressaltar a importância de analisar a escala da janela, pois o tamanho (quantidade de pontos) dos componentes (Aproximação e Detalhe) diminui conforme aumenta o nível de decomposição. No entanto, essa é a referência para localização em relação ao sinal original. Apesar dos coeficientes diminuírem de tamanho, não há perda de informações e é possível retornar ao sinal original por meio da Transformada Wavelet Inversa. Para uma análise no nível 4, por exemplo, o sinal precisa ser decomposto três vezes antes e para realizar a Transformada Inversa precisa-se dos coeficientes dos quatro níveis.

As escalas das janelas dependem do intervalo do sinal original e apesar de se ter adotado um nível de escala próximo ao período escolhido, não foi possível definir a escala de uma hora, de um dia, ou de uma semana. Para se obter uma janela exata de uma hora, os dados de entrada deveriam ter períodos de 7,5 minutos (nível 3) ou 3,5 minutos (nível 4). Para 1 dia (24 horas) o intervalo de entrada deveria ser de 5,625 minutos (nível 8) ou 2,8125 (nível 9) e, por fim, para uma semana o ideal seria de 4,921875 minutos (nível 11). 
Se o intervalo de entrada fosse a cada segundo, seria possível adaptar a amostragem a fim de utilizar esses intervalos. Como os dados utilizados para esta pesquisa foram analisados de 5 em 5 minutos, trabalhou-se apenas com intervalos próximos.

\subsection{CONSIDERAÇÕES FINAIS}

Este capítulo apresentou a forma como os dados foram obtidos, as etapas para o seu tratamento, como o banco de dados final foi estruturado e o sinal de entrada de fluxo de tráfego e velocidade veicular foram gerados. Em seguida foram abordadas as especificações necessárias para aplicação da Transformada Wavelet Discreta e a caracterização dos coeficientes gerados.

Após estabelecer esses parâmetros, com o auxílio dos métodos complementares, o Capítulo 4 aborda o método para reconhecimento de padrões e o Capítulo 5, o método para detecção de anomalia. 


\section{ReCONHECIMENTO DE PADRÕES EM DAdOS}

\section{DE TRÁFEGO}

Nesse capítulo é tratado o segundo objetivo específico para cumprir o objetivo global: reconhecer padrões no comportamento do tráfego. Na literatura há diversos estudos que avaliaram métodos para reconhecimento de padrões do tráfego (CHUNG, 2003; GHOSH; BASU; O'MAHONY, 2006; IVAN, 2002; JIANG; ADELI, 2004; RAKHA; AERDE, 1995; STATHOUPOULOS; KARLAFTIS, 2001; THOMAS; WEIJERMARS, BERKUM, 2008; WEIJERMARS; BERKUM, 2005).

Dentre essas pesquisas, apenas três utilizaram a Transformada Wavelet em seus métodos: Chung (2003), Jiang e Adeli (2004) e Ghosh, Basu e O’Mahony (2006). Chung (2003), com o intuito de classificar dados históricos de tempo de viagem, determinou padrões ao longo de uma rota em Tóquio (Japão). 0 autor dividiu o dia em dois períodos: (AM) entre 07:00 e 13:00; e (PM) entre 15:00 e 20:00. O método consistiu em aplicar a Transformada Wavelet para suavização das curvas e agrupar padrões através de análise de cluster. Chung (2003) concluiu que o período AM podia ser agrupado em dias da semana, sábados, domingos e feriados, enquanto que o período PM, os dias da semana deveriam ser tratados separadamente.

Jiang e Adeli (2004) compararam os coeficientes gerados por uma Transformada Wavelet Discreta e uma Transformada Wavelet Discreta de Multirresolução a partir de uma função de autocorrelação estatística. Uma das conclusões apontou que a Transformada Wavelet Discreta de Multirresolução pode capturar propriedades sutis do fluxo de tráfego, incluindo singularidades sem perda de detalhes.

Ghosh, Basu e O'Mahony (2006) utilizaram o coeficiente de aproximação gerado pela Transformada Wavelet para representar a tendência diária do fluxo de tráfego e separadamente, modelaram o coeficiente de detalhe. Em seguida, adicionaram à tendência e obter uma natureza aproximada do fluxo de tráfego ao longo de um dia.

Esses trabalhos reforçam as vantagens da Transformada Wavelet como uma 
ferramenta útil. Esta pesquisa, por sua vez, pretende realizar uma análise exploratória dos coeficientes gerados a partir de dados históricos para reunir o máximo de informações do comportamento de tráfego, antes do seu uso em qualquer uma de suas aplicações.

Este capítulo está dividido em três seções. A primeira apresenta o procedimento usado para o reconhecimento de padrões usada nesta dissertação. 0 segundo, é a análise dos resultados nos dados em que o método foi aplicado. Por fim, são apresentadas as considerações finais do capítulo.

\subsection{MÉTODO PARA RECONHECIMENTO DE PADRÕES}

O método proposto para reconhecimento de padrões nesta pesquisa está dividido em três etapas. A primeira etapa é a escolha do coeficiente gerado pela Transformada Wavelet, o que inclui: o tipo de dado de tráfego veicular (fluxo ou velocidade), qual coeficiente gerado foi utilizado (Detalhe ou Aproximação) e qual nível de decomposição foi escolhido para as análises. A segunda etapa define a análise de agrupamento aplicada. Nessa etapa são definidos: o procedimento (hierárquico ou não-hierárquico), o método e a distância de similaridade. Por fim, a terceira etapa consiste em aplicar esses dois procedimentos nos sinais originais divididos por dia, primeiro no período de um ano e depois a cada mês separadamente, para o sentido Leste e Oeste da rodovia, encerrando assim, a terceira etapa desse procedimento.

Com os agrupamentos formados, são apresentadas as curvas suavizadas pela Transformada Wavelet para cada cluster, reconhecendo assim, o padrão de tráfego para esses dias. A Figura 4-1 apresenta a estrutura do procedimento utilizado para o reconhecimento de padrões no comportamento do tráfego e cada passo desse procedimento é apresentado em detalhes nesta seção. 
Figura 4-1 - Etapas do método proposto para reconhecimento de padrões no comportamento do tráfego

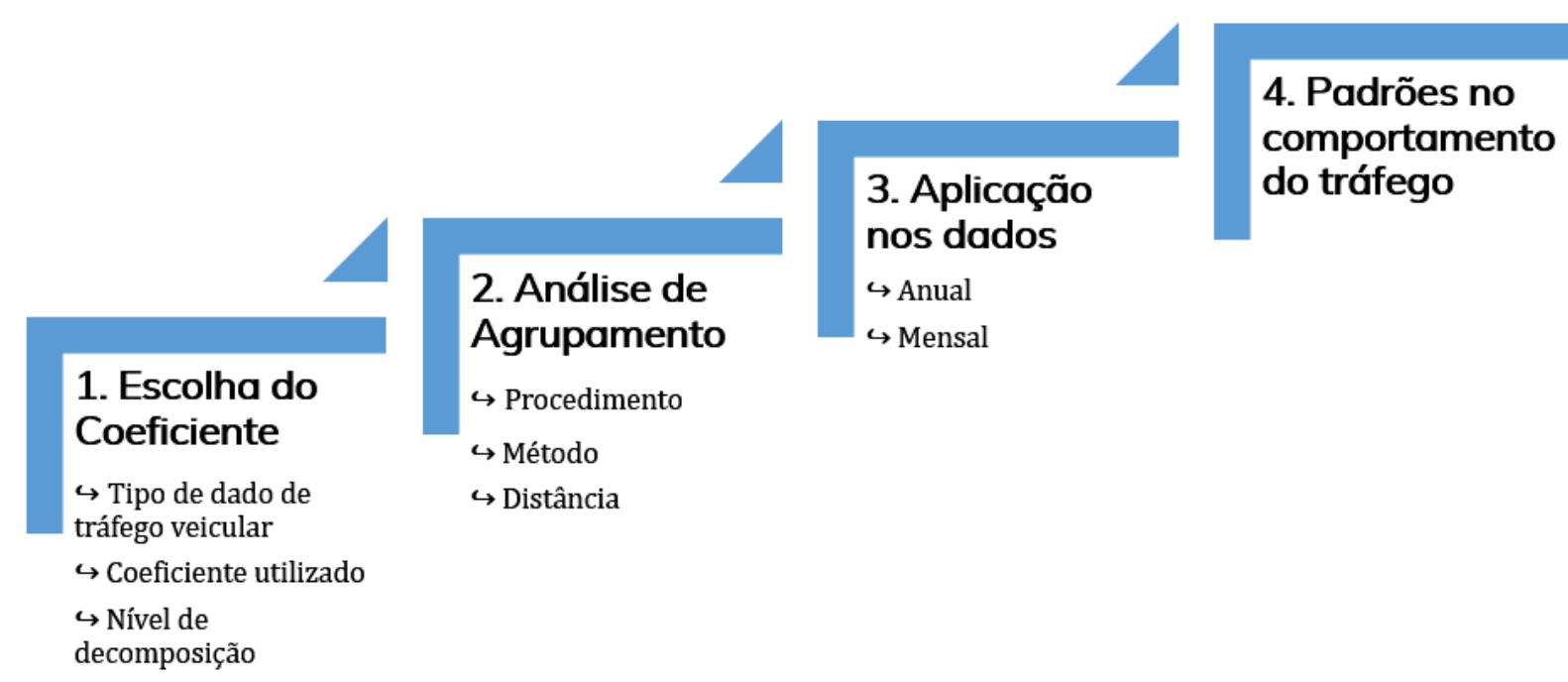

Fonte: Elaborada pelo autor

\subsubsection{Escolha do coeficiente analisado}

A primeira etapa para o reconhecimento de padrões foi escolher quais dados seriam utilizados. A caracterização da corrente de tráfego foi realizada a partir dos dados de taxas de fluxo e velocidade de tráfego. No entanto, para analisar padrões no comportamento do tráfego foi utilizado apenas os dados de fluxo. Isso porque o fluxo apresenta um comportamento ao longo do dia mais bem definido do que a velocidade veicular. Conforme destaca Chung (2003), os padrões do tempo de viagem (derivados da velocidade e distância do ponto $\mathrm{A}$ ao $\mathrm{B}$ da rota analisada) são muito diferentes entre os períodos de tarde e noite a qualquer dia específico da semana.

Após definir a utilização dos dados de fluxo de tráfego, foi definido qual dos dois componentes (Detalhe ou Aproximação) gerados pela Transformada Wavelet seria utilizado. 0 Coeficiente de Detalhe, resultado de filtro passa-alta, apresenta a diferença de frequência no sinal analisado. Em contrapartida, o Componente de Aproximação é gerado por filtro passa-baixa, resultando em sinais suavizados do sinal original, livre de ruídos, mas preservando suas características iniciais. A Figura 4-2 apresenta o sinal original e os coeficientes gerado pela Transformada Wavelet de Haar. O primeiro gráfico, linha vermelha, apresenta os dados de fluxo de tráfego em uma resolução de 5 minutos para o período de uma semana, que começa no domingo (Dia 1) e encerra no sábado (Dia 7). 0 segundo gráfico, linha azul, apresenta o coeficiente de aproximação no nível 1 e por fim, o terceiro gráfico, linha verde, apresenta o coeficiente de detalhe para o nível 1. A Figura 
4-2 apresenta a nítida diferença entre os coeficientes gerados. Enquanto o coeficiente de aproximação se assemelha ao sinal original, o coeficiente de detalhe, aparenta ser ruidoso. Portanto, para o reconhecimento de padrões foi utilizado o componente de aproximação.

Figura 4-2 - Coeficiente de Aproximação e Detalhe no nível para um sinal no período de uma semana

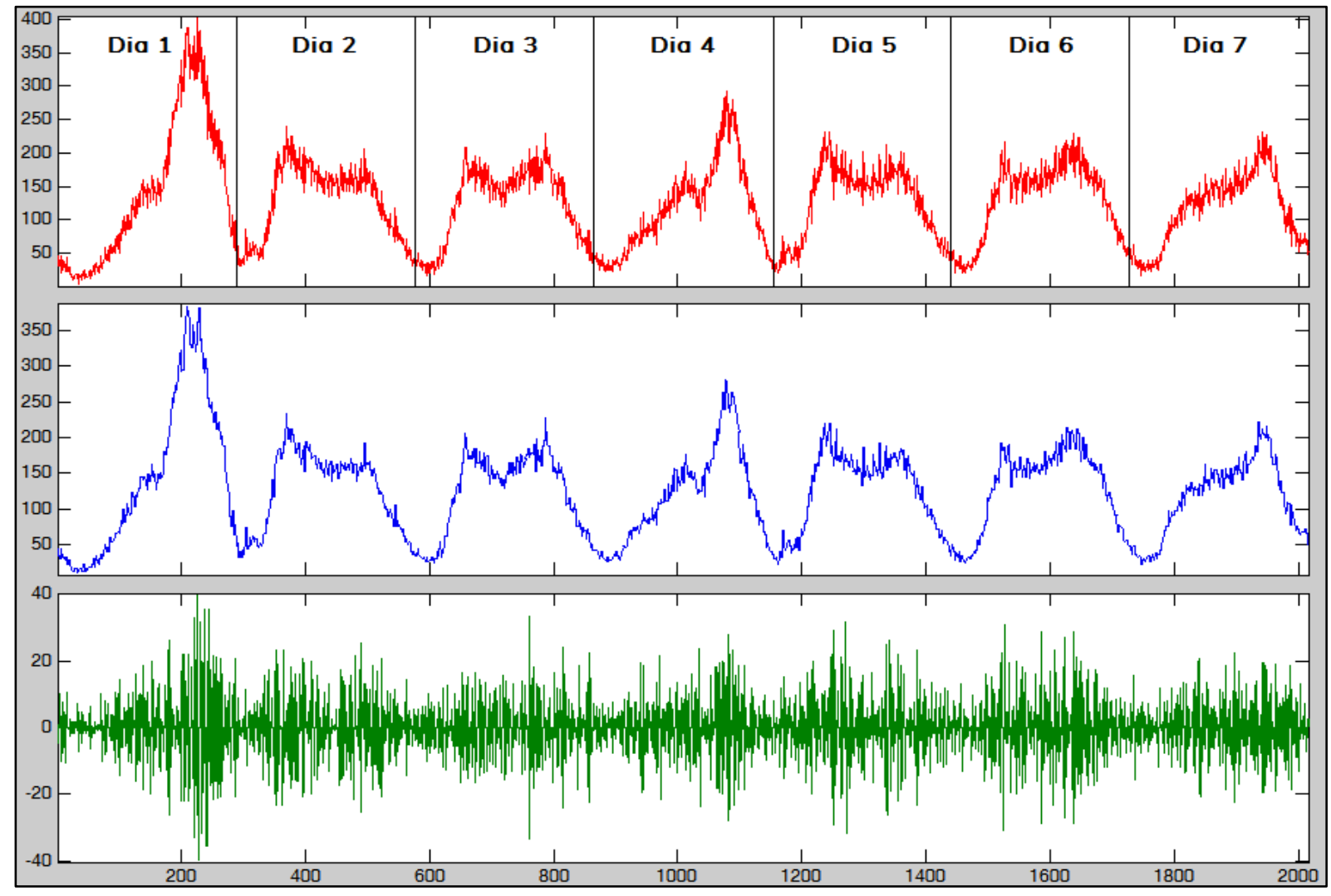

Fonte: Elaborada pelo autor

Após definir os dados de entrada e qual Coeficiente seria analisado, determinou-se o nível de decomposição da Transformada Wavelet. Essa escolha interfere na escala em que o sinal é analisado. Conforme visto na seção 3.2.2 do Capítulo 3, a partir do tamanho do intervalo do sinal original, cada nível resultará em um intervalo diferente. Na área de Engenharia de Transportes, de modo geral a análise do comportamento do fluxo horário é o parâmetro mais importante, tanto em planejamento, projeto como na análise operacional de sistemas de transportes. Dessa forma, o nível 4 de decomposição foi definido para esta análise por ser o nível mais próximo a uma hora (80 minutos). Nesse nível o Componente de Aproximação contém 18 pontos que representam as características do sinal original com 288 pontos. Vale ressaltar que independentemente do nível de decomposição da Transformada Wavelet, não há perdas de informação do sinal 
original, pois a propriedade da Transformada Inversa garante a reconstrução do sinal original a partir dos Componentes de Aproximação e Detalhe.

Assim, o Componente utilizado para o reconhecimento de padrão foi o Componentes de Aproximação no nível 4 ( $C A 4$ ) gerado pela decomposição da Transformada Wavelet de Haar dos dados de fluxo de tráfego. Após definir o coeficiente utilizado, foi definido qual técnica seria utilizada para formar grupos com os sinais mais similares entre si.

\subsubsection{Análise de agrupamento}

A Análise de Cluster é um conjunto de técnicas que agrupa os elementos com base em suas características. Cada grupo tende a ter objetos similares entre si, enquanto os diferentes grupos apresentam significativa diferença em suas características. Assim, o objetivo da análise de agrupamentos é maximizar a homogeneidade dos objetos dentro das classes e maximizar a heterogeneidade entre as classes (KAUFMAN; ROUSSEUW, 1990; HAIR et al., 2005). Geralmente, a análise de agrupamento é usada para fins exploratórios, podendo ser usada também para formação de taxonomia, simplificação de dados ou ainda identificação de relações (HAIR et al., 2005).

Diversos trabalhos relatam as aplicações de análise de agrupamento em áreas da Engenharia de Transportes (CHUNG, 2003; WEIJERMARS; BERKUM, 2005; THOMAS; WEIJERMARS; BERKUM, 2008), outros trabalhos utilizaram esse tipo de análise para classificação de dados (CUNHA; SETTI, 2008; ZHU et al., 2016), economia de transportes (KUMAR et al., 2016), prevenção de acidentes (OÑA et al., 2016) e Sistema de Informação de Tráfego (ARKIAN et al., 2014; NALDI et al., 2013).

Para a aplicação da análise de cluster é necessário definir a medida de similaridade a ser calculada nas variáveis e o algoritmo de agrupamento, para então realizar e interpretar os agrupamentos. Similaridade é a medida de correspondência ou semelhança entre os objetos a serem agrupados. Pode ser medida de diversas maneiras, tais como: correlacionais, de distância e de associação. Sendo que a escolha do método depende dos tipos de variáveis em análise.

Medidas correlacionais são os coeficientes de correlação entre os objetos medidos sob diversas variáveis, representando a similaridade pela correspondência de padrões. Medidas de distância baseiam-se na proximidade entre as observações, concentrando-se 
na magnitude dos valores. As medidas de distância comumente usadas são a distância euclidiana, a distância euclidiana quadrada e distância city-block. Por fim, medidas de associação são utilizadas para comparar objetos de cujas características são medidas apenas em termos não métricos (medida nominal ou ordinal) (HAIR et al., 2005). Após definir a medida de distância a ser utilizada, define-se o algoritmo de agrupamento.

Os algoritmos de agrupamentos são divididos em duas categorias: hierárquico e não-hierárquico. A escolha do algoritmo deve se basear na maximização da heterogeneidade entre os grupos e homogeneidade dos objetos dentro do mesmo. Procedimentos hierárquicos de agrupamento consistem em sucessivos agrupamentos ou divisões de elementos, onde os mesmos serão agregados ou desagregados. Os grupos formados são geralmente representados por dendograma, onde cada ramo representa um elemento e a raiz o agrupamento de todos os elementos. Já os procedimentos nãohierárquicos consistem em se fixar inicialmente um número $k$ de classes que serão constituídos e classificados os elementos. 0 método mais conhecido de procedimento não-hierárquico é o $k$-means (HAIR et al., 2005).

0 método de agrupamento definido para esta pesquisa foi o procedimento hierárquico de Ward utilizando a distância euclidiana quadrática pois tende a produzir agrupamentos com tamanhos aproximados, minimizando a variação interna dos grupos (HAIR et al., 2005; WEIJERMARS; BERKUM, 2005). Já a distância euclidiana quadrática por ser uma medida que representa o comprimento de um segmento de reta entre dois objetos, é recomendada para o método centroide e de Ward (HAIR et al., 2005).

\subsection{ANÁlise dos Resultados}

Para facilitar a compreensão e análise dos resultados, o método para o reconhecimento de padrões foi aplicado em dados de entrada distintos. Primeiro foi aplicado no sinal completo de um ano, depois analisado para cada mês independente, para o mesmo período de um ano. Em seguida, foi analisado o fluxo direcional da rodovia, aplicando o método no sentido Leste e Oeste. Por fim, foi realizado uma análise comparativa com métodos empíricos utilizados para definir padrões do comportamento de tráfego. 


\subsubsection{Análise por período}

Primeiramente, o método proposto nesta pesquisa foi aplicado no período de um ano completo (01/09/2011 à 31/08/2012) no sentido Leste da Rodovia Presidente Castelo Branco, km 51,9, decomposto pela Transformada Wavelet de Haar em quatro níveis. Em seguida, foi aplicado a Análise de Cluster com o método hierárquico de Ward para a formação de grupos.

Foram avaliados cenários de 3 a 15 clusters formados. Em geral, os resultados obtidos não foram satisfatórios, pois os feriados formaram vários grupos isolados e o restante dos dias do ano permaneceram juntos em apenas dois grupos. Foi possível identificar grupos formados por dias típicos da semana a partir de 7 clusters (Figura 4-3), porém ainda com interferência de feriados que ocorreram durante a semana, assim como os dias anteriores e posteriores a algum feriado.

Da Figura 4-3, observa-se que o grupo 1 (G1) é formado predominantemente pelas terças, quartas e quintas-feiras. 0 grupo 2 (G2) é formado na maioria pelas sextas-feiras, com exceção do dia 6 de abril (feriado - sexta-feira da Paixão) e 8 de junho (pós-feriado Corpus Christi 07/06/2012). Além de sextas-feiras, o grupo 2 também é formado pelos dias úteis das duas últimas semanas de dezembro, a primeira de janeiro e os pré-feriados 14 de novembro (Proclamação da República - 15/11/2011), 5 de abril (sexta-feira da Paixão - 06/04/2012) e 30 de abril (Dia do Trabalho - 01/05/2012). Isso ilustra que o comportamento dos pré-feriados se manteve similar aos de sextas-feiras. 
Figura 4-3- Resultado da análise de agrupamento com 7 clusters para o período de um ano

\begin{tabular}{|c|c|c|c|c|c|c|c|c|c|c|c|c|c|c|c|c|c|c|c|c|c|c|c|c|c|c|c|c|}
\hline \multicolumn{7}{|c|}{ Setembro de 2011} & \multicolumn{8}{|c|}{ Outubro de 2011} & \multicolumn{7}{|c|}{ Novembro de 2011} & \multicolumn{7}{|c|}{ Dezembro de 2011} \\
\hline D & $\mathbf{s}$ & $\mathbf{T}$ & $\mathbf{Q}$ & \begin{tabular}{|l|}
$\mathbf{Q}$ \\
\end{tabular} & $\mathbf{s}$ & $\mathbf{s}$ & D & & & $\mathbf{T}$ & $\mathbf{Q}$ & $\mathbf{Q}$ & $\mathbf{s}$ & $\mathbf{s}$ & D & $\mathbf{s}$ & $\mathbf{T}$ & $\mathbf{Q}$ & $\mathbf{Q}$ & $\mathbf{s}$ & $\mathbf{s}$ & \begin{tabular}{|l|}
$\mathbf{D}$ \\
\end{tabular} & $\mathbf{s}$ & $\mathbf{T}$ & \begin{tabular}{l|l}
$\mathbf{Q}$ & \\
\end{tabular} & $\mathbf{Q}$ & $\mathbf{s}$ & $\mathbf{s}$ \\
\hline & & & & 1 & 2 & 3 & & & & & & & & 1 & & & 1 & 2 & 3 & 4 & 5 & & & & & 1 & 2 & 3 \\
\hline 4 & 5 & 6 & 7 & 8 & 9 & 10 & 2 & & & 4 & 5 & 6 & 7 & 8 & 6 & 7 & 8 & 9 & 10 & 11 & 12 & \begin{tabular}{|l|}
4 \\
\end{tabular} & 5 & 6 & 7 & 8 & 9 & 10 \\
\hline 11 & 12 & 13 & 14 & 15 & 16 & 17 & $s$ & 9 & & 11 & 12 & 13 & 14 & 15 & 13 & 14 & 15 & 16 & 17 & 18 & 19 & \begin{tabular}{|l|}
11 \\
\end{tabular} & 12 & 13 & . 14 & 15 & 16 & 17 \\
\hline 18 & 19 & 20 & 21 & 22 & 23 & 24 & 1 & \begin{tabular}{|l|l}
6 & 1 \\
1
\end{tabular} & & 18 & 19 & 20 & 21 & 22 & 20 & 21 & 22 & 23 & 24 & 25 & 26 & 18 & 19 & 20 & 21 & 22 & 232 & 24 \\
\hline \multirow[t]{2}{*}{25} & 26 & 27 & 28 & 29 & 30 & & 2 & & & 25 & 26 & 27 & 28 & 29 & 27 & 28 & 29 & 30 & & & & 25 & 26 & 27 & 28 & 29 & $30:$ & 31 \\
\hline & & & & & & & 3 & $0 / 3$ & & & & & & & & & & & & & & & & & & & & \\
\hline \multicolumn{7}{|c|}{ * 7: Independencia do Brasil } & \multicolumn{8}{|c|}{ * 12: Nsa. Sra. Aparecida } & \multicolumn{7}{|c|}{$\begin{array}{l}\text { * 2: Finados } \\
\text { 15: Proclamação da Repúblic } \\
\text { 20: Consciência Negra }\end{array}$} & \multicolumn{6}{|c|}{ * 25: Natal } & \\
\hline \multicolumn{7}{|c|}{ Janeiro de 2012} & \multicolumn{8}{|c|}{ Fevereiro de 2012} & \multicolumn{7}{|c|}{ Março de 2012} & \multicolumn{7}{|c|}{ Abril de 2012} \\
\hline D & $\mathbf{s}$ & \begin{tabular}{l|l}
$\mathbf{T}$ & \\
\end{tabular} & $\mathbf{Q}$ & $\mathbf{Q}$ & $\mathbf{s}$ & $\mathbf{s}$ & $\mathbf{D}$ & 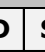 & & $\mathbf{T}$ & $\mathbf{Q}$ & $\mathbf{Q}$ & $\mathbf{s}$ & $\mathbf{s}$ & D & $\mathbf{s}$ & $\mathbf{T}$ & $\mathbf{Q}$ & $\mathbf{Q}$ & $\mathbf{s}$ & $\mathbf{s}$ & \begin{tabular}{|l|}
$\mathbf{D}$ \\
\end{tabular} & $\mathbf{s}$ & $\mathbf{T}$ & \begin{tabular}{l|l}
$\mathbf{Q}$ \\
\end{tabular} & $\mathbf{Q}$ & $\mathbf{s}$ & $\mathbf{s}$ \\
\hline 1 & 2 & 3 & 4 & 5 & 6 & 7 & & & & & 1 & 2 & 3 & 4 & & & & & 1 & 2 & 3 & 1 & 2 & 3 & 4 & 5 & 6 & 7 \\
\hline 8 & 9 & \begin{tabular}{l|l}
10 & \\
\end{tabular} & 11 & 12 & 13 & 14 & 5 & 5 & & 7 & 8 & 9 & 10 & 11 & 4 & 5 & 6 & 7 & 8 & 9 & 10 & 8 & 9 & 10 & 11 & 12 & 13 . & 14 \\
\hline 15 & 16 & 17 & 18 & 19 & 20 & 21 & 1 & 2 & & 14 & 15 & 16 & 17 & 18 & 11 & 12 & 13 & 14 & 15 & 16 & 17 & 15 & 16 & 17 & 18 & 19 & 202 & 21 \\
\hline 22 & 23 & 24 & 25 & 26 & 27 & 28 & 1 & 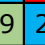 & & 21 & 22 & 23 & 24 & 25 & 18 & 19 & 20 & 21 & 22 & 23 & 24 & 22 & 23 & 24 & 25 & 26 & $27 ?$ & 28 \\
\hline \multirow[t]{2}{*}{29} & 30 & 31 & & & & & 2 & $6 \sqrt{2}$ & & 28 & 29 & & & & 25 & 26 & 27 & 28 & 29 & 30 & 31 & 29 & 30 & & & & & \\
\hline & & & & & & & & & & & & & & & & & & & & & & & & & & & & \\
\hline \multicolumn{15}{|c|}{ 1: Confraternização Universi } & & & & & & & & \multicolumn{7}{|c|}{ * 6: Sexta-feira da Paixão } \\
\hline \multicolumn{7}{|c|}{ 25: Aniversário de São Paulo } & \multicolumn{8}{|c|}{ 22: Cinzas } & & & & & & & & \multicolumn{7}{|c|}{$\begin{array}{c}\text { 8: Páscoa } \\
\text { 21: Tiradentes } \\
\text { 22: Descobrimento do Bras }\end{array}$} \\
\hline \multicolumn{7}{|c|}{ Maio de 2012} & & & & tho & de & 201 & & & & & Ulho & de & 201 & & & & Agc & ostc & o de & 201 & & \\
\hline D & $\mathbf{S}$ & $\mathbf{T}$ & $\mathbf{Q}$ & $\mathbf{Q}$ & $\mathbf{S}$ & $\mathbf{S}$ & D & 5 & & $\mathbf{T}$ & $\mathbf{Q}$ & $\mathbf{Q}$ & $\mathbf{S}$ & $\mathbf{s}$ & $\mathbf{D}$ & \begin{tabular}{|l|} 
\\
\end{tabular} & $\mathbf{T}$ & $\mathbf{Q}$ & $\mathbf{Q}$ & S & $\mathbf{s}$ & \begin{tabular}{|l|}
$\mathbf{D}$ \\
\end{tabular} & $\mathbf{S}$ & $\mathbf{T}$ & $\mathbf{Q}$ & \begin{tabular}{l|} 
\\
\end{tabular} & $S$ & $\mathbf{s}$ \\
\hline & & 1 & 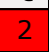 & 3 & 4 & 5 & & & & & & & 1 & 2 & 1 & 2 & 3 & 4 & 5 & 6 & 7 & & & & 1 & 2 & 3 & 4 \\
\hline 6 & 7 & 8 & 9 & 10 & 11 & 12 & 3 & & & 5 & 6 & 7 & 8 & 9 & 8 & 9 & 10 & 11 & 12 & 13 & 14 & 5 & 6 & 7 & 8 & 9 & \begin{tabular}{l|l}
10 \\
\end{tabular} & 11 \\
\hline 13 & \begin{tabular}{|l|}
14 \\
\end{tabular} & 15 & 16 & 17 & 18 & 19 & 1 & & & 12 & 13 & 14 & 15 & 16 & 15 & 16 & 17 & 18 & 19 & 20 & 21 & \begin{tabular}{|l|}
12 \\
\end{tabular} & 13 & 14 & 15 & 16 & 17 & 18 \\
\hline 20 & 21 & 22 & 23 & 24 & 25 & 26 & $\overline{1}$ & & & 19 & 20 & 21 & 22 & 23 & 22 & 23 & 24 & 25 & 26 & 27 & 28 & \begin{tabular}{|l|}
19 \\
\end{tabular} & 20 & 21 & 22 & 23 & 24 & 25 \\
\hline 27 & 28 & 29 & 30 & 31 & & & 2 & 4 & & 26 & 27 & 28 & 29 & 30 & 29 & 30 & 31 & & & & & \begin{tabular}{|l|}
26 \\
\end{tabular} & 27 & 28 & \begin{tabular}{|l|}
29 \\
\end{tabular} & 30 & 31 & \\
\hline & & & & & & & & & & & & & & & & & & & & & & & & & & & & \\
\hline & $\begin{array}{r}* 1: \\
13:\end{array}$ & $\begin{array}{l}\text { Dia c } \\
\text { : Dia }\end{array}$ & $\begin{array}{l}\text { do } \\
\text { das }\end{array}$ & Trabã & & & & & & Co & rpus & Chis & & & & & & nalis & & le 19 & & & & $2: \mathrm{D}$ & ia do & ${ }_{S \mathrm{SPa}}$ & & \\
\hline & jenda & & & G1 & & & 2 & & & G3 & & & G4 & & G5 & & & $\mathbf{G 6}$ & & & G7 & & & & & & & \\
\hline
\end{tabular}

Fonte: Elaborada pelo autor

O terceiro grupo (G3) foi formado pelos sábados e mais 7 feriados do ano: (i) 7 de setembro - Independência do Brasil; (ii) 12 de outubro - Nossa Senhora Aparecida; (iii) 2 de novembro - Finados; (iv) 25 de janeiro - Aniversário de São Paulo; (v) 6 de abril sexta-feira da Paixão; (vi) 21 de abril - Tiradentes; e (vii) 7 de junho - Corpus Christi, além de 4 dias de pré-feriado: 13/11/2011, 19/12/2011, 30/12/2011 e 19/02/2012. Analisando o terceiro grupo, pode-se notar que os feriados e a véspera de alguns feriados de maior intensidade mantêm característica similar aos sábados.

O quarto grupo (G4) foi formado predominantemente por domingos, com exceção 
de quatro domingos deste período: 13 de novembro (pré-feriado), 19 de fevereiro (préferiado), 8 de abril (feriado - Páscoa) e 10 de junho (pós-feriado).

O grupo 5 (G5) foi formado na maioria por segundas-feiras, com exceção dos dias 14 de novembro (pré-feriado), 19 de dezembro, 26 de dezembro (pós-feriado), 02 de janeiro (pós-feriado), 20 de fevereiro (pré-feriado), 09 de abril (pós-feriado), 30 de abril (préferiado) e 9 de julho (feriado estadual - Revolução Constitucionalista de 1932). Além das segundas-feiras, outros dias da semana formaram o G5, tais como: 08/09 (pós-feriado); 13/10 (pós-feriado); 03/11 (pós-feriado); 16/11 (pós-feriado); 14, 15 e 16 de fevereiro (semana anterior à Páscoa); 02 de maio (pós-feriado); e 10 de julho (pós-feriado). Destaca-se no G5 que as segundas-feiras que não fizeram parte do grupo foram influenciadas por feriados próximos de maior intensidade, como por exemplo, o feriado do dia 1 de janeiro, enquanto os dias posterior a feriados de menor intensidade fazem parte do G5, como por exemplo o dia 13 de outubro. Esse efeito pode indicar o comportamento diferente dos dias anteriores e posteriores aos feriados, de acordo com a importância do feriado.

0 grupo 6 (G6) foi formado por 5 feriados e um pós-feriado. Os feriados são: 15 de novembro (Proclamação da República), 21 de fevereiro (Carnaval), 8 de abril (Páscoa), 1 de maio (Dia do Trabalho) e 9 de julho (Revolução Constitucionalista de 1932). 0 pósferiado foi o dia 10 de junho (07/06/2012 - Corpus Christi). Por fim, o grupo 7 (G7) foi formado pelo feriado do dia 22 de fevereiro (Quarta-feira de Cinzas), no entanto é o dia posterior ao Carnaval (21/02/2012), assim como os outros dias do grupo é formado por pós-feriados: 26 de dezembro (25/12/2011 - Natal), 2 de janeiro (01/01/2012 Confraternização Universal) e 9 de abril (08/04/2012 - Páscoa). Nota-se que são dias posteriores a feriados de grande intensidade e influência no fluxo de tráfego.

De forma geral, os grupos formados utilizando os dados de fluxo de tráfego do ano inteiro formaram grupos mantendo um padrão pelo dia da semana, no entanto os feriados influenciaram os dias anteriores e posteriores. Na Figura 4-4 é apresentado o perfil formado pelo $\mathrm{CA}_{4}$ para cada grupo gerado. 
Figura 4-4 - Grupos formados para 7 agrupamentos com o $C A_{4}$ para o período de um ano

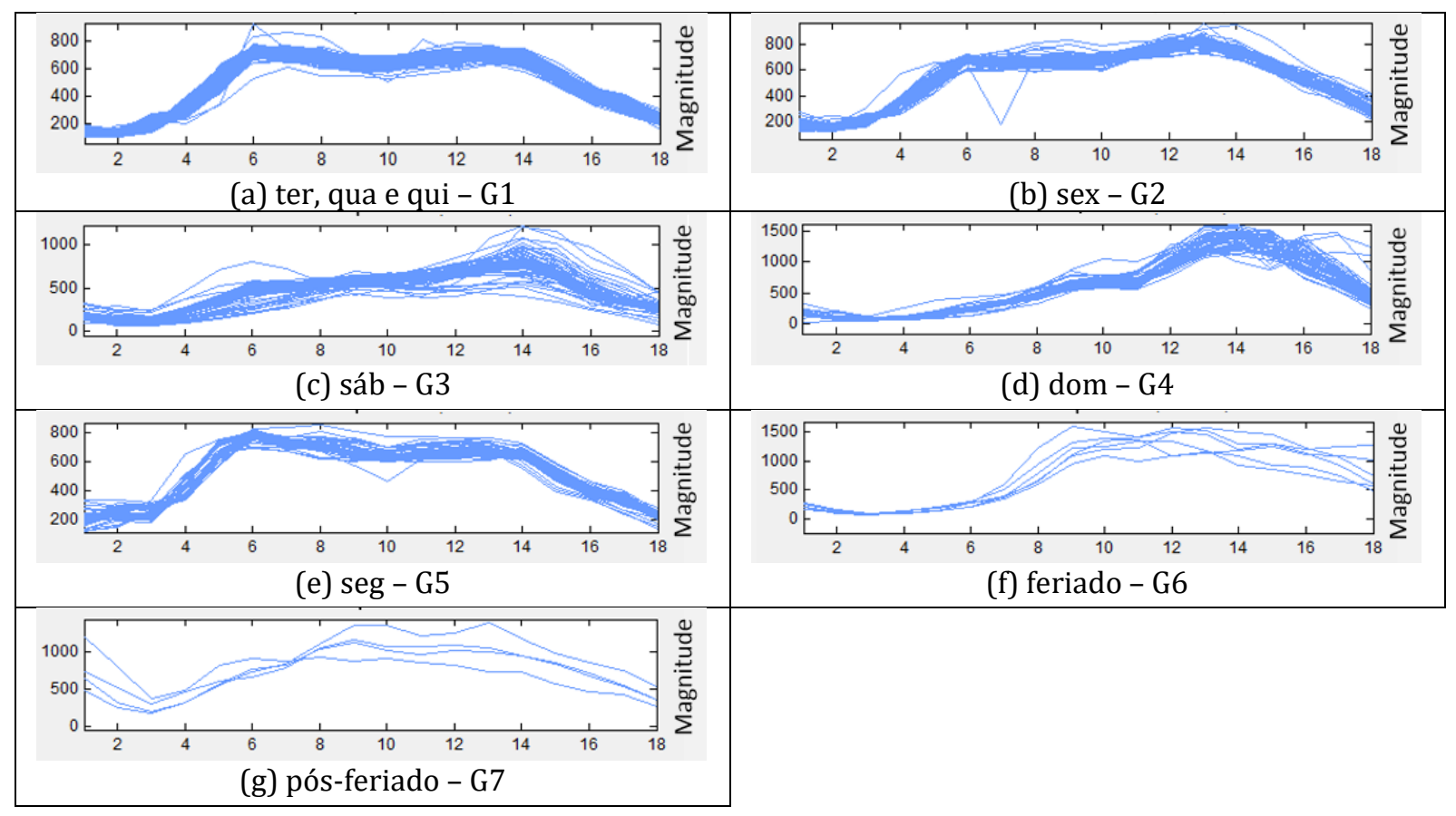

Fonte: Elaborada pelo autor

Como o objetivo é reconhecer padrões no comportamento do tráfego, optou-se por aplicar o método proposto em um sinal de menor período de tempo, aplicando as análises em sinais mensais. Essa opção também é justificada pela dificuldade de se obter o sinal de tráfego sem falhas em um ano completo.

O procedimento para reconhecimento foi aplicado mês a mês do intervalo de um ano analisado para o mesmo sensor na Rodovia Presidente Castelo Branco km 51,9, no sentido Leste. Para efeito de ilustração dos resultados obtidos para o período mensal foram selecionados apenas três meses: (i) setembro/2011 como um mês com feriado, (ii) dezembro/2011 por ser um mês com evento especial (recesso de fim de ano e férias escolares) e (iii) março/2012, mês sem feriados. O Apêndice 4.1 traz em detalhes os resultados das análises de agrupamento para 7 cluster de cada mês do período investigado.

0 mês de setembro foi selecionado devido ao feriado do dia 7 (Independência do Brasil). Inicialmente foram avaliados agrupamentos de 3 a 7 clusters (Figura 4-5). Para melhor visualização dos resultados, cada agrupamento está apresentado em forma de calendários, com o início da semana aos domingos, e cada cor representa um cluster formado dentro de cada análise. 
Figura 4-5 - Resultado das análises de agrupamento para o $C A_{4}$ de setembro - Leste

\begin{tabular}{|c|c|c|c|c|c|c|}
\hline \multicolumn{7}{|c|}{ 3 Grupos } \\
\hline D & S & T & Q & Q & S & S \\
\hline & & & & 1 & 2 & 3 \\
\hline 4 & 5 & 6 & 7 & 8 & 9 & 10 \\
\hline 11 & 12 & 13 & 14 & 15 & 16 & 17 \\
\hline 18 & 19 & 20 & 21 & 22 & 23 & 24 \\
\hline 25 & 26 & 27 & 28 & 29 & 30 & \\
\hline
\end{tabular}

\begin{tabular}{|c|c|c|c|c|c|c|}
\hline \multicolumn{7}{|c|}{ 4 Grupos } \\
\hline D & S & T & Q & Q & S & S \\
\hline & & & & 1 & 2 & 3 \\
\hline 4 & 5 & 6 & 7 & 8 & 9 & 10 \\
\hline 11 & 12 & 13 & 14 & 15 & 16 & 17 \\
\hline 18 & 19 & 20 & 21 & 22 & 23 & 24 \\
\hline 25 & 26 & 27 & 28 & 29 & 30 & \\
\hline
\end{tabular}

\begin{tabular}{|c|c|c|c|c|c|c|}
\hline \multicolumn{7}{|c|}{ 5 Grupos } \\
\hline D & S & T & Q & Q & S & S \\
\hline & & & & 1 & 2 & 3 \\
\hline 4 & 5 & 6 & 7 & 8 & 9 & 10 \\
\hline 11 & 12 & 13 & 14 & 15 & 16 & 17 \\
\hline 18 & 19 & 20 & 21 & 22 & 23 & 24 \\
\hline 25 & 26 & 27 & 28 & 29 & 30 & \\
\hline
\end{tabular}

\begin{tabular}{|c|c|c|c|c|c|c|}
\hline \multicolumn{7}{|c|}{ 6 Grupos } \\
\hline D & S & T & Q & Q & S & S \\
\hline & & & & 1 & 2 & 3 \\
\hline 4 & 5 & 6 & 7 & 8 & 9 & 10 \\
\hline 11 & 12 & 13 & 14 & 15 & 16 & 17 \\
\hline 18 & 19 & 20 & 21 & 22 & 23 & 24 \\
\hline 25 & 26 & 27 & 28 & 29 & 30 & \\
\hline
\end{tabular}

\begin{tabular}{|c|c|c|c|c|c|c|}
\hline \multicolumn{7}{|c|}{ 7 Grupos } \\
\hline D & S & T & Q & Q & S & S \\
\hline & & & & 1 & 2 & 3 \\
\hline 4 & 5 & 6 & 7 & 8 & 9 & 10 \\
\hline 11 & 12 & 13 & 14 & 15 & 16 & 17 \\
\hline 18 & 19 & 20 & 21 & 22 & 23 & 24 \\
\hline 25 & 26 & 27 & 28 & 29 & 30 & \\
\hline
\end{tabular}

Legenda: $\square\left[\begin{array}{l}\square \\ \square\end{array}\right.$

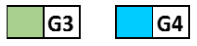

\section{G5}

G6 $\square$ G7

Fonte: Elaborada pelo autor

$\mathrm{Na}$ formação de três grupos: os dias úteis (segunda à sexta-feira) formaram um único grupo, com exceção de uma quarta-feira, justamente o feriado no dia 7; já os sábados e o feriado formaram outro; e os domingos compuseram o último grupo. Esta classificação revela que o feriado é muito similar ao comportamento dos sábados, para este mês. Em quatro clusters, um novo grupo foi formado, separando as sextas-feiras do restante dos dias úteis. Em 5 clusters, as segundas-feiras e uma quinta-feira do mês - sendo este o dia seguinte ao feriado (8) foram separadas no novo cluster (G5 - 5 grupos). Em seis clusters o dia 11 foi separado do grupo de domingo. E por fim, em sete clusters, o feriado do dia 7 que anteriormente estava no grupo de sábados foi separado formando um novo grupo (G7 - 7 grupos).

Nota-se que os clusters formados a cada cenário caracterizam uma configuração distinta dos dias da semana. Como esta pesquisa é uma análise exploratória do comportamento do tráfego, compreender e analisar esses cenários se torna uma das tarefas, pois cada cenário pode ser útil para diferentes situações. Por exemplo, para analisar apenas dias úteis (segunda à sexta-feira), excluindo fim de semana e feriados, o grupo 1 do cenário de 3 grupos (G1 - 3 grupos), seria a melhor opção.

Como a semana tem sete dias, um cenário que agrupasse cada tipo de dia em um grupo, seria ideal para representar cada dia separadamente. No entanto, as terças, quartas e quintas-feiras se mantiveram em todos os agrupamentos nos sete cenários, com exceção do feriado e o dia seguinte, confirmando sua similaridade, corroborando com a hipótese de Weijermaras e Berkum (2005) dos dias núcleo da semana e com a hipótese de Cunha (2007) em que as terças, quartas e quintas-feiras mantêm o mesmo comportamento. Baseado nisso, foi considerado nesta pesquisa como dia útil típico, as terças, quartas e quintas-feiras.

Para conseguir definir os comportamentos em dias típicos do mês de setembro 
foram necessários 5 clusters (Figura 4-6). Na Figura 4-6(a) é apresentado o perfil do grupo de dias úteis típicos formados pelo $C A 4$. Em (b) confirma que o dia 7 de setembro, apesar de ser um feriado, não apresentou comportamento atípico em relação a todos os dias do mês, mas sim um comportamento similar aos sábados. 0 feriado só foi separado do grupo de sábado, quando foi utilizado sete agrupamentos. A Figura 4-6 (c), (d) e (e) apresenta o perfil formado pelos $C A_{4}$ para o domingo, sexta-feira e segunda-feira mais o dia 8 de setembro (pós-feriado), respectivamente.

Figura 4-6 - Grupos formados para 5 agrupamentos com o $C A_{4}$ de setembro - Leste

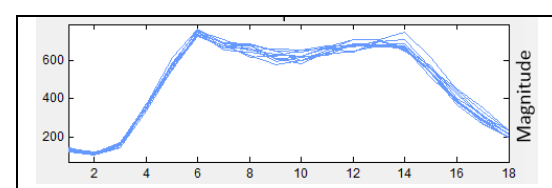

(a) ter, qua e qui - G1

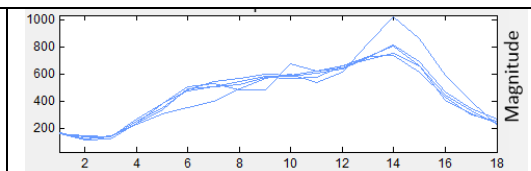

(b) sáb e feriado - G2

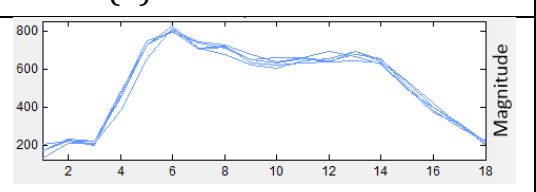

(e) seg e pós-feriado - G5

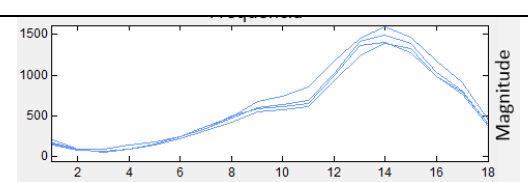

(c) dom - G3

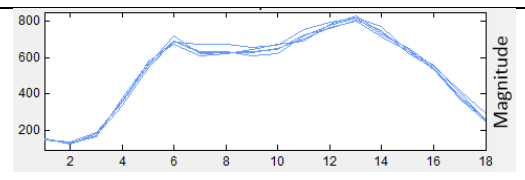

(d) sex - G4

Fonte: Elaborada pelo autor

0 próximo mês a ser analisado foi o mês de dezembro. Em dezembro de 2011, além do feriado do Natal (25 de dezembro) feriado nacional que ocorreu no último domingo do mês, houve também uma variação no tráfego devido ao recesso de fim de ano. A análise da influência desse período no comportamento do tráfego está apresentada na Figura 4-7.

Figura 4-7 - Resultado das análises de agrupamento para o $C A_{4}$ de dezembro - Leste

\begin{tabular}{|c|c|c|c|c|c|c|}
\hline \multicolumn{7}{|c|}{ 3 Grupos } \\
\hline D & S & T & Q & Q & S & S \\
\hline & & & & 1 & 2 & 3 \\
\hline 4 & 5 & 6 & 7 & 8 & 9 & 10 \\
\hline 11 & 12 & 13 & 14 & 15 & 16 & 17 \\
\hline 18 & 19 & 20 & 21 & 22 & 23 & 24 \\
\hline 25 & 26 & 27 & 28 & 29 & 30 & 31 \\
\hline
\end{tabular}

\begin{tabular}{|c|c|c|c|c|c|c|}
\hline \multicolumn{7}{|c|}{ 4 Grupos } \\
\hline D & S & T & Q & Q & S & S \\
\hline & & & & 1 & 2 & 3 \\
\hline 4 & 5 & 6 & 7 & 8 & 9 & 10 \\
\hline 11 & 12 & 13 & 14 & 15 & 16 & 17 \\
\hline 18 & 19 & 20 & 21 & 22 & 23 & 24 \\
\hline 25 & 26 & 27 & 28 & 29 & 30 & 31 \\
\hline
\end{tabular}

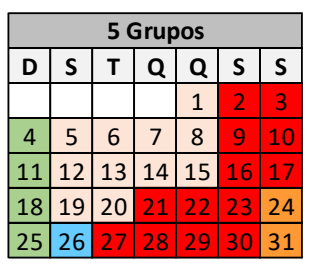

\begin{tabular}{|c|c|c|c|c|c|c|}
\hline \multicolumn{7}{|c|}{ 6 Grupos } \\
\hline D & S & T & Q & Q & S & S \\
\hline & & & & 1 & 2 & 3 \\
\hline 4 & 5 & 6 & 7 & 8 & 9 & 10 \\
\hline 11 & 12 & 13 & 14 & 15 & 16 & 17 \\
\hline 18 & 19 & 20 & 21 & 22 & 23 & 24 \\
\hline 25 & 26 & 27 & 28 & 29 & 30 & 31 \\
\hline
\end{tabular}

\begin{tabular}{|c|c|c|c|c|c|c|}
\hline \multicolumn{7}{|c|}{ 7 Grupos } \\
\hline D & S & T & Q & Q & S & S \\
\hline & & & & 1 & 2 & 3 \\
\hline 4 & 5 & 6 & 7 & 8 & 9 & 10 \\
\hline 11 & 12 & 13 & 14 & 15 & 16 & 17 \\
\hline 18 & 19 & 20 & 21 & 22 & 23 & 24 \\
\hline 25 & 26 & 27 & 28 & 29 & 30 & 31 \\
\hline
\end{tabular}

Legenda: \begin{tabular}{ll|l|l|}
$\square$ & $\mathbf{G 1}$ \\
$\square$ & $\mathbf{G} 2$
\end{tabular}

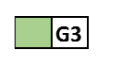

G5 \begin{tabular}{|l|l|l|}
\hline & $\mathbf{G 6}$ \\
\hline & $\mathbf{G 7}$ \\
\hline
\end{tabular}

Fonte: Elaborada pelo autor

Em três agrupamentos os pontos de destaque são: os domingos continuam formando um único grupo (G3 - 3 grupos); os sábados de 24/dez (véspera de Natal) e 31/dez (véspera de Ano Novo) formaram um grupo isolado (G2 - 3 grupos); por fim, os demais dias (segunda à sábado) formaram outro grupo (G1 - 3 grupos). Para quatro 
agrupamentos, o dia 26 (pós-Natal) demonstrou um comportamento atípico, formando um grupo isolado (G4 - 4 grupos). Em cinco agrupamentos, nota-se claramente que as sextas-feiras, sábados e a semana entre o Natal e o Ano Novo (21 a 30 de dezembro) apresentam um comportamento peculiar, revelando que de fato esses eventos alteram sobremaneira o tráfego veicular. 0 dia do feriado (25/dez) só tem comportamento diferente dos demais dias em seis agrupamentos (G6 - 6 grupos).

Após analisar cada um dos agrupamentos ficou evidente que o feriado influencia bastante o tráfego nos dias anteriores e seguintes ao próprio feriado. Já o recesso do fim de ano influenciou no comportamento de todo o mês de dezembro, não encontrando assim um padrão para os dias úteis deste mês. A Figura 4-8 apresenta a análise de agrupamento para cinco grupos, ilustrando que não existe uma similaridade bem definida no comportamento do fluxo de tráfego no mês de dezembro. Percebe-se que dois grupos (G2 e G4) concentraram os dias atípicos (véspera e pós-feriado), por outro lado, outros dois grupos (G1 e G5) agruparam os dias úteis.

Figura 4-8 - Grupos formados para 5 agrupamentos com o $C A_{4}$ de dezembro - Leste

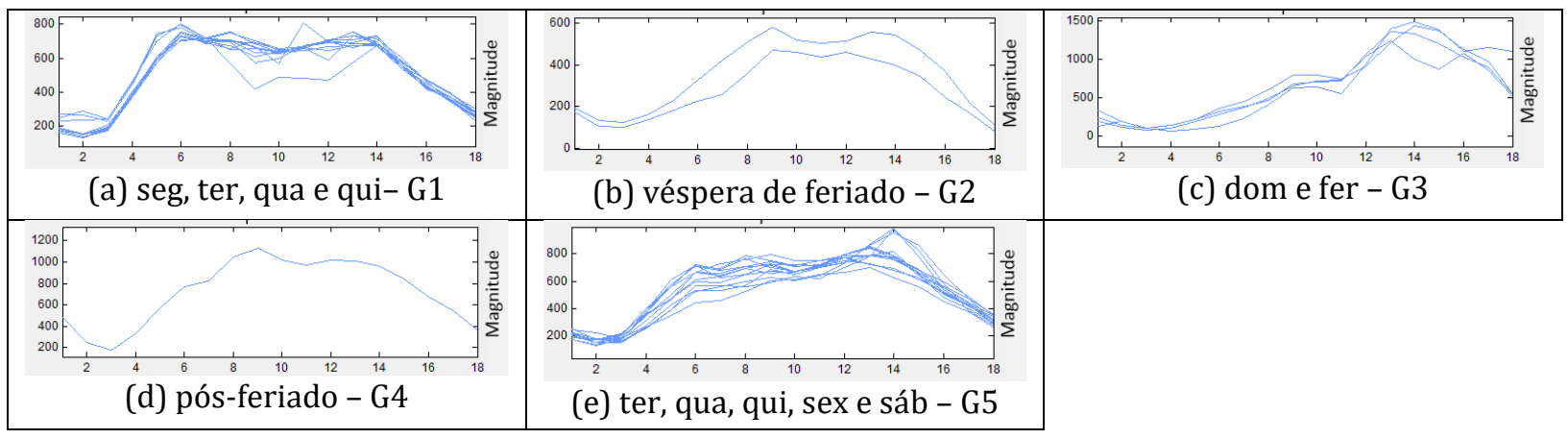

Fonte: Elaborada pelo autor

Por fim, apresenta-se a análise do mês de março, pois não apresentou feriado ou evento especial, aplicando-se o mesmo método. Os resultados dos agrupamentos estão ilustrados na Figura 4-9. 
Figura 4-9 - Resultado das análises de agrupamento para o $C A_{4}$ de março - Leste

\begin{tabular}{|c|c|c|c|c|c|c|}
\hline \multicolumn{7}{|c|}{ 3 Grupos } \\
\hline D & $\mathbf{S}$ & $\mathbf{T}$ & $\mathbf{Q}$ & $\mathbf{Q}$ & $\mathbf{S}$ & $\mathbf{S}$ \\
\hline & & & & 1 & 2 & 3 \\
\hline 4 & 5 & 6 & 7 & 8 & 9 & 10 \\
\hline 11 & 12 & 13 & 14 & 15 & 16 & 17 \\
\hline 18 & 19 & 20 & 21 & 22 & 23 & 24 \\
\hline 25 & 26 & 27 & 28 & 29 & 30 & 31 \\
\hline
\end{tabular}

Legenda: \begin{tabular}{l|l|l|}
$\square$ & $\mathbf{G 1}$ \\
$\square$ & $\mathbf{G 2}$ \\
\hline
\end{tabular}

\begin{tabular}{|c|c|c|c|c|c|c|}
\hline \multicolumn{7}{|c|}{ 4 Grupos } \\
\hline $\mathbf{D}$ & $\mathbf{S}$ & $\mathbf{T}$ & $\mathbf{Q}$ & $\mathbf{Q}$ & $\mathbf{S}$ & $\mathbf{S}$ \\
\hline & & & & 1 & 2 & 3 \\
\hline 4 & 5 & 6 & 7 & 8 & 9 & 10 \\
\hline 11 & 12 & 13 & 14 & 15 & 16 & 17 \\
\hline 18 & 19 & 20 & 21 & 22 & 23 & 24 \\
\hline 25 & 26 & 27 & 28 & 29 & 30 & 31 \\
\hline
\end{tabular}

\begin{tabular}{|c|c|c|c|c|c|c|}
\hline \multicolumn{7}{|c|}{ 5 Grupos } \\
\hline $\mathbf{D}$ & $\mathbf{S}$ & $\mathbf{T}$ & $\mathbf{Q}$ & $\mathbf{Q}$ & $\mathbf{S}$ & $\mathbf{S}$ \\
\hline & & & & 1 & 2 & 3 \\
\hline 4 & 5 & 6 & 7 & 8 & 9 & 10 \\
\hline 11 & 12 & 13 & 14 & 15 & 16 & 17 \\
\hline 18 & 19 & 20 & 21 & 22 & 23 & 24 \\
\hline 25 & 26 & 27 & 28 & 29 & 30 & 31 \\
\hline
\end{tabular}

\begin{tabular}{|c|c|c|c|c|c|c|}
\hline \multicolumn{7}{|c|}{$\mathbf{6}$ Grupos } \\
\hline $\mathbf{D}$ & $\mathbf{S}$ & $\mathbf{T}$ & $\mathbf{Q}$ & $\mathbf{Q}$ & $\mathbf{S}$ & $\mathbf{S}$ \\
\hline & & & & 1 & 2 & 3 \\
\hline 4 & 5 & 6 & 7 & 8 & 9 & 10 \\
\hline 11 & 12 & 13 & 14 & 15 & 16 & 17 \\
\hline 18 & 19 & 20 & 21 & 22 & 23 & 24 \\
\hline 25 & 26 & 27 & 28 & 29 & 30 & 31 \\
\hline
\end{tabular}

Fonte: Elaborada pelo autor

Nota-se que para 3 grupos, o G1 compreende os dias de segunda à quinta-feira; já o G2 todas as sextas-feiras e os sábados; por fim o G3 os domingos. Para 4 grupos: as sextasfeiras e os sábados se dividiram em dois grupos distintos. Com 5 grupos as segundasfeiras (G5) se separaram das terças, quartas e quintas-feiras (G1); e os demais grupos prevalecem como anteriormente. Observa-se também que a partir de seis agrupamentos a tendência foi separar os domingos em grupos distintos, enquanto as terças, quartas e quintas-feiras continuaram agrupadas, revelando uma forte similaridade no comportamento de tráfego, corroborando a hipótese de dias úteis típicos de Cunha (2007). Assim, há evidências que cinco grupos seja a melhor opção para definir dias típicos de tráfego. Baseado nesta hipótese, a Figura 4-10 ilustra o padrão do tráfego para os cinco grupos formados.

Figura 4-10 - Grupos formados para 5 agrupamentos com o $C A_{4}$ de março - Leste

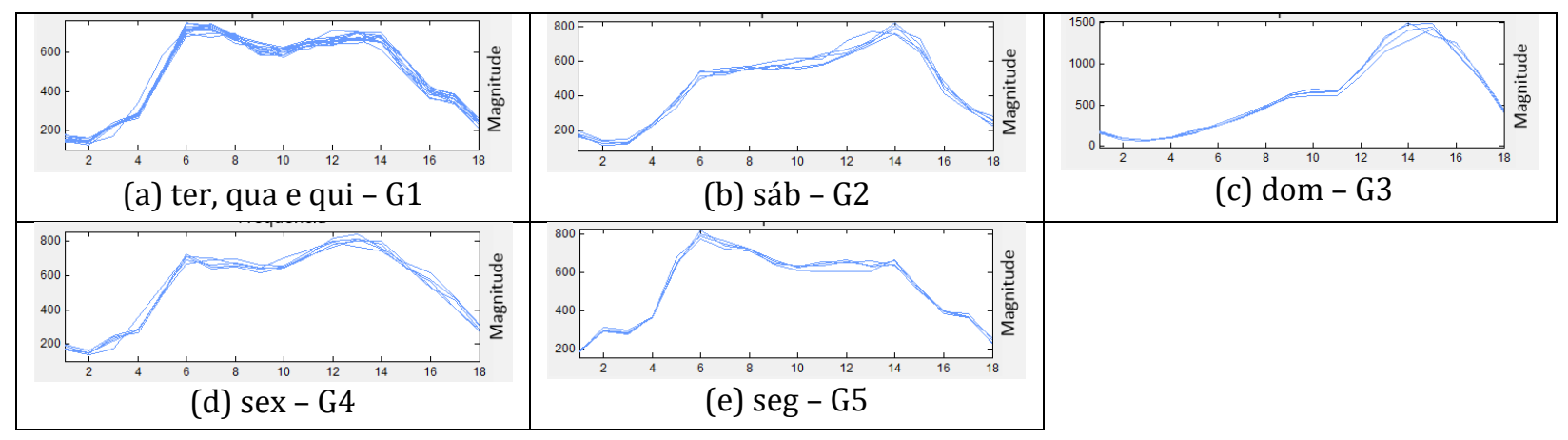

Fonte: Elaborada pelo autor

\subsubsection{Análise por fluxo direcional}

A fim de analisar a interferência do sentido de tráfego no comportamento da via, o método proposto para o reconhecimento de padrões também foi aplicado para o sentido Oeste (capital - interior). Assim como no sentido Leste, no sentido Oeste também foi 
analisado os dados no período de um ano e a cada mês. Mas para ilustrar os resultados obtidos foram escolhidos os mesmos meses: (i) setembro/2011 - mês com feriado, (ii) dezembro/2011- mês com evento especial e (iii) março/2012 - mês sem feriados.

Novamente, o primeiro mês analisado no sentido Oeste foi o mês de setembro devido ao ferido do dia 7. Foram avaliados agrupamentos de 3 a 7 clusters (Figura 4-11).

Figura 4-11 - Resultados das análises de agrupamento para o $C A_{4}$ de setembro - Oeste

\begin{tabular}{|c|c|c|c|c|c|c|}
\hline \multicolumn{7}{|c|}{ 3 Grupos } \\
\hline D & S & T & Q & Q & S & S \\
\hline & & & & 1 & 2 & 3 \\
\hline 4 & 5 & 6 & 7 & 8 & 9 & 10 \\
\hline 11 & 12 & 13 & 14 & 15 & 16 & 17 \\
\hline 18 & 19 & 20 & 21 & 22 & 23 & 24 \\
\hline 25 & 26 & 27 & 28 & 29 & 30 & \\
\hline
\end{tabular}

\begin{tabular}{|c|c|c|c|c|c|c|}
\hline \multicolumn{7}{|c|}{ 4 Grupos } \\
\hline D & S & T & Q & Q & S & S \\
\hline & & & & 1 & 2 & 3 \\
\hline 4 & 5 & 6 & 7 & 8 & 9 & 10 \\
\hline 11 & 12 & 13 & 14 & 15 & 16 & 17 \\
\hline 18 & 19 & 20 & 21 & 22 & 23 & 24 \\
\hline 25 & 26 & 27 & 28 & 29 & 30 & \\
\hline
\end{tabular}

\begin{tabular}{|c|c|c|c|c|c|c|}
\hline \multicolumn{7}{|c|}{ 5 Grupos } \\
\hline $\mathbf{D}$ & $\mathbf{S}$ & $\mathbf{T}$ & $\mathbf{Q}$ & $\mathbf{Q}$ & $\mathbf{S}$ & $\mathbf{S}$ \\
\hline & & & & 1 & 2 & 3 \\
\hline 4 & 5 & 6 & 7 & 8 & 9 & 10 \\
\hline 11 & 12 & 13 & 14 & 15 & 16 & 17 \\
\hline 18 & 19 & 20 & 21 & 22 & 23 & 24 \\
\hline 25 & 26 & 27 & 28 & 29 & 30 & \\
\hline
\end{tabular}

\begin{tabular}{|c|c|c|c|c|c|c|}
\hline \multicolumn{7}{|c|}{$\mathbf{6}$ Grupos } \\
\hline $\mathbf{D}$ & $\mathbf{S}$ & $\mathbf{T}$ & $\mathbf{Q}$ & $\mathbf{Q}$ & $\mathbf{S}$ & $\mathbf{S}$ \\
\hline & & & & 1 & 2 & 3 \\
\hline 4 & 5 & 6 & 7 & 8 & 9 & 10 \\
\hline 11 & 12 & 13 & 14 & 15 & 16 & 17 \\
\hline 18 & 19 & 20 & 21 & 22 & 23 & 24 \\
\hline 25 & 26 & 27 & 28 & 29 & 30 & \\
\hline
\end{tabular}

\begin{tabular}{|c|c|c|c|c|c|c|}
\hline \multicolumn{7}{|c|}{ 7 Grupos } \\
\hline D & S & T & Q & Q & S & S \\
\hline & & & & 1 & 2 & 3 \\
\hline 4 & 5 & 6 & 7 & 8 & 9 & 10 \\
\hline 11 & 12 & 13 & 14 & 15 & 16 & 17 \\
\hline 18 & 19 & 20 & 21 & 22 & 23 & 24 \\
\hline 25 & 26 & 27 & 28 & 29 & 30 & \\
\hline
\end{tabular}

Legenda: \begin{tabular}{ll|l|}
$\square$ & $\mathbf{G 1}$ \\
\hline & $\mathbf{G} 2$ \\
\hline
\end{tabular}

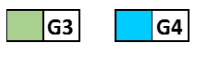

G5 $\square$ G6 $\square$ G7

Fonte: Elaborada pelo autor

Observa-se que desde 3 agrupamentos o tráfego no sentido Oeste se diferencia do sentido Leste, embora o cluster de sábados e o feriado (G2 - 3 grupos) tenha se preservado, no sentido Oeste aparece um grupo de sextas-feiras e a véspera do feriado (G3 - 3 grupos); além disso, os domingos se agruparam com o restante dos dias da semana (G1 - 3 grupos). A partir de quatro agrupamentos, os domingos foram separados em um grupo (G4 - 4 grupos). Em cinco agrupamentos o feriado (7/set) se isolou em um grupo (G5 - 5 grupos), enquanto que a véspera deste feriado (6/set) ficou isolado no G6 em 6 grupos. Em sete agrupamentos um dia (16/set) começa a separar do grupo das sextasfeiras.

Essa diferença nos agrupamentos entre o sentido Leste e Oeste ilustra a diferença no comportamento do tráfego em sentidos opostos, embora no mesmo local e período. Enquanto na pista Leste (sentido Capital), os domingos e o pós-feriado apresentaram maiores variações no tráfego; a pista Oeste (sentido Interior) apresentou as maiores variações durante as sextas-feiras e a véspera de feriado. A Figura 4-12 detalha os agrupamentos formados com cinco grupos na Figura 4-11. 
Figura 4-12 - Grupos formados para 5 agrupamentos com o $C A_{4}$ de setembro - Oeste

\begin{tabular}{|c|c|c|}
\hline (a) seg, ter, qua e qui- G1 & (b) sáb-G2 & 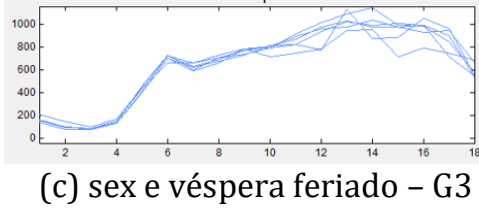 \\
\hline 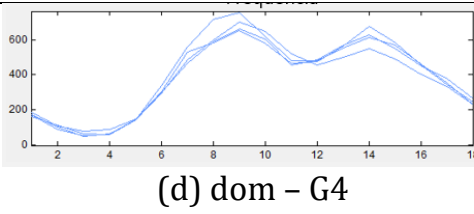 & 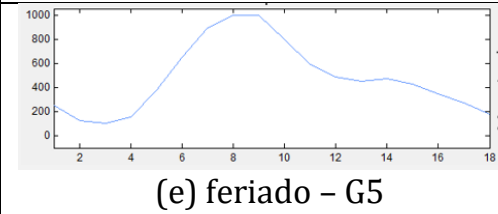 & \\
\hline
\end{tabular}

Fonte: Elaborada pelo autor

0 mês de dezembro no sentido Oeste também foi analisado, devido ao feriado do Natal (25 de dezembro) e ao recesso de fim de ano. A Figura 4-13 apresenta a influência desse período no comportamento do tráfego no sentido Oeste.

Figura 4-13 - Resultados das análises de agrupamento para o CA4 de dezembro - Oeste

\begin{tabular}{|c|c|c|c|c|c|c|}
\hline \multicolumn{7}{|c|}{ 3 Grupos } \\
\hline $\mathbf{D}$ & $\mathbf{S}$ & $\mathbf{T}$ & $\mathbf{Q}$ & $\mathbf{Q}$ & $\mathbf{S}$ & $\mathbf{S}$ \\
\hline & & & & 1 & 2 & 3 \\
\hline 4 & 5 & 6 & 7 & 8 & 9 & 10 \\
\hline 11 & 12 & 13 & 14 & 15 & 16 & 17 \\
\hline 18 & 19 & 20 & 21 & 22 & 23 & 24 \\
\hline 25 & 26 & 27 & 28 & 29 & 30 & 31 \\
\hline
\end{tabular}

\begin{tabular}{|c|c|c|c|c|c|c|}
\hline \multicolumn{7}{|c|}{ 4 Grupos } \\
\hline D & S & T & $\mathbf{Q}$ & $\mathbf{Q}$ & $\mathbf{S}$ & $\mathbf{S}$ \\
\hline & & & & 1 & 2 & 3 \\
\hline 4 & 5 & 6 & 7 & 8 & 9 & 10 \\
\hline 11 & 12 & 13 & 14 & 15 & 16 & 17 \\
\hline 18 & 19 & 20 & 21 & 22 & 23 & 24 \\
\hline 25 & 26 & 27 & 28 & 29 & 30 & 31 \\
\hline
\end{tabular}

\begin{tabular}{|c|c|c|c|c|c|c|}
\hline \multicolumn{7}{|c|}{ 5 Grupos } \\
\hline $\mathbf{D}$ & $\mathbf{S}$ & $\mathbf{T}$ & $\mathbf{Q}$ & $\mathbf{Q}$ & $\mathbf{S}$ & $\mathbf{S}$ \\
\hline & & & & 1 & 2 & 3 \\
\hline 4 & 5 & 6 & 7 & 8 & 9 & 10 \\
\hline 11 & 12 & 13 & 14 & 15 & 16 & 17 \\
\hline 18 & 19 & 20 & 21 & 22 & 23 & 24 \\
\hline 25 & 26 & 27 & 28 & 29 & 30 & 31 \\
\hline
\end{tabular}

\begin{tabular}{|c|c|c|c|c|c|c|}
\hline \multicolumn{7}{|c|}{ 6 Grupos } \\
\hline $\mathbf{D}$ & $\mathbf{S}$ & $\mathbf{T}$ & $\mathbf{Q}$ & $\mathbf{Q}$ & $\mathbf{S}$ & $\mathbf{S}$ \\
\hline & & & & 1 & 2 & 3 \\
\hline 4 & 5 & 6 & 7 & 8 & 9 & 10 \\
\hline 11 & 12 & 13 & 14 & 15 & 16 & 17 \\
\hline 18 & 19 & 20 & 21 & 22 & 23 & 24 \\
\hline 25 & 26 & 27 & 28 & 29 & 30 & 31 \\
\hline
\end{tabular}

\begin{tabular}{|c|c|c|c|c|c|c|}
\hline \multicolumn{7}{|c|}{ 7 Grupos } \\
\hline D & S & T & Q & Q & S & S \\
\hline & & & & 1 & 2 & 3 \\
\hline 4 & 5 & 6 & 7 & 8 & 9 & 10 \\
\hline 11 & 12 & 13 & 14 & 15 & 16 & 17 \\
\hline 18 & 19 & 20 & 21 & 22 & 23 & 24 \\
\hline 25 & 26 & 27 & 28 & 29 & 30 & 31 \\
\hline
\end{tabular}

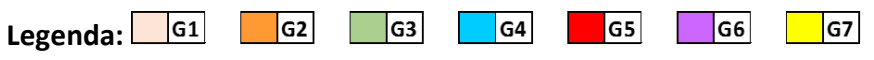

Fonte: Elaborada pelo autor

Em três agrupamentos, o cluster 1 (G1 - 3 grupos) é composto por domingos, segundas, terças, quartas e as 3 primeiras quintas-feiras. 0 cluster 2 (G2 - 3 grupos) é formado pelas sextas-feiras e o as duas últimas quintas-feiras do mês. E o cluster 3 é formado pelos sábados com exceção do dia 31/dez (véspera de feriado - 01/01 Confraternização Universal). Em quatro agrupamentos, os domingos e o dia 31/dez formou um novo grupo (G4 - 4 grupos). Para cinco agrupamentos, a quinta e a sexta-feira anteriores ao feriado de Natal e de Ano Novo formaram um novo grupo (G5 - 5 grupos). Em seis agrupamentos o dia 24 (véspera de Natal) formou um novo grupo isolado (G6 - 6 grupos), assim como o dia 23 formou um novo grupo também isolado em sete agrupamentos (G7 - 7 grupos).

Após analisar os agrupamentos formados no sentido Oeste, nota-se que os feriados de Natal e Ano Novo (domingo) influenciaram apenas alguns dias pré-feriado. Assim como o próprio feriado de Natal manteve seu comportamento similar aos outros domingos, ao 
invés de formar algum grupo isolado. Observa-se também que os feriados influenciaram apenas as quintas, sextas e sábados, ao contrário do sentido Leste em que o feriado influenciou as duas últimas semanas de dezembro. A Figura 4-14 apresenta a análise de agrupamento para cinco grupos, ilustrando a similaridade dos dias dentro dos grupos formados e a diferença de um grupo para o outro.

Figura 4-14 - Grupos formados para 5 agrupamentos com o $C A_{4}$ de dezembro - Oeste

\begin{tabular}{|c|c|c|}
\hline $\begin{array}{l}\frac{1000}{2000} \\
\text { (a) seg, ter, qua e qui- G1 }\end{array}$ & 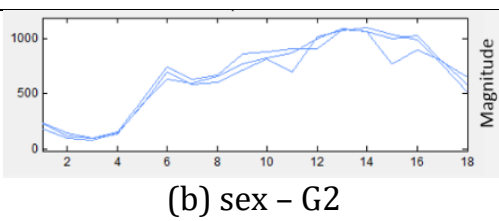 & 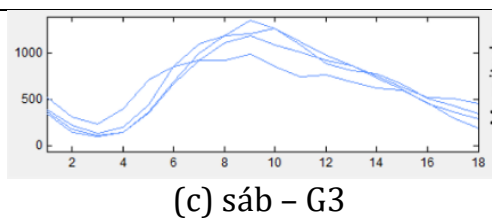 \\
\hline $\begin{array}{l}20000 \\
\text { son }\end{array}$ & $\begin{array}{ll} \\
\text { (e) qui e sex do pré-feriado - G5 }\end{array}$ & \\
\hline
\end{tabular}

Fonte: Elaborada pelo autor

Como o mês de março não apresentava feriado ou evento especial foi analisado também para o sentido Oeste, aplicando-se o mesmo método e os resultados do agrupamento estão apresentados na Figura 4-15.

Figura 4-15 - Resultados das análises de agrupamento para o $C A_{4}$ de março - Oeste

\begin{tabular}{|c|c|c|c|c|c|c|}
\hline \multicolumn{7}{|c|}{ 3 Grupos } \\
\hline D & S & T & Q & Q & S & S \\
\hline & & & & 1 & 2 & 3 \\
\hline 4 & 5 & 6 & 7 & 8 & 9 & 10 \\
\hline 11 & 12 & 13 & 14 & 15 & 16 & 17 \\
\hline 18 & 19 & 20 & 21 & 22 & 23 & 24 \\
\hline 25 & 26 & 27 & 28 & 29 & 30 & 31 \\
\hline
\end{tabular}

\begin{tabular}{|c|c|c|c|c|c|c|}
\hline \multicolumn{7}{|c|}{ 4 Grupos } \\
\hline D & $\mathbf{S}$ & $\mathbf{T}$ & $\mathbf{Q}$ & $\mathbf{Q}$ & $\mathbf{S}$ & $\mathbf{S}$ \\
\hline & & & & 1 & 2 & 3 \\
\hline 4 & 5 & 6 & 7 & 8 & 9 & 10 \\
\hline 11 & 12 & 13 & 14 & 15 & 16 & 17 \\
\hline 18 & 19 & 20 & 21 & 22 & 23 & 24 \\
\hline 25 & 26 & 27 & 28 & 29 & 30 & 31 \\
\hline
\end{tabular}

\begin{tabular}{|c|c|c|c|c|c|c|}
\hline \multicolumn{7}{|c|}{ 5 Grupos } \\
\hline D & S & $\mathbf{T}$ & $\mathbf{Q}$ & $\mathbf{Q}$ & $\mathbf{S}$ & $\mathbf{S}$ \\
\hline & & & & 1 & 2 & 3 \\
\hline 4 & 5 & 6 & 7 & 8 & 9 & 10 \\
\hline 11 & 12 & 13 & 14 & 15 & 16 & 17 \\
\hline 18 & 19 & 20 & 21 & 22 & 23 & 24 \\
\hline 25 & 26 & 27 & 28 & 29 & 30 & 31 \\
\hline
\end{tabular}

\begin{tabular}{|c|c|c|c|c|c|c|}
\hline \multicolumn{7}{|c|}{ 6 Grupos } \\
\hline D & S & $\mathbf{T}$ & $\mathbf{Q}$ & $\mathbf{Q}$ & $\mathbf{S}$ & $\mathbf{S}$ \\
\hline & & & & 1 & 2 & 3 \\
\hline 4 & 5 & 6 & 7 & 8 & 9 & 10 \\
\hline 11 & 12 & 13 & 14 & 15 & 16 & 17 \\
\hline 18 & 19 & 20 & 21 & 22 & 23 & 24 \\
\hline 25 & 26 & 27 & 28 & 29 & 30 & 31 \\
\hline
\end{tabular}

\begin{tabular}{|c|c|c|c|c|c|c|}
\hline \multicolumn{7}{|c|}{ 7 Grupos } \\
\hline D & S & T & Q & Q & S & S \\
\hline & & & & 1 & 2 & 3 \\
\hline 4 & 5 & 6 & 7 & 8 & 9 & 10 \\
\hline 11 & 12 & 13 & 14 & 15 & 16 & 17 \\
\hline 18 & 19 & 20 & 21 & 22 & 23 & 24 \\
\hline 25 & 26 & 27 & 28 & 29 & 30 & 31 \\
\hline
\end{tabular}

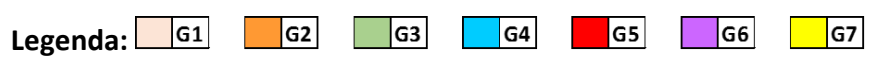

Fonte: Elaborada pelo autor

Nota-se que para 3 grupos, o G1 compreende os dias de domingo a quinta-feira, o G2 todas as sextas-feiras e o G3 todos os sábados. Para 4 agrupamentos, os domingos formam um novo grupo (G4 - 4 grupos). Em 5 agrupamentos as segundas-feiras formaram um novo cluster (G5 - 5 grupos). Em seis agrupamentos, os dias 27 e 29 se isolam em um novo grupo (G6 - 6 grupos) e por fim, em sete agrupamentos, o dia 5 se isola em um grupo (G7 -7 grupos).

Analisando os agrupamentos formados, nota-se que os grupos de sextas e sábados 
mantém um comportamento de forte similaridade com os sinais que os compõem, mantendo-se em grupos intactos de 3 a 7 agrupamentos. Ao contrário do sentido Leste, onde os domingos que formaram em um grupo desde 3 agrupamentos e manteve-se até 7 agrupamentos, com exceção do dia 4 que se isolou em um novo grupo. Mas novamente a partir de 6 agrupamentos ocorre a tendência de isolar alguns dias em novos grupos distintos. Assim, há evidências que cinco grupos seja a melhor opção para definir dias típicos de tráfego. Sendo assim, a Figura 4-16 ilustra o padrão do tráfego para cinco grupos formados.

Figura 4-16 - Grupos formados para 5 agrupamentos com o $C A_{4}$ de março - Oeste

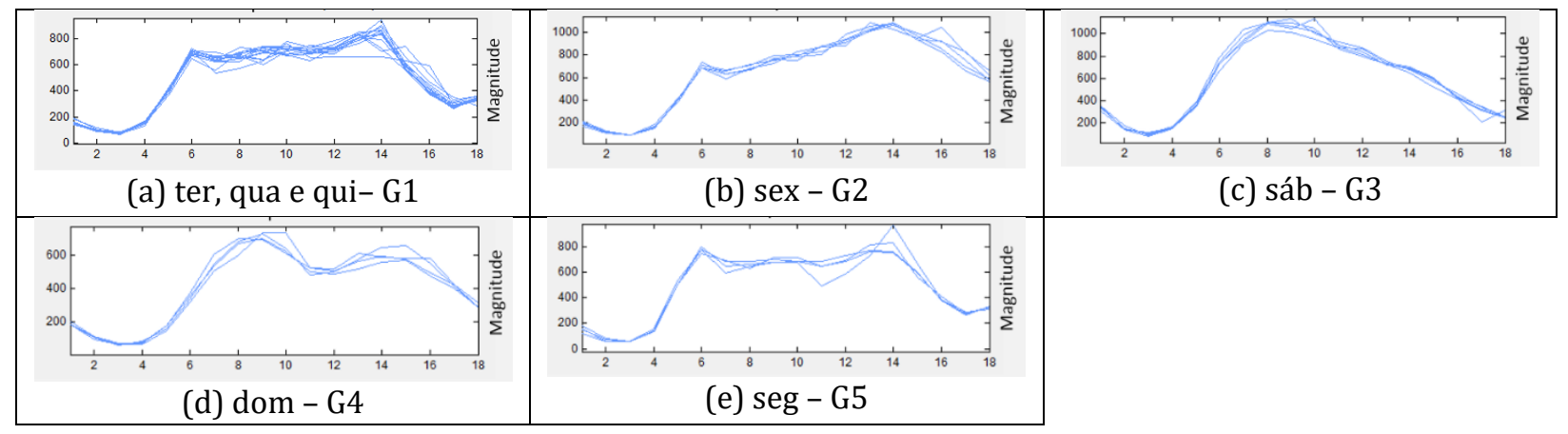

Fonte: Elaborada pelo autor

\subsubsection{Análise comparativa com outros estudos}

Foram comparados os resultados obtidos nesta dissertação para o reconhecimento de padrões no comportamento do fluxo de tráfego com os métodos apresentados na revisão bibliográfica para representação das variações no comportamento do fluxo de tráfego. Inicialmente foi comparado os resultados desta pesquisa com as principais formas de representação da literatura, volume horário, volume diário e volume subhorário (OLIVEIRA, 2004; ROESS; MCSHANE; PRASSAS, 1998). Em seguida, foi comparado com os trabalhos de Weijermars e Berkum (2005) pois também utilizaram a análise de agrupamentos em seu método, porém há um tratamento e pré-classificação dos dados. Por fim, foi comparado com o método de Cunha (2007), por apresentar uma definição do dia útil típico utilizado na prática, ao aplicar a média horária do fluxo de tráfego de terças, quartas e quintas-feiras sem a influência de feriados. 


\subsubsection{Análise comparativa com as principais representações da literatura}

Conforme visto no Capítulo 2, as principais representações da literatura quanto as variações temporais do fluxo de tráfego baseiam-se em representações diárias, horárias e sub-horárias. Para uma análise comparativa com essas representações, a seguir, é apresentado a porcentagem do Volume Horário Médio Anual e em Dias Úteis e o Volume Horário Médio e em Dias Úteis em relação ao Volume Total Diário, assim como a média dos coeficientes de aproximação $4(C A 4)$ para as mesmas situações analisadas nesse capítulo.

Na análise do Volume Horário Médio Anual foi analisado o período de 01/09/2011 à 31/08/2012, no sentido Leste da rodovia analisada. Nesta representação (Figura 4-17) foi feita a média horária para cada hora do dia (VHM), considerando todos os dias do ano, ao contrário do método proposto nesta dissertação, que primeiro formou grupos com as mesmas características para, em seguida, analisar os perfis formados. Comparando o perfil do VHM com a forma dos coeficientes de aproximação $4\left(C A_{4}\right)$ de cada grupo formado nesta dissertação para o mesmo período analisado (Figura 4-17 (G1 à G7)), notase que a mesma se assemelha ao perfil de sábado (Figura 4-17 (G3 em destaque)). No entanto, não se assemelha aos outros seis perfis formados.

Em seguida, foi analisado o Volume Horário Médio Anual em Dias Úteis (VHMDU), Figura 4-17. Comparando o perfil do VHMDU com os perfis encontrados nesta dissertação, nota-se que o VHMDU apresentou similaridade apenas ao perfil de sexta-feira (Figura 4-17 (G2 em destaque)), mas não se assemelha aos grupos formados pelos outros dias úteis (Figura 4-17 (G1: terça, quarta e quinta-feira e G5: segunda-feira)). Essas comparações apontam a falha em utilizar os VHM e VHMDU para representar todos os dias do ano com apenas um perfil.

Para comparar os perfis obtidos pelo método dessa dissertação e do Volume Horário Médio e do Volume Horário Médio em Dias Úteis no período mensal, foi utilizado novamente os meses de setembro, dezembro e março conforme é apresentado na Figura 4-18). 
Figura 4-17 - Volume Horário Médio (VHM), Volume Horário Médio em Dias Úteis (VHMDU) e Médias dos $C A_{4}$ para o ano analisado

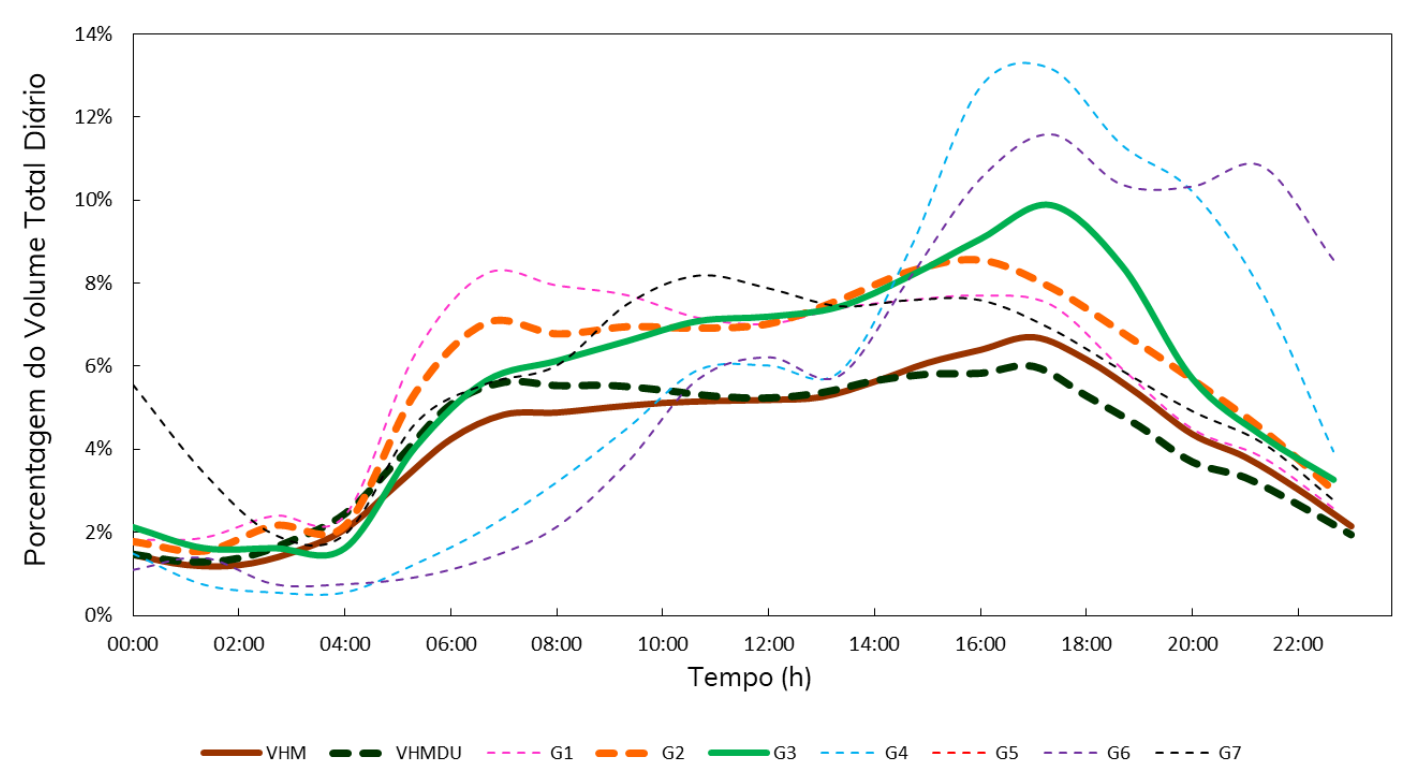

Fonte: Elaborada pelo autor

Figura 4-18 - Volume Horário Médio (VHM), Volume Horário Médio em Dias Úteis (VHMDU) e Médias dos $C A_{4}$ para os meses analisados

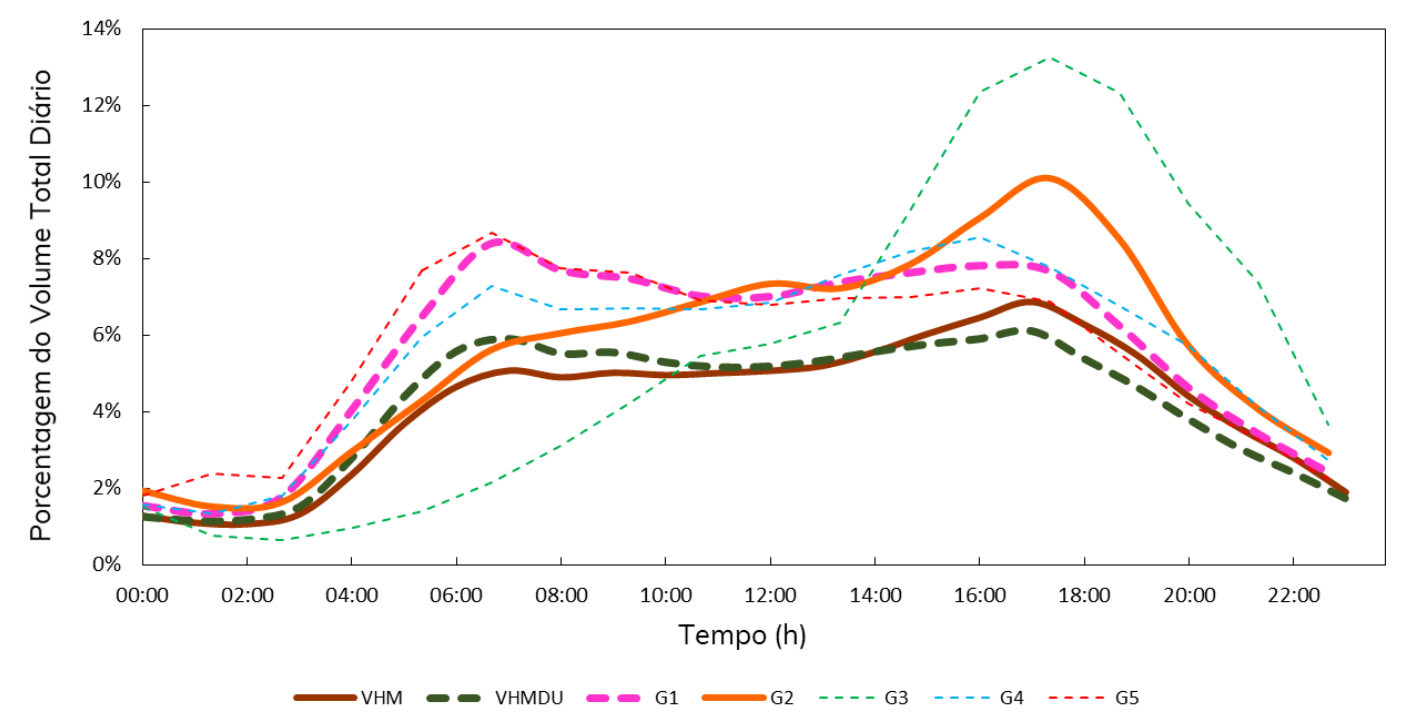

(a) Setembro 


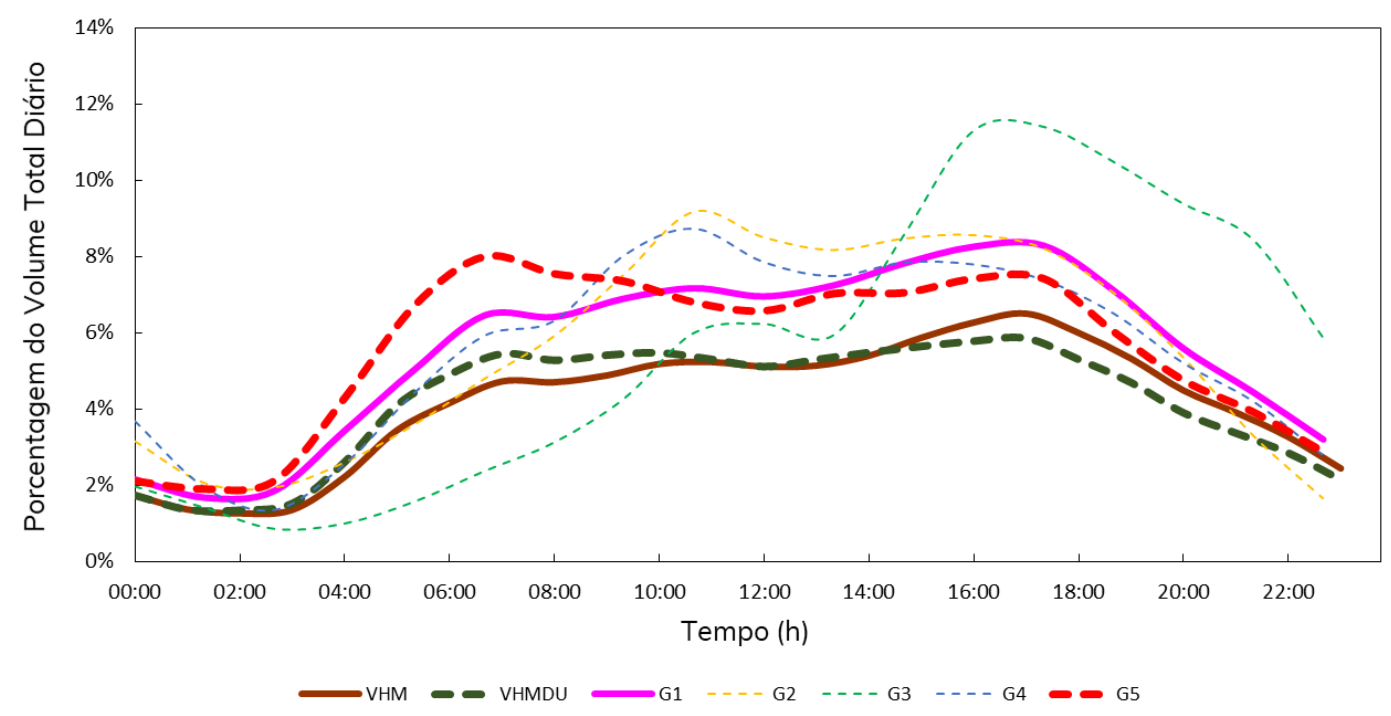

(b) Dezembro

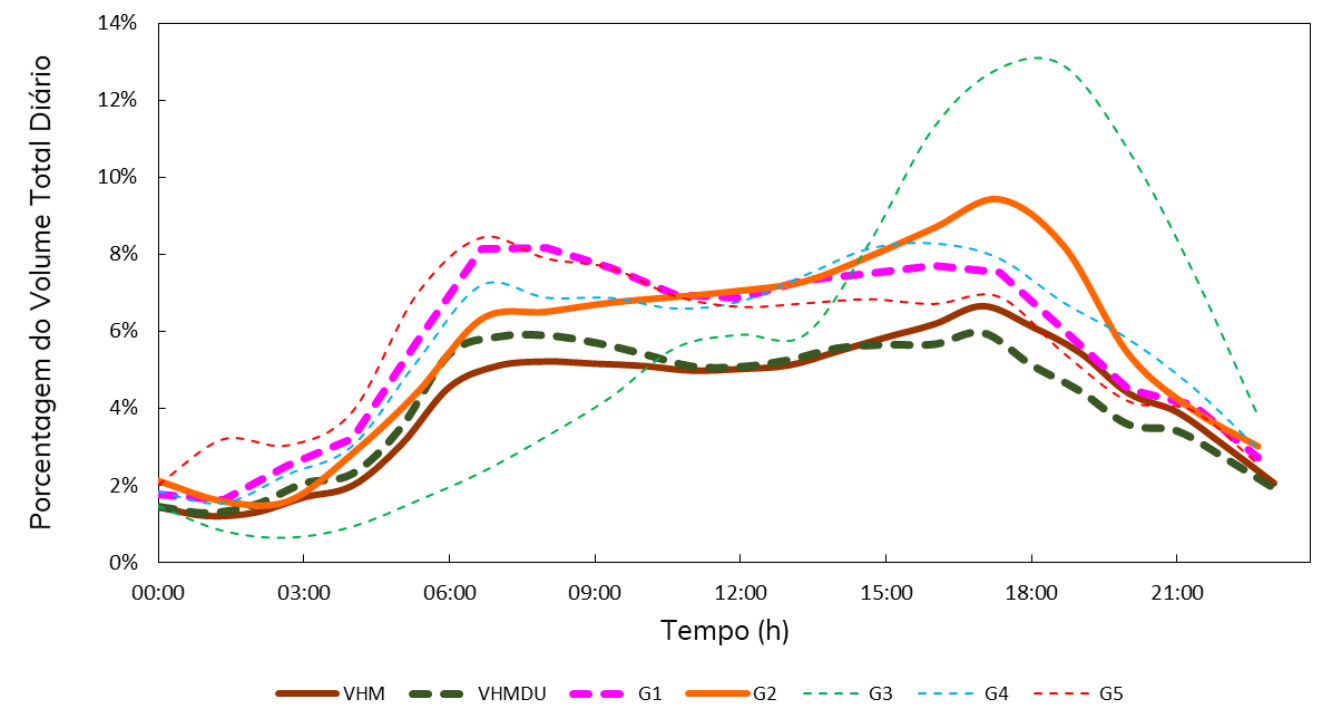

(c) Março

Fonte: Elaborada pelo autor

Comparando os perfis de Volume Horário Médio a cada mês com os perfis de cada grupo encontrados nesta dissertação, nota-se que o VHM do mês de setembro é similar ao perfil de sábado (Figura 4-18 (a - G2 em destaque)). No mês de dezembro, o perfil com forma mais semelhante foi o grupo formado por terça-feira, quarta-feira, quinta-feira, sexta-feira e sábado (Figura 4-18 (b - G1 em destaque)). Por fim, para o mês de março, o perfil mais semelhante ao VHM foi o grupo de sábados (Figura 4-18 (c - G2 em destaque)).

No entanto, os perfis de Volume Horário Médio em Dias Úteis apresentaram semelhança com outros perfis definidos nesta pesquisa. 0 mês de setembro apresentou 
similaridade com o grupo de terça, quarta e quinta-feira (Figura 4-18 (a - G1 em destaque)), o mês de dezembro apresentou maior similaridade com a curva de terça, quarta, quinta, sexta-feira e sábado (Figura 4-18 (b -G5)). Por fim, o mês de março, apresentou similaridade com o grupo de terça, quarta e quinta-feira (Figura 4-18 (c - G1 em destaque)).

Essas comparações entre os formatos das curvas a cada mês, mesmo que entre perfis formados por Volume Horário Médio, Volume Horário Médio em Dia Úteis e Coeficiente de Aproximação derivado da Transformada Wavelet ilustra que cada tipo de dia, apresenta características distintas e a representação por Volume Horário Médio não ilustra todos os perfis, assim como o Volume Horário Médio em Dias Úteis se assemelha a um grupo de dia útil em específico, mas não representa os outros grupos. Esses resultados apontam para as deficiências em utilizar essas médias para definir o comportamento da corrente de tráfego.

\subsubsection{Análise comparativa a Weijermars e Berkum (2005)}

Para ilustrar as diferenças entre os métodos foi aplicado o método de Weijermars e Berkum (2005) nos mesmos meses utilizados para análise mensal desta pesquisa: setembro de 2011, dezembro de 2011 e março de 2012 no sentido Leste. No entanto, esse método foi aplicado apenas no conjunto de dados de dias úteis, eliminando assim os sábados e domingos, pois o interesse dessas comparações é analisar se os grupos formados por dias úteis correspondem aos mesmo grupos formados nessa dissertação sem a pré-classificação dos dados.

Weijermars e Berkum (2005) com base nos seus resultados indicam quatro grupos padrões para os dias úteis: (1) segundas-feiras, (2) núcleo dos dias da semana (core weekdays), (3) sextas-feiras e (4) dias dentro do período de férias. Baseado nisso, serão formados de 3 a 5 grupos, utilizando os mesmos parâmetros: Procedimento Hierárquico, método de Ward e distância euclidiana quadrática (coincide com os parâmetros definidos no método desta dissertação). A Figura 4-19 apresentada os 3 cenários para o mês de setembro, a Figura 4-20 para o mês de dezembro e a Figura 4-21 para o mês de março. 
Figura 4-19 - Resultados das análises de agrupamento baseado no método de Weijermars e Berkum (2005) de setembro no sentido Leste

\begin{tabular}{|c|c|c|c|c|c|c|}
\hline \multicolumn{7}{|c|}{ 3 Grupos } \\
\hline D & S & T & Q & Q & S & S \\
\hline & & & & 1 & 2 & \\
\hline & 5 & 6 & 7 & 8 & 9 & \\
\hline & 12 & 13 & 14 & 15 & 16 & \\
\hline & 19 & 20 & 21 & 22 & 23 & \\
\hline & 26 & 27 & 28 & 29 & 30 & \\
\hline
\end{tabular}

\begin{tabular}{|c|c|c|c|c|c|c|}
\hline \multicolumn{7}{|c|}{ 4 Grupos } \\
\hline D & S & T & Q & Q & S & S \\
\hline & & & & 1 & 2 & \\
\hline & 5 & 6 & 7 & 8 & 9 & \\
\hline & 12 & 13 & 14 & 15 & 16 & \\
\hline & 19 & 20 & 21 & 22 & 23 & \\
\hline & 26 & 27 & 28 & 29 & 30 & \\
\hline
\end{tabular}

\begin{tabular}{|c|c|c|c|c|c|c|}
\hline \multicolumn{7}{|c|}{ 5 Grupos } \\
\hline D & $\mathbf{S}$ & $\mathbf{T}$ & $\mathbf{Q}$ & $\mathbf{Q}$ & $\mathbf{S}$ & $\mathbf{S}$ \\
\hline & & & & 1 & 2 & \\
\hline & 5 & 6 & 7 & 8 & 9 & \\
\hline & 12 & 13 & 14 & 15 & 16 & \\
\hline & 19 & 20 & 21 & 22 & 23 & \\
\hline & 26 & 27 & 28 & 29 & 30 & \\
\hline
\end{tabular}

Legenda:

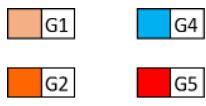

G3

Fonte: Elaborada pelo autor

Figura 4-20 - Resultados das análises de agrupamento baseado no método de Weijermars e Berkum (2005) de dezembro no sentido Leste

\begin{tabular}{|c|c|c|c|c|c|c|}
\hline \multicolumn{7}{|c|}{ 3 Grupos } \\
\hline D & S & T & Q & Q & S & S \\
\hline & & & & 1 & 2 & \\
\hline & 5 & 6 & 7 & 8 & 9 & \\
\hline & 12 & 13 & 14 & 15 & 16 & \\
\hline & 19 & 20 & 21 & 22 & 23 & \\
\hline & 26 & 27 & 28 & 29 & 30 & \\
\hline
\end{tabular}

\begin{tabular}{|r|r|r|r|r|r|r|}
\hline \multicolumn{7}{|c|}{ 4 Grupos } \\
\hline D & S & T & Q & Q & S & S \\
\hline & & & & 1 & 2 & \\
\hline & 5 & 6 & 7 & 8 & 9 & \\
\hline & 12 & 13 & 14 & 15 & 16 & \\
\hline & 19 & 20 & 21 & 22 & 23 & \\
\hline & 26 & 27 & 28 & 29 & 30 & \\
\hline
\end{tabular}

\begin{tabular}{|c|c|c|c|c|c|c|}
\hline \multicolumn{7}{|c|}{ S Grupos } \\
\hline D & S & T & Q & Q & S & S \\
\hline & & & & 1 & 2 & \\
\hline & 5 & 6 & 7 & 8 & 9 & \\
\hline & 12 & 13 & 14 & 15 & 16 & \\
\hline & 19 & 20 & 21 & 22 & 23 & \\
\hline & 26 & 27 & 28 & 29 & 30 & \\
\hline
\end{tabular}

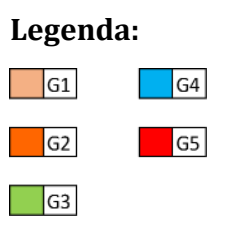

Fonte: Elaborada pelo autor

Figura 4-21 - Resultados das análises de agrupamento baseado no método de Weijermars e Berkum (2005) de março no sentido Leste

\begin{tabular}{|c|c|c|c|c|c|c|}
\hline \multicolumn{7}{|c|}{ 3 Grupos } \\
\hline D & S & T & Q & Q & S & S \\
\hline & & & & 1 & 2 & \\
\hline & 5 & 6 & 7 & 8 & 9 & \\
\hline & 12 & 13 & 14 & 15 & 16 & \\
\hline & 19 & 20 & 21 & 22 & 23 & \\
\hline & 26 & 27 & 28 & 29 & 30 & \\
\hline
\end{tabular}

\begin{tabular}{|c|c|c|c|c|c|c|}
\hline \multicolumn{7}{|c|}{ 4 Grupos } \\
\hline $\mathbf{D}$ & $\mathbf{S}$ & $\mathbf{T}$ & $\mathbf{Q}$ & $\mathbf{Q}$ & $\mathbf{S}$ & $\mathbf{S}$ \\
\hline & & & & 1 & 2 & \\
\hline & 5 & 6 & 7 & 8 & 9 & \\
\hline & 12 & 13 & 14 & 15 & 16 & \\
\hline & 19 & 20 & 21 & 22 & 23 & \\
\hline & 26 & 27 & 28 & 29 & 30 & \\
\hline
\end{tabular}

\begin{tabular}{|c|c|c|c|c|c|c|}
\hline \multicolumn{7}{|c|}{ 5 Grupos } \\
\hline D & S & T & Q & Q & S & S \\
\hline & & & & 1 & 2 & \\
\hline & 5 & 6 & 7 & 8 & 9 & \\
\hline & 12 & 13 & 14 & 15 & 16 & \\
\hline & 19 & 20 & 21 & 22 & 23 & \\
\hline & 26 & 27 & 28 & 29 & 30 & \\
\hline
\end{tabular}

Legenda:

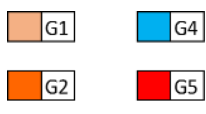

$\square \mathrm{G} 3$

Fonte: Elaborada pelo autor

Os resultados obtidos por esse método refletem os resultados do método proposto nesta pesquisa. No entanto, como os fins de semana foram excluídos da análise, o número final de agrupamentos formados para cada mês comparado ao utilizado neste trabalho é diferente.

No mês de setembro, o quarto agrupamento de Weijermars e Berkum (2005) é similar ao cenário de 5 grupos no método utilizado nesta pesquisa (Figura 4-5), com os grupos de: (i) segunda-feira e pós-feriado, (ii) sexta-feira e (iii) terça, quarta e quinta-feira iguais, no entanto, nesta dissertação considerou-se o fim de semana para os agrupamentos e o feriado (7/set - quarta-feira) ficou no grupo de sábado, enquanto no método comparado isolou-se em um grupo. 0 mês de dezembro obteve um agrupamento similar comparando 5 agrupamentos de Weijermars e Berkum (2005) aos 5 agrupamentos do método proposto (Figura 4-7). No método de Weijermars e Berkum 
(2005) todas as sextas-feiras, com exceção do dia 30, e os dias úteis das duas últimas semanas se concentravam em um grupo enquanto os dias úteis das duas primeiras semanas se concentravam em outro e o pós-feriado (26/dez) formava um grupo sozinho, porém no método comparado, as três primeiras segundas-feiras formaram um grupo e no método proposto não. Por fim, o mês de março obteve os mesmos agrupamentos com 3 grupos de Weijermars e Berkum e 5 grupos no método proposto (Figura 4-9), sendo que os dois grupos a mais do método proposto foi justamente o grupo de sábado e o grupo de domingo. Essas diferenças indicam que ambos chegam a resultados similares, no entanto, pelo método de Weijermars e Berkum (2005) além de selecionar os dados com antecedência, é necessário formar uma quantidade de grupo diferente a cada mês analisado.

Entretanto, a maior diferença entre os métodos é a resolução dos dados. Para o mesmo agrupamento definido nesta pesquisa e os agrupamentos dos meses ilustrados nota-se um sinal com ruídos que para obter alguma média ou definir um perfil seria necessário algum tratamento de dados. A Figura 4-22 apresenta o método comparado para o mês de setembro, a Figura 4-23 para o mês de dezembro e a Figura 4-24 para o mês de março.

Figura 4-22 - Grupos formados para 4 agrupamentos baseado no método de Weijermars e Berkum (2005) de setembro no sentido Leste

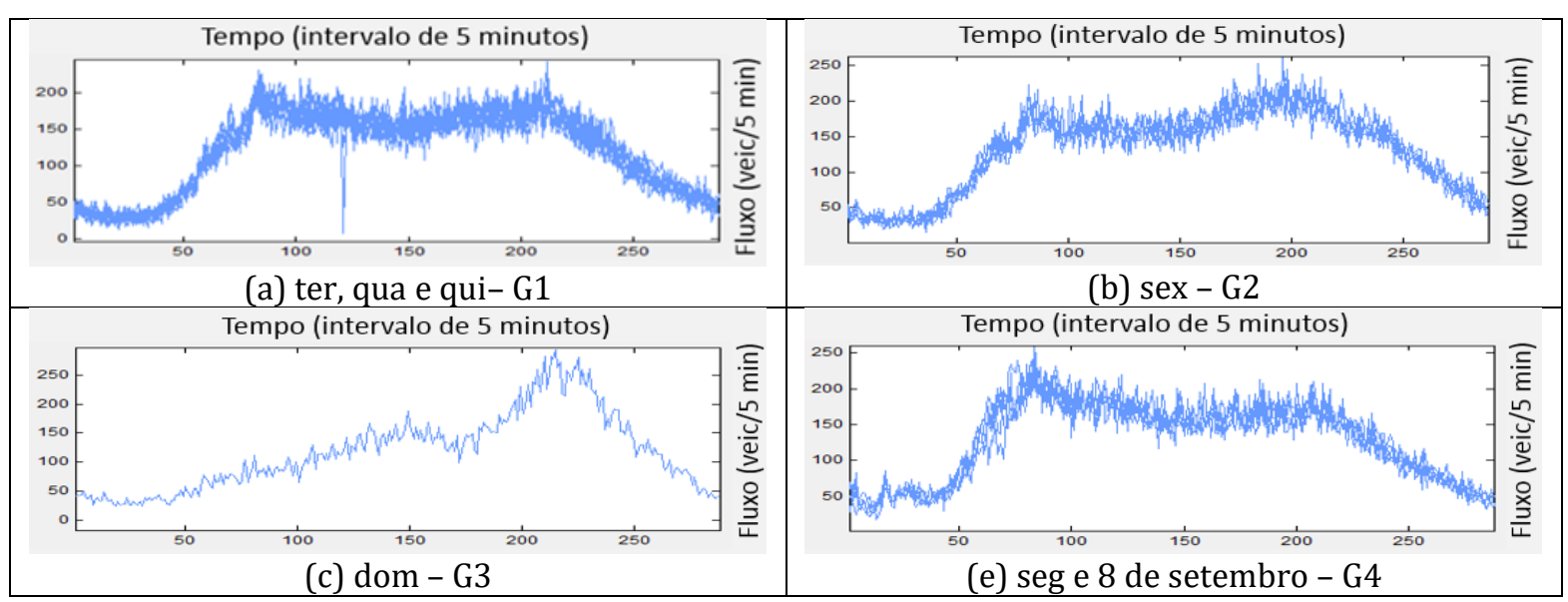

Fonte: Elaborada pelo autor 
Figura 4-23 - Grupos formados para 5 agrupamentos baseado no método de Weijermars e Berkum (2005) de dezembro no sentido Leste

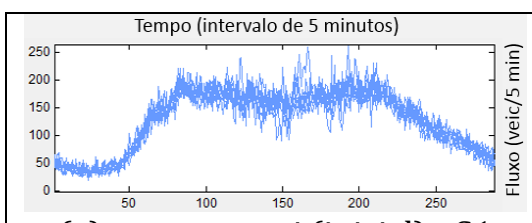

(a) ter, qua e qui (inicial)- G1

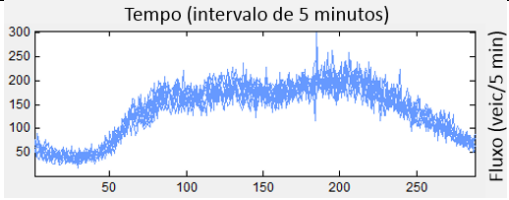

(d) ter, qua e qui (final) e sex - G4

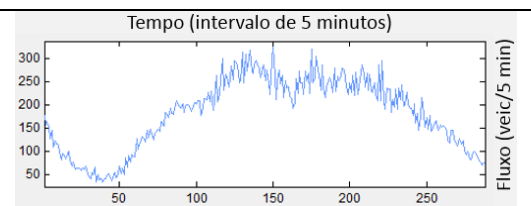

(b) 26 de dezembro - G2

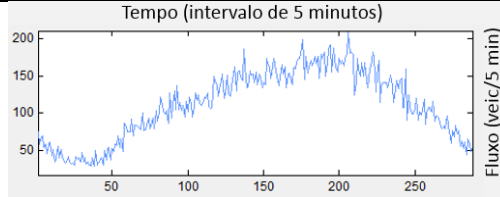

(e) 30 de dezembro - G5

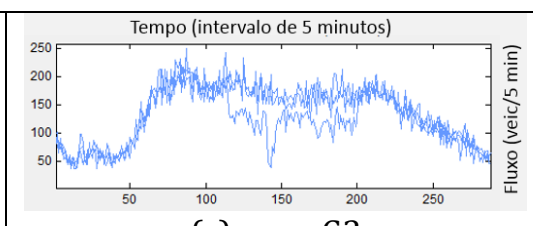

(c) seg - G3

Fonte: Elaborada pelo autor

Figura 4-24 - Grupos formados para 3 agrupamentos baseado no método de Weijermars e Berkum (2005) de março no sentido Leste

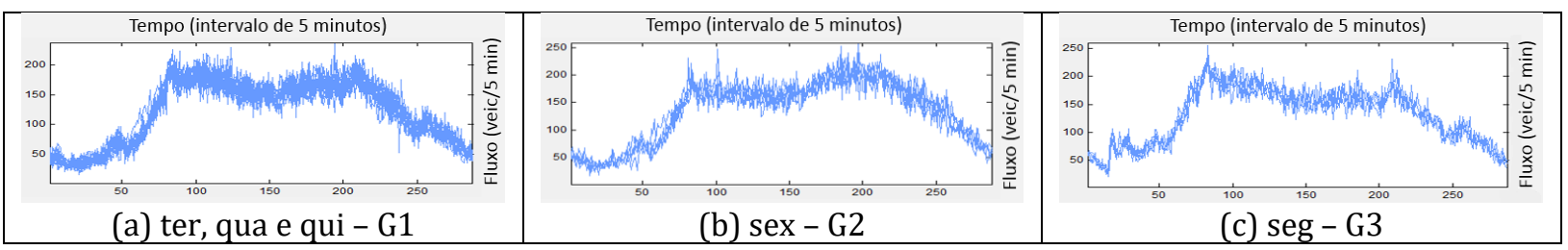

Fonte: Elaborada pelo autor

\subsubsection{Análise comparativa com Cunha (2007)}

O último estudo a ser comparado que analisa o comportamento do tráfego e determinou o fluxo de tráfego em dias úteis é o método de Cunha (2007). 0 autor se baseou em três critérios para estabelecer o método. Em linhas gerais, esses critérios foram: (1) eliminar feriados nacionais e estaduais do banco de dados, (2) eliminar os demais dias da semana influenciados por cada feriado e (3) determinar a média dos volumes horários utilizando apenas as terças, quartas e quintas-feiras.

Para comparar com o método de Cunha (2007) foi utilizado os mesmos critérios para analisar os dados no período de um ano (de 01/09/2011 a 31/08/2012) e para os meses analisados nesta dissertação (set/2011, dez/2011 e mar/2012) da Rodovia Presidente Castelo Branco no km 51,9. Os resultados obtidos são apresentados na Figura 4-25.

Comparando os quatro perfis obtidos pelo método de Cunha (2007) e os perfis formados nesta dissertação, é possível notar que para o período anual o perfil mais similar foi o G1 (Figura 4-25 (a - G1 em destaque)) formado pelas terças, quartas e quintas-feiras. 
Para o mês de setembro os perfis que apresentaram maior similaridade foram os G1 (terças, quartas e quintas-feiras), G4 (sextas-feiras) e G5 (segunda e pós-feriado) (Figura 4-25 (b)). Para o mês de dezembro, os perfis que apresentaram maior similaridade com o VHM obtido por Cunha (2007) foi o G5 (terças, quartas, quintas, sextas-feiras e sábados) (Figura 4-25 (c)). Por fim, para o mês de março, os perfis que apresentaram maior similaridade foram os G1 (terças, quartas e quintas-feiras) e G5 (segundas-feiras) (Figura 4-25(d)).

Figura 4-25 - Volume Horário Médio para terças, quartas e quintas-feiras e Médias dos $C A_{4}$

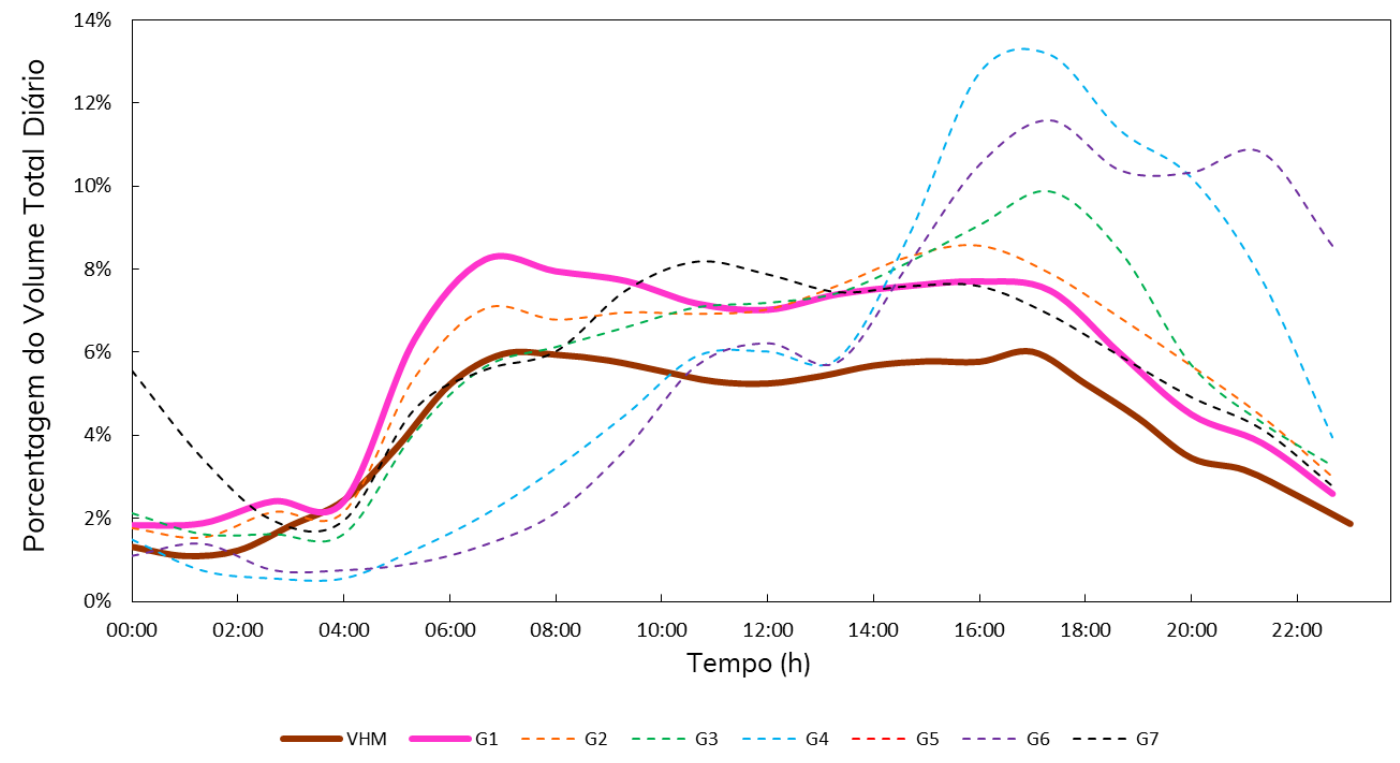

(a) Volume Horário Médio Anual

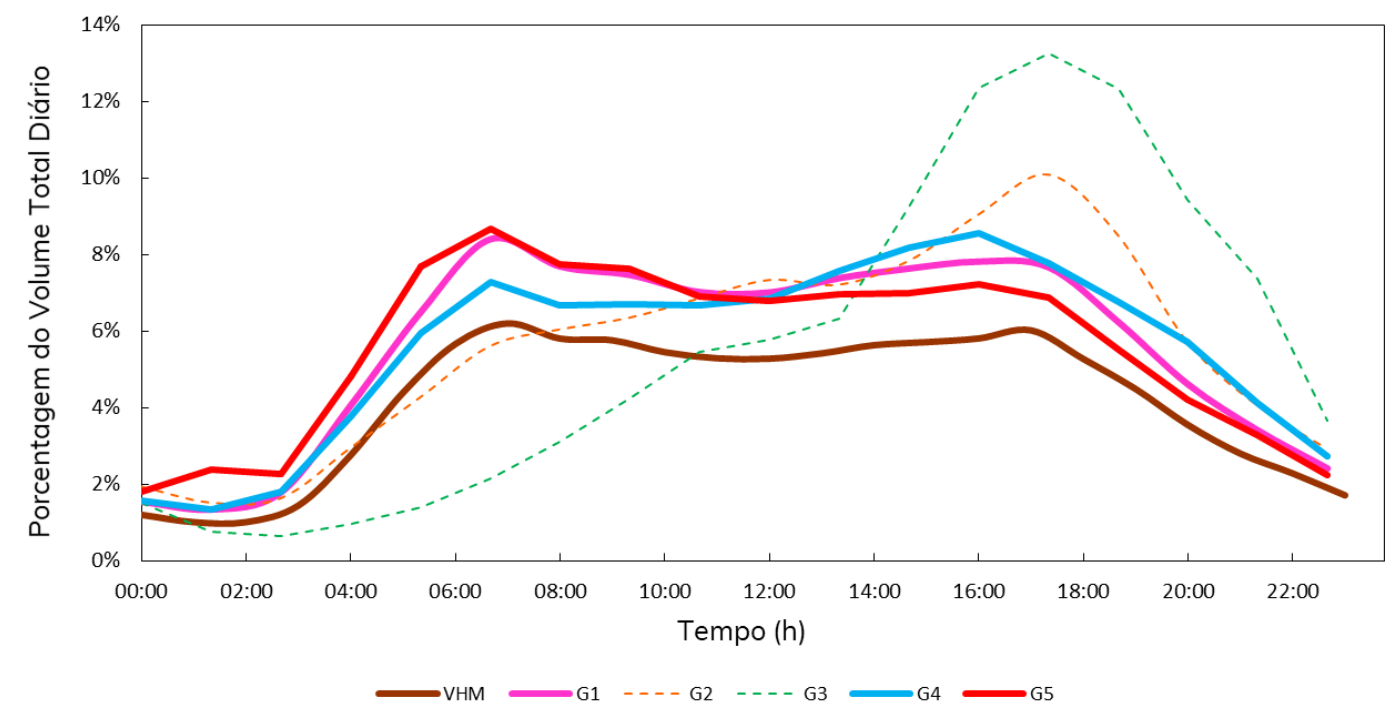

(b) Volume Horário Médio Mensal - Setembro 


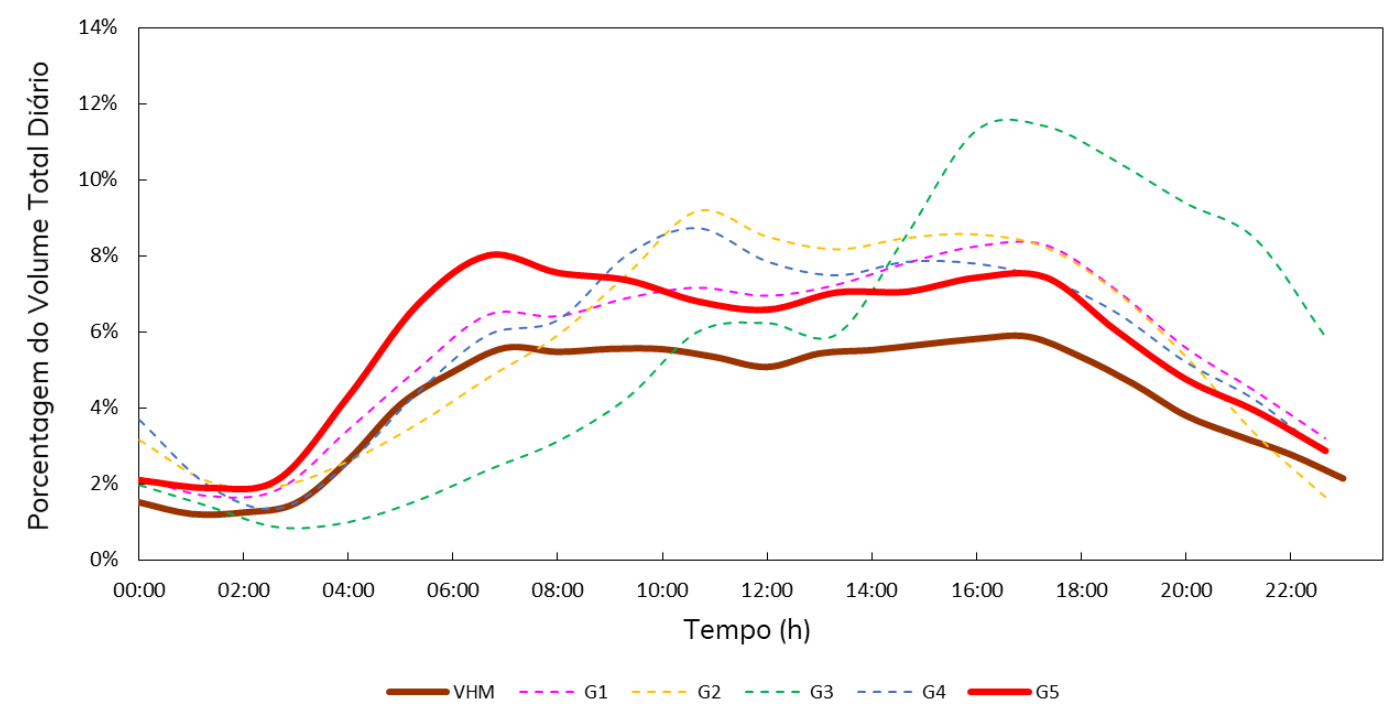

(c) Volume Horário Médio Mensal - Dezembro

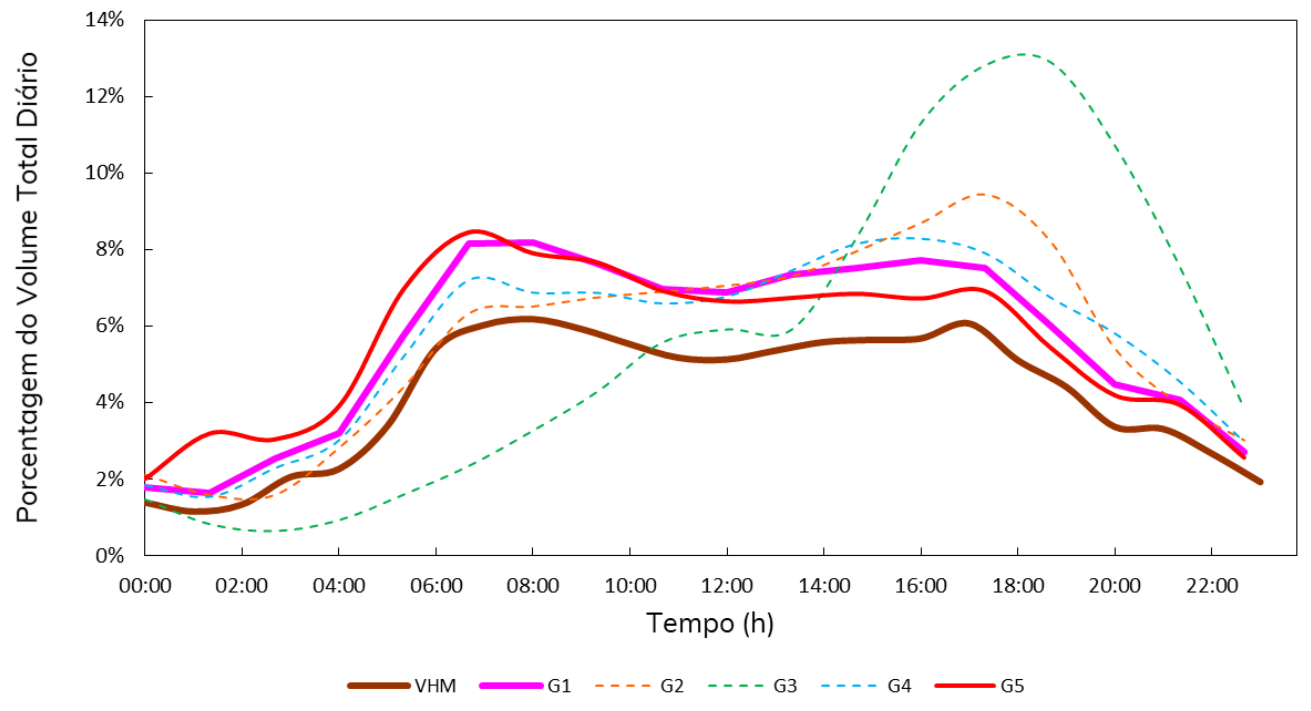

(d) Volume Horário Médio Mensal - Março

Fonte: Elaborada pelo autor

Comparando os métodos proposto e de Cunha (2007), conclui-se que os perfis são similares, apesar de usarem resoluções diferentes, porém o método de Cunha é dependente da experiência do pesquisador para filtrar o banco de dados, principalmente em relação aos feriados regionais. Nesta pesquisa também foram utilizados dados das rodovias do estado de São Paulo, mas cada região tem seus próprios eventos. 0 método de Cunha (2007) visava apenas os dias úteis típicos, no entanto, o método proposto explorou os diferentes perfis que ocorrem durante a semana, sendo que um deles era o perfil de dia útil típico. Por fim, a abordagem de Cunha (2007) não permite voltar aos dados originais, ou seja, determinando o perfil de Volume Horário Médio Anual, não é 
possível a partir dessa média voltar aos dados originais e analisar para outro período ou escala, ao contrário do método proposto que permite a Transformada Inversa e volta aos dados originais.

\subsection{CONSIDERAÇÕES FINAIS}

Esse capítulo tratou o segundo objetivo específico desta pesquisa: reconhecer padrões no comportamento do tráfego. Apresentou o procedimento para o reconhecimento de padrões dividido em três etapas: escolha do coeficiente, análise de agrupamento e aplicação nos dados por período.

A partir dos resultados obtidos, analisando o período anual e mensal, concluiu-se que o período mensal é melhor para definir os grupos de dias típicos, pois o período anual sofre maior influência de diversos feriados com impacto distinto nos dias anteriores e posteriores aos mesmos. 0 sensor escolhido para análise continha apenas duas horas de falhas no período de um ano. No entanto, conforme visto no Capítulo 3, é comum os dados coletados apresentarem falhas por períodos de horas a meses. Para também evitar esse problema, períodos mensais são a melhor solução para se trabalhar com banco de dados com a menor quantidade possível de dados faltantes.

Nas análises mensais, os resultados indicaram que o feriado influencia os outros dias da semana, corroborando com os critérios propostos por Cunha (2007). No entanto, os resultados apontam que não só o dia em que o feriado ocorre, mas também o tipo de feriado e o sentido da rodovia influenciam no comportamento do tráfego. Por exemplo, o feriado do dia 7 de setembro (Independência do Brasil) ocorreu na quarta-feira, pelos critérios de Cunha (2007) além de eliminar o feriado (quarta-feira), eliminar-se-iam a terça e a quinta-feira do banco de dados. Porém, o método de análise proposto indica que esse feriado influencia ou o dia anterior ou posterior, dependendo da direção da rodovia, e a exclusão dos dados do dia anterior e posterior para os dois sentidos da rodovia, ocasiona em perda de informação do banco de dados.

Essa diferença nos agrupamentos entre o sentido Leste e Oeste ilustra a diferença no comportamento do tráfego em sentidos opostos, embora no mesmo local e período. Enquanto na pista Leste (sentido Capital), os domingos e o pós-feriado apresentaram maiores variações no tráfego; a pista Oeste (sentido Interior) apresentou as maiores 
variações durante as sextas-feiras e a véspera de feriado.

Outro fator influente no comportamento do tráfego foi a véspera de fim de ano, férias escolares e feriados de maior impacto no fluxo de tráfego (Natal e Ano Novo). Os resultados para o mês de dezembro indicaram que esses eventos especiais afetam o comportamento do mês inteiro, dividindo em duas quinzenas distintas, principalmente no sentido Leste (Interior - Capital), não permitindo classificar um padrão de dias típicos para esse mês. Portanto, as representações referenciais na literatura, Tráfego Diário Médio e Tráfego Diário Médio em Dias Úteis não caracterizam nenhum grupo específico nem da primeira e nem da segunda quinzena do mês, indicando uma falha nesse tipo de representação.

Por fim, ao analisar um mês sem feriados ou eventos especiais (março), os resultados indicaram que a ausência de perturbações no tráfego reflete em padrões de comportamento bem distintos, diferenciando dias de semana de finais de semana. Com cinco grupos, obteve-se: (a) Domingo, (b) Segunda-feira, (c) Terça, Quarta e Quinta-feira, (d) Sexta-feira e (e) Sábado. Esses resultados corroboram com o método proposto por Weijermars e Berkum (2005), porém sem pré-classificar os dados e com perfis suavizados, livre de ruídos.

De modo geral, em todas as análises, os domingos, sábados e sextas-feiras formam grupos distintos dos demais dias da semana, permanecendo sempre em grupos isolados. As terças, quartas e quintas-feiras tiveram o comportamento de tráfego mais similares entre si, permanecendo sempre em um mesmo grupo. Esses resultados também corroboram com trabalhos anteriores (WEIJERMARS; BERKUM, 2005; CUNHA, 2007), que definiram os dias úteis típicos de tráfego como sendo: terças, quartas e quintas-feiras. 



\section{DetecÇÃo de ANOMALIAS EM DAdos de}

\section{TRÁFEGO}

Uma característica marcante e inerente do fluxo de tráfego é a sua variação, tanto temporal quanto espacial. Devido à sua importância em todos os campos da Engenharia de Transportes são fundamentais a sua análise e compreensão. Todavia para definir o tráfego em dias típicos utiliza-se comumente de médias horárias ou métodos empíricos que eliminam dias atípicos do banco de dados.

No entanto, esses dados excluídos considerados como atípicos podem fornecer informações valiosas do comportamento da corrente de tráfego. Castro-Neto et al. (2009), investigando a previsão do fluxo de tráfego a curto prazo em dias típicos e atípicos, apontam para as limitações em utilizar apenas dados em situações típicas neste tipo de análise, pois para os sistemas de transportes inteligentes é fundamental a previsão exata do fluxo de tráfego a curto prazo em condições atípicas, como acidentes veiculares, intempéries, zonas de trabalho e feriados.

Segundo Zheng e Washington (2012), estruturas irregulares e fenômenos transitórios de um sinal, muitas vezes contêm ricas informações do fenômeno estudado. Considerando a aplicação em Engenharia de Transportes, essas irregularidades podem indicar a ativação ou desativação de um gargalo, alterações no estado do fluxo de tráfego e ocorrências de eventos anormais. Porém, o ruído aleatório e sistemático contido em dados do tráfego veicular torna a detecção de singularidades um grande desafio, pois ao suavizar o impacto do ruído no sinal, pode-se perder as singularidades autênticas dos dados (ZHENG; WASHINGTON, 2012).

Zheng e Washington (2012) compararam a Transformada Wavelet com outros métodos comumente usados na Engenharia de Tráfego para o processamento de dados (média, média móvel, diferença de segunda ordem da soma cumulativa e curva cumulativa oblíqua). Os autores concluíram que essas técnicas atenuam o impacto do ruído, distorcendo ou perdendo totalmente a informação original e singularidades 
potencialmente importantes.

Outros estudos também analisam esses eventos atípicos no tráfego utilizando a Transformada Wavelet, tanto em detecção automática de incidentes de autoestrada (ADELI; SAMANT, 2000; GHOSH-DASTIDAR; ADELI, 2003; KARIM; ADELI, 2002; JEONG et al. 2009; KARIM; ADELI, 2003; SAMANT; ADELI, 2000; SAMANT; ADELI, 2001; TENG; QI, 2003) quanto em detecção de oscilações do tráfego (MOHAN et al., 2014; ZHENG et al., 2011; ZHENG; WHASHINGTON, 2012).

Em linhas gerais, os estudos que se concentram em detecção automática de incidentes de autoestrada buscam detectar de forma rápida e precisa os incidentes para o gerenciamento eficiente do tráfego em rodovias (SAMANT; ADELI, 2000). Incidentes de trânsito e acidentes em rodovias resultam frequentemente em lesões graves (até mesmo fatais), congestionamento de tráfego extenso e atraso prolongado (JEONG et al. 2009). Por sua vez, os estudos relacionados à detecção de oscilações do tráfego analisam as informações inferidas nos coeficientes da Transformada Wavelet, como origem, propagação e extensão do congestionamento do tráfego (MOHAN et al., 2014; ZHENG et al., 2011)

Nesse contexto, esta dissertação visa realizar uma análise exploratória dos coeficientes da Transformada Wavelet a partir da extração do máximo de informações possíveis, através da análise dos diferentes tipos de dias e o fluxo direcional da rodovia em diferentes níveis da Transformada Wavelet, complementando a análise do comportamento do tráfego realizada no Capítulo 4. Além de contribuir com a necessidade prática de explorar a teoria Wavelet na aplicação em Engenharia de Transportes. Apesar de ser uma técnica relativamente nova, estudos pioneiros têm demonstrado o potencial das Wavelets na análise de dados de tráfego.

Nesta pesquisa, os momentos atípicos do tráfego foram considerados como anomalias. Entende-se como anômalo ou anomalia uma irregularidade ou o que se desvia da norma, da generalidade (DICIONÁRIO PRIBERAM DA LÍNGUA PORTUGUESA, 2008). Neste capítulo é descrito e analisado os procedimentos para detectar anomalias no tráfego veicular e identificar o período em que elas ocorrem a partir da Transformada Wavelet, cumprindo assim, o terceiro objetivo específico desta dissertação.

Inicialmente foi definido o que é anomalia e qual método auxiliar à Transformada Wavelet seria escolhido para detectar as mesmas. Em seguida, é apresentado os critérios 
para análise das anomalias. Por fim, é realizada uma análise exploratória do método definido e apresentada as considerações finais do capítulo.

\subsection{Definição de Anomalia em Sinais de Tráfego Veicular Utilizando a TRANSFORMADA WAVELETDISCRETA}

Os coeficientes gerados pela Transformada Wavelet são séries que representam o conteúdo de alta e baixa frequência a cada decomposição. Analisando essas séries é possível filtrar os ruídos a cada nível de decomposição. De forma geral, esses ruídos são qualquer degradação do sinal original, caracterizado por oscilações nítidas. No entanto, definir o que é ruído no sinal pode se tornar uma tarefa difícil pois depende do tipo de sinal, da análise realizada e do objetivo (KAPLAN, 2001). Ao utilizar a Transformada Wavelet em dados de tráfego e aplicar a definição de ruído, são obtidas as informações das maiores oscilações do comportamento de tráfego.

A remoção de ruído no domínio Wavelet geralmente segue o método proposto por Donoho e Johnstone $(1994 ; 1995)$ que consiste nos seguintes passos:

a) Decompor o sinal de entrada aplicando a Transformada Wavelet;

b) Executar o thresholding dos coeficientes de detalhe baseado no valor de threshold estimado. Nesse estágio obtêm-se os coeficientes desprovidos de ruídos e extrai as informações necessárias;

c) Reconstruir a partir da Transformada Wavelet Discreta Inversa (TWDI) o sinal de entrada utilizando os coeficientes sem as componentes relativas aos ruídos.

No segundo passo, o valor de threshold $(\lambda)$ é estimado para encontrar um limiar ótimo entre os coeficientes que representam o ruído e o sinal real. 0 limiar de corte depende de um parâmetro de dispersão $\sigma .0$ parâmetro $\sigma$ pode ser estimado através de duas abordagens: (1) global, que pode ser aplicado a todos os níveis da Wavelet; ou (2) por nível o que implica em um limiar de corte $\lambda_{j}$ diferente a cada escala $j$.

Donoho e Johnstone (1994) propuseram um threshold universal, denominado VisuShrink, podendo ser uma abordagem por nível que determina um parâmetro de dispersão para cada nível da Transformada, ou de forma global, com um único parâmetro de dispersão para todos os níveis. O Visu-Shrink é dado pela equação: 


$$
\lambda=\sigma \sqrt{2 \log (n)}
$$

Sendo: $\sigma$ o desvio padrão do ruído e $n$ o comprimento do sinal.

Após determinar o valor limiar (threshold) é escolhido uma função que execute o thresholding ou limiarização nos coeficientes que estejam abaixo desse valor limiar (OLIVEIRA, 2016). As funções de thresholding mais conhecidas são a Hard-thresholding (Equação 5.2) e a Soft-thresholding (Equação 5.3), dadas respectivamente por:

$$
\begin{gathered}
\operatorname{thr}_{\lambda}^{H}(d)= \begin{cases}0, & \text { se }|d| \leq \lambda \\
d, & \text { se }|d|>\lambda\end{cases} \\
t h r_{\lambda}^{S}(d)= \begin{cases}0, & \text { se }|d| \leq \lambda \\
\operatorname{sign}(d)(|d|-\lambda), & \text { se }|d|>\lambda\end{cases}
\end{gathered}
$$

Sendo, thr a função thresholding e, $d$ o vetor analisado.

A função Hard-thresholding seleciona todos os coeficientes que forem maiores que o threshold, definindo o restante como zero. No entanto a função Soft-thresholding reduz os coeficientes menores que o threshold e mantém o restante. Segundo Morettin (1999), a escolha entre Hard-thresholding ou Soft-thresholding é muitas vezes feita caso a caso, dependendo da aplicação. A Figura 5-1 apresenta ambas funções.

Figura 5-1 -Funções Hard-thresholding e Soft-thresholding

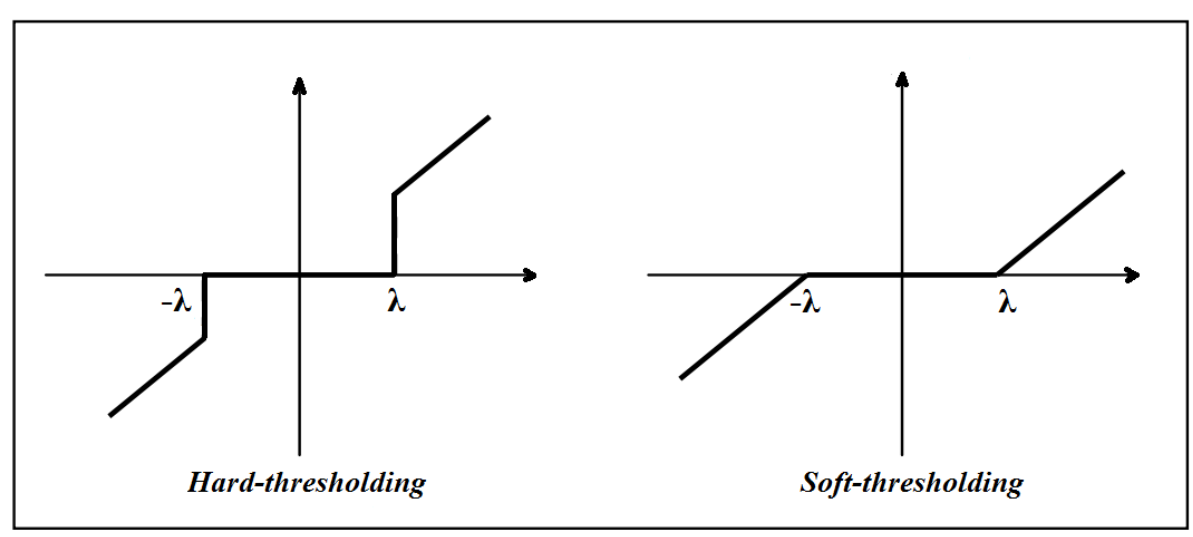

Fonte: Adaptada de Morettin (1999)

Como o objetivo específico desta pesquisa é realizar o tratamento dos dados de tráfego veicular, analisando as anomalias encontradas no comportamento do tráfego, a Transformada Wavelet Discreta Inversa não será aplicada pois não se deseja reconstruir 
o sinal original. Sendo assim, foi estimado apenas o valor threshold para cada nível, utilizando o Visu-Shrink de forma automática pelo programa Matlab. Em seguida, ao invés de aplicar o Hard-thresholding ou Soft-thresholding, foram analisados os valores acima desse limiar e ao invés de serem eliminadas como ruídos, foram definidos como anomalias no comportamento de tráfego e analisados no presente capítulo.

\subsection{CRITÉRIOS PARA ANÁLISE DE ANOMALIAS}

Devido a definição de anomalia para este método, as mesmas ocorreram onde houve maior variação no comportamento do tráfego. Como visto no Capítulo 2, o fluxo de tráfego sofre variação temporal (ao longo do dia, semana, mês e ano), espacial (sentido e faixa de tráfego) e variações especiais, como jogos de futebol, shows, eventos regionais e feriados (DNIT, 2006). Para explorar o maior número de variações no comportamento do tráfego, foram determinadas as seguintes medidas:

a) Os dados foram analisados todos os dias durante o período de um ano completo no mesmo sensor para analisar variações temporais.

b) Para analisar as variações espaciais, os dados foram analisados com a soma de todos os veículos em todas as faixas mas para os dois sentidos da rodovia (Leste e Oeste) separadamente.

c) Por fim, para analisar as variações especiais, foram considerados todos os feriados que ocorreram nesse período. Para isso, considerou feriados nacionais, estaduais e municipais da cidade de São Paulo, devido à localização do sensor (entre São Paulo e o interior, a $50 \mathrm{~km}$ de distância da capital). A Tabela 5.1 apresenta todos os feriados no intervalo de dados analisados set/2011 à ago/2012. 
Tabela 5.1 - Feriados no período de setembro/2011 a agosto/2012

\begin{tabular}{lll}
\hline Data & Dia da Semana & Feriado \\
\hline $\mathbf{0 7 / 0 9 / 2 0 1 1}$ & quarta-feira & Independência do Brasil \\
$\mathbf{1 2 / 1 0 / 2 0 1 1}$ & quarta-feira & Nossa Sra. Aparecida \\
$\mathbf{0 2 / 1 1 / 2 0 1 1}$ & quarta-feira & Finados \\
$\mathbf{1 5 / 1 1 / 2 0 1 1}$ & terça-feira & Proclamação da República \\
$\mathbf{2 0 / 1 1 / 2 0 1 1}$ & domingo & Consciência Negra \\
$\mathbf{2 5 / 1 1 / 2 0 1 1}$ & domingo & Natal \\
$\mathbf{0 1 / 0 1 / 2 0 1 2}$ & domingo & Confraternização Universal \\
$\mathbf{2 5 / 0 1 / 2 0 1 2}$ & quarta-feira & Aniversário de São Paulo \\
$\mathbf{2 1 / 0 2 / 2 0 1 2}$ & terça-feira & Carnaval \\
$\mathbf{2 2 / 0 2 / 2 0 1 2}$ & quarta-feira & Cinzas \\
$\mathbf{0 6 / 0 4 / 2 0 1 2}$ & sexta-feira & Sexta-feira da Paixão \\
$\mathbf{0 8 / 0 4 / 2 0 1 2}$ & domingo & Páscoa \\
$\mathbf{2 1 / 0 4 / 2 0 1 2}$ & sábado & Tiradentes \\
$\mathbf{2 2 / 0 4 / 2 0 1 2}$ & domingo & Descobrimento do Brasil \\
$\mathbf{0 1 / 0 5 / 2 0 1 2}$ & terça-feira & Dia do Trabalho \\
$\mathbf{1 3 / 0 5 / 2 0 1 2}$ & domingo & Dia das Mães \\
$\mathbf{0 7 / 0 6 / 2 0 1 2}$ & quinta-feira & Corpus Christi \\
$\mathbf{0 9 / 0 7 / 2 0 1 2}$ & segunda-feira & Revolução Constitucionalista de 1932 \\
$\mathbf{1 2 / 0 8 / 2 0 1 2}$ & domingo & Dia dos Pais \\
\hline
\end{tabular}

Fonte: Elaborada pelo autor

Nota-se que os feriados ocorreram em dias da semana diferentes e podem influenciar os outros dias da semana de forma distinta. Por exemplo, o feriado da Páscoa ocorre sempre aos domingos, no entanto pode influenciar no comportamento do tráfego da segunda-feira. Para definir a influência dos feriados nos outros dias da semana, foi utilizado o mesmo critério de Cunha (2007) (Tabela 2.2 - Capítulo 2), mas ao invés de eliminar os feriados e os dias influenciados pelos mesmos, foi feita a análise com todos os dias e as anomalias que ocorreram nesse período de influência também foram classificadas como feriado. Anteriormente, no Capítulo 4, foi analisado e discutido a influência dos feriados nos outros dias da semana a cada direção da rodovia, porém nesse capítulo não é uma das tarefas analisar se as anomalias ocorrem no dia anterior ou posterior ao feriado e sim se as anomalias ocorrem no intervalo de influência do feriado, pois a proposta é analisar simultaneamente o padrão do fluxo de tráfego e as anomalias, de forma que uma análise complemente a outra. Baseado nisso e para simplificar a classificação das anomalias, foram classificadas como feriado as que ocorreram no dia do próprio feriado ou em um dia influenciado pelo mesmo.

Para detecção de anomalias foram utilizados os coeficientes dos níveis 1, 2, 3, 4, 8 e 11. Devido às características de cada componente gerado pela Transformada Wavelet, para detecção de anomalias foi utilizado apenas os coeficientes de detalhe. A Figura 5-2 
ilustra as análises realizadas.

Figura 5-2 - Sinais discretos analisados

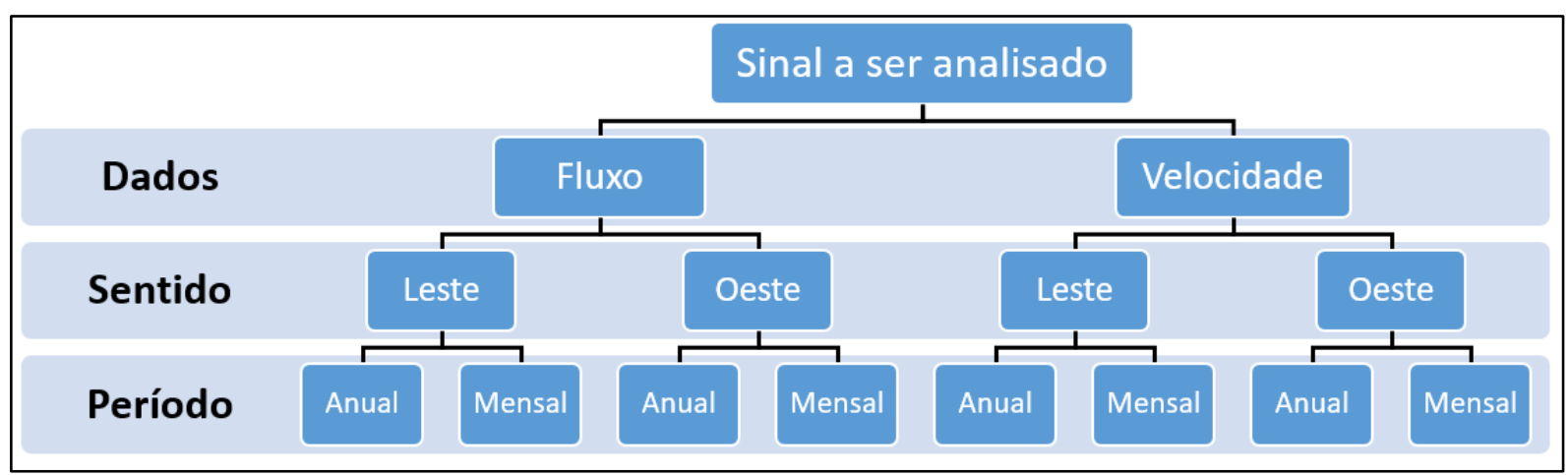

Fonte: Elaborada pelo autor

\subsection{ANOMALIAS NOS DADOS FLUXO DE TRÁFEGO}

Inicialmente foi analisado o sinal de fluxo de tráfego. Foi aplicado a Transformada Wavelet de Haar para cada sinal discreto que será analisado a seguir. Cada subnível dessa seção está dividido por sentido da rodovia e período anual e mensal.

\subsubsection{Sentido Leste Anual}

0 primeiro sinal de fluxo de tráfego foi no sentido Leste da rodovia contendo todos os dias no período de um ano. Os níveis 1, 2, 3 e 4 (Figura 5-3) apresentaram a maior quantidade de anomalias. Nesses níveis, a resolução da janela é muito pequena $(10,20$, 40 e 80 minutos, respectivamente) comparado ao sinal de um ano (527.040 minutos). Segundo Daubechies (1992), em níveis muito baixos, especialmente o primeiro nível, os coeficientes Wavelets contêm muitos ruídos. Porém, conforme aumenta o nível de decomposição, a resolução da janela aumenta e os ruídos são filtrados. Para melhor compreensão, a Figura 5-3 apresenta a quantidade de pontos espaçadas na resolução de cada janela. 
Figura 5-3 - Coeficientes de detalhe em 11 níveis

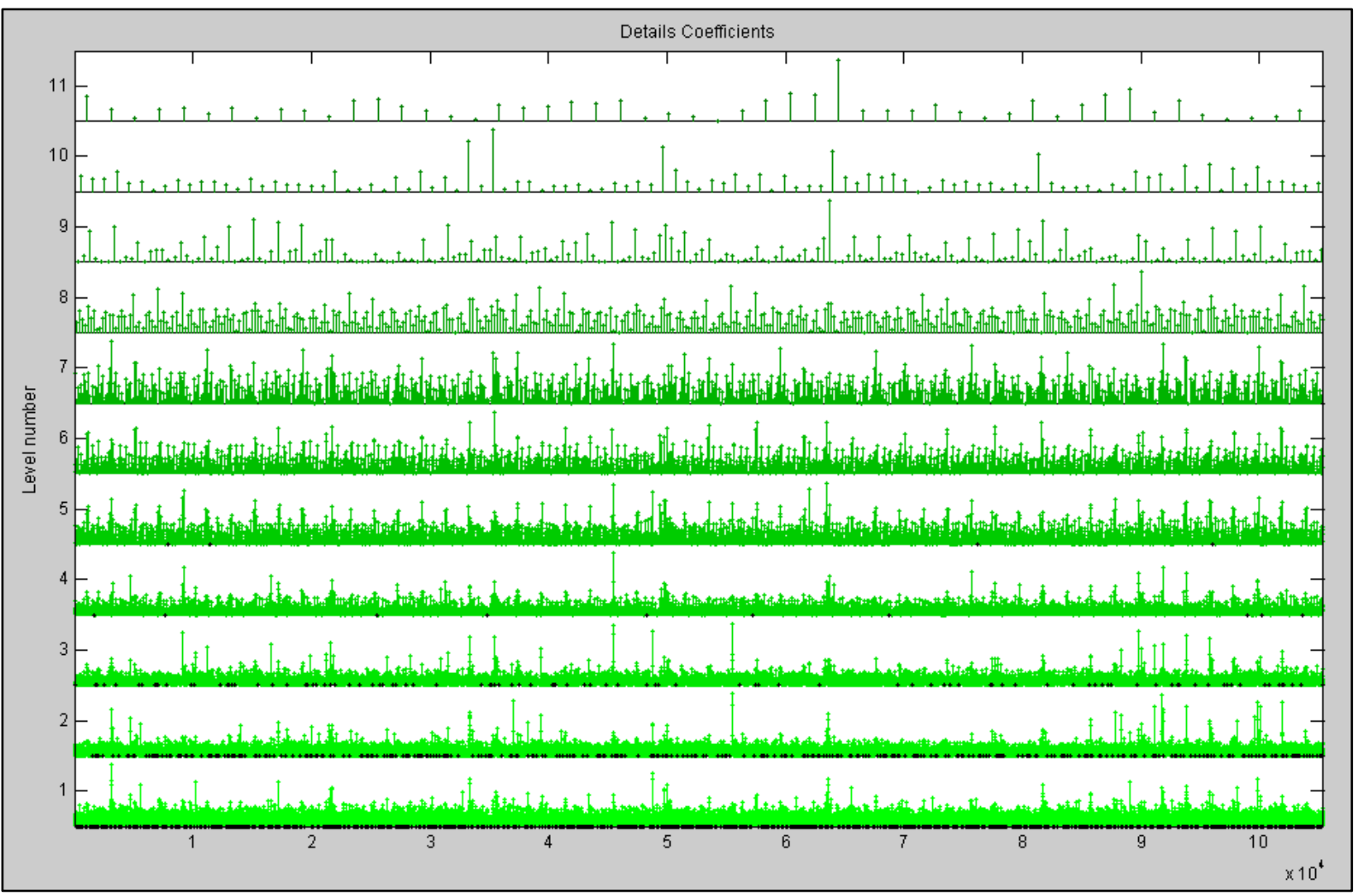

Fonte: Elaborada pelo autor

Em seguida foi calculado o valor threshold para cada nível analisado. A Figura 5-4 apresenta os coeficientes de detalhe para cada nível e seus respectivos valores limiares indicados pela linha tracejada em destaque. 0 Apêndice 5.1 apresenta uma tabela com todos os pontos definidos como anomalias a cada nível.

Figura 5-4 - Coeficientes de detalhe gerados pelos dados de Fluxo Leste Anual de set/2011 a ago/2012

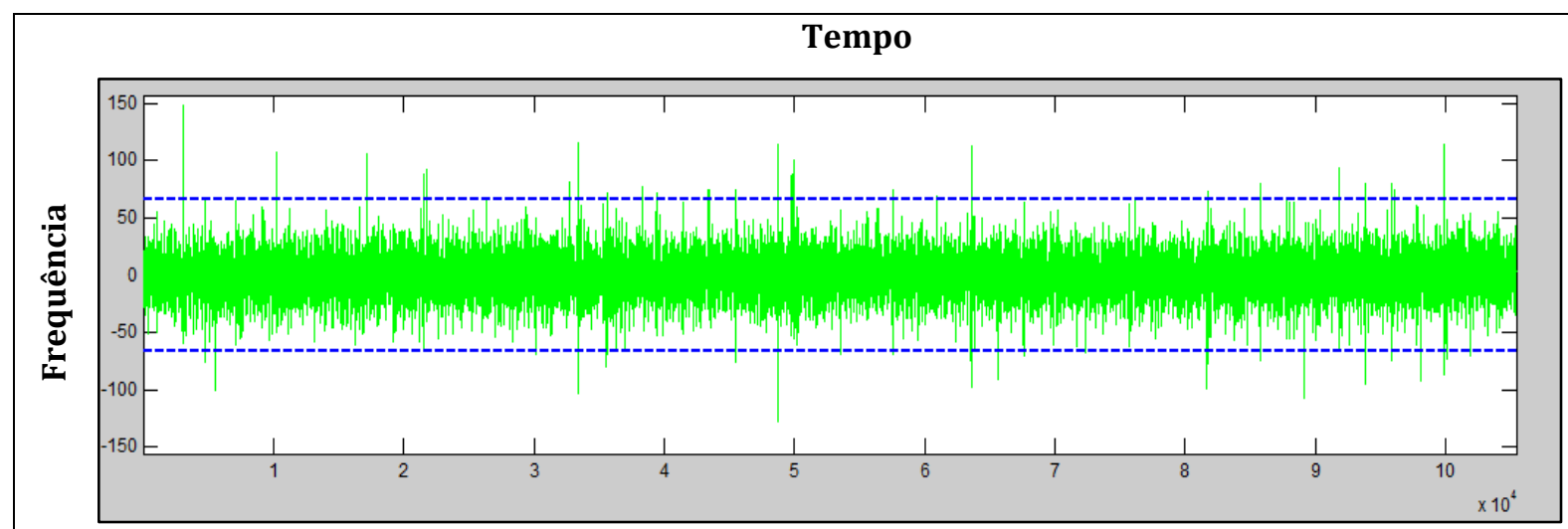

(a) Coeficiente de detalhe 1 - Threshold de 66,905 


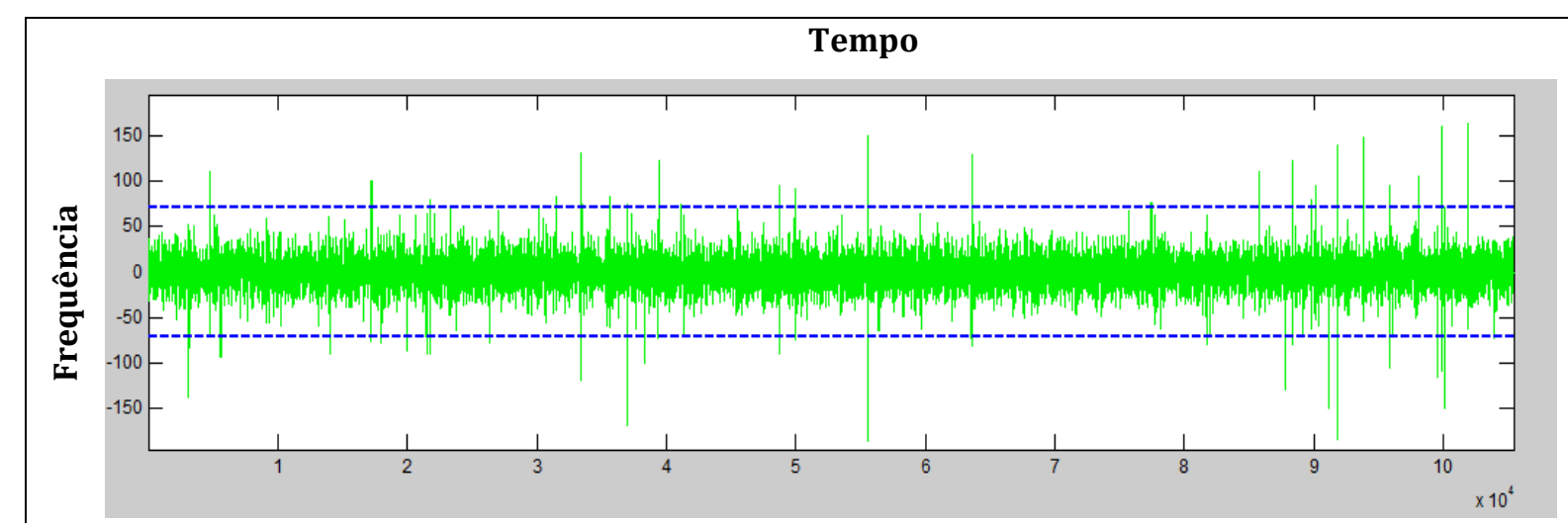

(b) Coeficiente de detalhe 2 - Threshold de 70,715

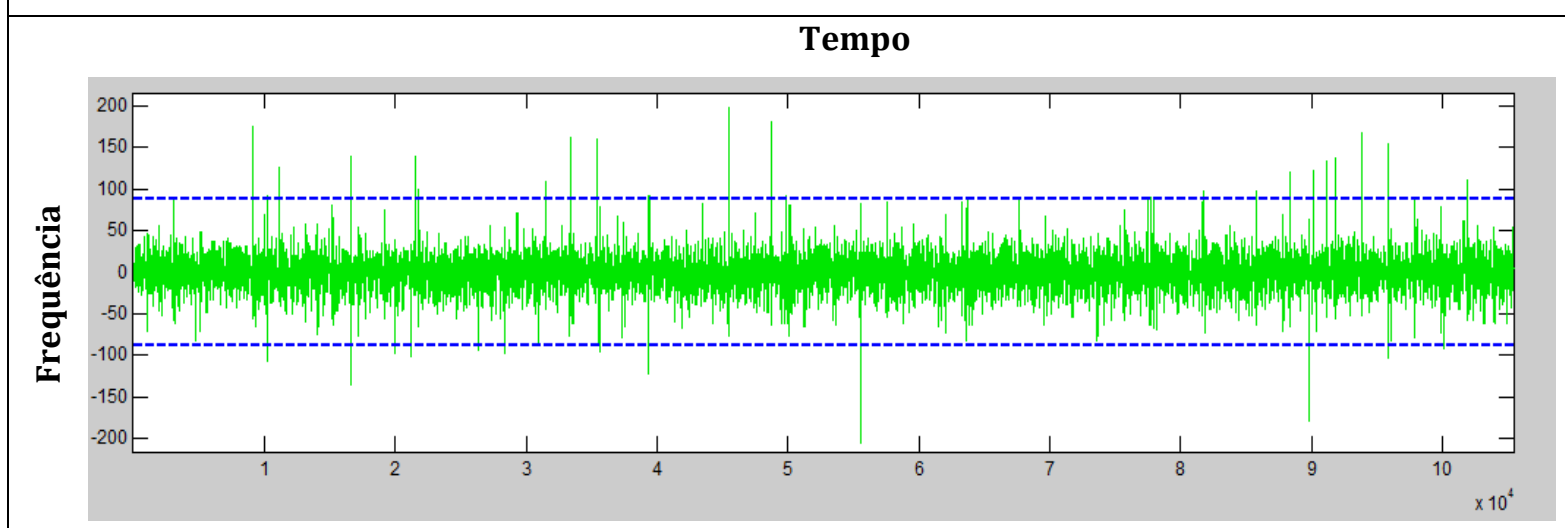

(c) Coeficiente de detalhe 3 - Threshold de 88,143

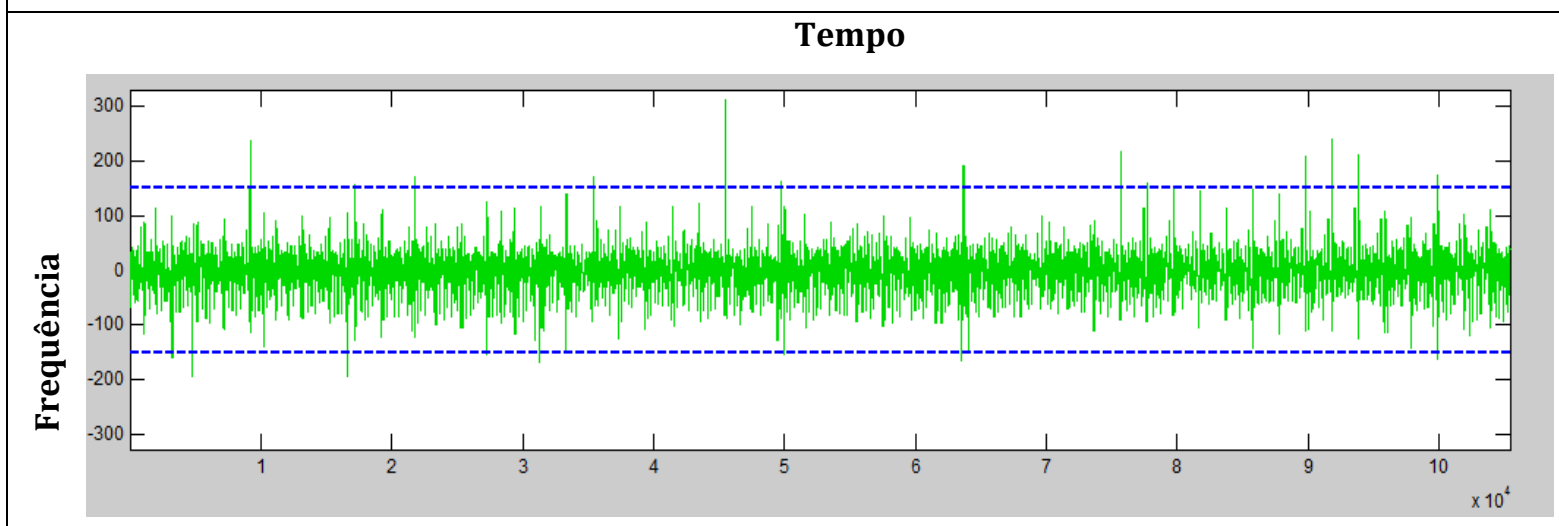

(d) Coeficiente de detalhe 4 - Threshold de 151,757 


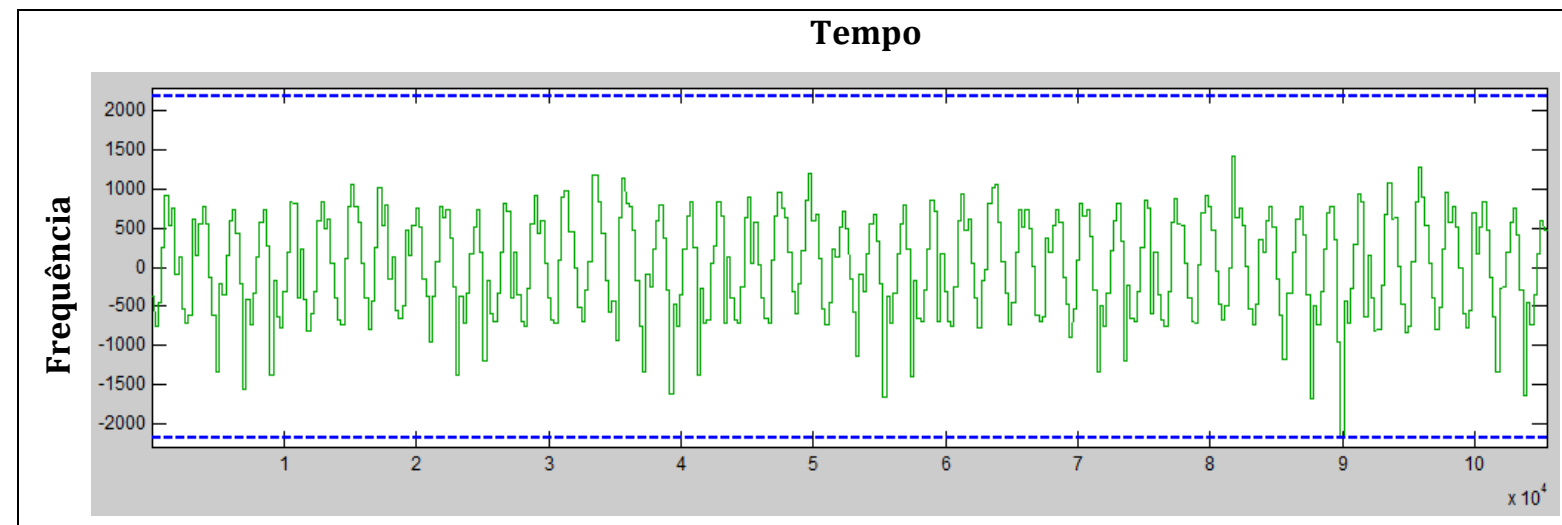

(e) Coeficiente de detalhe 8 - Threshold de 2210,281

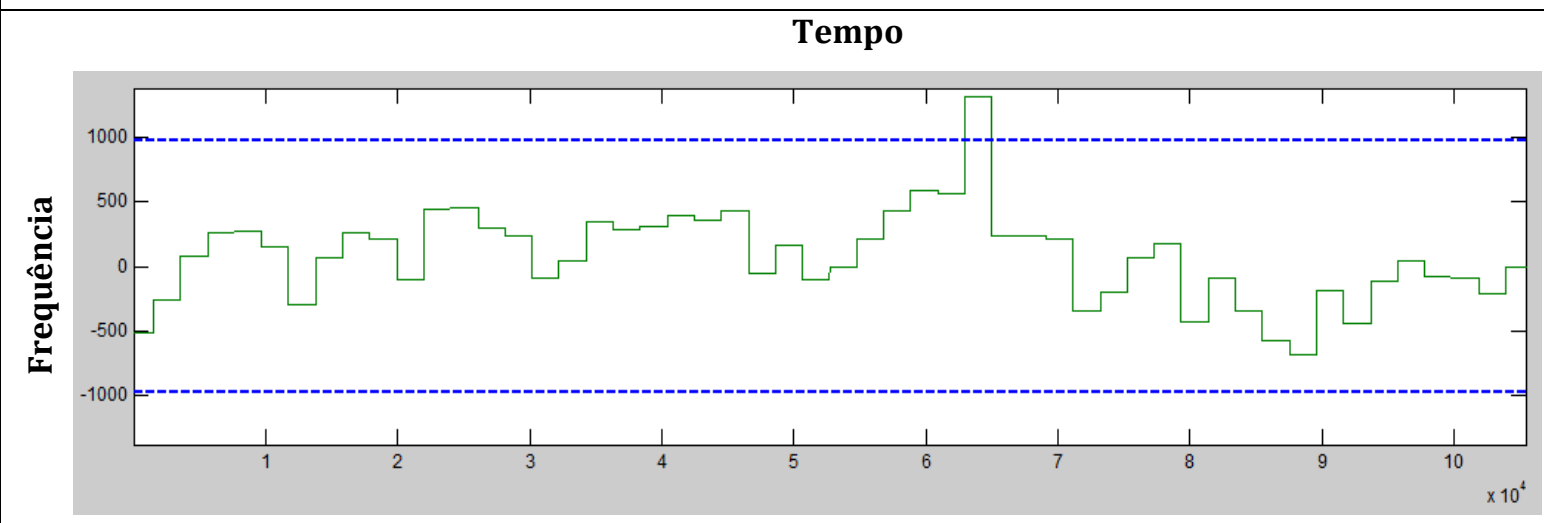

(f) Coeficiente de detalhe 11 - Threshold de 978,025

Fonte: Elaborada pelo autor

Os níveis 1, 2, 3 e 4 apresentaram maiores quantidades de anomalias por apresentarem as menores resoluções das janelas, sendo as primeiras reduções no sinal. No entanto, esses ruídos também foram analisados conforme o dia em que ocorriam, a partir do somatório de anomalias identificadas a cada dia e por nível do detalhe. A Tabela 5.2 apresenta a porcentagem do total de anomalias identificadas para os quatro primeiros níveis de decomposição, separados pelos dias da semana e feriado.

De acordo com a Tabela 5.2, nota-se que as anomalias identificadas estão em média concentradas principalmente durante os feriados $(43,13 \%)$ e aos domingos $(38,17 \%)$. Os sábados representaram apenas $4 \%$ do total de anomalias, enquanto os dias de semana (segunda à sexta-feira) somam 15\%. Isso levanta uma hipótese de que a maior concentração de oscilações no fluxo de tráfego ocorre aos domingos e feriados no sentido Leste da rodovia, ou seja, no sentido Interior - Capital (São Paulo). Com bases nesses resultados é possível avaliar, de forma geral, o comportamento do tráfego local. As 
anomalias que ocorreram nos dias classificados como feriados e domingos apontam para um comportamento atípico nessas duas classificações de dias, o que pode ser justificado pela viagem do usuário do interior a capital, indicando o retorno para casa nos dias úteis, devido o sentido da rodovia. Enquanto que os dias úteis não apresentaram maiores oscilações.

Tabela 5.2 - Frequência de anomalias encontradas por dia em cada nível investigado - Fluxo Leste Anual

\begin{tabular}{lrrrrr}
\hline \multicolumn{1}{r}{ Dia } & Nível 1 (\%) & Nível 2 (\%) & Nível 3(\%) & Nível 4 (\%) & Média (\%) \\
\hline Feriado & 49.23 & 45.95 & 33.33 & 44.00 & $\mathbf{4 3 . 1 3}$ \\
Dom & 35.38 & 31.08 & 42.22 & 44.00 & $\mathbf{3 8 . 1 7}$ \\
Seg & 3.08 & 4.05 & 2.22 & 4.00 & $\mathbf{3 . 3 4}$ \\
Ter & 1.54 & 4.05 & 2.22 & 0.00 & $\mathbf{1 . 9 5}$ \\
Qua & 3.08 & 2.70 & 2.22 & 0.00 & $\mathbf{2 . 0 0}$ \\
Qui & 3.08 & 2.70 & 8.89 & 0.00 & $\mathbf{3 . 6 7}$ \\
Sex & 3.08 & 1.35 & 6.67 & 4.00 & $\mathbf{3 . 7 7}$ \\
Sáb & 1.54 & 8.11 & 2.22 & 4.00 & $\mathbf{3 . 9 7}$ \\
\hline
\end{tabular}

Fonte: Elaborada pelo autor

No nível 8 (Figura 5-4e) o sinal foi decomposto 7 vezes e a resolução da janela agrega os fluxos em períodos de 21 horas e 20 minutos, o que representa a janela mais próxima de um dia inteiro, pois o próximo nível agrega períodos de 42 horas e 40 minutos. Observa-se na Figura 5-4(e) que não foi identificada nenhuma anomalia acima do valor threshold. Isso aponta que para essa janela de dados não houve oscilações acima do valor limiar. Na prática, isso representa que nem mesmo o dia com maior oscilação manteve um comportamento atípico em relação aos outros dias do ano. 0 dia mais próximo ao threshold foi o dia 09/07/2012, feriado no estado de São Paulo (Revolução Constitucionalista de 1932) que ocorreu em uma segunda-feira, explicando assim essa maior oscilação nesse dia, devido ao comportamento atípico do usuário em feriados. Ainda analisando a Figura 5-4(e), nota-se que para essa janela de tempo próxima a um dia, o $D_{8}$ manteve a oscilação da frequência, dando indícios de certo padrão no comportamento do tráfego veicular diário.

No entanto, o nível 11 identificou apenas uma única anomalia que termina em 15/04/2012 às 13:15. Neste nível, como a janela representa um período de 7 dias 2 horas e 40 minutos, essa anomalia corresponde a semana do dia 08/04/2012 às 10:35 (Domingo de Páscoa) ao dia 15/04/2012 às 13:15. Essa semana apresentou uma oscilação maior do que as outras semanas do ano, pois teve um comportamento atípico das outras nesse período de um ano. Esse resultado é importante pois indica que, ao analisar um 
sinal de um ano inteiro, a semana mais crítica do ano ocorre no feriado da Páscoa.

Para investigar quais dessas anomalias prevaleciam a cada nova decomposição do sinal, a Tabela 5.3 descreve as anomalias que se mantiveram em pelo menos três dos seis níveis analisados (coluna 1), a sua janela correspondente ao sinal original em cada nível que se mantinham (coluna 2 a 7) e a classificação pelo tipo de dia.

Tabela 5.3 - Anomalias que se mantiveram em no mínimo 3 níveis no Fluxo Leste Anual

\begin{tabular}{|c|c|c|c|c|c|c|c|}
\hline & Nível 1 & Nível 2 & Nível 3 & Nível 4 & Nível 8 & Nível 11 & Dia \\
\hline $\mathbf{A}$ & $\begin{array}{r}11 / 09 / 11 \\
19: 35 \text { à 19:45 }\end{array}$ & $\begin{array}{r}11 / 09 / 11 \\
19: 35 \text { à 19:55 }\end{array}$ & $\begin{array}{r}11 / 09 / 11 \\
19: 15 \text { à 19:55 }\end{array}$ & - & - & - & Dom \\
\hline B & $\begin{array}{r}15 / 11 / 11 \\
15: 35 \text { à } 15: 45\end{array}$ & $\begin{array}{r}15 / 11 / 11 \\
15: 35 \text { à 15:55 }\end{array}$ & - & $\begin{array}{r}15 / 11 / 11 \\
14: 35 \text { à } 15: 55\end{array}$ & - & - & Fer \\
\hline C & $\begin{array}{r}17 / 02 / 12 \\
08: 05 \text { à } 08: 15\end{array}$ & $\begin{array}{r}17 / 02 / 12 \\
07: 55 \text { à } 08: 15\end{array}$ & $\begin{array}{r}17 / 02 / 12 \\
07: 55 \text { à } 08: 35\end{array}$ & & - & - & Fer \\
\hline D & $\begin{array}{r}08 / 04 / 12 \\
18: 15 \text { à } 18: 25\end{array}$ & $\begin{array}{r}08 / 04 / 12 \\
18: 15 \text { à } 18: 35\end{array}$ & & $\begin{array}{r}08 / 04 / 12 \\
17: 15 \text { à 18:35 }\end{array}$ & - & $\begin{array}{r}08 / 04 / 12 \\
10: 35 \text { à } \\
15 / 04 / 12 \\
13: 15\end{array}$ & Fer \\
\hline E & $\begin{array}{r}15 / 07 / 12 \\
20: 15 \text { à 20:25 }\end{array}$ & $\begin{array}{r}15 / 07 / 12 \\
20: 15 \text { à } 20: 35\end{array}$ & $\begin{array}{r}15 / 07 / 12 \\
19: 55 \text { à } 20: 35\end{array}$ & $\begin{array}{r}15 / 07 / 12 \\
19: 55 \text { à } 21: 15\end{array}$ & - & - & Dom \\
\hline$F$ & $\begin{array}{r}22 / 07 / 12 \\
19: 25 \text { à 19:35 }\end{array}$ & $\begin{array}{r}22 / 07 / 12 \\
19: 15 \text { à 19:35 }\end{array}$ & $\begin{array}{r}22 / 07 / .12 \\
19: 15 \text { à 19:55 }\end{array}$ & $\begin{array}{r}22 / 07 / 12 \\
18: 35 \text { à 19:55 }\end{array}$ & - & - & Dom \\
\hline G & $\begin{array}{r}29 / 07 / 12 \\
18: 35 \text { à 18:45 }\end{array}$ & $\begin{array}{r}29 / 07 / 12 \\
18: 35 \text { à } 18: 55\end{array}$ & $\begin{array}{r}29 / 07 / 12 \\
18: 35 \text { à 19:15 }\end{array}$ & - & - & - & Dom \\
\hline H & $\begin{array}{r}12 / 08 / 12 \\
19: 45 \text { à } 19: 55\end{array}$ & $\begin{array}{r}12 / 08 / 12 \\
19: 35 \text { à } 19: 55\end{array}$ & - & $\begin{array}{r}12 / 08 / 12 \\
18: 35 \text { à } 19: 55\end{array}$ & - & - & Fer \\
\hline
\end{tabular}

Fonte: Elaborada pelo autor

Analisando as anomalias que permaneceram na maioria dos coeficientes de interesse, nota-se que todas correspondiam ou aos domingos (A, E, F e G) ou aos feriados (B, C, D e H). Esses resultados apontam para oscilações que mesmo filtradas diversas vezes e a resolução da janela tenha aumentado, elas se mantiveram, indicando uma anomalia importante no fluxo de tráfego, pois se mantiveram acima do valor limiar. Por terem ocorrido aos domingos e feriados, esses resultados reforçam o comportamento atípico desses dias da semana.

\subsubsection{Sentido Leste Mensal}

Nesta seção, pretende-se investigar se o tamanho do sinal original influencia na 
detecção das anomalias. Para isso, o sinal de um ano completo (01/09/2011 à 31/08/2012) foi separado em sinais mensais independente. No Apêndice 5.2 estão detalhadas todas as anomalias para os seis níveis de decomposição: 1, 2, 3, 4, 8 e 11 . A Tabela 5.4 apresenta a porcentagem do total de anomalias para os quatro primeiros níveis de decomposição em cada dia da semana.

Tabela 5.4 - Porcentagem de anomalias por tipo de dia a cada nível - Fluxo Leste Mensal

\begin{tabular}{lrrrrr}
\hline \multicolumn{1}{r}{ Dia } & Nível 1 (\%) & Nível 2 (\%) & Nível 3(\%) & Nível 4 (\%) & Média (\%) \\
\hline Feriado & 41.07 & 36.19 & 36.00 & 41.03 & $\mathbf{3 8 . 5 7}$ \\
Dom & 37.50 & 37.14 & 44.00 & 43.59 & $\mathbf{4 0 . 5 6}$ \\
Seg & 3.57 & 5.71 & 2.67 & 2.56 & $\mathbf{3 . 6 3}$ \\
Ter & 4.46 & 3.81 & 2.67 & 2.56 & $\mathbf{3 . 3 8}$ \\
Qua & 3.57 & 5.71 & 1.33 & 0.00 & $\mathbf{2 . 6 5}$ \\
Qui & 4.46 & 1.90 & 5.33 & 2.56 & $\mathbf{3 . 5 7}$ \\
Sex & 2.68 & 1.90 & 4.00 & 2.56 & $\mathbf{2 . 7 9}$ \\
Sáb & 2.68 & 7.62 & 4.00 & 5.13 & $\mathbf{4 . 8 6}$ \\
\hline
\end{tabular}

Fonte: Elaborada pelo autor

De forma análoga a análise anterior, as anomalias detectadas do nível 1 ao 4 ocorreram em sua maioria nos feriados (média de 38,57\%) e aos domingos (média de 40,56\%). Os sábados representaram média de 4,86\%, enquanto os dias da semana (segunda à sexta-feira) somam 16\%. E o coeficiente de detalhe 8 apresentou 3 anomalias (Apêndice 4.2): 01/01/2012 às 21:15 (Fer - Dom), 10/06/2012 às 18:35 (Fer - Dom) e 09/07/2012 às 21:15 (Fer - Seg), todas classificadas como feriado e duas delas (01/01/2012 e 10/06/2012) no domingo. Essas constatações reforçam a influência dos domingos e feriados nas oscilações do fluxo de tráfego nesse período no sentido Leste dessa rodovia.

Apesar das anomalias no nível 1, 2, 3 e 4 terem sido apresentadas em porcentagem, houve maior número de oscilações nas análises mensais do que na anual (Apêndice 5.1 e 5.2). Assim como no nível 11, ao invés de ter sido detectada apenas uma anomalia como no período anual, foram encontradas 13 . Ou seja, ao analisar o período anual, apenas uma semana teve oscilação de magnitude acima do valor limiar, enquanto ao analisar os meses separadamente, em média uma semana por mês concentrou maior número de oscilações, indicando uma semana atípica comparada ao restante do mês. A Tabela 5.5 apresenta as anomalias definidas para a análise mensal e se continha algum feriado. 
Tabela 5.5 - Anomalias no nível 11 - Fluxo Leste Mensal

\begin{tabular}{lll}
\hline & Anomalia & Feriado \\
\hline $\mathbf{1}$ & $08 / 10 / 201102: 35-15 / 10 / 201105: 15$ & SIM $(12 / 10 / 2011)$ \\
$\mathbf{2}$ & $22 / 10 / 201107: 55-29 / 10 / 201110: 35$ & NÃO \\
$\mathbf{3}$ & $15 / 11 / 201105: 15-22 / 11 / 201107: 55$ & SIM $(15 / 11 / 2011)$ \\
$\mathbf{4}$ & $31 / 12 / 201123: 55-08 / 01 / 201202: 35$ & SIM $(01 / 01 / 2012)$ \\
$\mathbf{5}$ & $22 / 01 / 201207: 55-29 / 01 / 201210: 35$ & SIM $(25 / 01 / 2012)$ \\
$\mathbf{6}$ & $08 / 04 / 201202: 35-15 / 04 / 201205: 15$ & SIM $(08 / 04 / 2012)$ \\
$\mathbf{7}$ & $30 / 04 / 201223: 55-08 / 05 / 201202: 35$ & SIM $(01 / 05 / 2012)$ \\
$\mathbf{8}$ & $30 / 05 / 201223: 55-08 / 06 / 201202: 35$ & SIM $(07 / 06 / 2012)$ \\
$\mathbf{9}$ & $08 / 06 / 201202: 35-15 / 06 / 201205: 15$ & SIM $(07 / 06 / 2012)$ \\
$\mathbf{1 0}$ & $15 / 06 / 201205: 15-22 / 06 / 201207: 55$ & NÃO \\
$\mathbf{1 1}$ & $08 / 07 / 201202: 35-15 / 07 / 201205: 15$ & SIM $(09 / 07 / 2012)$ \\
$\mathbf{1 2}$ & $22 / 07 / 201207: 55-29 / 07 / 201210: 35$ & NÃO \\
$\mathbf{1 3}$ & $31 / 07 / 201223: 55-08 / 08 / 201202: 35$ & NÃO \\
\hline
\end{tabular}

Fonte: Elaborada pelo autor

Nota-se que de 13 semanas atípicas na análise mensal, 9 continham feriados, ou seja $69,2 \%$. Isso reforça novamente a influência do feriado e os dias da semana que o mesmo influência (lembrando que a categoria feriado no método proposto refere-se aos feriados e os dias influenciados pelos mesmos) na oscilação do tráfego veicular, pois entre as semanas classificadas como atípicas nas análises mensais, a maioria continha feriados em sua janela de tempo.

Observa-se também, que na análise mensal foi possível obter maior número de informações do que na análise anual, confirmando a hipótese desta seção, de que o tamanho do sinal original interfere diretamente na quantidade de anomalias definidas. Como o sinal de um ano é aproximadamente 12 vezes maior do que um sinal mensal, na análise anual sobressaem apenas as anomalias que impactam em relação ao ano todo. Isso porque na análise anual é definido apenas um threshold por nível de decomposição, portanto para ser considerada uma anomalia, as oscilações devem estar acima do threshold definido para o ano inteiro. Uma anomalia que fique acima desse valor limiar em relação ao mês em que ocorre, pode não ficar acima do valor limiar para o ano inteiro. Devido a essa diferença entre os resultados das análises mensais e anuais e buscando analisar o máximo de informações, os itens a seguir do presente capítulo apresentam apenas os resultados da análise mensal, porém para os doze meses.

\subsubsection{Sentido Oeste Mensal}

De forma similar a análise dos dados de fluxo de tráfego no sentido Leste, para o 
sentido Oeste, a Transformada Wavelet de Haar foi aplicada para o período anual e a cada mês separadamente. No entanto, a seguir é analisado apenas o período mensal, pois como discutido anteriormente, o período mensal apresenta mais informações de anomalias do que o período anual. 0 Apêndice 5.3 detalha os resultados das anomalias do sinal e a Tabela 5.6 apresenta a porcentagem do total de anomalias para os quatro primeiros níveis para cada tipo de dia.

Tabela 5.6 - Porcentagem de anomalias por tipo de dia a cada nível - Fluxo Oeste Mensal

\begin{tabular}{lrrrrr}
\hline \multicolumn{1}{r}{ Dia } & Nível 1 (\%) & Nível 2 (\%) & Nível 3(\%) & Nível 4 (\%) & Média (\%) \\
\hline Feriado & 34.18 & 29.41 & 28.57 & 25.64 & $\mathbf{2 9 . 4 5}$ \\
Dom & 5.06 & 3.92 & 5.71 & 2.56 & $\mathbf{4 . 3 2}$ \\
Seg & 3.80 & 3.92 & 8.57 & 15.38 & $\mathbf{7 . 9 2}$ \\
Ter & 5.70 & 3.92 & 14.29 & 2.56 & $\mathbf{6 . 6 2}$ \\
Qua & 2.53 & 2.94 & 4.29 & 5.13 & $\mathbf{3 . 7 2}$ \\
Qui & 6.33 & 6.86 & 8.57 & 5.13 & $\mathbf{6 . 7 2}$ \\
Sex & 24.68 & 22.55 & 12.86 & 23.08 & $\mathbf{2 0 . 7 9}$ \\
Sáb & 17.72 & 26.47 & 17.14 & 20.51 & $\mathbf{2 0 . 4 6}$ \\
\hline
\end{tabular}

Fonte: Elaborada pelo autor

No sentido Oeste, as anomalias em média se concentraram nos feriados $(29,45 \%)$, sextas-feiras $(20,79 \%)$ e sábados $(20,46 \%)$. Esses resultados ressaltam o impacto direcional do fluxo nos dias da semana. Como era de se esperar, os feriados ocorreram em ambos os sentidos da via, porém o sentido do tráfego mostrou uma diferença: no sentido Leste os feriados representaram média de 39\% das oscilações, enquanto o sentido Oeste a média foi de 30\%. A principal diferença dos resultados foi com relação aos dias da semana, enquanto no sentido Leste as anomalias foram detectadas na maioria das vezes aos domingos, no sentido Oeste foram mais expressivas nas sextas-feiras e sábados, agora do sentido Capital (São Paulo) - Interior. Com base nesses resultados é possível avaliar de forma geral o comportamento do tráfego local. As anomalias nas sextas-feiras e sábados apontam para um comportamento atípico nesses dias, que pode ser justificado pela viagem do usuário a lazer nos fins de semana

\subsection{ANOMALIAS NOS DADOS DE VELOCIDADE}

O mesmo método para análise de anomalia no fluxo de tráfego foi aplicado para os dados de velocidade veicular. A seguir estão as análises para os períodos mensais no sentido Leste e Oeste do sensor analisado. 


\subsubsection{Sentido Leste Mensal}

0 mesmo método aplicado para os dados de fluxo de tráfego para detectar anomalias, foi aplicado para os dados de velocidade veicular. Os resultados obtidos para o sentido Leste da rodovia encontram-se na Tabela 5.7, que apresenta a porcentagem de anomalias para os quatro primeiros níveis em cada tipo de dia. 0 Apêndice 5.4 contêm as anomalias em cada nível de decomposição analisado.

Tabela 5.7 - Porcentagem de anomalias por tipo de dia a cada nível - Velocidade Leste Mensal

\begin{tabular}{lrrrrr}
\hline \multicolumn{1}{r}{ Dia } & Nível 1 (\%) & Nível 2 (\%) & Nível 3(\%) & Nível 4 (\%) & Média (\%) \\
\hline Feriado & 24.55 & 29.17 & 30.83 & 33.33 & $\mathbf{2 9 . 4 7}$ \\
Dom & 40.91 & 36.31 & 37.50 & 40.28 & $\mathbf{3 8 . 7 5}$ \\
Seg & 4.55 & 10.71 & 12.50 & 8.33 & $\mathbf{9 . 0 2}$ \\
Ter & 7.73 & 5.36 & 5.00 & 2.78 & $\mathbf{5 . 2 2}$ \\
Qua & 4.09 & 2.98 & 1.67 & 4.17 & $\mathbf{3 . 2 3}$ \\
Qui & 9.09 & 8.33 & 8.33 & 6.94 & $\mathbf{8 . 1 8}$ \\
Sex & 4.09 & 4.76 & 1.67 & 0.00 & $\mathbf{2 . 6 3}$ \\
Sáb & 5.00 & 2.38 & 2.50 & 4.17 & $\mathbf{3 . 5 1}$ \\
\hline
\end{tabular}

Fonte: Elaborada pelo autor

Nota-se que os dados de velocidades oscilaram mais do que os dados de fluxo de tráfego, pois apresentaram maior número de anomalias por nível analisado. No entanto, os dados de velocidade mantiveram a concentração de anomalias similar a cada tipo de dia dos dados de fluxo. 68\% das anomalias por nível foram classificadas como feriado ou domingo, mas a porcentagem de feriados caiu de $38,57 \%$ para $29,47 \%$ e o domingo de 40,56\% para 38,75\%, aumentando o número de anomalias identificadas nos dias úteis. No apêndice 4.4 encontra-se uma tabela com as anomalias em cada nível de decomposição analisado para os dados mensais de velocidade no sentido Leste.

No nível 8 de janela de tempo próximo a um dia (21 horas e 20 minutos) obteve-se sete anomalias nos dados de velocidade (Tabela 5.8), ao invés de três anomalias como nos dados de fluxo de tráfego. Observa-se que três dessas anomalias correspondem a um dia de feriado, outras três o fim de tarde de domingo e a manhã de segunda-feira, e uma anomalia correspondente a um dia útil. Com base nesses resultados, nota-se que nas resoluções próximas a um dia, as anomalias também foram predominantemente aos feriados e domingos. No entanto, como a janela do nível 8 não abrange as 24 horas do dia, todos os domingos que foram definidos como anomalias abrangeram o período noturno com a madrugada de segunda-feira, mostrando que as anomalias ocorrentes no domingo não ocorrem no período da manhã de domingo, entre o sábado e o domingo, até porque o 
fluxo de tráfego é maior no período noturno do que o diurno no domingo.

Tabela 5.8 - Anomalias no nível 8 - Velocidade Leste Mensal

\begin{tabular}{lll}
\hline & Anomalia & Dia \\
\hline $\mathbf{1}$ & $08 / 11 / 201123: 55-09 / 11 / 201121: 15$ & quarta-feira \\
$\mathbf{2}$ & $18 / 12 / 201118: 35-19 / 12 / 2011$ 15:55 & domingo para segunda-feira \\
$\mathbf{3}$ & $31 / 12 / 201123: 55-01 / 01 / 201221: 15$ & feriado \\
$\mathbf{4}$ & $21 / 02 / 201210: 35-22 / 02 / 201207: 55$ & feriado \\
$\mathbf{5}$ & $07 / 04 / 201223: 55-08 / 04 / 201223: 55$ & feriado \\
$\mathbf{6}$ & $27 / 05 / 201215: 55-28 / 05 / 201213: 15$ & domingo para segunda-feira \\
$\mathbf{7}$ & $15 / 07 / 201205: 55-16 / 07 / 201202: 35$ & domingo para segunda-feira \\
\hline
\end{tabular}

Fonte: Elaborada pelo autor

As anomalias definidas no nível 11 estão apresentadas na Tabela 5.9 a seguir. Notase que assim como os dados de fluxo, para os de velocidade também foram definidas 13 anomalias. No entanto, para os dados de velocidade apenas em 5 dessas 13 semanas $(38,46 \%)$ ocorriam feriados. Esses resultados indicam que os dados de velocidade também determinaram anomalias, porém sendo menos sensíveis a influência dos feriados do que o fluxo $(69,2 \%)$.

Tabela 5.9 - Anomalias no nível 11 - Velocidade Leste Mensal

\begin{tabular}{lll}
\hline & Anomalia & Feriado \\
\hline $\mathbf{1}$ & $08 / 09 / 201102: 35-15 / 09 / 201105: 15$ & SIM $(07 / 09 / 2011)$ \\
$\mathbf{2}$ & $08 / 11 / 201102: 35-15 / 11 / 201105: 15$ & $\operatorname{SIM}(15 / 11 / 2011)$ \\
$\mathbf{3}$ & $15 / 11 / 201105: 15-22 / 11 / 201107: 55$ & $\operatorname{SIM}(15 / 11 / 2012)$ \\
$\mathbf{4}$ & $15 / 12 / 201105: 15-22 / 12 / 201107: 55$ & NÃO \\
$\mathbf{5}$ & $31 / 12 / 201123: 55-08 / 01 / 201202: 35$ & SIM $(01 / 01 / 2012)$ \\
$\mathbf{6}$ & $08 / 01 / 201202: 35-15 / 01 / 201205: 15$ & NÃO \\
$\mathbf{7}$ & $15 / 01 / 201205: 15-22 / 01 / 201207: 55$ & NÃO \\
$\mathbf{8}$ & $08 / 03 / 201202: 35-15 / 03 / 201205: 15$ & NÃO \\
$\mathbf{9}$ & $22 / 03 / 201207: 55-29 / 03 / 201210: 35$ & NÃO \\
$\mathbf{1 0}$ & $08 / 04 / 201202: 35-15 / 04 / 201205: 15$ & SIM $(08 / 04 / 2012)$ \\
$\mathbf{1 1}$ & $15 / 05 / 201205: 15-22 / 05 / 201207: 55$ & NÃO \\
$\mathbf{1 2}$ & $15 / 06 / 201205: 15-22 / 06 / 201207: 55$ & NÃO \\
$\mathbf{1 3}$ & $15 / 07 / 201205: 15-22 / 07 / 201207: 55$ & NÃO \\
\hline
\end{tabular}

Fonte: Elaborada pelo autor

\subsubsection{Sentido Oeste Mensal}

Os resultados obtidos para análise de anomalia na velocidade veicular no sentido Oeste da rodovia estão na Tabela 5.10, que apresenta a porcentagem de anomalias para os quatro primeiros níveis em cada tipo de dia. 0 Apêndice 5.5 contêm as anomalias em 
cada nível de decomposição analisado.

Tabela 5.10 - Porcentagem de anomalias por tipo de dia a cada nível - Velocidade Oeste Mensal

\begin{tabular}{lrrrrr}
\hline \multicolumn{1}{r}{ Dia } & Nível 1 (\%) & Nível 2 (\%) & Nível 3(\%) & Nível 4 (\%) & Média (\%) \\
\hline Feriado & 20.44 & 26.06 & 24.14 & 32.26 & $\mathbf{2 5 . 7 2}$ \\
Dom & 20.99 & 11.97 & 17.24 & 9.68 & $\mathbf{1 4 . 9 7}$ \\
Seg & 18.23 & 19.01 & 12.64 & 14.52 & $\mathbf{1 6 . 1 0}$ \\
Ter & 10.50 & 11.27 & 10.34 & 12.90 & $\mathbf{1 1 . 2 5}$ \\
Qua & 4.97 & 0.00 & 0.00 & 4.84 & $\mathbf{2 . 4 5}$ \\
Qui & 4.97 & 7.04 & 12.64 & 9.68 & $\mathbf{8 . 5 8}$ \\
Sex & 9.39 & 14.79 & 10.34 & 4.84 & $\mathbf{9 . 8 4}$ \\
Sáb & 10.50 & 9.86 & 12.64 & 11.29 & $\mathbf{1 1 . 0 7}$ \\
\hline
\end{tabular}

Fonte: Elaborada pelo autor

Nota-se que os feriados continuam sendo o que mais concentram anomalias com um média $25,72 \%$. Porém os dados de velocidade no sentido oeste foram os dados que ficaram mais distribuídos por tipo de dia.

No nível 8 foram definidas seis anomalias (Tabela 5.11). Observa-se que todas ocorreram no fim de semana, ao contrário dos níveis de menor escala (1, 2, 3 e 4). Ao contrário das janelas de menor resolução, ao analisar os dados de velocidade na escala de um dia, os que continham oscilações acima do valor limiar correspondiam aos finais de semana.

Tabela 5.11 - Anomalias no nível 8 - Velocidade Leste Mensal

\begin{tabular}{lll}
\hline & Anomalia & Dia \\
\hline $\mathbf{1}$ & $17 / 02 / 2012$ 21:15-18/02/2012 18:35 & sexta-feira para sábado \\
$\mathbf{2}$ & $25 / 03 / 201221: 15-26 / 03 / 201218: 35$ & domingo para segunda-feira \\
$\mathbf{3}$ & $29 / 04 / 201210: 35-30 / 04 / 201207: 55$ & domingo para segunda-feira \\
$\mathbf{4}$ & $14 / 07 / 201207: 55-15 / 07 / 201205: 15$ & sábado para domingo \\
$\mathbf{5}$ & $27 / 07 / 201215: 55-28 / 07 / 201213: 15$ & sexta-feira para sábado \\
$\mathbf{6}$ & $19 / 08 / 201215: 55-20 / 08 / 201213: 15$ & domingo para segunda-feira \\
\hline
\end{tabular}

Fonte: Elaborada pelo autor

Por fim, o nível 11 é apresentado na Tabela 5.12. É possível notar que apenas metade das anomalias continham períodos de feriado (6 de 12). Para os dados analisados, isso indica que as resoluções em escalas menores foram mais suscetíveis aos dias da semana, enquanto janelas maiores (nível 8 e 11) foram mais suscetíveis ao fim de semana. 
Tabela 5.12 - Anomalias no nível 11 - Velocidade Oeste Mensal

\begin{tabular}{lll}
\hline & Anomalia & Feriado \\
\hline $\mathbf{1}$ & $08 / 09 / 201102: 35-15 / 09 / 201105: 15$ & SIM $(07 / 09 / 2011)$ \\
$\mathbf{2}$ & $31 / 10 / 201123: 55-08 / 11 / 201102: 35$ & SIM $(02 / 11 / 2011)$ \\
$\mathbf{3}$ & $08 / 11 / 201102: 35-15 / 11 / 201105: 15$ & SIM $(15 / 11 / 2011)$ \\
$\mathbf{4}$ & $15 / 11 / 201105: 15-22 / 11 / 201107: 55$ & SIM $(15 / 11 / 2011)$ \\
$\mathbf{5}$ & $22 / 11 / 201107: 55-29 / 11 / 201110: 35$ & NÃO \\
$\mathbf{6}$ & $15 / 02 / 201205: 15-22 / 02 / 201207: 55$ & SIM $(21$ e 22/02/2012) \\
$\mathbf{7}$ & $29 / 02 / 201223: 55-08 / 03 / 201202: 35$ & NÃO \\
$\mathbf{8}$ & $08 / 05 / 201202: 35-15 / 05 / 201205: 15$ & NÃO \\
$\mathbf{9}$ & $22 / 05 / 201207: 55-29 / 05 / 201210: 35$ & NÃO \\
$\mathbf{1 0}$ & $31 / 05 / 201223: 55-08 / 06 / 201202: 35$ & SIM $(31 / 05 / 2012)$ \\
$\mathbf{1 1}$ & $15 / 06 / 201205: 15-22 / 06 / 201207: 55$ & NÃO \\
$\mathbf{1 2}$ & $31 / 07 / 201223: 55-08 / 08 / 201202: 35$ & NÃO \\
\hline
\end{tabular}

Fonte: Elaborada pelo autor

\subsection{IDENTIFICAÇÃO DE FALHAS NO SENSOR}

O objetivo deste item foi investigar a capacidade da Transformada Wavelet também detectar anomalias que representem as falhas de registro do sensor. Embora tenha sido escolhido um banco de dados de um ano completo, ainda assim esse conjunto de dados tem uma falha de registro do sensor, o qual deixou de registar duas horas no ano, em dois períodos: 16/10/2011, das 01:55 às 02:50; e 17/02/2012, das 08:15 às 09:10. Nesses períodos, optou-se por preencher com zero os valores de fluxo e velocidade.

A Tabela 5.13 apresenta o poder de detecção da Transformada Wavelet para falhas de registros, utilizado para isso o sinal no período anual e mensal.

Tabela 5.13 - Falhas no sensor detectadas

\begin{tabular}{lll}
\hline Sinal & $\mathbf{1}(\mathbf{1 6 / 1 0 / 2 0 1 1 ~ 0 1 : 5 5}$ às 02:50) & $\mathbf{2 ( 1 7 / 0 2 / 2 0 1 2 ~ 0 8 : 1 5}$ às 09:10) \\
\hline Fluxo Leste (Anual) & NÃO & SIM (Níveis 1, 2 e 3) \\
Fluxo Leste & NÃO & SIM (Níveis 1,2 e 3) \\
Fluxo Oeste & NÃO & SIM (Níveis 1,2 e 3) \\
Velocidade Leste & SIM (Níveis $1,2,3$ e 4) & SIM (Níveis $1,2,3$ e 4) \\
Velocidade Oeste & SIM (Níveis $1,2,3$ e 4) & SIM (Níveis $1,2,3$ e 4) \\
\hline
\end{tabular}

Fonte: Elaborada pelo autor

Nota-se que a falha do sensor 1 não foi detectada nos dados de fluxo (Anual ou Mensal, Leste ou Oeste). Essa falha ocorreu de madrugada, hora em que o fluxo de tráfego é próximo a zero, portanto não apresentou uma grande oscilação comparado com outros períodos semelhantes. Entretanto, os dados de velocidade (Leste e Oeste), nos quatro primeiros níveis que correspondem até o período de 80 minutos, identificaram essa falha 
como uma anomalia, pois nesse horário a velocidade da corrente de tráfego tende a ser maior, e uma hora inteira com a velocidade zero gera uma grande oscilação no sinal, sendo assim detectada como anomalia nos quatro primeiros níveis.

A falha de sensor 2, ocorreu no período da manhã e foi detectada nos quatro sinais. No entanto, para os dados de fluxo foi definida como anomalia até o nível 3 (40 minutos), no nível 4 (80 minutos) não. Já nos sinais de velocidade, a falha de sensor 2 é definida como anomalia do nível 1 ao 4.

\subsection{Análise Comparativa com o Volume Horário Percentual}

Outra forma de caracterização do tráfego veicular é a partir do volume horário expresso como porcentagem do volume médio diário anual na $i$-ésima hora mais carregada do ano, designada como Fator K, obtida através da ordenação decrescente dos volumes observados. Entre essas horas, determina-se qual servirá de base para o projeto e operações da rodovia. No Brasil, geralmente são usadas entre 30aㅡ e a 50ª (DNIT, 2006), enquanto nos Estados Unidos é considerado entre a 30 a e a 100 a (TRB, 2010). A Figura 5-5 apresenta o volume horário como porcentagem do volume médio diário anual para as 1000 horas mais carregadas entre setembro de 2011 e agosto de 2012 no km 51,9 da Rodovia Presidente Castelo Branco.

Figura 5-5 - Volume Horário para as 1.000 horas mais carregadas

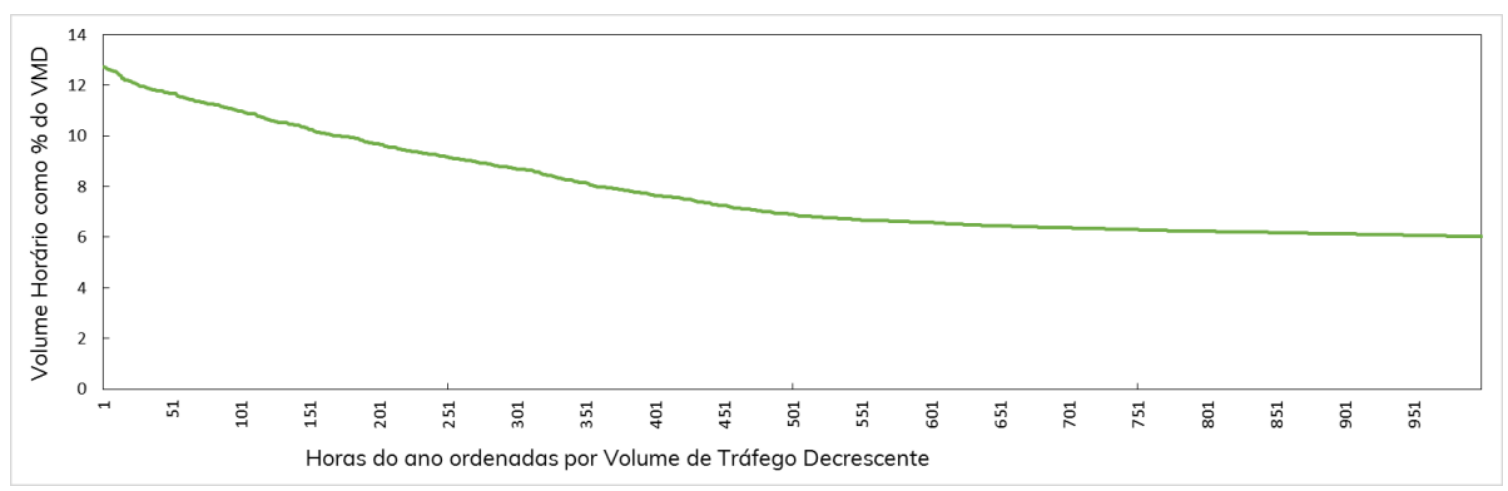

Fonte: Elaborada pelo autor

Na 30 a hora mais carregada do ano o volume observado foi de 4.488 veíc/h, para $50^{\text {a }}$ foi de 4.390 veíc/h e para $100^{a}$ foi de 4128 veíc/h. Para analisar se o método proposto para detectar anomalias também extraia informações das horas mais congestionadas, foi 
analisado se as 30 horas mais carregadas do ano foram detectadas nas análises realizadas nesse capítulo no nível 4, por ser o mais próximo a 1 hora (80 minutos). A Tabela 5.14 apresenta as 30 horas mais carregas do volume de tráfego, quando ocorreram, o Fator $\mathrm{K}$ e se foi detectado nas análises de Fluxo Anual, Fluxo Mensal e Velocidade Mensal.

Tabela 5.14 - Volume Horário para as 30 horas mais carregadas

\begin{tabular}{lrrrrrr}
\hline $\begin{array}{l}\boldsymbol{i} \text {-ésima } \\
\text { hora }\end{array}$ & $\begin{array}{r}\text { Volume Horário } \\
\text { (veíc/h) }\end{array}$ & Fator $\boldsymbol{K}$ & Dia e hora & $\begin{array}{r}\text { Fluxo } \\
\text { Anual }\end{array}$ & $\begin{array}{r}\text { Fluxo } \\
\text { Mensal }\end{array}$ & $\begin{array}{r}\text { Velocidade } \\
\text { Mensal }\end{array}$ \\
\hline $\mathbf{1}$ & 4778 & 12.725 & $29 / 07 / 201217: 00$ & & & $\mathbf{X}$ \\
$\mathbf{2}$ & 4777 & 12.723 & $11 / 09 / 201118: 00$ & & & \\
$\mathbf{3}$ & 4765 & 12.691 & $22 / 07 / 201217: 00$ & & & \\
$\mathbf{4}$ & 4757 & 12.669 & $10 / 06 / 201215: 00$ & & & $\mathbf{X}$ \\
$\mathbf{5}$ & 4745 & 12.637 & $01 / 07 / 201218: 00$ & & $\mathbf{X}$ & $\mathbf{X}$ \\
$\mathbf{6}$ & 4743 & 12.632 & $22 / 07 / 201218: 00$ & $\mathbf{X}$ & $\mathbf{X}$ & $\mathbf{X}$ \\
$\mathbf{7}$ & 4730 & 12.597 & $12 / 08 / 201218: 00$ & & & $\mathbf{X}$ \\
$\mathbf{8}$ & 4726 & 12.587 & $11 / 09 / 201117: 00$ & & $\mathbf{X}$ & \\
$\mathbf{9}$ & 4713 & 12.552 & $08 / 04 / 201211: 00$ & $\mathbf{X}$ & & \\
$\mathbf{1 0}$ & 4713 & 12.552 & $15 / 07 / 201217: 00$ & & & \\
$\mathbf{1 1}$ & 4697 & 12.510 & $09 / 07 / 201216: 00$ & & & \\
$\mathbf{1 2}$ & 4674 & 12.448 & $22 / 07 / 201216: 00$ & & & $\mathbf{X}$ \\
$\mathbf{1 3}$ & 4660 & 12.411 & $29 / 07 / 201216: 00$ & & & \\
$\mathbf{1 4}$ & 4653 & 12.392 & $12 / 08 / 201217: 00$ & $\mathbf{X}$ & $\mathbf{X}$ & \\
$\mathbf{1 5}$ & 4615 & 12.291 & $25 / 12 / 201117: 00$ & & $\mathbf{X}$ & \\
$\mathbf{1 6}$ & 4608 & 12.273 & $08 / 01 / 201219: 00$ & & & $\mathbf{X}$ \\
$\mathbf{1 7}$ & 4587 & 12.217 & $19 / 08 / 201218: 00$ & & \\
$\mathbf{1 8}$ & 4586 & 12.214 & $05 / 02 / 201218: 00$ & $\mathbf{X}$ & $\mathbf{X}$ & \\
$\mathbf{1 9}$ & 4581 & 12.201 & $09 / 07 / 201217: 00$ & & & \\
$\mathbf{2 0}$ & 4569 & 12.169 & $01 / 07 / 201217: 00$ & & & $\mathbf{X}$ \\
$\mathbf{2 1}$ & 4565 & 12.158 & $10 / 06 / 201216: 00$ & & & \\
$\mathbf{2 2}$ & 4564 & 12.155 & $15 / 07 / 201216: 00$ & & & $\mathbf{X}$ \\
$\mathbf{2 3}$ & 4548 & 12.113 & $11 / 03 / 201217: 00$ & & & \\
$\mathbf{2 4}$ & 4546 & 12.107 & $08 / 04 / 201212: 00$ & & & \\
$\mathbf{2 5}$ & 4537 & 12.083 & $05 / 08 / 201217: 00$ & & & \\
$\mathbf{2 6}$ & 4522 & 12.043 & $25 / 12 / 201118: 00$ & & $\mathbf{X}$ \\
$\mathbf{2 7}$ & 4504 & 11.996 & $26 / 08 / 201217: 00$ & & & \\
$\mathbf{2 8}$ & 4498 & 11.980 & $18 / 03 / 201217: 00$ & & & \\
$\mathbf{2 9}$ & 4493 & 11.966 & $30 / 10 / 201118: 00$ & $\mathbf{X}$ & & \\
$\mathbf{3 0}$ & 4488 & 11.953 & $18 / 09 / 201117: 00$ & & & \\
\hline
\end{tabular}

Fonte: Elaborada pelo autor

A análise do Fluxo no sentido Leste no período Anual detectou 5 entre as 30 horas mais carregadas do tráfego (16,67\%), a análise do Fluxo no sentido Leste no período Mensal detectou $8(26,67 \%)$ e a análise da Velocidade no sentido Leste no período Mensal detectou 13 (43,3\%). Esses resultados confirmam que a análise no sinal de velocidade detecta maior número de oscilações, pois em relação aos dados de fluxo de tráfego, seja anual ou mensal, detectou a maior quantidade de horas carregadas. No entanto, não foram mais do que $50 \%$ dessas horas, isso indica que concentrar a maior quantidade de volume 
de tráfego não é, necessariamente, concentrar as maiores oscilações nos sinais gerados de fluxo de tráfego ou velocidade veicular.

\subsection{CONSIDERAÇÕES FINAIS}

Este capítulo apresentou o método proposto para detectar anomalias em sinais gerados pela Transformada Wavelet a partir de dados de tráfego veicular. Em seguida, o método foi aplicado em um sensor da Rodovia Presidente Castelo Branco para diferentes períodos de tempo e em ambos sentidos da rodovia.

Os resultados indicaram que os primeiros níveis de decomposição (1, 2, 3 e 4) apresentam maior número de anomalias por apresentarem as menores resoluções das janelas. No nível 8, no qual a janela de tempo comparada ao sinal original representa 21 horas e 20 minutos, as anomalias indicaram os dias com comportamento atípicos em relação aos outros dias do ano. Por fim, no nível 11 a janela é próxima a uma semana (7 dias 2 horas e 40 minutos) e esse resultado indicou a semana com mais oscilações em relação ao sinal analisado, seja mensal ou anual.

Entre as análises mensais e anuais, os resultados indicaram que analisar os meses separadamente concentra maior número de anomalias, pois na análise anual sobressaem apenas as anomalias que impactam em relação ao ano todo. Nas análises por sentido da via foi possível avaliar de forma geral o comportamento do tráfego local, sendo que no sentido Leste a maior concentração de anomalias ocorreu nos feriados e domingos e no sentido Oeste nos feriados, sextas-feiras e sábados, ressaltando o impacto direcional no comportamento do tráfego. Já as análises do fluxo de tráfego e velocidade veicular, demonstraram que os dados de velocidade oscilaram mais do que os dados de fluxo de tráfego, pois apresentaram o maior número de anomalias por nível analisado. No entanto a distribuição de anomalia por tipo de dia foi similar.

Por fim, para identificar falhas no sensor o método foi eficiente e não conseguiu identificar apenas a falha que ocorreu durante a madrugada no sinal fluxo de tráfego, pois naquele período o sinal era próximo a zero e as falhas foram preenchidas com zero também, não apresentando assim alta oscilação para ser identificada. Realizada a detecção de anomalias nos períodos atípicos, o próximo capítulo apresenta a aplicação conjunta dos métodos de reconhecimentos de padrões e detecção de anomalias. 


\section{APLICAÇÃo do MÉTOdO EM DifERENTES}

\section{CONDIÇÕES DE TRÁFEGO}

O método proposto para reconhecimento de padrões e detecção de anomalias, Capítulo 4 e 5 respectivamente, foram feitos a partir de uma análise exploratória utilizando a Transformada Wavelet Discreta e métodos complementares. A análise foi realizada em dados históricos do tráfego veicular do sensor da Rodovia Presidente Castelo Branco (SP-280) no km 51,90, sentido Leste e Oeste. Os resultados obtidos foram satisfatórios e foram discutidos em seus respectivos capítulos. Neste capítulo será realizada a análise do método proposto em diferentes condições de tráfego, considerando variações temporal e espacial.

As situações analisadas abrangiam três características distintas: (1) dados de tráfego veicular em diferentes situações, (2) composição do tráfego para diferentes tipos de veículos e (3) resolução dos dados de entrada. Cada característica é analisada nas seções do presente capítulo. Na seção 6.1 são apresentados os resultados para três situações relacionadas aos dados do tráfego veicular. Inicialmente, são avaliados dados de um mesmo sensor em época diferente. Em seguida, são avaliados os resultados para dados de uma mesma época em um sensor de uma rodovia diferente. Por fim, são avaliados dados na mesma época e mesma rodovia, mas com classificação distinta da via (expressa e marginal).

A seção 6.2 expõe a segunda característica analisada: tipo de veículo. Em vista de que as análises até o momento foram realizadas utilizando o tráfego como um todo, o objetivo nesta seção é explorar os métodos propostos para cada categoria de veículo (automóveis, caminhões e motos).

A seção 6.3 analisa a resolução dos dados. Os dados analisados anteriormente, obtidos pela Concessionária ViaOeste, apresentavam intervalos de 5 minutos. Na penúltima seção são analisados dados da Concessionária AutoBan com intervalo de tempo de 6 minutos. Na última seção são apresentadas as considerações finais do capítulo.áfego 


\subsection{DADOS DE TRÁFEGO VEICULAR EM DIFERENTES SITUAÇÕES}

Nesta seção são investigadas diferentes situações dos dados de tráfego veicular, considerando variações temporal e espacial. A primeira situação analisada investiga dados do mesmo sensor analisado anteriormente, porém em uma época diferente. Em seguida, é investigado a mesma época do método proposto, porém analisando dados de outra rodovia. Por fim, são analisados dados da mesma rodovia no mesmo período de tempo avaliado anteriormente, porém na via expressa e na via marginal.

\subsubsection{Mesmo local em época diferente}

Para analisar o mesmo sensor da Rodovia Presidente Castelo Branco, localizado no km 51,9 em época diferente a analisada anteriormente (set/2011 a ago/2012), foi aplicado o método proposto para reconhecer padrões e detectar anomalias nos dados do mês de junho do ano posterior, 2013. 0 mês de junho foi escolhido por não apresentar nenhum feriado e nenhuma falha no sensor. No entanto no dia 30 de maio de 2013 foi feriado de Corpus Christi, influenciando os dias 1 e 2 de junho como feriado de acordo com os critérios de Cunha (2007). Diferente do Capítulo 5, no qual é apresentado a análise de detecção de anomalias para todos os meses do ano analisados em conjunto, neste capítulo é aplicado o método em apenas um mês. Para não gerar maior volume de Apêndices, as anomalias detectadas são apresentadas apenas em sua classificação para os quatro primeiros níveis e indicadas no texto quando ocorrer nos níveis 8 e 11. Os resultados obtidos são apresentados a seguir, no sentido Leste e Oeste da rodovia.

\section{Leste}

Primeiro foi aplicado o método para reconhecer padrões no fluxo de tráfego. A Figura 6-1 apresenta os grupos formados pelo Coeficiente de Aproximação no nível 4 (CA4) para o mês de junho de 2013. 
Figura 6-1 - Resultado das análises de agrupamento para o $C A_{4}$ - Fluxo Leste - Mesmo local em época diferente

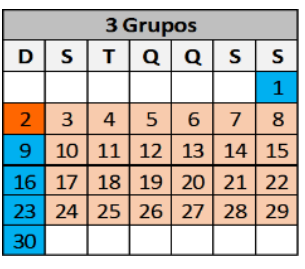

Legenda: \begin{tabular}{|l|l|l|}
\hline & G1 & $\mathbf{G} 2$ \\
\hline
\end{tabular}

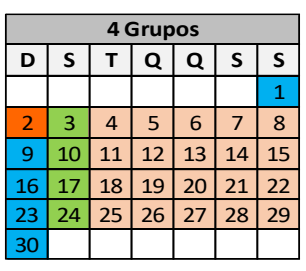

G3
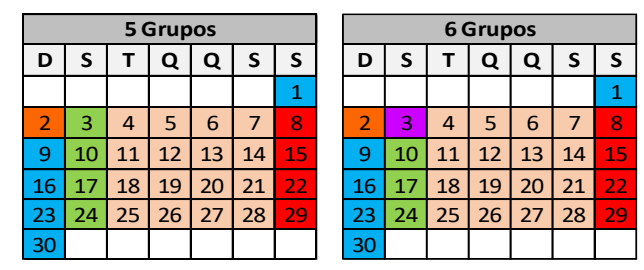

G5 \begin{tabular}{|l|l|l|l|l|l|}
\hline & G6 \\
\hline & $\mathbf{G 7}$ \\
\hline
\end{tabular}

Fonte: Elaborada pelo autor

Analisando os grupos formados a cada cenário (3 a 7 grupos), notou-se que para 3 grupos, o G1 compreendeu os dias de segunda-feira a sábado, o G2, o dia 2 e o G3, o dia 1 e os domingos, com exceção do dia 2. Para 4 agrupamentos as segundas-feiras (G4 - 4 grupos) formaram um grupo distinto, saindo do G1. Com 5 grupos, os sábados (G5 - 5 grupos) se separaram das terças, quartas, quintas e sextas-feiras (G1 - 5 grupos) e os demais grupos prevaleceram como anteriormente. Observou-se também que a partir de seis agrupamentos, houve uma tendência de isolar alguns dias em novos grupos, pois em 6 agrupamentos, o dia 3 foi separado das outras segundas-feiras e em 7 agrupamentos o dia 30 foi separado do grupo de domingo, enquanto que as terças, quartas, quintas e sextas-feiras continuaram agrupadas, revelando uma forte similaridade no comportamento de tráfego.

Esses resultados indicaram que assim como no Capítulo 4, os perfis de dias típicos são formados por 5 agrupamentos. No entanto, na análise para o mês sem feriados (mar/2012), o grupo de dias úteis típicos foi formado por terças, quartas e quintas-feiras. No ano seguinte, essa análise em um mês também sem feriados (apesar da influência do feriado no dia 30/maio), as sextas-feiras apresentaram forte similaridade com esses dias da semana, denominados dias úteis típicos, alterando a sua nova configuração para terças, quartas, quintas e sextas-feiras. Baseado nesta afirmação, a Figura 6-2 ilustra o padrão do tráfego para os cinco grupos formados. 
Figura 6-2 - Grupos formados para 5 agrupamentos com o $C A_{4}$ - Fluxo Leste - Mesmo local em época diferente

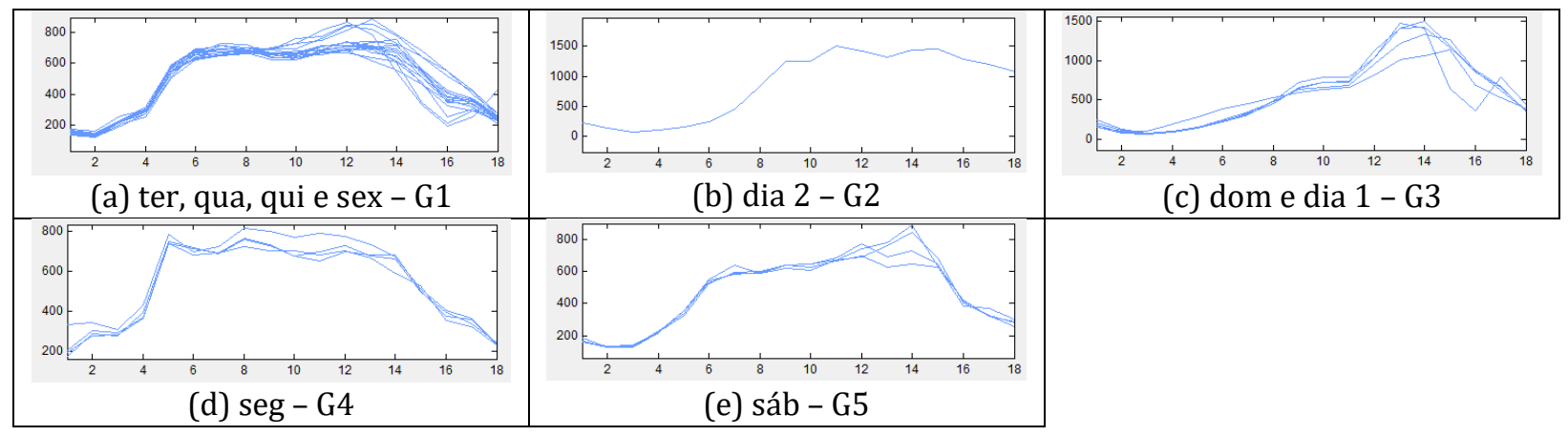

Fonte: Elaborada pelo autor

A segunda análise foi de detecção de anomalia. A Transformada Wavelet Discreta de Haar foi aplicada nos dados de junho de 2013 no sentido Leste da rodovia. A Tabela 6.1 e Tabela 6.2 apresentam a porcentagem do total de anomalias para os quatro primeiros níveis em cada tipo de dia para os dados de fluxo de tráfego e velocidade veicular, respectivamente.

Tabela 6.1 - Frequência de anomalias encontradas por dia em cada nível investigado - Fluxo Leste Mesmo local em época diferente

\begin{tabular}{lrrrrr}
\hline \multicolumn{1}{c}{ Dia } & Nível 1 (\%) & Nível 2 (\%) & Nível 3(\%) & Nível 4 (\%) & Média (\%) \\
\hline Feriado & 41.67 & 33.33 & 50.00 & 25.00 & $\mathbf{3 7 . 5 0}$ \\
Dom & 41.67 & 50.00 & 50.00 & 75.00 & $\mathbf{5 4 . 1 7}$ \\
Seg & 8.33 & 16.67 & 0.00 & 0.00 & $\mathbf{6 . 2 5}$ \\
Ter & 8.33 & 0.00 & 0.00 & 0.00 & $\mathbf{2 . 0 8}$ \\
Qua & 0.00 & 0.00 & 0.00 & 0.00 & $\mathbf{0 . 0 0}$ \\
Qui & 0.00 & 0.00 & 0.00 & 0.00 & $\mathbf{0 . 0 0}$ \\
Sex & 0.00 & 0.00 & 0.00 & 0.00 & $\mathbf{0 . 0 0}$ \\
Sáb & 0.00 & 0.00 & 0.00 & 0.00 & $\mathbf{0 . 0 0}$ \\
\hline
\end{tabular}

Fonte: Elaborada pelo autor

Tabela 6.2 - Frequência de anomalias encontradas por dia em cada nível investigado - Velocidade Leste Mesmo local em época diferente

\begin{tabular}{lrrrrr}
\hline \multicolumn{1}{r}{ Dia } & Nível 1 (\%) & Nível 2 (\%) & Nível 3(\%) & Nível 4 (\%) & Média (\%) \\
\hline Feriado & 44.44 & 25.00 & 44.44 & 42.86 & $\mathbf{3 9 . 1 9}$ \\
Dom & 11.11 & 25.00 & 22.22 & 28.57 & $\mathbf{2 1 . 7 3}$ \\
Seg & 11.11 & 12.50 & 11.11 & 14.29 & $\mathbf{1 2 . 2 5}$ \\
Ter & 22.22 & 37.50 & 22.22 & 0.00 & $\mathbf{2 0 . 4 9}$ \\
Qua & 11.11 & 0.00 & 0.00 & 0.00 & $\mathbf{2 . 7 8}$ \\
Qui & 0.00 & 0.00 & 0.00 & 0.00 & $\mathbf{0 . 0 0}$ \\
Sex & 0.00 & 0.00 & 0.00 & 0.00 & $\mathbf{0 . 0 0}$ \\
Sáb & 0.00 & 0.00 & 0.00 & 14.29 & $\mathbf{3 . 5 7}$ \\
\hline
\end{tabular}

Fonte: Elaborada pelo autor

Nos dados de fluxo de tráfego, as anomalias concentraram-se no domingo $(54,17 \%)$ 
e no feriado (37,50\%) totalizando $91,67 \%$ das anomalias detectadas. As anomalias detectadas do nível 1 ao 4 ocorreram em sua maioria aos domingos e feriados, reforçando a influência dos mesmos nesse local e sentido da rodovia. No nível 8 não ocorreu nenhuma anomalia e no nível 11, ocorreram no dia 08/06/2013 às 02:35 e 22/06/2013 às 07:55, os quais correspondem a primeira e terceira semanas do mês, indicando que nessas duas semanas ocorreram as oscilações de maiores frequências no tráfego em relação as outras duas semanas.

Nos dados de velocidade veicular, as anomalias se concentraram no feriado $(39,19 \%)$, no domingo $(21,73 \%)$ e na terça-feira $(20,49 \%)$, totalizando $(81,41 \%)$. Assim como nas análises do Capítulo 5, as anomalias de velocidade também se concentraram nos domingos e feriados. Porém, foram detectadas mais oscilações nos dias úteis dos dados de velocidade veicular do que nos dados de fluxo de tráfego para esse sensor. Esses resultados reforçam a afirmativa de que os dados de velocidade são mais sensíveis para detectar anomalias em diferentes dias. No nível 8 foi detectada apenas uma anomalia, no domingo, dia 02/06/2013 às 18:38, indicando que nesse dia, caracterizado como feriado, ocorreu o maior número de oscilações na velocidade do que no restante do mês.

\section{Oeste}

Após analisar os dados para o sentido Leste, foram analisados os dados do sensor do sentido Oeste da Rodovia Presidente Castelo Branco no km 51,9 do mês de junho de 2013. Assim como para o sentido Leste, no sentido Oeste, inicialmente, aplicou-se o método para reconhecer padrões no fluxo de tráfego e os resultados obtidos são apresentados na Figura 6-3.

Figura 6-3 - Resultado das análises de agrupamento para o $C A_{4}$ - Fluxo Oeste - Mesmo local em época diferente

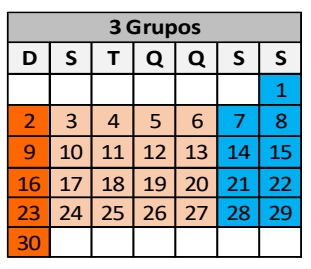

Legenda: \begin{tabular}{l|l|l|l|}
\hline & $\mathbf{G 1}$ & $\mathbf{G} \mathbf{2}$ \\
\hline
\end{tabular}

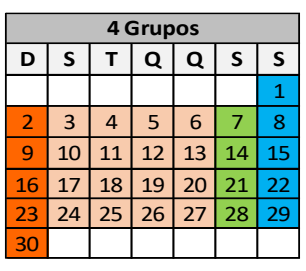

G3
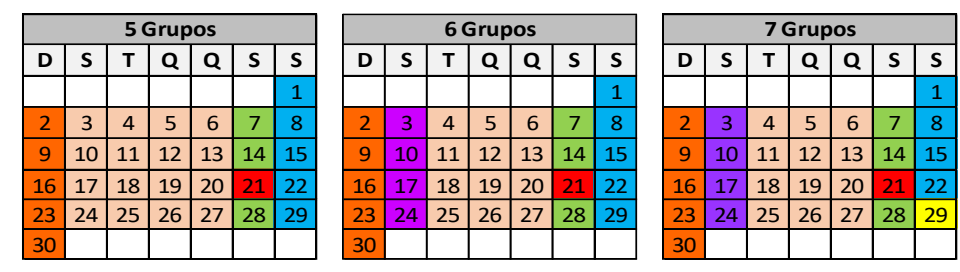

Fonte: Elaborada pelo autor

Analisando cada cenário de agrupamento, notou-se que para 3 grupos, o G1 
compreende os dias de segunda a quinta-feira, o G2 os domingos e o G3 as sextas-feiras e sábados. Para 4 agrupamentos, as sextas-feiras formaram um novo grupo (G4 - 4 grupos), separando-se dos sábados (G3 - 4 grupos). Em 5 agrupamentos o dia 21 foi isolado em um novo grupo (G5 - 5 grupos). Em 6 agrupamentos, as segundas-feiras formam o G6 se separando das terças, quartas e quintas-feiras (G1). Por fim, em 7 grupos, o dia 29 se isolou em um novo grupo.

Após analisar os agrupamentos formados no sentido Oeste, percebeu-se que os domingos possuem forte similaridade pois formaram um grupo desde o cenário 3 até o 7 . Observou-se também que cinco grupos definiram o comportamento para os diferentes dias típicos da semana: (1) domingo, (2) segunda-feira, (3) terça, quarta e quinta-feira, (4) sexta-feira e (5) sábado. No entanto, esses 5 grupos foram obtidos no cenário de 6 agrupamentos, visto que no cenário com 5 grupos, a sexta-feira 21 ficou em um grupo separado (G5 - 5 grupos). Baseando-se nisso, a Figura 6-4 ilustra o padrão do tráfego para os cinco grupos formados.

Figura 6-4 - Grupos formados para 5 agrupamentos com o $C A_{4}$ - Fluxo Oeste - Mesmo local em época diferente

\begin{tabular}{|c|c|c|}
\hline 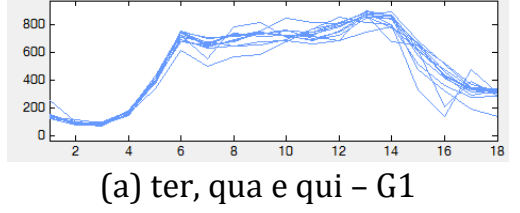 & 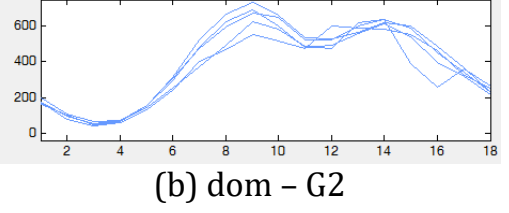 & 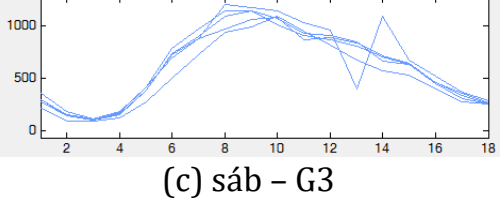 \\
\hline 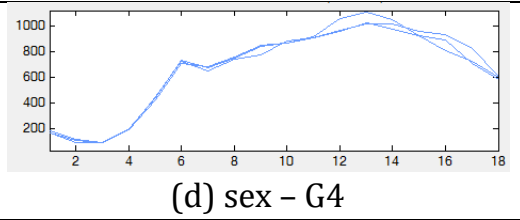 & 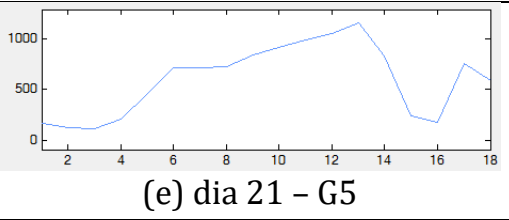 & 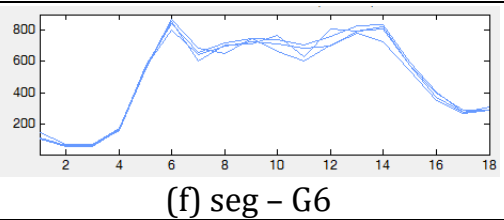 \\
\hline
\end{tabular}

Fonte: Elaborada pelo autor

Após aplicar o método de reconhecimento de padrões, foi analisado o método de detecção de anomalia para os dados de fluxo e velocidade no sentido Oeste. A Tabela 6.3 e a Tabela 6.4 apresentam a porcentagem do total de anomalias para os quatro primeiros níveis em cada tipo de dia para os dados de fluxo de tráfego e velocidade, respectivamente. 
Tabela 6.3 - Frequência de anomalias encontradas por dia em cada nível investigado - Fluxo Oeste Mesmo local em época diferente

\begin{tabular}{lrrrrr}
\hline \multicolumn{1}{r}{ Dia } & Nível 1 (\%) & Nível 2 (\%) & Nível 3(\%) & Nível 4 (\%) & Média (\%) \\
\hline Feriado & 8.33 & 16.67 & 0.00 & 0.00 & $\mathbf{6 . 2 5}$ \\
Dom & 0.00 & 0.00 & 0.00 & 0.00 & $\mathbf{0 . 0 0}$ \\
Seg & 0.00 & 0.00 & 0.00 & 0.00 & $\mathbf{0 . 0 0}$ \\
Ter & 8.33 & 0.00 & 9.09 & 0.00 & $\mathbf{4 . 3 6}$ \\
Qua & 0.00 & 0.00 & 0.00 & 0.00 & $\mathbf{0 . 0 0}$ \\
Qui & 8.33 & 8.33 & 27.27 & 25.00 & $\mathbf{1 7 . 2 3}$ \\
Sex & 8.33 & 8.33 & 18.18 & 50.00 & $\mathbf{2 1 . 2 1}$ \\
Sáb & 66.67 & 66.67 & 45.45 & 25.00 & $\mathbf{5 0 . 9 5}$ \\
\hline
\end{tabular}

Fonte: Elaborada pelo autor

Tabela 6.4 - Frequência de anomalias encontradas por dia em cada nível investigado - Velocidade Oeste Mesmo local em época diferente

\begin{tabular}{lrrrrr}
\hline \multicolumn{1}{c}{ Dia } & Nível 1 (\%) & Nível 2 (\%) & Nível 3(\%) & Nível 4 (\%) & Média (\%) \\
\hline Feriado & 5.00 & 28.57 & 0.00 & 20.00 & $\mathbf{1 3 . 3 9}$ \\
Dom & 25.00 & 14.29 & 0.00 & 40.00 & $\mathbf{1 9 . 8 2}$ \\
Seg & 20.00 & 0.00 & 0.00 & 0.00 & $\mathbf{5 . 0 0}$ \\
Ter & 5.00 & 0.00 & 0.00 & 0.00 & $\mathbf{1 . 2 5}$ \\
Qua & 5.00 & 0.00 & 0.00 & 0.00 & $\mathbf{1 . 2 5}$ \\
Qui & 10.00 & 14.29 & 16.67 & 0.00 & $\mathbf{1 0 . 2 4}$ \\
Sex & 10.00 & 0.00 & 16.67 & 20.00 & $\mathbf{1 1 . 6 7}$ \\
Sáb & 20.00 & 42.86 & 66.67 & 20.00 & $\mathbf{3 7 . 3 8}$ \\
\hline
\end{tabular}

Fonte: Elaborada pelo autor

Analisando os resultados para os dados de fluxo de tráfego (Tabela 6.3), atentou-se para o fato de que as anomalias se concentraram nos grupos de sábado (50,95\%), de sexta-feira $(21,21 \%)$ e de quinta-feira (17,23\%), totalizando $89,39 \%$ das anomalias detectadas. Apesar do feriado não ter influenciado tanto quanto no sentido Leste, novamente as anomalias se concentraram nos sábados e nas sextas-feiras, assim como no sentido Oeste no período mensal analisado no Capítulo 5. Não foi detectada nenhuma anomalia no nível 8 e no nível 11, foi detectada apenas uma, no dia 08/06/2013 às 02:35 (01/06/2013 00:00 à 08/06/2013 às 02:35), indicando que a primeira semana apresentou oscilações de maiores frequências no fluxo de tráfego que as demais.

Analisando as anomalias obtidas para os dados de velocidade (Tabela 6.4), observou-se que, assim como nos dados de fluxo de tráfego, o dia que mais concentrou anomalias foi o sábado (37,38\%). No entanto, a quinta $(10,24 \%)$ e a sexta-feira $(11,67 \%)$ se tornaram menos anômalas, enquanto que o domingo $(19,82 \%)$ e o feriado $(13,39 \%)$. Esses resultados indicaram que diferente do sentido Leste, no sentido Oeste, as anomalias se concentram no sábado ao invés de domingos e feriados, corroborando com os resultados atingidos no Capítulo 5. Por fim, o nível 8 detectou apenas uma anomalia na 
quarta-feira, 26/06/2013 às 18:35, indicando maior oscilação nesse dia em relação aos outros do mês. No nível 11 não foi detectado nenhuma anomalia.

\subsubsection{Mesma época em locais diferentes}

Para analisar a mesma época (set/2011 a ago/2012) em um local diferente, foi aplicado o método proposto para detectar anomalias e reconhecer padrões na Rodovia Raposo Tavares no km 34,0 no mês de agosto de 2012. Essa rodovia e sensor foram escolhidos por não apresentarem falhas na coleta de dados e, sendo uma rodovia diferente, apresenta um comportamento de tráfego distinto. No mês de agosto de 2012, ocorreu o feriado do dia dos pais no dia 12 (domingo). Os resultados obtidos para cada sentido (Leste e Oeste) são apresentados a seguir.

\section{Leste}

Primeiro foi aplicado o método para reconhecer padrões no fluxo de tráfego. A Figura 6-5 apresenta os grupos formados pelo Coeficiente de Aproximação no nível 4 para o mês de agosto de 2012 no sentido Leste da Rodovia Raposo Tavares no km 34,0.

Figura 6-5 - Resultado das análises de agrupamento para o $C A_{4}$ - Fluxo Leste - Mesma época em locais diferentes

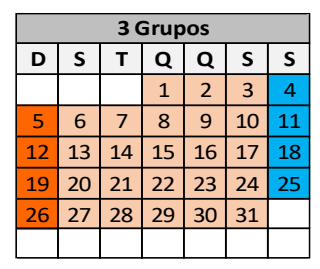

Legenda: \begin{tabular}{|l|l|l|}
\hline & G1 & $\mathbf{G 2}$ \\
\hline
\end{tabular}

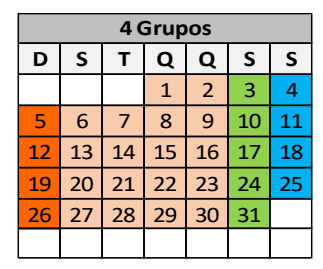

G3
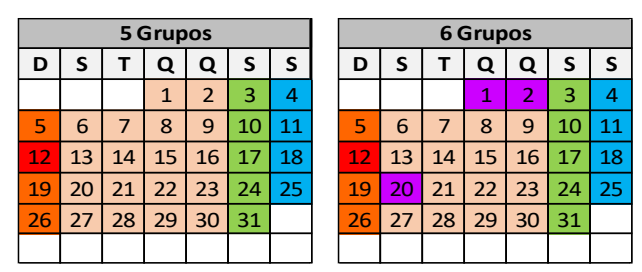

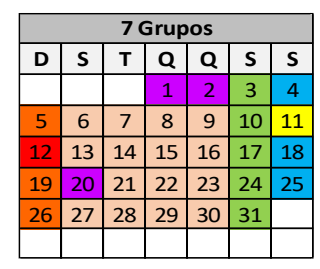

\section{G5 $\square$ G6 $\square$ G7}

Fonte: Elaborada pelo autor

Analisando os grupos formados a cada cenário, notou-se que para 3 grupos, o G1 compreendeu os dias de segunda a sexta-feira, o G2 os domingos e o G3 os sábados. Nesse cenário, ficou evidente a separação entre fim de semana e dias úteis. Para 4 agrupamentos, as sextas-feiras saíram do G1 e formaram um grupo distinto (G4 - 4 grupos). A partir de 5 agrupamentos, alguns dias são isolados em um novo grupo: em agrupamentos foi o feriado do dia 12 (G5 - 5 grupos), para 6 agrupamentos foram os dias 1, 2 e 20 (G6 - 6 grupos) e para 7 agrupamentos, o dia 11. Esses resultados indicaram que com 5 
agrupamentos foi possível definir o comportamento dos dias típicos em cinco grupos: (1) domingo, (2) segunda, terça, quarta e quinta-feira, (3) sexta-feira, (4) sábado e (5) feriado. Tomando estas por base, a Figura 6-6 apresenta os perfis desses grupos. Percebe-se que apesar de apresentar um comportamento distinto da Rodovia Presidente Castelo Branco no mesmo período, o perfil de cada dia apresentou grande similaridade com os dias que compõem o mesmo grupo, comprovando a validade do método para rodovias distintas, como analisado anteriormente.

Figura 6-6 - Grupos formados para 5 agrupamentos com o $C A_{4}$ - Fluxo Leste - Mesma época em locais diferentes

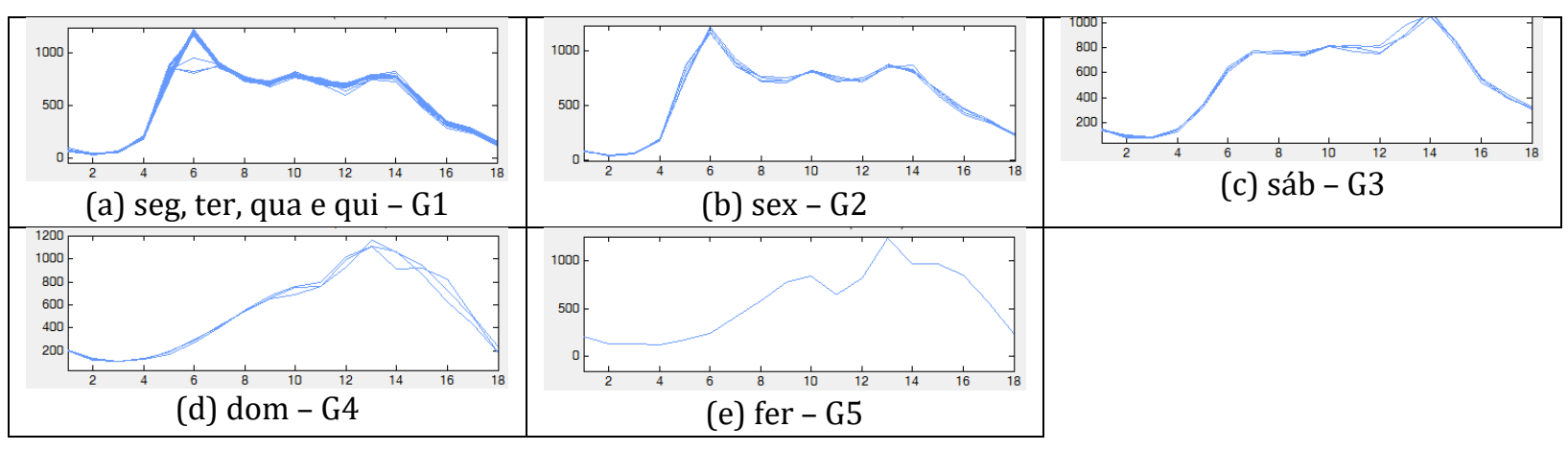

Fonte: Elaborada pelo autor

A segunda análise foi de detecção de anomalia. A Tabela 6.5 e a Tabela 6.6 apresentam a porcentagem do total de anomalias para os quatro primeiros níveis em cada tipo de dia para os dados de fluxo de tráfego e de velocidade veicular, respectivamente.

Tabela 6.5 - Frequência de anomalias encontradas por dia em cada nível investigado - Fluxo Leste Mesma época em locais diferentes

\begin{tabular}{lrrrrr}
\hline \multicolumn{1}{r}{ Dia } & Nível 1 (\%) & Nível 2 (\%) & Nível 3(\%) & Nível 4 (\%) & Média (\%) \\
\hline Feriado & 42.86 & 50.00 & 33.33 & 0.00 & $\mathbf{3 1 . 5 5}$ \\
Dom & 14.29 & 0.00 & 0.00 & 0.00 & $\mathbf{3 . 5 7}$ \\
Seg & 14.29 & 0.00 & 0.00 & 0.00 & $\mathbf{3 . 5 7}$ \\
Ter & 0.00 & 0.00 & 0.00 & 0.00 & $\mathbf{0 . 0 0}$ \\
Qua & 14.29 & 50.00 & 16.67 & 50.00 & $\mathbf{3 2 . 7 4}$ \\
Qui & 14.29 & 0.00 & 16.67 & 50.00 & $\mathbf{2 0 . 2 4}$ \\
Sex & 0.00 & 0.00 & 16.67 & 0.00 & $\mathbf{4 . 1 7}$ \\
Sáb & 0.00 & 0.00 & 16.67 & 0.00 & $\mathbf{4 . 1 7}$ \\
\hline
\end{tabular}

Fonte: Elaborada pelo autor 
Tabela 6.6 - Frequência de anomalias encontradas por dia em cada nível investigado - Velocidade Leste Mesma época em locais diferentes

\begin{tabular}{lrrrrr}
\hline \multicolumn{1}{r}{ Dia } & Nível 1 (\%) & Nível 2 (\%) & Nível 3(\%) & Nível 4 (\%) & Média (\%) \\
\hline Feriado & 10.34 & 10.00 & 14.29 & 25.00 & $\mathbf{1 4 . 9 1}$ \\
Dom & 17.24 & 15.00 & 23.81 & 37.50 & $\mathbf{2 3 . 3 9}$ \\
Seg & 3.45 & 0.00 & 0.00 & 0.00 & $\mathbf{0 . 8 6}$ \\
Ter & 17.24 & 15.00 & 4.76 & 0.00 & $\mathbf{9 . 2 5}$ \\
Qua & 34.48 & 20.00 & 19.05 & 12.50 & $\mathbf{2 1 . 5 1}$ \\
Qui & 6.90 & 10.00 & 9.52 & 12.50 & $\mathbf{9 . 7 3}$ \\
Sex & 6.90 & 15.00 & 14.29 & 12.50 & $\mathbf{1 2 . 1 7}$ \\
Sáb & 10.34 & 10.00 & 14.29 & 25.00 & $\mathbf{1 4 . 9 1}$ \\
\hline
\end{tabular}

Fonte: Elaborada pelo autor

Nos dados de fluxo de tráfego (Tabela 6.5), as anomalias se concentraram na quartafeira $(32,74 \%)$, no feriado $(31,55 \%)$ e na quinta-feira $(20,24 \%)$, totalizando $84,53 \%$ das anomalias detectadas. No nível 8 não foi apresentado nenhuma anomalia e no nível 11 foi detectada anomalia no dia 22/08/2012 às 07:55, indicando oscilações de maiores frequências na terceira semana do mês.

Nos dados de velocidade veicular (Tabela 6.6), as anomalias se concentraram na quarta-feira $(21,51 \%)$ e no domingo $(23,39 \%)$, totalizando $(44,9 \%)$. Porém, os feriados $(14,91 \%)$, os sábados $(14,91 \%)$ e as sextas-feiras $(12,17 \%)$ apresentaram considerável quantidade de anomalias (41,99\%). Esses resultados indicaram que as anomalias de velocidade para o mês de agosto na Rodovia Raposo Tavares apresentaram as anomalias distribuídas ao longo da semana. No nível 8 foi detectada uma anomalia entre o domingo e a segunda-feira (19/08/2012 às 15:55 a 20/08/2012 às 13:15), indicando que neste dia ocorreu oscilação de maior frequência, e no nível 11, nos dias 08/08/2012 às 02:35 e 15/08/2012 às 05:15, indicando maiores oscilações na primeira e segunda semana do mês.

\section{Oeste}

Após analisar os dados para o sentido Leste, foram analisados os dados do sensor no sentido Oeste da Rodovia Raposo Tavares no km 34,0 no mês de agosto de 2012. Inicialmente foi aplicado o método para reconhecer padrões no fluxo de tráfego. Os resultados obtidos são apresentados na Figura 6-7. 
Figura 6-7 - Resultado das análises de agrupamento para o $C A_{4}$ - Fluxo Oeste - Mesma época em locais diferentes

\begin{tabular}{|c|c|c|c|c|c|c|}
\hline \multicolumn{7}{|c|}{ 3 Grupos } \\
\hline D & S & T & Q & Q & S & S \\
\hline & & & 1 & 2 & 3 & 4 \\
\hline 5 & 6 & 7 & 8 & 9 & 10 & 11 \\
\hline 12 & 13 & 14 & 15 & 16 & 17 & 18 \\
\hline 19 & 20 & 21 & 22 & 23 & 24 & 25 \\
\hline 26 & 27 & 28 & 29 & 30 & 31 & \\
\hline & & & & & & \\
\hline
\end{tabular}

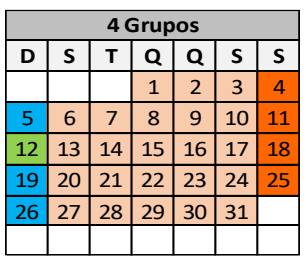

Legenda: \begin{tabular}{l|l|l|}
\hline & $\mathbf{G 1}$ & $\mathbf{G} 2$ \\
\hline
\end{tabular}
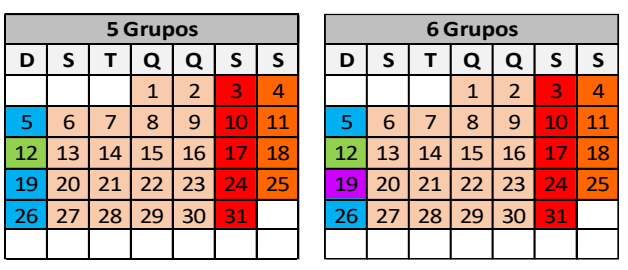

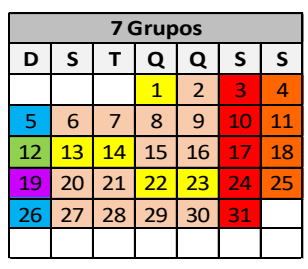

\begin{tabular}{ll|l|l|l|l|l|l|l|l|l|l|l|l|l|l|}
\hline & G3 & G6 & G5 \\
\hline
\end{tabular}

Fonte: Elaborada pelo autor

Analisando os grupos formados a cada cenário, notou-se que para 3 grupos, o G1 compreendeu os dias de segunda a sexta-feira, o G2 os sábados e o G3 os domingos. Assim como para o sentido Leste, nesse agrupamento, ficou evidente a separação dos dias entre fim de semana e dias úteis. Para 4 agrupamentos, o feriado do dia dos pais foi separado do G3 e formou um grupo isolado (G4 - 4 grupos). Em 5 agrupamentos, as sextas-feiras (G5) formaram um grupo distinto (G5 - 5 grupos), separando-se do G1. Para 6 grupos, o dia 19 foi separado do grupo de domingos e para 7 grupos, alguns dias úteis, de segunda a quinta-feira, formaram um novo grupo, mas não apresentaram um padrão de tipo de dia.

Assim como no sentido Leste, esses resultados indicaram que com 5 agrupamentos foi possível definir o comportamento dos dias típicos em cinco grupos: (1) domingo, (2) segunda, terça, quarta e quinta-feira, (3) sexta-feira, (4) sábado e (5) feriado. Baseandose nisso, a Figura 6-8 apresenta os perfis desses grupos. Percebe-se, que assim como no sentido Leste, no sentido Oeste o perfil de cada dia apresentou grande similaridade com os dias que compõem o mesmo grupo, mas um comportamento distinto da Rodovia Presidente Castelo Branco, corroborando novamente com a validade do método para rodovias distintas. 
Figura 6-8 - Grupos formados para 5 agrupamentos com o $C A_{4}$ - Fluxo Oeste - Mesma época em locais diferentes

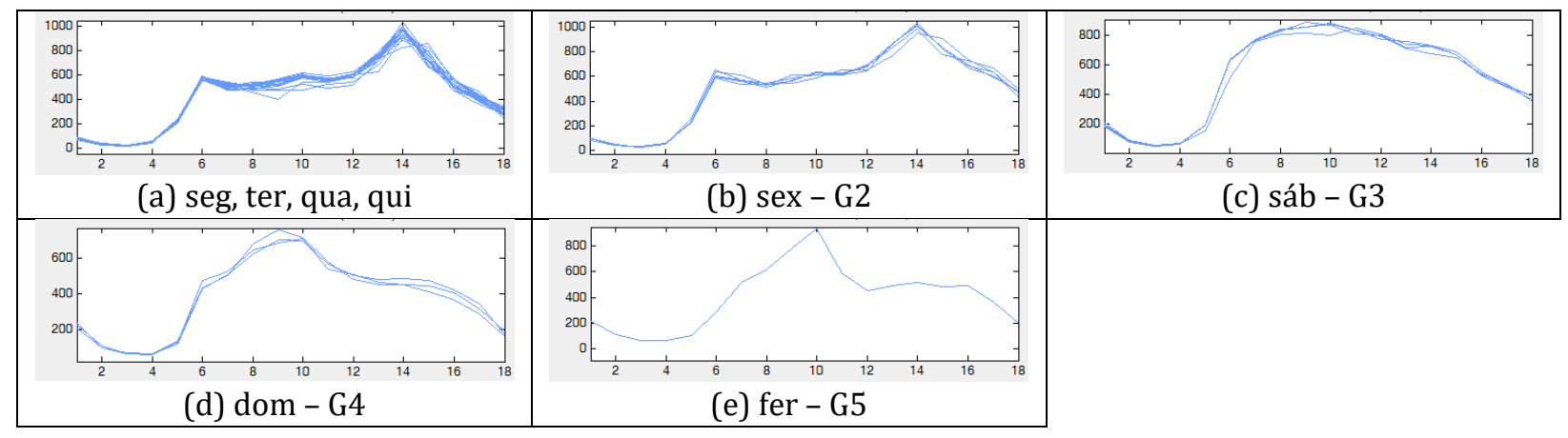

Fonte: Elaborada pelo autor

Em relação à comparação entre o sentido Leste e Oeste da Rodovia Raposo Tavares, apesar de apresentarem exatamente o mesmo grupo de dias típicos, as curvas se mostraram distintas, como por exemplo, o grupo formado por segundas, terças, quartas e quintas-feiras. Para o sentido Oeste (Figura 6-8(a)), o pico ocorreu no ponto 14, que corresponde aproximadamente às 18:00, enquanto que no sentido Leste, o pico para o mesmo grupo de dias (Figura 6-6(a)), ocorreu no ponto 6, aproximadamente às 8:00 da manhã. O mesmo aconteceu para os outros grupos formados. Esse resultado evidencia a influência do fluxo direcional em rodovias distintas. Enquanto na Rodovia Presidente Castelo Branco o fluxo direcional apresentou variações diárias no decorrer da semana, na Rodovia Raposo Tavares, o fluxo direcional apresentou variações horárias ao longo do dia. Nesse caso, observa-se as viagens com origem nas residências e destino ao trabalho, sentido Interior para Capital, predominantemente no período da manhã. 0 contrário se deu no período da tarde, sentido Capital para Interior, quando os usuários saem do trabalho e voltam para suas residências.

Após aplicar o método de reconhecimento de padrões, foi aplicado o método de detecção de anomalia. Os resultados obtidos são apresentados na Tabela 6.7 e na Tabela 6.8, para os dados de fluxo de tráfego e velocidade veicular, respectivamente. 
Tabela 6.7 - Frequência de anomalias encontradas por dia em cada nível investigado - Fluxo Oeste Mesma época em locais diferentes

\begin{tabular}{lrrrrr}
\hline \multicolumn{1}{c}{ Dia } & Nível 1 (\%) & Nível 2 (\%) & Nível 3(\%) & Nível 4 (\%) & Média (\%) \\
\hline Feriado & 10.00 & 10.00 & 33.33 & 0.00 & $\mathbf{1 7 . 7 8}$ \\
Dom & 10.00 & 0.00 & 0.00 & 0.00 & $\mathbf{3 . 3 3}$ \\
Seg & 10.00 & 0.00 & 33.33 & 0.00 & $\mathbf{1 4 . 4 4}$ \\
Ter & 0.00 & 20.00 & 0.00 & 0.00 & $\mathbf{6 . 6 7}$ \\
Qua & 30.00 & 20.00 & 33.33 & 0.00 & $\mathbf{2 7 . 7 8}$ \\
Qui & 30.00 & 30.00 & 0.00 & 0.00 & $\mathbf{2 0 . 0 0}$ \\
Sex & 0.00 & 20.00 & 0.00 & 0.00 & $\mathbf{6 . 6 7}$ \\
Sáb & 10.00 & 0.00 & 0.00 & 0.00 & $\mathbf{3 . 3 3}$ \\
\hline
\end{tabular}

Fonte: Elaborada pelo autor

Tabela 6.8 - Frequência de anomalias encontradas por dia em cada nível investigado - Velocidade Oeste Mesma época em locais diferentes

\begin{tabular}{lrrrrr}
\hline \multicolumn{1}{c}{ Dia } & Nível 1 (\%) & Nível 2 (\%) & Nível 3(\%) & Nível 4 (\%) & Média (\%) \\
\hline Feriado & 4.55 & 7.69 & 12.50 & 0.00 & $\mathbf{6 . 1 8}$ \\
Dom & 0.00 & 0.00 & 0.00 & 0.00 & $\mathbf{0 . 0 0}$ \\
Seg & 18.18 & 7.69 & 25.00 & 36.36 & $\mathbf{2 1 . 8 1}$ \\
Ter & 11.36 & 0.00 & 0.00 & 0.00 & $\mathbf{2 . 8 4}$ \\
Qua & 25.00 & 46.15 & 31.25 & 36.36 & $\mathbf{3 4 . 6 9}$ \\
Qui & 31.82 & 38.46 & 31.25 & 27.27 & $\mathbf{3 2 . 2 0}$ \\
Sex & 6.82 & 0.00 & 0.00 & 0.00 & $\mathbf{1 . 7 0}$ \\
Sáb & 2.27 & 0.00 & 0.00 & 0.00 & $\mathbf{0 . 5 7}$ \\
\hline
\end{tabular}

Fonte: Elaborada pelo autor

Nos dados de fluxo de tráfego (Tabela 6.7), as anomalias se concentraram na quartafeira $(27,78 \%)$, na quinta-feira $(20,00 \%)$, no feriado $(17,78 \%)$ e na segunda-feira $(14,44 \%)$ totalizando $80,00 \%$ das anomalias detectadas. Nos níveis 8 e 11 não foram detectadas nenhuma anomalia.

Nos dados de velocidade veicular (Tabela 6.8), as anomalias se concentraram na quarta-feira $(34,69 \%)$, na quinta-feira $(32,20 \%)$ e na segunda-feira $(21,81 \%)$, totalizando $(88,70 \%)$. Tanto os resultados de fluxo de tráfego quanto os de velocidade veicular, indicaram que as anomalias no mês de agosto na Rodovia Raposo Tavares ficaram distribuídas ao longo da semana, enquanto que na análise mensal para a Rodovia Presidente Castelo Branco as anomalias se concentraram nas sextas-feiras, finais de semana e feriados (considerando os dois sentidos da rodovia). Esse resultado em conjunto aos resultados de reconhecimento de padrões é de suma importância por indicar a necessidade de análise do sinal antes de qualquer processamento, pois o comportamento varia entre uma rodovia e outra, e apenas excluir os dias atípicos ou aplicar um método pode mascarar essas oscilações, prejudicando análises futuras. 
Para os dados de velocidade, foram detectadas 3 anomalias no dia 8: 01/08/2012 às 21:15 (quarta-feira), 02/08/2012 às 18:35 (quinta-feira) e 20/08/2012 às 13:15 (segunda-feira), indicando que nesses três dias a velocidade apresentou mais oscilações que nos outros dias do mês, enquanto que no nível 11, foi detectada uma anomalia, 08/08/2012 02:35, indicando maior oscilação na primeira semana do mês.

\subsubsection{Mesma época e local, vias diferentes}

Buscando analisar a mesma rodovia (Presidente Castelo Branco) com classificação diferente das vias e na mesma época que foram analisados os resultados dos capítulos 4 e 5, escolheu-se o km 22,30 da Rodovia Presidente Castelo Branco pois continham dois sensores no mesmo ponto, um na via marginal e outro na via expressa. Ao contrário do sensor no km 51,90, o sensor do $\mathrm{km} \mathrm{22,30} \mathrm{apresentou} \mathrm{muitas} \mathrm{falhas} \mathrm{na} \mathrm{coleta} \mathrm{de} \mathrm{dados}$ para o mesmo período de um ano (set/2011 a ago/2012). Por esse motivo, a análise aplicada para esta seção foi no mês de novembro de 2011, apesar dos dois feriados existentes, dias 2 (Finados) e 15 (Proclamação da República). 0 intuito desta análise é investigar se o método reconhece padrões e anomalias distintas para os dois tipos de via. A seguir os resultados são apresentados por tipo de via (marginal ou expressa) nos dois sentidos da rodovia (Leste e Oeste).

\subsubsection{Via marginal}

a) Sentido Leste: Primeiro foi aplicado o método para reconhecimento de padrões no sentido Leste da via marginal nos dados de fluxo de tráfego no mês de novembro de 2011. Os resultados são apresentados na Figura 6-9.

Figura 6-9 - Resultado das análises de agrupamento para o $C A_{4}$ - Fluxo Leste - Mesma época e local, via Marginal

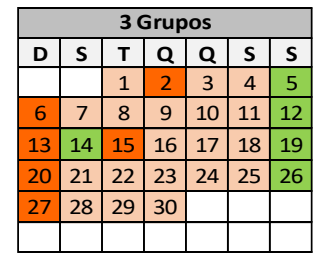

Legenda: \begin{tabular}{l|l|l|}
$\square$ & G1 \\
\hline
\end{tabular}

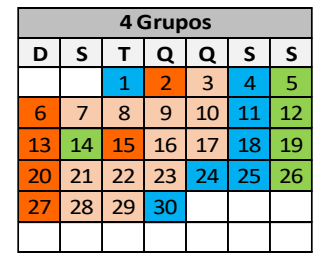

\begin{tabular}{|l|l|l|l|}
\hline & $\mathbf{G} 3$ & $\mathbf{G} 4$ \\
\hline
\end{tabular}

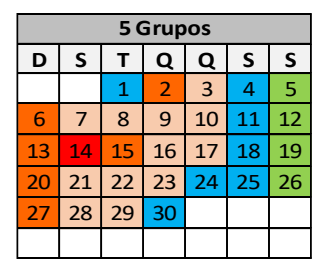

\begin{tabular}{|c|c|c|c|c|c|c|}
\hline \multicolumn{7}{|c|}{ 6 Grupos } \\
\hline D & S & T & Q & Q & S & S \\
\hline & & 1 & 2 & 3 & 4 & 5 \\
\hline 6 & 7 & 8 & 9 & 10 & 11 & 12 \\
\hline 13 & 14 & 15 & 16 & 17 & 18 & 19 \\
\hline 20 & 21 & 22 & 23 & 24 & 25 & 26 \\
\hline 27 & 28 & 29 & 30 & & & \\
\hline & & & & & & \\
\hline
\end{tabular}

\begin{tabular}{|c|c|c|c|c|c|c|}
\hline \multicolumn{7}{|c|}{ 7 Grupos } \\
\hline D & S & T & Q & Q & S & S \\
\hline & & 1 & 2 & 3 & 4 & 5 \\
\hline 6 & 7 & 8 & 9 & 10 & 11 & 12 \\
\hline 13 & 14 & 15 & 16 & 17 & 18 & 19 \\
\hline 20 & 21 & 22 & 23 & 24 & 25 & 26 \\
\hline 27 & 28 & 29 & 30 & & & \\
\hline & & & & & & \\
\hline
\end{tabular}

\begin{tabular}{l|l|l|l|}
\hline G5 & G6 \\
\hline
\end{tabular}

Fonte: Elaborada pelo autor 
Analisando os grupos formados a cada cenário, notou-se que para 3 grupos, o G1 compreendeu os dias de segunda a sexta-feira, com exceção dos dois feriados (dias 2 e 15) e o dia 14 (pré-feriado), o G2, os domingos e os feriados e o G3, os sábados e o pré-feriado (dia 14). Para 4 grupos, as sextas-feiras (G4) formaram um grupo distinto incluindo o dia 1 (pré-feriado), 24 e 30. Em 5 agrupamentos, o dia 14 foi isolado em um novo grupo. Em 6 agrupamentos, os dois feriados e o dia 13 (domingo anterior ao feriado) formaram um novo grupo. Por fim, em 7 agrupamentos, alguns dias úteis formaram um novo agrupamento, mas sem uma prévia definição de padrão em relação ao tipo de dia.

Esses resultados apontaram para uma forte influência dos dois feriados que ocorreram no mês, pois os mesmos influenciaram os dias anteriores a eles de forma que esses dias formaram um novo grupo isolado (dia 14, G5 - 5 grupos) ou foi agrupado a um outro tipo de dia (dia 1, G4 - 4 grupos). Além dos feriados e os dias influenciados pelo mesmo, os dias 24 e 30 também foram agrupados a um tipo de dia diferente ao que correspondem, não fazendo parte do G1. Apesar disso, é possível notar um comportamento típico para cada tipo de dia utilizando 5 agrupamentos, conforme apresenta a Figura 6.10.

Figura 6-10 - Grupos formados para 5 agrupamentos com o $C A_{4}$ - Fluxo Leste - Mesma época e local, via Marginal

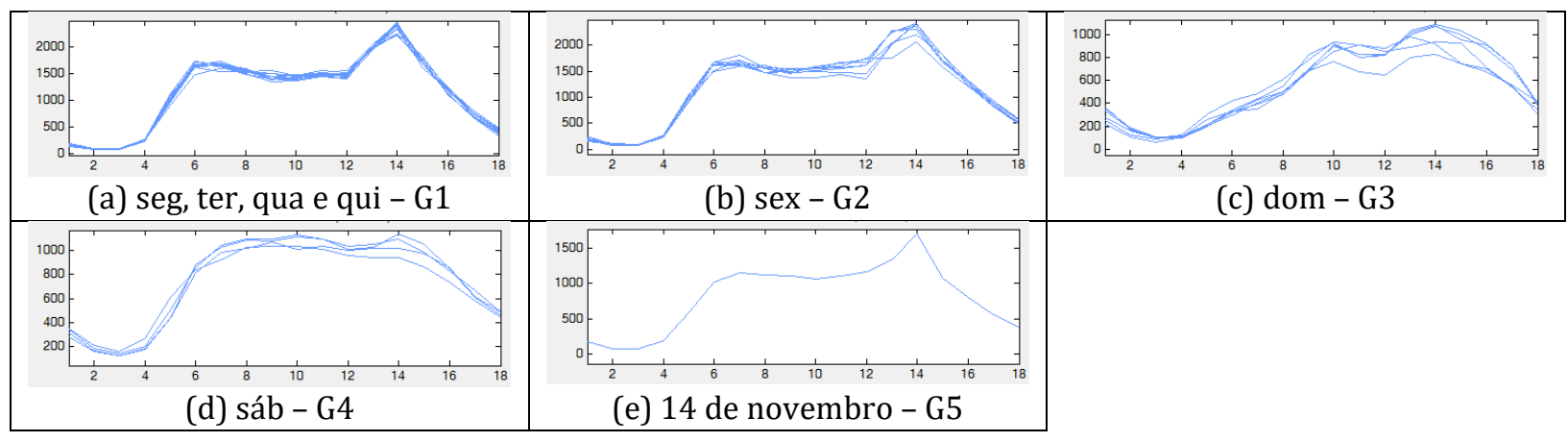

Fonte: Elaborada pelo autor

Nota-se que apesar de alguns dias da semana terem sido excluídos do G1, o grupo apresentou forte similaridade entre os perfis que o compõem, representando os dias úteis sem a necessidade de excluir as segundas-feiras e os pós-feriados (dias 3 e 16). Observouse também, a partir da análise dos feriados, os dias 24 e 30 não seriam excluídos. No entanto apresentaram um comportamento distinto aos dias úteis típicos e por esse motivo, foram separados do G1 de forma automática. Esses resultados reforçam a importância de se analisar as informações provenientes dos dados históricos em relação 
ao comportamento do tráfego antes de qualquer aplicação na Engenharia de Transportes.

A segunda análise aplicada à via marginal no sentido Leste foi de detecção de anomalia. As Tabela 6.9 e Tabela 6.10 apresentam a porcentagem do total de anomalias para os quatro primeiros níveis em cada tipo de dia para os dados de fluxo de tráfego e velocidade veicular, respectivamente.

Tabela 6.9 - Frequência de anomalias encontradas por dia em cada nível investigado - Fluxo Leste Mesma época e local, via Marginal

\begin{tabular}{lrrrrr}
\hline \multicolumn{1}{r}{ Dia } & Nível 1 (\%) & Nível 2 (\%) & Nível 3(\%) & Nível 4 (\%) & Média (\%) \\
\hline Feriado & 30.77 & 33.33 & 33.33 & 0.00 & $\mathbf{2 4 . 3 6}$ \\
Dom & 0.00 & 0.00 & 0.00 & 0.00 & $\mathbf{0 . 0 0}$ \\
Seg & 15.38 & 8.33 & 8.33 & 66.67 & $\mathbf{2 4 . 6 8}$ \\
Ter & 0.00 & 0.00 & 16.67 & 0.00 & $\mathbf{4 . 1 7}$ \\
Qua & 30.77 & 8.33 & 8.33 & 0.00 & $\mathbf{1 1 . 8 6}$ \\
Qui & 15.38 & 41.67 & 33.33 & 0.00 & $\mathbf{2 2 . 6 0}$ \\
Sex & 7.69 & 8.33 & 0.00 & 33.33 & $\mathbf{1 2 . 3 4}$ \\
Sáb & 0.00 & 0.00 & 0.00 & 0.00 & $\mathbf{0 . 0 0}$ \\
\hline
\end{tabular}

Fonte: Elaborada pelo autor

Tabela 6.10 - Frequência de anomalias encontradas por dia em cada nível investigado - Velocidade Leste - Mesma época e local, via Marginal

\begin{tabular}{lrrrrr}
\hline \multicolumn{1}{r}{ Dia } & Nível 1 (\%) & Nível 2 (\%) & Nível 3(\%) & Nível 4 (\%) & Média (\%) \\
\hline Feriado & 42.86 & 16.67 & 23.08 & 14.29 & $\mathbf{2 4 . 2 2}$ \\
Dom & 4.76 & 0.00 & 0.00 & 0.00 & $\mathbf{1 . 1 9}$ \\
Seg & 9.52 & 5.56 & 0.00 & 14.29 & $\mathbf{7 . 3 4}$ \\
Ter & 14.29 & 27.78 & 15.38 & 14.29 & $\mathbf{1 7 . 9 3}$ \\
Qua & 4.76 & 22.22 & 0.00 & 14.29 & $\mathbf{1 0 . 3 2}$ \\
Qui & 14.29 & 11.11 & 38.46 & 14.29 & $\mathbf{1 9 . 5 4}$ \\
Sex & 4.76 & 16.67 & 23.08 & 28.57 & $\mathbf{1 8 . 2 7}$ \\
Sáb & 4.76 & 0.00 & 0.00 & 0.00 & $\mathbf{1 . 1 9}$ \\
\hline
\end{tabular}

Fonte: Elaborada pelo autor

Nos dados de fluxo de tráfego (Tabela 6.9) as anomalias foram detectadas nos dados de segunda-feira $(24,68 \%)$, feriado $(24,36 \%)$ e quinta-feira $(22,60 \%)$, totalizando $71,64 \%$. No entanto, ocorreu anomalia na sexta-feira $(12,34 \%)$, quarta-feira $(11,86 \%)$ e terça-feira $(4,17 \%)$. Esses resultados indicam que as anomalias foram distribuídas ao longo da semana ao invés de se concentrarem em apenas um tipo de dia. 0 nível 8 não detectou nenhuma anomalia e o nível 11 detectou nos dias 15/11/2011 às 05:15 e 29/11/2011 às 10:35, indicando que a segunda e quarta semanas tiveram oscilações de maior frequência no sinal de tráfego em relação ao mês analisado.

Nos dados de velocidade veicular, as anomalias detectadas ocorreram em maior quantidade no feriado (24,22\%), mas apresentaram quantidades significativas para os 
outros dias da semana: quinta-feira $(19,54 \%)$, sexta-feira $(18,27 \%)$, terça-feira $(17,93)$ e quarta-feira (10,32\%), totalizando 66,06\% para esses dias. Assim como nos dados de fluxo de tráfego, as oscilações no sinal de velocidade veicular para via marginal no sentido Leste foram distribuídas nos dias da semana. No nível 8 não foram detectadas anomalias e no nível 11 foram duas, 22/11/2011 às 07:55 e 29/11/2011 às 10:35, indicando que as duas últimas semanas do mês tiveram maior número de oscilações.

b) Sentido Oeste: Foi aplicado o método para reconhecimento de padrões no sentido Oeste da via marginal nos dados de fluxo de tráfego no mês de novembro de 2011. Os resultados são apresentados na Figura 6-11.

Figura 6-11 - Resultado das análises de agrupamento para o $C A_{4}$ - Fluxo Oeste - Mesma época e local, via Marginal

\begin{tabular}{|c|c|c|c|c|c|c|}
\hline \multicolumn{7}{|c|}{ 3 Grupos } \\
\hline D & S & T & Q & Q & S & S \\
\hline & & 1 & 2 & 3 & 4 & 5 \\
\hline 6 & 7 & 8 & 9 & 10 & 11 & 12 \\
\hline 13 & 14 & 15 & 16 & 17 & 18 & 19 \\
\hline 20 & 21 & 22 & 23 & 24 & 25 & 26 \\
\hline 27 & 28 & 29 & 30 & & & \\
\hline & & & & & & \\
\hline
\end{tabular}

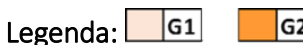

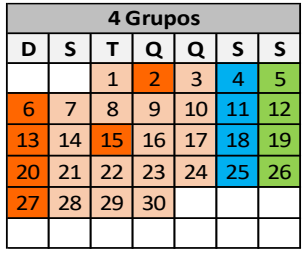

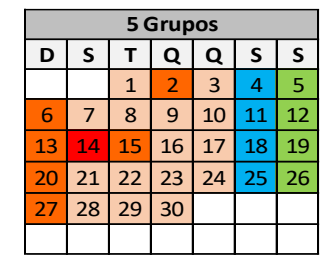

G5 \begin{tabular}{|l|l|l|}
$\square$ & G6 \\
\hline & $\mathbf{G 7}$ \\
\hline
\end{tabular}

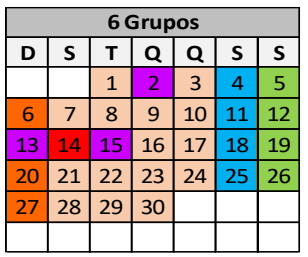

\begin{tabular}{|c|c|c|c|c|c|c|}
\hline \multicolumn{7}{|c|}{ 7 Grupos } \\
\hline D & S & T & $\mathbf{Q}$ & $\mathbf{Q}$ & $\mathbf{S}$ & $\mathbf{S}$ \\
\hline & & 1 & 2 & 3 & 4 & 5 \\
\hline 6 & 7 & 8 & 9 & 10 & 11 & 12 \\
\hline 13 & 14 & 15 & 16 & 17 & 18 & 19 \\
\hline 20 & 21 & 22 & 23 & 24 & 25 & 26 \\
\hline 27 & 28 & 29 & 30 & & & \\
\hline & & & & & & \\
\hline
\end{tabular}

Fonte: Elaborada pelo autor

Analisando os grupos formados a cada cenário, para 3 grupos, o G1 compreendeu os dias de segunda a sexta-feira, com exceção dos dois feriados (dias 2 e 15), o G2, os domingos e os feriados e o G3, os sábados. Nesse agrupamento, ficou evidente a separação dos dias entre fim de semana, feriado e dias úteis. Para 4 agrupamentos, as sextas-feiras formaram um grupo distinto (G4 - 4 grupos), separando-se do G1. Em 5 agrupamentos, o dia 14 (pré-feriado) foi isolado em um novo grupo (G5 - 5 grupos). Em 6 agrupamentos, os dois feriados e o dia 13 (domingo anterior ao feriado) formaram o novo grupo, G6. Por fim, em 7 agrupamentos, o dia 12, foi isolado no G7. Assim como no sentido Leste os grupos de dias típicos foi formado em 5 agrupamentos com os mesmos perfis, conforme apresentado na Figura 6-12. 
Figura 6-12 - Grupos formados para 5 agrupamentos com o $C A_{4}$ - Fluxo Oeste - Mesma época e local, via Marginal

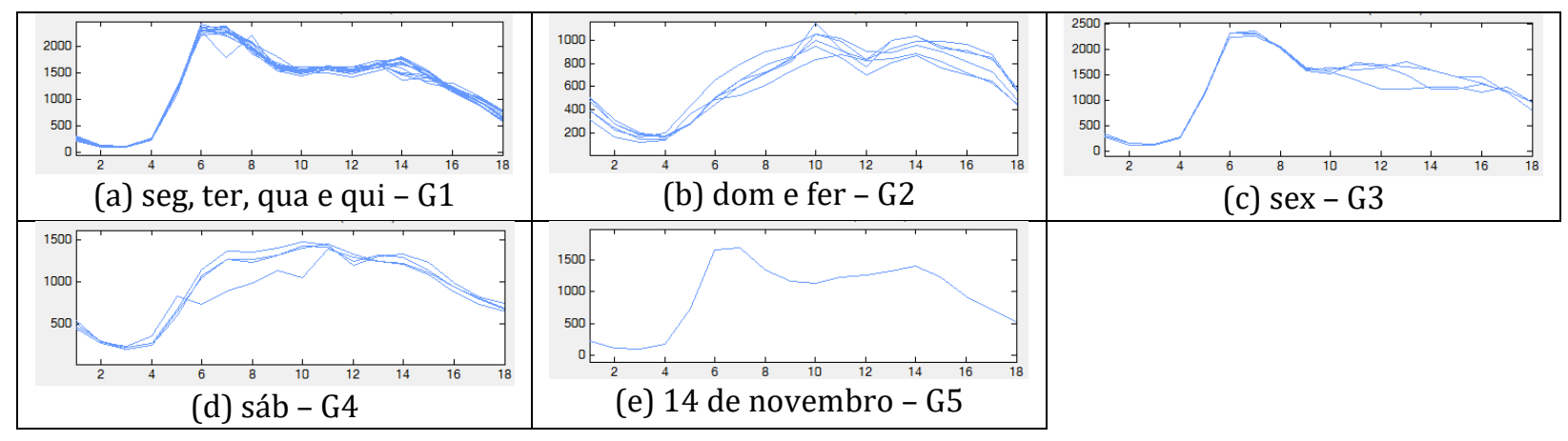

Fonte: Elaborada pelo autor

Apesar de definir os mesmos agrupamentos do sentido Leste, os perfis apresentados no sentido Oeste apresentaram características distintas para cada perfil. Por exemplo, o G1, foi formado por segundas, terças, quartas e quintas-feiras nos dois sentidos da rodovia, no entanto é nítida a diferença entre um perfil e outro. Nota-se que para o sentido Oeste (Figura 6-12 (a)) o pico ocorreu no ponto 6, que corresponde a aproximadamente às 8:00 da manhã, enquanto que no sentido Leste, o pico ocorreu no ponto 14 (Figura 6-10 (a)), que corresponde a aproximadamente às 18:00. 0 mesmo aconteceu para os outros grupos formados. Esses resultados evidenciam novamente, a influência do fluxo direcional nas variações horárias ao longo do dia.

Em seguida, foi realizada a análise de detecção de anomalia. As Tabela 6.11 e Tabela 6.12 apresentam a porcentagem do total de anomalias para os quatro primeiros níveis em cada tipo de dia para os dados de fluxo de tráfego e velocidade veicular, respectivamente, para a via marginal no sentido Oeste.

Tabela 6.11 - Frequência de anomalias encontradas por dia em cada nível investigado - Fluxo Oeste Mesma época e local, via Marginal

\begin{tabular}{lrrrrr}
\hline \multicolumn{1}{c}{ Dia } & Nível 1 (\%) & Nível 2 (\%) & Nível 3(\%) & Nível 4 (\%) & Média (\%) \\
\hline Feriado & 30.00 & 18.18 & 25.00 & 27.78 & $\mathbf{2 5 . 2 4}$ \\
Dom & 0.00 & 0.00 & 0.00 & 0.00 & $\mathbf{0 . 0 0}$ \\
Seg & 0.00 & 9.09 & 10.00 & 11.11 & $\mathbf{7 . 5 5}$ \\
Ter & 50.00 & 54.55 & 20.00 & 16.67 & $\mathbf{3 5 . 3 0}$ \\
Qua & 0.00 & 0.00 & 15.00 & 16.67 & $\mathbf{7 . 9 2}$ \\
Qui & 10.00 & 9.09 & 15.00 & 16.67 & $\mathbf{1 2 . 6 9}$ \\
Sex & 10.00 & 9.09 & 15.00 & 11.11 & $\mathbf{1 1 . 3 0}$ \\
Sáb & 0.00 & 0.00 & 0.00 & 0.00 & $\mathbf{0 . 0 0}$ \\
\hline
\end{tabular}

Fonte: Elaborada pelo autor 
Tabela 6.12 - Frequência de anomalias encontradas por dia em cada nível investigado - Velocidade Oeste - Mesma época e local, via Marginal

\begin{tabular}{lrrrrr}
\hline \multicolumn{1}{c}{ Dia } & Nível 1 (\%) & Nível 2 (\%) & Nível 3(\%) & Nível 4 (\%) & Média (\%) \\
\hline Feriado & 26.47 & 20.00 & 37.50 & 33.33 & $\mathbf{2 9 . 3 3}$ \\
Dom & 0.00 & 0.00 & 0.00 & 0.00 & $\mathbf{0 . 0 0}$ \\
Seg & 0.00 & 5.00 & 12.50 & 6.67 & $\mathbf{6 . 0 4}$ \\
Ter & 26.47 & 20.00 & 12.50 & 20.00 & $\mathbf{1 9 . 7 4}$ \\
Qua & 8.82 & 7.50 & 4.17 & 6.67 & $\mathbf{6 . 7 9}$ \\
Qui & 11.76 & 20.00 & 20.83 & 13.33 & $\mathbf{1 6 . 4 8}$ \\
Sex & 26.47 & 22.50 & 8.33 & 13.33 & $\mathbf{1 7 . 6 6}$ \\
Sáb & 0.00 & 5.00 & 4.17 & 6.67 & $\mathbf{3 . 9 6}$ \\
\hline
\end{tabular}

Fonte: Elaborada pelo autor

Nos dados de fluxo de tráfego no sentido Oeste da via marginal (Tabela 6.11), a maioria das anomalias foram detectadas nos dados de terça-feira (35,30\%), feriado $(25,24 \%)$, quinta-feira $(12,69 \%)$ e sexta-feira (11,30\%), totalizando $84,53 \%$. Esses resultados indicaram que assim como no sentido Leste, as anomalias também foram distribuídas durante a semana. 0 nível 8 não apresentou anomalia e o nível 11 apresentou uma, 15/11/2011 às 05:15, mostrando que a segunda semana do mês apresentou oscilação de maior frequência.

Assim como nos dados de fluxo de tráfego, as anomalias no sentido Oeste da via marginal nos dados de velocidade veicular (Tabela 6.12) também detectou anomalias ao longo da semana. A maioria das anomalias ocorreram no feriado $(29,33 \%)$, terça-feira $(19,74)$, sexta-feira $(17,66 \%)$ e quinta-feira $(16,48 \%)$, totalizando $83,21 \%$. No nível 8 não foram detectadas anomalias e no nível 11 foram duas, 22/11/2011 às 07:55 e $29 / 11 / 2011$ às 10:35, indicando que as duas últimas semanas do mês tiveram maior número de oscilações.

As análises tanto de reconhecimento de padrão quanto de detecção de anomalia na via marginal para os sentidos Leste e Oeste, utilizando os dados de fluxo e velocidade veicular, indicaram que o comportamento nesta situação foi influenciado pelo fluxo direcional. No entanto, ao contrário das análises realizadas na Rodovia Presidente Castelo Branco no km 51,9, as variações horárias sofreram maior influência do que as variações diárias ao longo da semana. A distribuição das anomalias ao longo da semana corrobora com esse resultado, pois não há concentração de anomalias em feriados ou em apenas um dia da semana. Isso reforça a importância da análise dos dados antes de qualquer aplicação dos dados históricos, pois qualquer mudança de característica da via resulta em um comportamento diferente que deve ser analisado com atenção. 


\subsubsection{Via expressa}

a) Sentido Leste: Após analisar a via marginal, foi aplicado o método para reconhecimento de padrões no sentido Leste da via expressa nos dados de fluxo de tráfego no mês de novembro de 2011. Os resultados são apresentados na Figura 6-13.

Figura 6-13 - Resultado das análises de agrupamento para o $C A_{4}$ - Fluxo Leste - Mesma época e local, Via Expressa

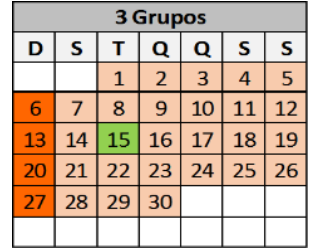

Legenda: $\square \mathbf{G 1}$

\begin{tabular}{|c|c|c|c|c|c|c|}
\hline \multicolumn{7}{|c|}{ 4 Grupos } \\
\hline D & S & T & Q & Q & S & S \\
\hline & & 1 & 2 & 3 & 4 & 5 \\
\hline 6 & 7 & 8 & 9 & 10 & 11 & 12 \\
\hline 13 & 14 & 15 & 16 & 17 & 18 & 19 \\
\hline 20 & 21 & 22 & 23 & 24 & 25 & 26 \\
\hline 27 & 28 & 29 & 30 & & & \\
\hline & & & & & & \\
\hline
\end{tabular}

G2.

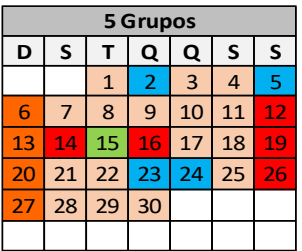

\begin{tabular}{|c|c|c|c|c|c|c|}
\hline \multicolumn{7}{|c|}{ 6 Grupos } \\
\hline D & S & T & $\mathbf{Q}$ & $\mathbf{Q}$ & $\mathbf{S}$ & $\mathbf{S}$ \\
\hline & & 1 & 2 & 3 & 4 & 5 \\
\hline 6 & 7 & 8 & 9 & 10 & 11 & 12 \\
\hline 13 & 14 & 15 & 16 & 17 & 18 & 19 \\
\hline 20 & 21 & 22 & 23 & 24 & 25 & 26 \\
\hline 27 & 28 & 29 & 30 & & & \\
\hline & & & & & & \\
\hline
\end{tabular}

\begin{tabular}{|c|c|c|c|c|c|c|}
\hline \multicolumn{7}{|c|}{ 7 Grupos } \\
\hline D & $\mathbf{S}$ & $\mathbf{T}$ & $\mathbf{Q}$ & $\mathbf{Q}$ & $\mathbf{S}$ & $\mathbf{S}$ \\
\hline & & 1 & 2 & 3 & 4 & 5 \\
\hline 6 & 7 & 8 & 9 & 10 & 11 & 12 \\
\hline 13 & 14 & 15 & 16 & 17 & 18 & 19 \\
\hline 20 & 21 & 22 & 23 & 24 & 25 & 26 \\
\hline 27 & 28 & 29 & 30 & & & \\
\hline & & & & & & \\
\hline
\end{tabular}

Fonte: Elaborada pelo autor

Analisando os grupos formados a cada cenário, notou-se que para 3 grupos, o G1 compreendeu os dias de segunda a sábado, com exceção do feriado no dia 15, o G2, os domingos e o G3, o feriado do dia 15. Em 4 agrupamentos, os dias 2, 5, 23 e 24 formaram um novo grupo (G4 - 4 grupos). Em 5 agrupamentos, os dias 14 (pré-feriado), 16 (pósferiado) e sábados (com exceção do dia 5) formaram o G5, indicando similaridade entre esses dias influenciados pelo feriado com os sábados. A partir de 6 agrupamentos, dias isolados formam novos grupos.

Esses resultados indicaram que os feriados apresentaram um comportamento distinto aos outros dias do mês. Atentou-se para o fato que desde 3 agrupamentos o feriado do dia 15 formou um grupo isolado e em 7 agrupamentos, o feriado do dia 2 acabou formando um grupo sozinho também. Observou-se também que os domingos apresentaram forte similaridade entre si, formando o mesmo grupo em todos os cenários. Devido à influência dos dois feriados e devido aos dias 5, 23 e 24 formarem um grupo isolado, definir um grupo distinto para cada tipo de dia de forma manual poderia se tornar uma tarefa difícil e suscetível a erros. No entanto, baseando-se nos agrupamentos obtidos a partir do quinto agrupamento foi possível identificar os dias úteis típicos com maior similaridade entre si que representam o mês em questão no tipo de via analisada, conforme Figura 6-14. 
Figura 6-14 - Grupos formados para 5 agrupamentos com o $C A_{4}$ - Fluxo Leste - Mesma época e local, Via Expressa

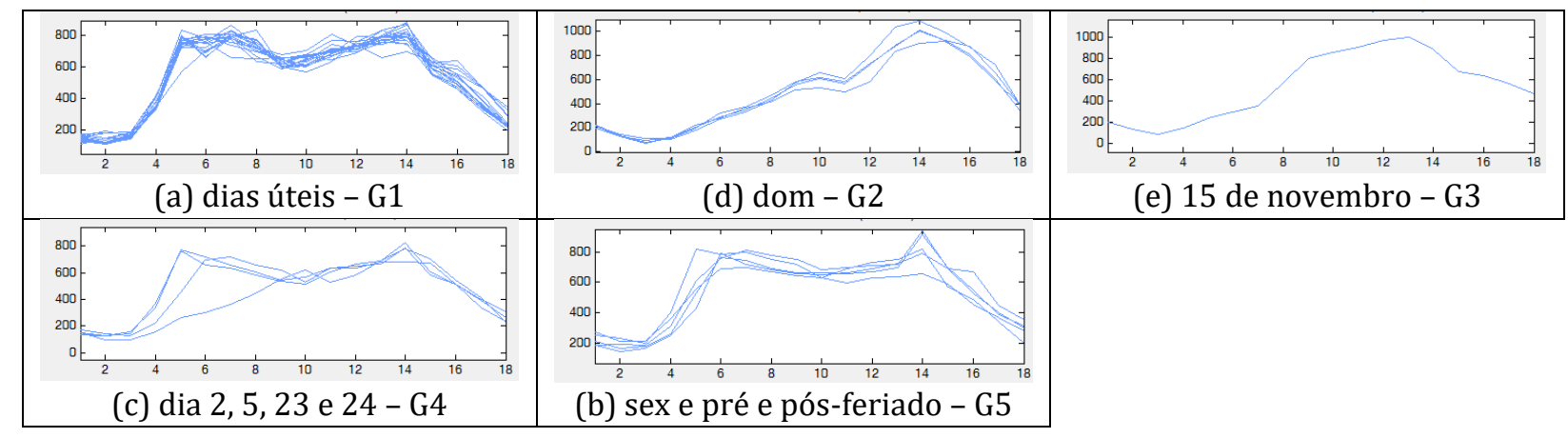

Fonte: Elaborada pelo autor

Analisando os resultados obtidos para o comportamento do tráfego no sentido Leste para a via expressa (Figura 6-14) e marginal (Figura 6-10), constatou-se que são perfis distintos entre si. Enquanto na via marginal o dia 14 de novembro (pré-feriado) se isolou em um grupo por ter um comportamento distinto do restante do mês, na via expressa foi o próprio feriado do dia 15 que apresentou um comportamento distinto. Além dos agrupamentos terem sido diferentes, o perfil de comportamento obtido para cada via também apresentou curvas distintas para as vias marginal e expressa.

Após aplicar o método de reconhecimento de padrões na via expressa no sentido Leste, foi realizada a análise de detecção de anomalia. As Tabela 6.13 e Tabela 6.14 apresentam a porcentagem do total de anomalias para os quatro primeiros níveis em cada tipo de dia para os dados de fluxo de tráfego e velocidade veicular, respectivamente.

Tabela 6.13 - Frequência de anomalias encontradas por dia em cada nível investigado - Fluxo Leste Mesma época e local, Via Expressa

\begin{tabular}{lrrrrr}
\hline \multicolumn{1}{r}{ Dia } & Nível 1 (\%) & Nível 2 (\%) & Nível 3(\%) & Nível 4 (\%) & Média (\%) \\
\hline Feriado & 50.00 & 25.00 & 25.00 & 0.00 & $\mathbf{2 5 . 0 0}$ \\
Dom & 0.00 & 0.00 & 0.00 & 0.00 & $\mathbf{0 . 0 0}$ \\
Seg & 0.00 & 0.00 & 0.00 & 0.00 & $\mathbf{0 . 0 0}$ \\
Ter & 12.50 & 25.00 & 25.00 & 100.00 & $\mathbf{4 0 . 6 3}$ \\
Qua & 37.50 & 50.00 & 25.00 & 0.00 & $\mathbf{2 8 . 1 3}$ \\
Qui & 0.00 & 0.00 & 25.00 & 0.00 & $\mathbf{6 . 2 5}$ \\
Sex & 0.00 & 0.00 & 0.00 & 0.00 & $\mathbf{0 . 0 0}$ \\
Sáb & 0.00 & 0.00 & 0.00 & 0.00 & $\mathbf{0 . 0 0}$ \\
\hline
\end{tabular}

Fonte: Elaborada pelo autor 
Tabela 6.14 - Frequência de anomalias encontradas por dia em cada nível investigado - Velocidade Leste - Mesma época e local, Via Expressa

\begin{tabular}{lrrrrr}
\hline \multicolumn{1}{r}{ Dia } & Nível 1 (\%) & Nível 2 (\%) & Nível 3(\%) & Nível 4 (\%) & Média (\%) \\
\hline Feriado & 38.46 & 42.86 & 20.00 & 0.00 & $\mathbf{2 5 . 3 3}$ \\
Dom & 7.69 & 0.00 & 0.00 & 0.00 & $\mathbf{1 . 9 2}$ \\
Seg & 0.00 & 0.00 & 0.00 & 0.00 & $\mathbf{0 . 0 0}$ \\
Ter & 23.08 & 28.57 & 80.00 & 100.00 & $\mathbf{5 7 . 9 1}$ \\
Qua & 15.38 & 14.29 & 0.00 & 0.00 & $\mathbf{7 . 4 2}$ \\
Qui & 7.69 & 0.00 & 0.00 & 0.00 & $\mathbf{1 . 9 2}$ \\
Sex & 7.69 & 0.00 & 0.00 & 0.00 & $\mathbf{1 . 9 2}$ \\
Sáb & 0.00 & 14.29 & 0.00 & 0.00 & $\mathbf{3 . 5 7}$ \\
\hline
\end{tabular}

Fonte: Elaborada pelo autor

Nos dados de fluxo de tráfego no sentido Leste da via expressa, as anomalias se concentraram na terça-feira $(40,63 \%)$, quarta-feira $(28,13 \%)$ e feriado $(25,00 \%)$, totalizando 93,76\%. Não foram detectadas anomalias nos níveis 8 e 11 .

Nos dados de velocidade, as anomalias concentraram-se nas terças-feiras $(57,91 \%)$ e feriados $(25,33 \%)$, totalizando $83,24 \%$. No nível 8 foi detectada uma anomalia na terçafeira (08/11/2011 às 23:55), indicando que o dia 8 apresentou maior oscilação de frequência em relação aos outros dias do mês de novembro. No nível 11, foram detectadas duas anomalias, 22/11/2011 às 07:55 e 29/11/2011 às 10:35, indicando que as duas últimas semanas do mês tiveram maior oscilação de frequência. Esses resultados indicaram que ao contrário da via marginal, a via expressa concentrou as oscilações tanto de fluxo de tráfego quanto de velocidade, no meio da semana (terça e quarta-feira) e no feriado.

b) Sentido Oeste: Após analisar os dados do sentido Leste, foi aplicado o método para reconhecimento de padrões no sentido Oeste da via expressa nos dados de fluxo de tráfego no mês de novembro de 2011. Os resultados são apresentados na Figura 6-15.

Figura 6-15 - Resultado das análises de agrupamento para o $C A_{4}$ - Fluxo Oeste - Mesma época e local, Via Expressa
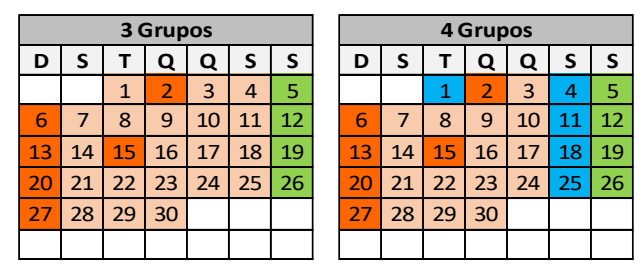
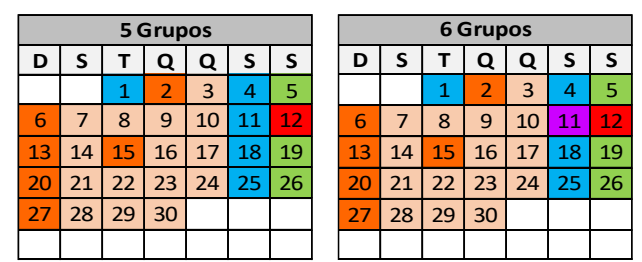

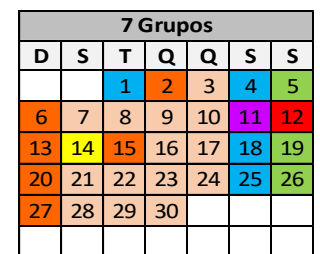

Legenda: \begin{tabular}{|l|l|l|}
\hline & $\mathbf{G 1}$ \\
\hline & $\mathbf{G} 2$ \\
\hline
\end{tabular}

G3

G4.

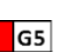

G6

G7

Fonte: Elaborada pelo autor 
Analisando os grupos formados, foi possível observar que para 3 grupos, o G1 compreendeu os dias de segunda à sexta-feira, com exceção dos feriados no dia 2 e 15, o G2, os domingos e os feriados e o G3, os sábados. Nesse agrupamento, fica evidente a separação dos dias entre fim de semana, feriado e dias úteis. Para 4 grupos, as sextasfeiras e o dia 1 (pré-feriado) formaram um novo grupo. A partir de 5 agrupamentos, cada novo grupo formado continha apenas um dia: dia 12 no G5, dia 11 no G6 e dia 14 (préferiado) no G7. Esses três dias foram influenciados pelo feriado do dia 15 de acordo com os critérios de Cunha (2007).

Os resultados indicaram que os domingos, sextas-feiras e sábados formaram grupos distintos com boa similaridade entre os dias que os compunham, pois mantiveram-se em diferentes cenários. Os feriados apresentaram comportamento de tráfego similar aos domingos, pois também se manteve em todos os agrupamentos. Já os dias úteis típicos podem ser definido pelo grupo G1 de cinco agrupamentos, formado pelas segundas, terças, quartas e quintas-feiras, pois foi composto pelos mesmos dias em todos os cenários, com exceção dos feriados e pré-feriados, indicando também forte similaridade entre os dias que o formavam. Baseando-se nisso, a Figura 6-16 apresenta o perfil dos grupos formados.

Figura 6-16 - Grupos formados para 5 agrupamentos com o $C A_{4}$ - Fluxo Oeste - Mesma época e local, Via Expressa

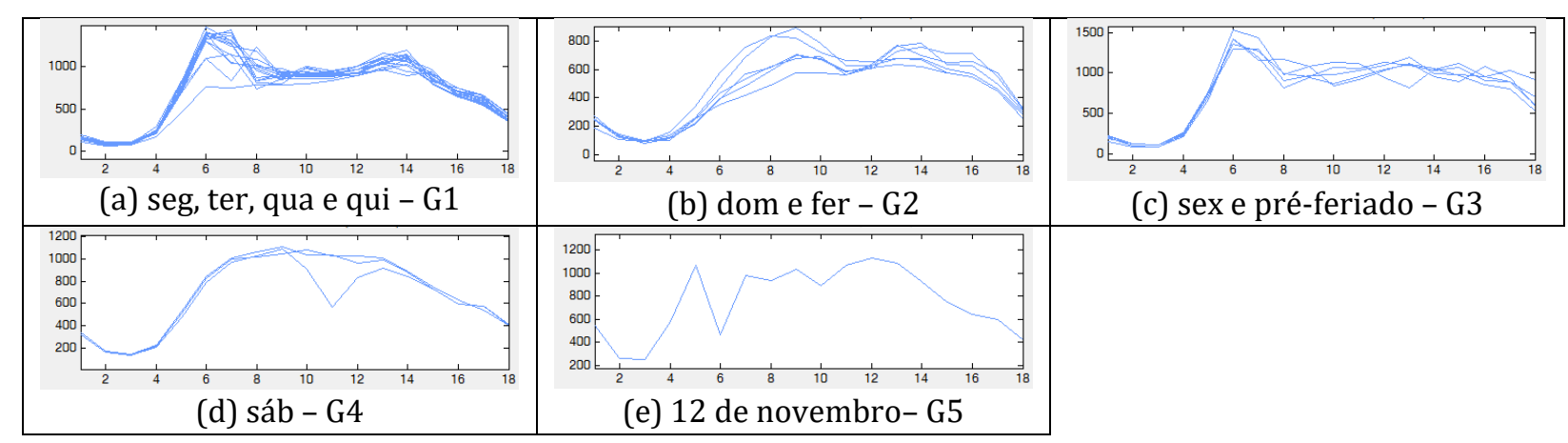

Fonte: Elaborada pelo autor

Para encerrar as análises na via expressa, foi realizada a análise de detecção de anomalia no sentido Oeste. As Tabela 6.15 e Tabela 6.16 apresentam a porcentagem do total de anomalias para os quatro primeiros níveis em cada tipo de dia para os dados de fluxo de tráfego e velocidade veicular. 
Tabela 6.15 - Frequência de anomalias encontradas por dia em cada nível investigado - Fluxo Oeste Mesma época e local, Via Expressa

\begin{tabular}{lrrrrr}
\hline \multicolumn{1}{r}{ Dia } & Nível 1 (\%) & Nível 2 (\%) & Nível 3(\%) & Nível 4 (\%) & Média (\%) \\
\hline Feriado & 54.55 & 50.00 & 42.86 & 0.00 & $\mathbf{3 6 . 8 5}$ \\
Dom & 0.00 & 0.00 & 0.00 & 0.00 & $\mathbf{0 . 0 0}$ \\
Seg & 0.00 & 0.00 & 14.29 & 0.00 & $\mathbf{3 . 5 7}$ \\
Ter & 13.64 & 8.33 & 28.57 & 50.00 & $\mathbf{2 5 . 1 4}$ \\
Qua & 0.00 & 0.00 & 0.00 & 0.00 & $\mathbf{0 . 0 0}$ \\
Qui & 9.09 & 8.33 & 14.29 & 50.00 & $\mathbf{2 0 . 4 3}$ \\
Sex & 18.18 & 16.67 & 0.00 & 0.00 & $\mathbf{8 . 7 1}$ \\
Sáb & 4.55 & 16.67 & 0.00 & 0.00 & $\mathbf{5 . 3 0}$ \\
\hline
\end{tabular}

Fonte: Elaborada pelo autor

Tabela 6.16 - Frequência de anomalias encontradas por dia em cada nível investigado - Velocidade Oeste - Mesma época e local, Via Expressa

\begin{tabular}{lrrrrr}
\hline \multicolumn{1}{r}{ Dia } & Nível 1 (\%) & Nível 2 (\%) & Nível 3(\%) & Nível 4 (\%) & Média (\%) \\
\hline Feriado & 26.47 & 18.52 & 30.00 & 41.67 & $\mathbf{2 9 . 1 6}$ \\
Dom & 0.00 & 0.00 & 0.00 & 0.00 & $\mathbf{0 . 0 0}$ \\
Seg & 2.94 & 0.00 & 0.00 & 0.00 & $\mathbf{0 . 7 4}$ \\
Ter & 26.47 & 18.52 & 25.00 & 25.00 & $\mathbf{2 3 . 7 5}$ \\
Qua & 2.94 & 0.00 & 0.00 & 0.00 & $\mathbf{0 . 7 4}$ \\
Qui & 14.71 & 33.33 & 25.00 & 8.33 & $\mathbf{2 0 . 3 4}$ \\
Sex & 20.59 & 22.22 & 10.00 & 16.67 & $\mathbf{1 7 . 3 7}$ \\
Sáb & 5.88 & 7.41 & 10.00 & 8.33 & $\mathbf{7 . 9 1}$ \\
\hline
\end{tabular}

Fonte: Elaborada pelo autor

Nos dados de fluxo de tráfego no sentido Oeste da via expressa, as anomalias se concentraram no feriado (36,85\%), terça-feira $(25,14 \%)$ e quinta-feira $(20,43 \%)$, totalizando 82,42\%. 0 nível 8 não apresentou anomalia, enquanto o nível 11 detectou duas, 15/11/2011 às 05:15 e 29/11/2011 às 10:35, indicando maior oscilação nesse sinal para a segunda e quarta semana do mês.

Nos dados de velocidade, as anomalias concentraram-se no feriado $(29,16 \%)$, terçafeira $(23,75 \%)$ e quinta-feira $(20,34)$, totalizando $73,25 \%$. A distribuição de anomalia para os dados de velocidade foi similar aos dados de fluxo de tráfego para os quatro primeiros níveis. No nível 8 foi detectada uma anomalia, 06/11/2011 às 07:55, indicando que foi o dia que apresentou mais oscilações no mês de novembro e no nível 11, não foram detectadas anomalias.

Comparando-se os resultados obtidos pelos dois métodos para as vias marginal e expressa, constatou-se que, apesar de serem no mesmo local e período, apresentaram comportamento e distribuição de anomalias diferentes. A partir desse resultado, é valido salientar a importância de construir uma análise dos dados históricos e ilustrar a 
complementação de um método no outro.

\subsection{TIPO DE VEÍCULO}

Buscando validar o método de reconhecimento de padrões e detecção de anomalias para outra composição de tráfego veicular, a presente seção analisa e discute os resultados obtidos para a aplicação do método em função da categoria do veículo: automóvel, caminhão e moto. Assim como nos Capítulos 4 e 5, o local analisado foi a Rodovia Presidente Castelo Branco no km 51,9 e o período analisado foi o mês de março de 2012 por não ter ocorrido feriado. A seguir, os resultados são apresentados por subseções que apresentam cada tipo de veículo, iniciando pelo automóvel, seguido pelo caminhão e por fim para a moto, no sentido Leste e Oeste para as três composições.

\subsubsection{Automóvel}

\section{Leste}

Primeiro foi aplicado o método para reconhecer padrões no fluxo de tráfego. A Figura 6-17 apresenta os grupos formados pelo Coeficiente de Aproximação no nível 4 no mês de março de 2012 no sentido Leste para a composição de tráfego formada por automóveis.

Figura 6-17 -- Resultado das análises de agrupamento para o $C A_{4}$ - Fluxo Leste - Automóvel

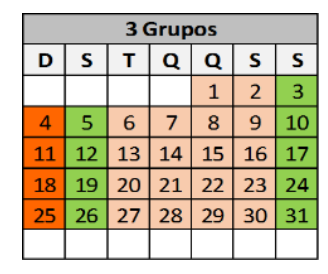

Legenda: \begin{tabular}{ll|l|l|}
$\square$ & $\mathbf{G 1}$ \\
$\square$ & $\mathbf{G} 2$
\end{tabular}
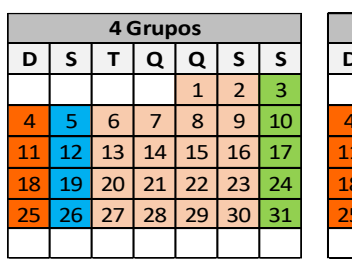
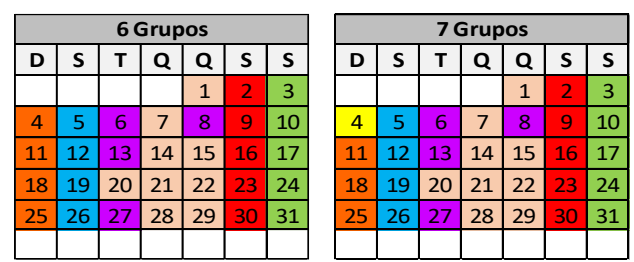

\section{\begin{tabular}{|l|l|l|l|l|l|l|l|l|l|}
\hline & G5 & $\square$ & G6 \\
\hline
\end{tabular}}

Fonte: Elaborada pelo autor

Analisando os grupos formados a cada cenário, notou-se que para 3 grupos, o G1 compreende os dias de terça à sexta-feira, o G2 os domingos e o G3, as segundas-feiras e sábados. No entanto, em 4 agrupamentos, as segundas-feiras (G4) formaram um grupo 
distinto (G4 - 4 grupos), separando-se dos sábados. Para o cenário de 5 grupos as sextasfeiras formamG5. Em 6 agrupamentos, as terças-feiras formaram o G6 e em 7 agrupamentos, o dia 4 é isolado em um novo grupo (G7 - 7 grupos). Esses agrupamentos indicam forte similaridade no grupo de segundas-feiras, sextas-feiras e sábados, pois assim que esses grupos foram formados, mantiveram-se sem alteração até 7 agrupamentos. Os domingos também apresentaram forte similaridade, pois mantiveramse em um único cluster de 3 a 6 agrupamentos. Baseado nessas semelhanças os dias típicos foram definidos com 5 clusters, apresentados na Figura 6-18. Ao analisar os perfis formados, confirma-se a similaridade em cada perfil e se nota similaridade com a composição de todos os veículos para o mesmo período (Figura 4-10).

Figura 6-18 - Grupos formados para 5 agrupamentos com o $C A_{4}$ - Fluxo Leste - Automóvel

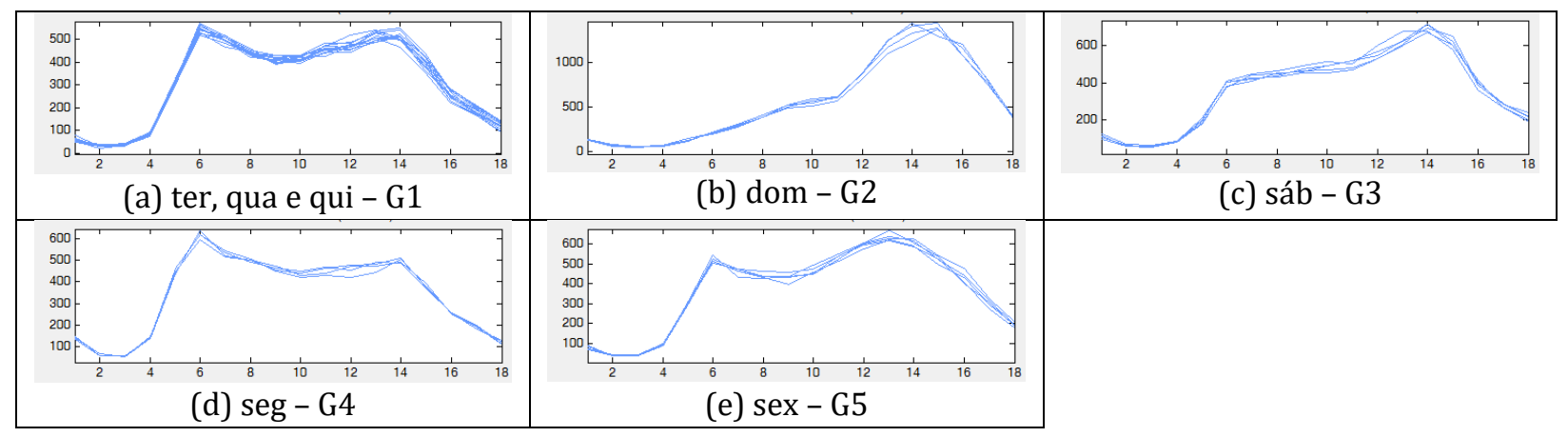

Fonte: Elaborada pelo autor

Após analisar o reconhecimento de padrões, foi aplicado o método para detectar anomalias nos dados de tráfego do automóvel. Os resultados obtidos são apresentados na Tabela 6.17 e Tabela 6.18, que apresentam a porcentagem do total de anomalias para os quatro primeiros níveis em cada tipo de dia para os dados de fluxo de tráfego e velocidade veicular, respectivamente.

Tabela 6.17 - Frequência de anomalias encontradas por dia em cada nível investigado - Fluxo Leste Automóvel

\begin{tabular}{lrrrrr}
\hline \multicolumn{1}{c}{ Dia } & Nível 1 (\%) & Nível 2 (\%) & Nível 3(\%) & Nível 4 (\%) & Média (\%) \\
\hline Feriado & 0.00 & 0.00 & 0.00 & 0.00 & $\mathbf{0 . 0 0}$ \\
Dom & 87.50 & 100.00 & 100.00 & 0.00 & $\mathbf{9 5 . 8 3}$ \\
Seg & 0.00 & 0.00 & 0.00 & 0.00 & $\mathbf{0 . 0 0}$ \\
Ter & 0.00 & 0.00 & 0.00 & 0.00 & $\mathbf{0 . 0 0}$ \\
Qua & 12.50 & 0.00 & 0.00 & 0.00 & $\mathbf{4 . 1 7}$ \\
Qui & 0.00 & 0.00 & 0.00 & 0.00 & $\mathbf{0 . 0 0}$ \\
Sex & 0.00 & 0.00 & 0.00 & 0.00 & $\mathbf{0 . 0 0}$ \\
Sáb & 0.00 & 0.00 & 0.00 & 0.00 & $\mathbf{0 . 0 0}$ \\
\hline
\end{tabular}


Tabela 6.18 - Frequência de anomalias encontradas por dia em cada nível investigado - Velocidade Leste - Automóvel

\begin{tabular}{lrrrrr}
\hline \multicolumn{1}{r}{ Dia } & Nível 1 (\%) & Nível 2 (\%) & Nível 3(\%) & Nível 4 (\%) & Média (\%) \\
\hline Feriado & 0.00 & 0.00 & 0.00 & 0.00 & $\mathbf{0 . 0 0}$ \\
Dom & 30.77 & 40.00 & 58.33 & 83.33 & $\mathbf{5 3 . 1 1}$ \\
Seg & 0.00 & 0.00 & 0.00 & 0.00 & $\mathbf{0 . 0 0}$ \\
Ter & 7.69 & 15.00 & 0.00 & 0.00 & $\mathbf{5 . 6 7}$ \\
Qua & 11.54 & 10.00 & 8.33 & 16.67 & $\mathbf{1 1 . 6 3}$ \\
Qui & 30.77 & 10.00 & 25.00 & 0.00 & $\mathbf{1 6 . 4 4}$ \\
Sex & 15.38 & 20.00 & 0.00 & 0.00 & $\mathbf{8 . 8 5}$ \\
Sáb & 3.85 & 5.00 & 8.33 & 0.00 & $\mathbf{4 . 2 9}$ \\
\hline
\end{tabular}

Fonte: Elaborada pelo autor

Ao analisar os dados de fluxo de tráfego no sentido Leste dos automóveis (Tabela 6.17) foi notado que as anomalias se concentraram principalmente aos domingos, chegando a representar $95,83 \%$ das anomalias detectadas, os outros 4,17\% foram registrados na quarta-feira. Isso indica que em relação ao fluxo de tráfego, os automóveis apresentam oscilações basicamente aos domingos, apontando esse dia como um dia crítico em relação aos outros dias da semana.

Por sua vez, os dados de velocidade veicular no sentido Leste dos automóveis (Tabela 6.18) igualmente indicaram maior concentração de anomalias aos domingos $(53,11 \%)$, porém os dias úteis também apresentaram parcela representativa: quinta-feira $(16,44 \%)$, quarta-feira $(11,63 \%)$, sexta-feira $(8,85 \%)$ e terça-feira $(5,67 \%)$, totalizando $42,58 \%$.

Nos níveis 8 e 11 não foram detectadas nenhuma anomalia nos dados de fluxo de tráfego e velocidade veicular, indicando que para a composição de automóveis, não ocorrem oscilações destoante aos outros dias ou semanas do sinal analisado.

\section{Oeste}

Após analisar o sentido Leste, foi aplicado o método para reconhecer padrões no fluxo de tráfego no sentido Oeste. A Figura 6-19 apresenta os grupos formados pelo Coeficiente de Aproximação no nível 4 para o mês de março de 2012 para a composição de tráfego formada por automóveis. 
Figura 6-19 - Resultado das análises de agrupamento para o $C A_{4}$ - Fluxo Oeste - Automóvel

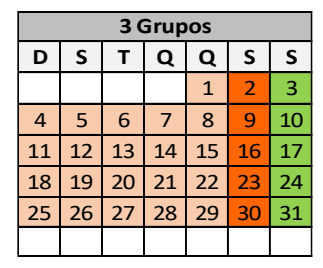

Legenda: $\square \mid \mathbf{G 1} \square \mathbf{G 2}$

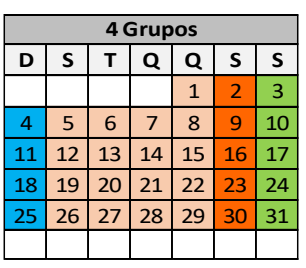

2

$\mid \mathbf{G 3}^{3}$

64

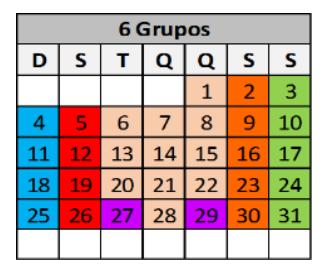

Fonte: Elaborada pelo autor

Analisando os grupos formados, nota-se que para 3 grupos, o G1 compreende os dias de domingo à quinta-feira, o G2 as sextas-feiras e o G3, os sábados. Para 4 grupos os domingos (G4 - 4 grupos) formaram um grupo distinto, separando-se do G1. Em seguida, no cenário de 5 grupos, as segundas-feiras formaram o G5, separando-se do G1. Notou-se que a partir de seis agrupamentos a tendência foi separar, em grupos isolados, os dias 27 e 29 (G6 - 6 grupos) e o dia 9 (G7 - 7 grupos). Esses resultados indicam que o comportamento do tráfego de automóveis apresenta um perfil bem definido a cada tipo de dia, favorecendo para determinar os dias típicos do fluxo de tráfego. Com base nas similaridades apresentadas nos cenários analisados, há evidências que cinco grupos seja a melhor opção para definir os dias típicos de tráfego. Baseado nesta hipótese, a Figura 6-20 ilustra os perfis dos padrões de tráfego formados. Ao analisar os perfis formados, é nítida a similaridade entre os dias a cada perfil.

Figura 6-20 - Grupos formados para 5 agrupamentos com o $C A_{4}$ - Fluxo Oeste - Automóvel

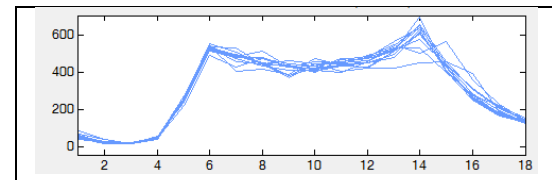

(a) ter, qua e qui - G1

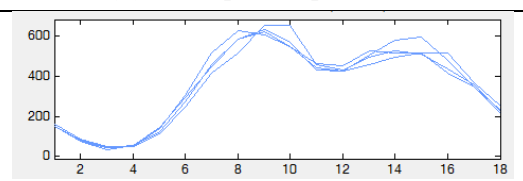

(d) dom - G4

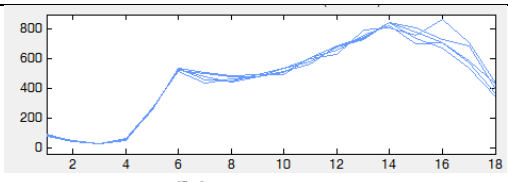

(b) sex - G2

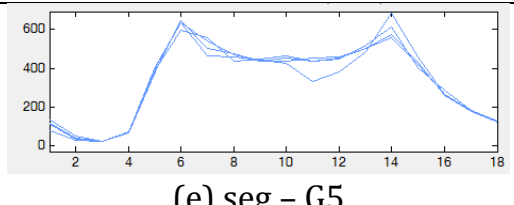

(e) seg - G5

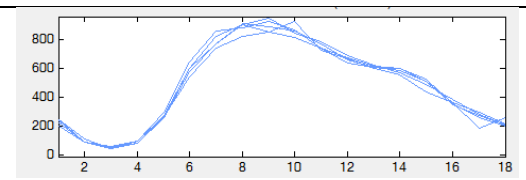

(c) sáb - G3

Fonte: Elaborada pelo autor

Após analisar o reconhecimento de padrões nos dados de fluxo de tráfego para os automóveis no sentido Oeste, foi aplicado o método para detectar anomalias. Os resultados obtidos são apresentados na Tabela 6.19 e Tabela 6.20, que apresentam a porcentagem do total de anomalias para os quatro primeiros níveis em cada tipo de dia 
para os dados de fluxo de tráfego e velocidade veicular, respectivamente.

Tabela 6.19 - Frequência de anomalias encontradas por dia em cada nível investigado - Fluxo Oeste Automóvel

\begin{tabular}{lrrrrr}
\hline \multicolumn{1}{r}{ Dia } & Nível 1 (\%) & Nível 2 (\%) & Nível 3(\%) & Nível 4 (\%) & Média (\%) \\
\hline Feriado & 0.00 & 0.00 & 0.00 & 0.00 & $\mathbf{0 . 0 0}$ \\
Dom & 0.00 & 0.00 & 40.00 & 0.00 & $\mathbf{1 0 . 0 0}$ \\
Seg & 12.50 & 0.00 & 0.00 & 66.67 & $\mathbf{1 9 . 7 9}$ \\
Ter & 12.50 & 0.00 & 0.00 & 0.00 & $\mathbf{3 . 1 3}$ \\
Qua & 0.00 & 0.00 & 0.00 & 0.00 & $\mathbf{0 . 0 0}$ \\
Qui & 12.50 & 16.67 & 40.00 & 0.00 & $\mathbf{1 7 . 2 9}$ \\
Sex & 37.50 & 66.67 & 20.00 & 0.00 & $\mathbf{3 1 . 0 4}$ \\
Sáb & 25.00 & 16.67 & 0.00 & 33.33 & $\mathbf{1 8 . 7 5}$ \\
\hline
\end{tabular}

Fonte: Elaborada pelo autor

Tabela 6.20 - Frequência de anomalias encontradas por dia em cada nível investigado - Velocidade Oeste - Automóvel

\begin{tabular}{lrrrrr}
\hline \multicolumn{1}{r}{ Dia } & Nível 1 (\%) & Nível 2 (\%) & Nível 3(\%) & Nível 4 (\%) & Média (\%) \\
\hline Feriado & 0.00 & 0.00 & 0.00 & 0.00 & $\mathbf{0 . 0 0}$ \\
Dom & 0.00 & 0.00 & 0.00 & 0.00 & $\mathbf{0 . 0 0}$ \\
Seg & 22.22 & 35.29 & 6.67 & 25.00 & $\mathbf{2 2 . 3 0}$ \\
Ter & 25.93 & 29.41 & 26.67 & 25.00 & $\mathbf{2 6 . 7 5}$ \\
Qua & 11.11 & 0.00 & 0.00 & 0.00 & $\mathbf{2 . 7 8}$ \\
Qui & 14.81 & 5.88 & 20.00 & 12.50 & $\mathbf{1 3 . 3 0}$ \\
Sex & 14.81 & 23.53 & 26.67 & 12.50 & $\mathbf{1 9 . 3 8}$ \\
Sáb & 11.11 & 5.88 & 20.00 & 25.00 & $\mathbf{1 5 . 5 0}$ \\
\hline
\end{tabular}

Fonte: Elaborada pelo autor

Ao contrário do sentido Leste, as anomalias no fluxo de tráfego dos automóveis (Tabela 6.19), ficaram distribuídas entre a sexta-feira (31,04\%), segunda-feira $(19,79 \%)$, sábado $(18,75 \%)$ e quinta-feira $(17,29 \%)$, totalizando $86,87 \%$, enquanto o domingo detectou apenas 10\%. Por sua vez, os dados de velocidade veicular (Tabela 6.20), não detectou nenhuma anomalia no domingo, mas detectou as anomalias distribuídas ao longo da semana, com uma concentração maior nas terças-feiras $(26,75 \%)$ e segundasfeiras (22,30\%). Os níveis 8 e 11 não detectaram anomalias no sentido Oeste, indicando que em ambos os sentidos da rodovia, a composição do tráfego formada apenas por automóveis, não sofre oscilações destoante aos outros dias ou semanas do mês analisado.

De maneira geral, os resultados da análise exploratória para a composição dos automóveis indicaram que foi mantido um padrão bem definido para cada perfil de dia típico, pois até mesmo a análise de anomalias foi distribuída ao longo da semana, denotando a complementação do método de reconhecimento de padrões no de detecção de anomalias. 


\subsubsection{Caminhão}

\section{Leste}

$\mathrm{Na}$ análise para a composição de tráfego formada por caminhões, primeiro foi aplicado o método para reconhecer padrões no fluxo de tráfego. A Figura 6-21 apresenta os grupos formados pelo Coeficiente de Aproximação no nível 4 para o mês de março de 2012 no sentido Leste.

Figura 6-21 - Resultado das análises de agrupamento para o $C A_{4}$ - Fluxo Leste - Caminhão

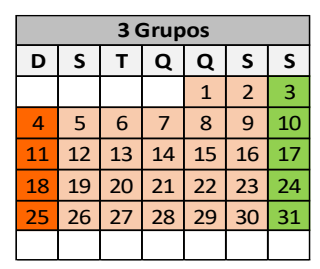

Legenda: $\square$ G1

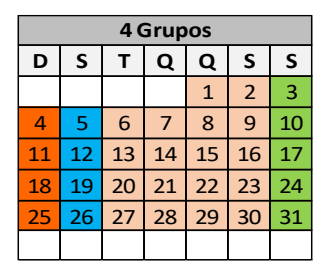

G2.

\begin{tabular}{|l|l|}
\hline & $\mathbf{G}$ \\
\hline
\end{tabular}
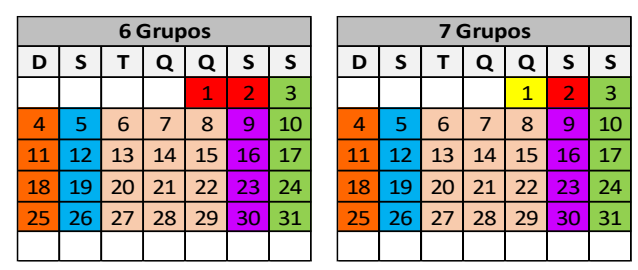

Analisando os grupos formados, nota-se que para 3 grupos, o G1 compreende os dias de segunda à sexta-feira, o G2 os domingos e o G3, os sábados. Essa configuração apresenta os grupos separados por fins de semana (G2 e G3) e dias úteis (G1). Já para 4 agrupamentos, as segundas-feiras formaram um novo grupo (G4), separando-se do grupo de dias úteis (G1 - 4 grupos). Em seguida, os dias 1 e 2 se isolaram em um novo grupo no G5 para 5 agrupamentos. Em 6 agrupamentos as sextas-feiras, com exceção do dia 2, formaram o G6 e o dia 1 foi isolado em um novo grupo no G7 de 7 agrupamentos, deixando assim tanto o dia 1 quanto o dia 2 em grupos isolados.

Foi observado que em seis cenários, apesar dos dias 1 e 2 estarem em um grupo isolado, é possível reconhecer perfis típicos do tráfego. A Figura 6-22 ilustra o padrão do tráfego para os seis grupos formados. 
Figura 6-22 - Grupos formados para 6 agrupamentos com o $C A_{4}$ - Fluxo Leste - Caminhão

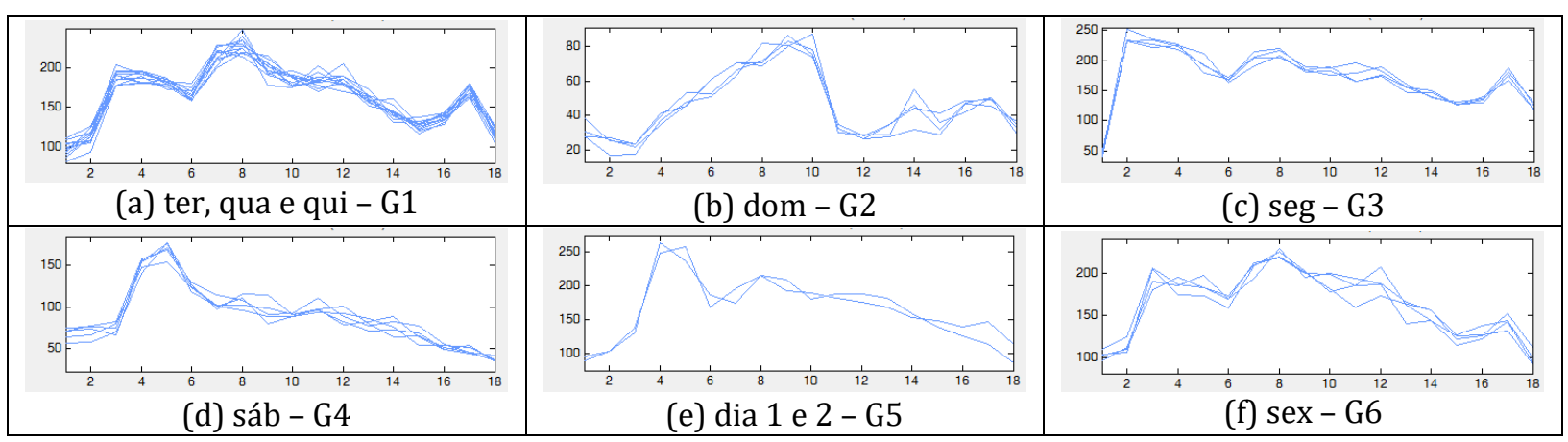

Fonte: Elaborada pelo autor

Ao analisar os perfis formados, notou-se que os perfis do comportamento do tráfego de caminhões são nitidamente distintos aos perfis do comportamento de automóveis (Figura 6.18) e de todos os veículos (Figura 4.10). Esses resultados indicam o fluxo de caminhões apresenta um comportamento diferente ao comportamento de automóveis ou em comparação a somatória de todos os veículos.

Após analisar o reconhecimento de padrões foi aplicado o método para detectar anomalias nos dados na composição de tráfego do caminhão. Os resultados obtidos são apresentados na Tabela 6.21e Tabela 6.22, que apresentam a porcentagem do total de anomalias para os quatro primeiros níveis em cada tipo de dia para os dados de fluxo de tráfego e velocidade veicular, respectivamente.

Tabela 6.21 - Frequência de anomalias encontradas por dia em cada nível investigado - Fluxo Leste Caminhão

\begin{tabular}{lrrrrr}
\hline \multicolumn{1}{c}{ Dia } & Nível 1 (\%) & Nível 2 (\%) & Nível 3(\%) & Nível 4 (\%) & Média (\%) \\
\hline Feriado & 0.00 & 0.00 & 0.00 & 0.00 & $\mathbf{0 . 0 0}$ \\
Dom & 0.00 & 0.00 & 0.00 & 0.00 & $\mathbf{0 . 0 0}$ \\
Seg & 100.00 & 100.00 & 0.00 & 0.00 & $\mathbf{5 0 . 0 0}$ \\
Ter & 0.00 & 0.00 & 0.00 & 0.00 & $\mathbf{0 . 0 0}$ \\
Qua & 0.00 & 0.00 & 0.00 & 25.00 & $\mathbf{6 . 2 5}$ \\
Qui & 0.00 & 0.00 & 0.00 & 75.00 & $\mathbf{1 8 . 7 5}$ \\
Sex & 0.00 & 0.00 & 100.00 & 0.00 & $\mathbf{2 5 . 0 0}$ \\
Sáb & 0.00 & 0.00 & 0.00 & 0.00 & $\mathbf{0 . 0 0}$ \\
\hline
\end{tabular}

Fonte: Elaborada pelo autor 
Tabela 6.22 - Frequência de anomalias encontradas por dia em cada nível investigado - Fluxo Leste Caminhão

\begin{tabular}{lrrrrr}
\hline Dia & Nível 1 (\%) & Nível 2 (\%) & Nível 3(\%) & Nível 4 (\%) & Média (\%) \\
\hline Feriado & 0.00 & 0.00 & 0.00 & 0.00 & 0.00 \\
Dom & 100.00 & 100.00 & 100.00 & 100.00 & 100.00 \\
Seg & 0.00 & 0.00 & 0.00 & 0.00 & 0.00 \\
Ter & 0.00 & 0.00 & 0.00 & 0.00 & 0.00 \\
Qua & 0.00 & 0.00 & 0.00 & 0.00 & 0.00 \\
Qui & 0.00 & 0.00 & 0.00 & 0.00 & 0.00 \\
Sex & 0.00 & 0.00 & 0.00 & 0.00 & 0.00 \\
Sáb & 0.00 & 0.00 & 0.00 & 0.00 & 0.00 \\
\hline
\end{tabular}

Fonte: Elaborada pelo autor

Ao analisar os dados de fluxo de tráfego no sentido Leste dos caminhões (Tabela 6.21) foi observado que $50 \%$ das anomalias ocorreram aos domingos, e os outros $50 \%$ entre sexta (25,00\%), quinta $(18,75 \%)$ e quarta-feira $(6,25 \%)$. Já nos dados de velocidade veicular (Tabela 6.22) todas as anomalias ocorreram no domingo. Portanto, para o tráfego dos caminhões, as sextas-feiras, início do final de semana e os domingos foram os que apresentaram oscilações acima do valor limiar para o mês de março de 2012.

No nível 8, os dados de fluxo de tráfego detectaram uma anomalia na segunda-feira: 05/03/2012 às 10:35, assim como os dados de velocidade: 12/03/2012 às 13:15. No entanto, como a janela de tempo no nível 8 corresponde a 21 horas e 40 minutos, essas anomalias tiveram início no período da noite no domingo e encerraram no período da manhã na segunda-feira, indicando esse período como o mais ocioso para o comportamento do tráfego dos caminhões nessa escala. No nível 11, apenas os dados de fluxo de tráfego detectaram anomalias: 22/03/2012 às 07:55 e 29/03/2012 às 10:35, indicando que as duas últimas semanas foram as que apresentaram maiores oscilações.

\section{Oeste}

Após analisar o sentido Leste, foi aplicado o método para reconhecer padrões no fluxo de tráfego no sentido Oeste. A Figura 6-23 apresenta os grupos formados pelo Coeficiente de Aproximação no nível 4 para o mês de março de 2012 na composição de tráfego formada pelos caminhões. 
Figura 6-23 - Resultado das análises de agrupamento para o $C A_{4}$ - Fluxo Oeste - Caminhão

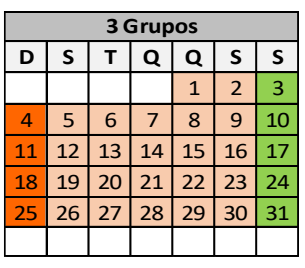

Legenda: \begin{tabular}{|l|l|l|}
\hline & $\mathbf{G 1}$ \\
\hline & $\mathbf{G} 2$ \\
\hline
\end{tabular}

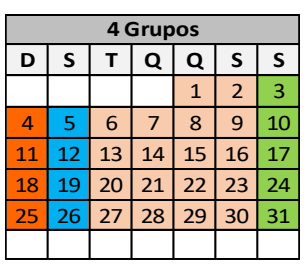

G3
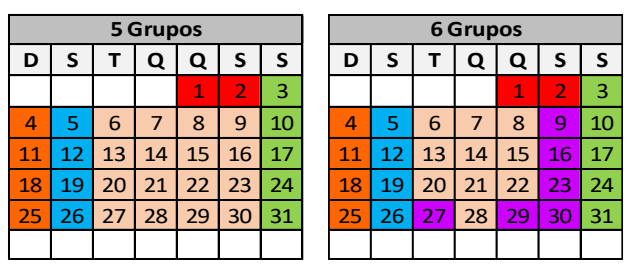

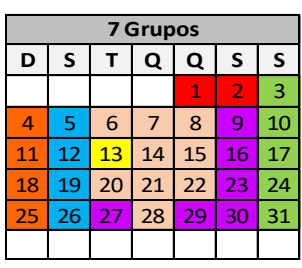

Fonte: Elaborada pelo autor

Observa-se que para 3 grupos, assim como no sentido Leste, os grupos formados indicaram o fim de semana (G2 e G3) e os dias úteis (G1). Já em 4 agrupamentos formouse o grupo de segunda-feira (G4 - 4 grupos). Em seguida, os dias 1 e 2 se isolaram em um novo grupo (G5 - 5 grupos). Em seis agrupamentos, um grupo de sexta-feira é formado (G6), com exceção do dia 2 e inclusão do dia 27 e 29 em função das suas similaridades com o perfil apresentado pelas sextas-feiras. Por fim, o sétimo agrupamento isolou o dia 13 (G7 - 7 grupos).

Analisando esses resultados, foi possível notar que os grupos de dias típicos foram formados em seis agrupamentos, conforme ilustra a Figura 6-24. Observa-se que os perfis formados pelos caminhões no sentido Oeste, assim como no sentido Leste, são muito distintos aos perfis obtidos para o comportamento dos automóveis (Figura 6-18) e para o comportamento da somatória de todos os veículos (Figura 4-10).

Figura 6-24 - Grupos formados para 6 agrupamentos com o $C A_{4}$ - Fluxo Oeste - Caminhão

\begin{tabular}{|c|c|c|}
\hline (a) ter, qua e qui $-\mathrm{G} 1$ & 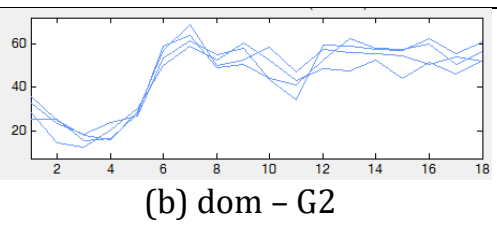 & 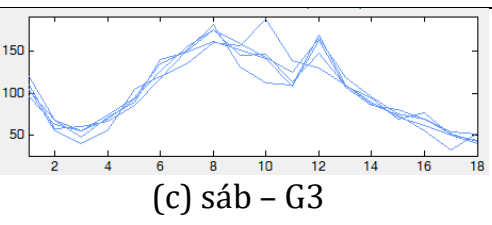 \\
\hline $\begin{array}{lllll}250 \\
200 \\
100 \\
100 \\
50 \\
0 \\
0\end{array}$ & 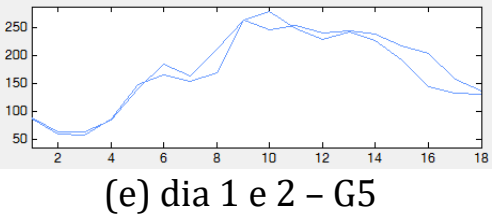 & 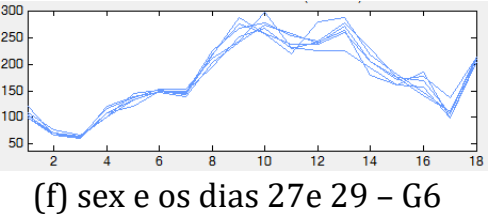 \\
\hline
\end{tabular}

Fonte: Elaborada pelo autor

Após analisar o reconhecimento de padrões, foi aplicado o método para detectar anomalias nos dados de tráfego dos caminhões no sentido Oeste. Os resultados obtidos são apresentados na Tabela 6.23 e Tabela 6.24, que apresentam a porcentagem do total de anomalias para os quatro primeiros níveis em cada tipo de dia para os dados de fluxo 
de tráfego e velocidade veicular, respectivamente.

Tabela 6.23 - Frequência de anomalias encontradas por dia em cada nível investigado - Fluxo Oeste Caminhão

\begin{tabular}{lrrrrr}
\hline \multicolumn{1}{r}{ Dia } & Nível 1 (\%) & Nível 2 (\%) & Nível 3(\%) & Nível 4 (\%) & Média (\%) \\
\hline Feriado & 0.00 & 0.00 & 0.00 & 0.00 & $\mathbf{0 . 0 0}$ \\
Dom & 0.00 & 0.00 & 0.00 & 0.00 & $\mathbf{0 . 0 0}$ \\
Seg & 0.00 & 20.00 & 0.00 & 33.33 & $\mathbf{1 3 . 3 3}$ \\
Ter & 16.67 & 20.00 & 0.00 & 0.00 & $\mathbf{9 . 1 7}$ \\
Qua & 0.00 & 20.00 & 50.00 & 66.67 & $\mathbf{3 4 . 1 7}$ \\
Qui & 16.67 & 40.00 & 50.00 & 0.00 & $\mathbf{2 6 . 6 7}$ \\
Sex & 66.67 & 0.00 & 0.00 & 0.00 & $\mathbf{1 6 . 6 7}$ \\
Sáb & 0.00 & 0.00 & 0.00 & 0.00 & $\mathbf{0 . 0 0}$ \\
\hline
\end{tabular}

Fonte: Elaborada pelo autor

Tabela 6.24 - Frequência de anomalias encontradas por dia em cada nível investigado - Velocidade Oeste - Caminhão

\begin{tabular}{lrrrrr}
\hline \multicolumn{1}{r}{ Dia } & Nível 1 (\%) & Nível 2 (\%) & Nível 3(\%) & Nível 4 (\%) & Média (\%) \\
\hline Feriado & 0.00 & 0.00 & 0.00 & 0.00 & $\mathbf{0 . 0 0}$ \\
Dom & 37.50 & 31.25 & 33.33 & 22.22 & $\mathbf{3 1 . 0 8}$ \\
Seg & 25.00 & 18.75 & 13.33 & 22.22 & $\mathbf{1 9 . 8 3}$ \\
Ter & 6.25 & 18.75 & 20.00 & 11.11 & $\mathbf{1 4 . 0 3}$ \\
Qua & 0.00 & 0.00 & 0.00 & 0.00 & $\mathbf{0 . 0 0}$ \\
Qui & 0.00 & 0.00 & 0.00 & 0.00 & $\mathbf{0 . 0 0}$ \\
Sex & 12.50 & 12.50 & 13.33 & 11.11 & $\mathbf{1 2 . 3 6}$ \\
Sáb & 18.75 & 18.75 & 20.00 & 33.33 & $\mathbf{2 2 . 7 1}$ \\
\hline
\end{tabular}

Fonte: Elaborada pelo autor

Ao analisar a Tabela 6.23, percebeu-se que as anomalias estão distribuídas ao longo da semana, enquanto que nos dados de velocidade (Tabela 6.24) a maioria das anomalias (53,79\%) foram concentradas nos domingos (31,08\%) e sábados (22,71\%). Esses resultados reforçam a diferença que a análise entre um tipo de dado e outro pode ocasionar, portanto as características de cada variável devem ser consideradas ao aplicar o método.

No nível 8, os dados de fluxo de tráfego não detectaram anomalias e os dados de velocidade detectaram uma anomalia no domingo 26/03/2012 às 18:35. No nível 11 , apenas os dados de fluxo de tráfego detectaram anomalias: 22/03/2012 às 07:55 e 29/03/2012 às 10:35, indicando que as duas últimas semanas foram as que apresentaram oscilações acima do valor limiar.

De maneira geral, a análise exploratória da composição do tráfego formado por caminhões foi capaz de identificar as variações do comportamento do tráfego ao longo do dia e as anomalias frequentes aos domingos. Esses resultados ilustraram a diferença real 
do fluxo de tráfego para caminhões em relação a outros veículos e é objeto de pesquisa de tantos outros trabalhos (DEMARCHI, 2000; CUNHA, 2007; PIVA, 2015).

\subsubsection{Moto}

\section{Leste}

Para analisar a composição de tráfego formada por motos foi aplicado o método proposto de reconhecer padrões no fluxo de tráfego. A Figura 6-25 apresenta os grupos formados pelo Coeficiente de Aproximação no nível 4 para o mês de março de 2012 no sentido Leste.

Figura 6-25 - Resultado das análises de agrupamento para o $C A_{4}$ - Fluxo Leste - Moto

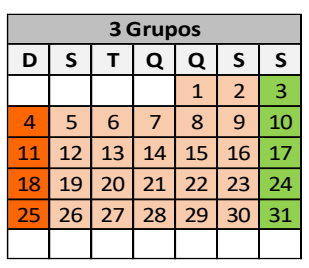

Legenda: \begin{tabular}{|l|l|l|}
\hline & G1 & $\mathbf{G} 2$ \\
\hline
\end{tabular}
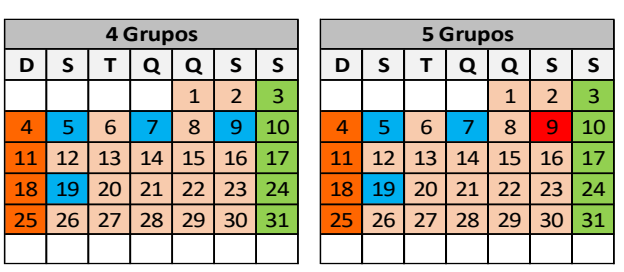

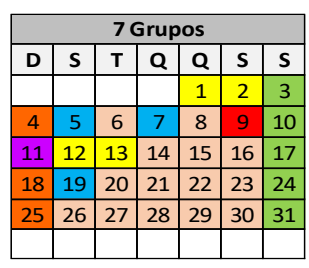

Fonte: Elaborada pelo autor

Ao analisar cada agrupamento, nota-se que para 3 agrupamentos foi o que melhor caracterizou dias típicos de tráfego, pois os grupos indicam o fim de semana (G2 e G3) e os dias úteis (G1). A partir de 4 agrupamentos foram formados apenas grupos com dias isolados, que não representam nenhum comportamento de dia típico. Esses resultados indicam que mesmo utilizando o coeficiente de aproximação gerado pela Transformada Wavelet no nível 4, o perfil de cada dia não apresenta forte similaridade entre si. Para representar esses resultados, a Figura 6-26 apresenta os perfis formados em cinco agrupamentos, pois foi o último agrupamento em que os grupos de sábados e domingos está completo, mas alguns dias já estavam apresentando comportamento distinto aos demais dias do mês formando grupos a partes (G4 e G5). 
Figura 6-26 - Grupos formados para 5 agrupamentos com o $C A_{4}$ - Fluxo Leste - Moto

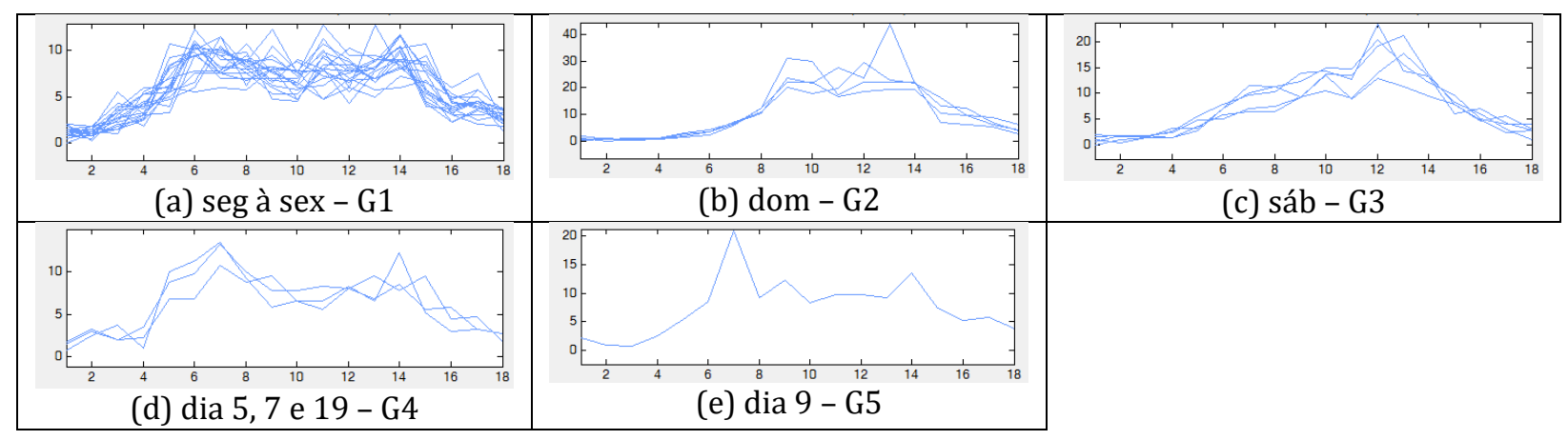

Fonte: Elaborada pelo autor

Após analisar o reconhecimento de padrões, foi aplicado o método para detectar anomalias nos dados de tráfego de moto no sentido Leste. Os resultados obtidos são apresentados na Tabela 6.25 e Tabela 6.26, que apresentam a porcentagem do total de anomalias para os quatro primeiros níveis em cada tipo de dia para os dados de fluxo de tráfego e velocidade veicular, respectivamente.

Tabela 6.25 - Frequência de anomalias encontradas por dia em cada nível investigado - Fluxo Leste Moto

\begin{tabular}{lrrrrr}
\hline \multicolumn{1}{r}{ Dia } & Nível 1 (\%) & Nível 2 (\%) & Nível 3(\%) & Nível 4 (\%) & Média (\%) \\
\hline Feriado & 0.00 & 0.00 & 0.00 & 0.00 & $\mathbf{0 . 0 0}$ \\
Dom & 59.26 & 66.67 & 71.43 & 50.00 & $\mathbf{6 1 . 8 4}$ \\
Seg & 0.00 & 0.00 & 0.00 & 0.00 & $\mathbf{0 . 0 0}$ \\
Ter & 0.00 & 0.00 & 0.00 & 0.00 & $\mathbf{0 . 0 0}$ \\
Qua & 0.00 & 0.00 & 0.00 & 16.67 & $\mathbf{4 . 1 7}$ \\
Qui & 3.70 & 0.00 & 0.00 & 0.00 & $\mathbf{0 . 9 3}$ \\
Sex & 3.70 & 8.33 & 14.29 & 16.67 & $\mathbf{1 0 . 7 5}$ \\
Sáb & 33.33 & 25.00 & 14.29 & 16.67 & $\mathbf{2 2 . 3 2}$ \\
\hline
\end{tabular}

Fonte: Elaborada pelo autor

Tabela 6.26 - Frequência de anomalias encontradas por dia em cada nível investigado - Velocidade Leste - Moto

\begin{tabular}{lrrrrr}
\hline \multicolumn{1}{r}{ Dia } & Nível 1 (\%) & Nível 2 (\%) & Nível 3(\%) & Nível 4 (\%) & Média (\%) \\
\hline Feriado & 0.00 & 0.00 & 0.00 & 0.00 & $\mathbf{0 . 0 0}$ \\
Dom & 0.00 & 0.00 & 0.00 & 0.00 & $\mathbf{0 . 0 0}$ \\
Seg & 0.00 & 0.00 & 0.00 & 0.00 & $\mathbf{0 . 0 0}$ \\
Ter & 0.00 & 0.00 & 100.00 & 0.00 & $\mathbf{5 0 . 0 0}$ \\
Qua & 0.00 & 0.00 & 0.00 & 100.00 & $\mathbf{5 0 . 0 0}$ \\
Qui & 0.00 & 0.00 & 0.00 & 0.00 & $\mathbf{0 . 0 0}$ \\
Sex & 0.00 & 0.00 & 0.00 & 0.00 & $\mathbf{0 . 0 0}$ \\
Sáb & 0.00 & 0.00 & 0.00 & 0.00 & $\mathbf{0 . 0 0}$ \\
\hline
\end{tabular}

Fonte: Elaborada pelo autor

Ao analisar os dados de fluxo de tráfego no sentido Leste para as motos (Tabela 6.25) 
foi notado que as anomalias se concentraram nos fins de semana: domingo (61,84\%) e sábado (22,32\%), corroborando com os agrupamentos formados. No nível 8 foi detectado apenas uma anomalia 18/03/2012 18:35, assim como no nível 11 29/03/2012 10:35, indicando apenas um dia e uma semana, respectivamente, com mais oscilações.

Já nos dados de velocidade, foram detectadas apenas uma anomalia no nível 3 (20/03/2012 05:15) e duas anomalias no nível 4 (07/03/2012 23:55 e 21/03/2012 06:35) de todos os níveis analisados. Isso porque, as oscilações nos dados de velocidade mantiveram-se dentro do valor limiar, portanto não classificando anomalias. A Figura 6-27 apresenta o Coeficiente de Detalhe no nível 1 gerado pelos dados de velocidades da moto para ilustrar as oscilações dentro do valor limiar, sendo que no nível 1, as oscilações estiveram abaixo do valor limiar.

Figura 6-27 - $C D_{1}$ gerado pelos dados de velocidade das motos no sentido Leste - Threshold de 169,414

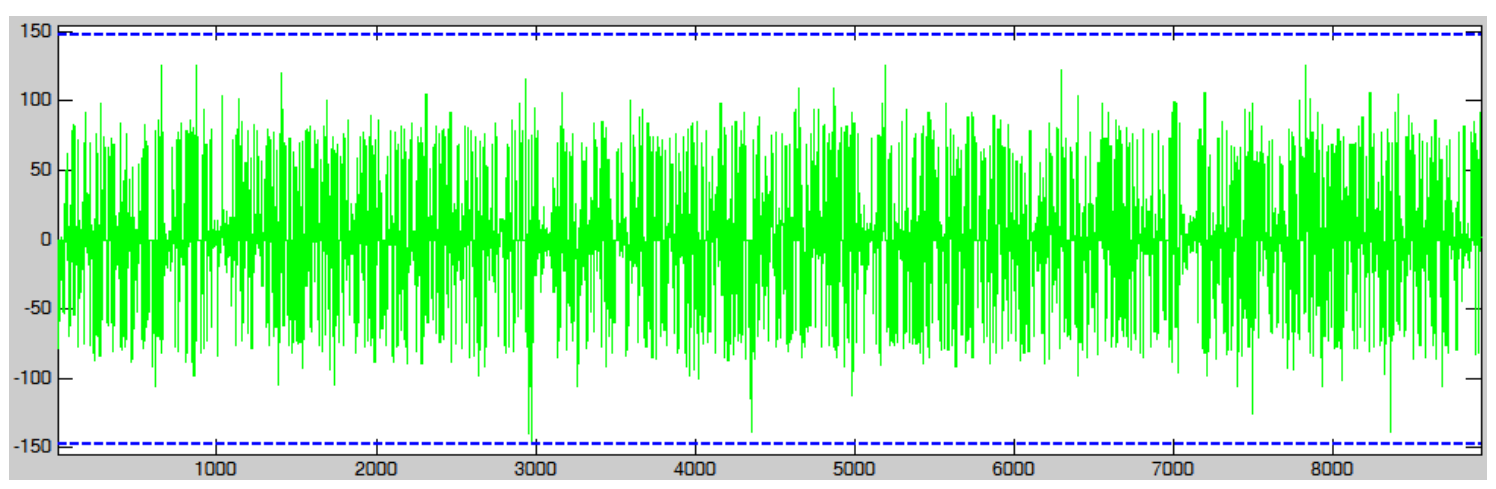

Fonte: Elaborada pelo autor

\section{Oeste}

Para analisar a composição de tráfego formada por motos no sentido Oeste, primeiro foi aplicado o método proposto de reconhecer padrões no fluxo de tráfego. A seguir, a Figura 6-28 apresenta os grupos formados pelo Coeficiente de Aproximação no nível 4 para o mês de março de 2012 no sentido Oeste. 
Figura 6-28 - Resultado das análises de agrupamento para o $C A_{4}$ - Fluxo Oeste - Moto

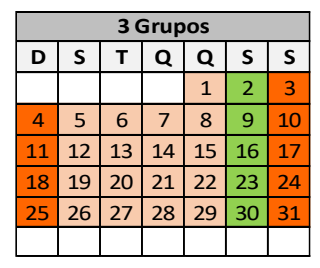

Legenda: $\square$ G1

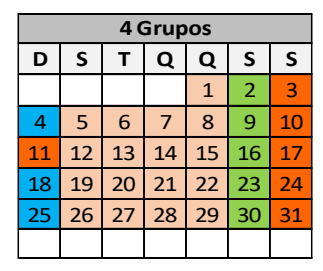

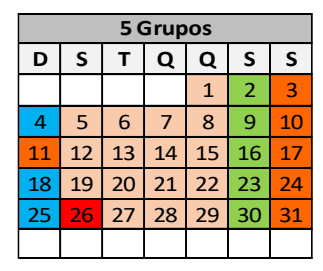

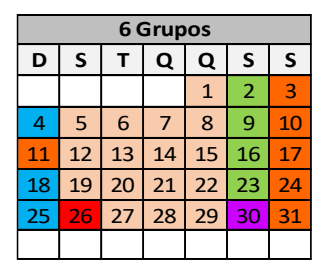

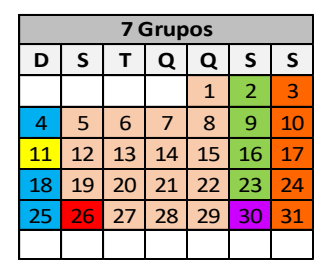

Fonte: Elaborada pelo autor

Ao contrário do sentido Leste (Figura 6-26), no sentido Oeste em três agrupamentos identificou o grupo de sexta-feira (G3 - 3 grupos) como dia típico, um grupo com as segundas, terças, quartas e quintas-feiras (G1 - 3 grupos) e fins de semana (G2 - 3 grupos). Os domingos no quarto agrupamento formaram um novo grupo (G4 - 4 grupos), dividindo-se dos sábados (G2 - 4 grupos), com exceção do dia 11 que continuou no grupo de sábados, por apresentar maior similaridade com esse grupo e a partir de cinco agrupamentos, alguns dias se isolaram em novos grupos. Novamente, esses resultados indicam que o comportamento fluxo de tráfego das motos é distinto a cada dia, independente do sentido do tráfego. Baseado nisso, a Figura 6-29 apresenta os perfis formados em cinco agrupamentos, cenário em que alguns dias começam a ser isolados em novos grupos, demonstrando dissimilaridade em relação aos outros dias do mês.

Figura 6-29 - Grupos formados para 5 agrupamentos com o $C A_{4}$ - Fluxo Oeste - Moto

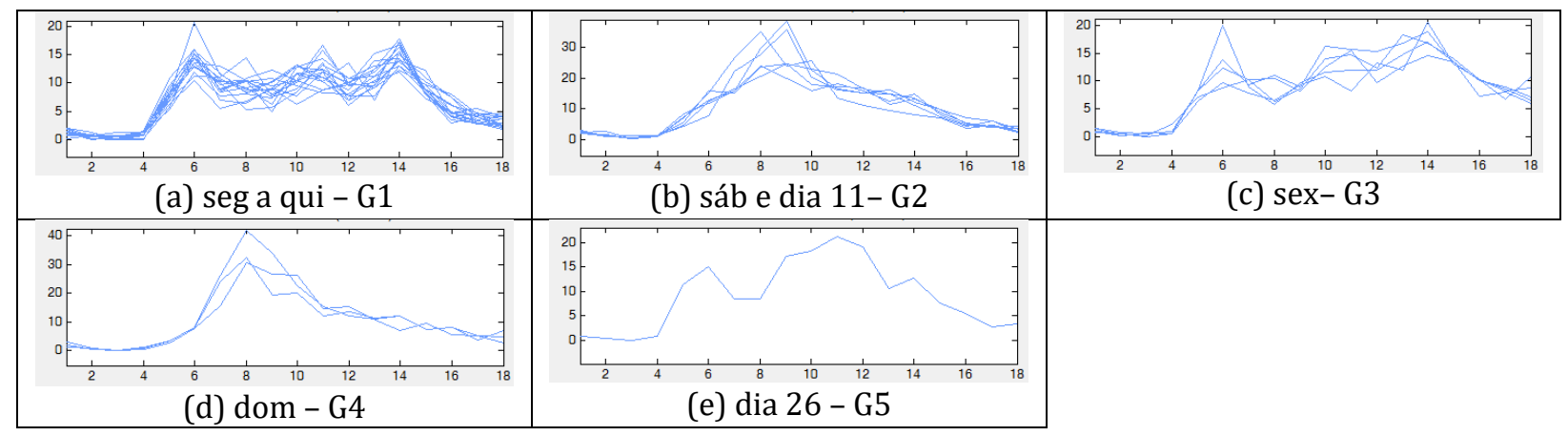

Fonte: Elaborada pelo autor

Após analisar o reconhecimento de padrões, foi aplicado o método para detectar anomalias nos dados de tráfego de motos no sentido Oeste. Os resultados obtidos são apresentados na Tabela 6.27 e Tabela 6.28, que apresentam a porcentagem do total de anomalias para os quatro primeiros níveis em cada tipo de dia para os dados de fluxo de tráfego e velocidade veicular, respectivamente. 
Tabela 6.27 - Frequência de anomalias encontradas por dia em cada nível investigado - Fluxo Oeste Moto

\begin{tabular}{lrrrrr}
\hline \multicolumn{1}{r}{ Dia } & Nível 1 (\%) & Nível 2 (\%) & Nível 3(\%) & Nível 4 (\%) & Média (\%) \\
\hline Feriado & 0.00 & 0.00 & 0.00 & 0.00 & $\mathbf{0 . 0 0}$ \\
Dom & 53.85 & 60.00 & 57.14 & 75.00 & $\mathbf{6 1 . 5 0}$ \\
Seg & 0.00 & 0.00 & 0.00 & 25.00 & $\mathbf{6 . 2 5}$ \\
Ter & 0.00 & 0.00 & 0.00 & 0.00 & $\mathbf{0 . 0 0}$ \\
Qua & 3.85 & 0.00 & 0.00 & 0.00 & $\mathbf{0 . 9 6}$ \\
Qui & 0.00 & 0.00 & 0.00 & 0.00 & $\mathbf{0 . 0 0}$ \\
Sex & 3.85 & 6.67 & 14.29 & 0.00 & $\mathbf{6 . 2 0}$ \\
Sáb & 38.46 & 33.33 & 28.57 & 0.00 & $\mathbf{2 5 . 0 9}$ \\
\hline
\end{tabular}

Fonte: Elaborada pelo autor

Tabela 6.28 - Frequência de anomalias encontradas por dia em cada nível investigado - Velocidade Oeste - Moto

\begin{tabular}{lrrrrr}
\hline \multicolumn{1}{r}{ Dia } & Nível 1 (\%) & Nível 2 (\%) & Nível 3(\%) & Nível 4 (\%) & Média (\%) \\
\hline Feriado & 0.00 & 0.00 & 0.00 & 0.00 & $\mathbf{0 . 0 0}$ \\
Dom & 0.00 & 0.00 & 0.00 & 0.00 & $\mathbf{0 . 0 0}$ \\
Seg & 0.00 & 0.00 & 0.00 & 0.00 & $\mathbf{0 . 0 0}$ \\
Ter & 0.00 & 0.00 & 0.00 & 0.00 & $\mathbf{0 . 0 0}$ \\
Qua & 0.00 & 0.00 & 0.00 & 0.00 & $\mathbf{0 . 0 0}$ \\
Qui & 0.00 & 0.00 & 0.00 & 0.00 & $\mathbf{0 . 0 0}$ \\
Sex & 0.00 & 0.00 & 0.00 & 0.00 & $\mathbf{0 . 0 0}$ \\
Sáb & 0.00 & 0.00 & 100.00 & 0.00 & $\mathbf{1 0 0 . 0 0}$ \\
\hline
\end{tabular}

Fonte: Elaborada pelo autor

Ao analisar os dados de fluxo de tráfego no sentido Oeste das motos (Tabela 6.27), foi notado que as anomalias se concentraram nos fins de semana: domingo $(61,50 \%)$ e sábado (25,09\%), totalizando $86,59 \%$ das anomalias, corroborando com os agrupamentos formados. No nível 8 e no nível 11 não foram detectadas nenhuma anomalia.

Já nos dados de velocidade, foram detectadas apenas uma anomalia no nível 3: 24/03/2012 às 23:55, pois assim como os dados de velocidade das motos no sentido Leste, no sentido Oeste, as oscilações mantiveram-se dentro do valor limiar. A Figura 6-30 apresenta o Coeficiente de Detalhe no nível 1 gerado pelos dados de velocidades das motos no sentido Oeste para ilustrar as oscilações dentro do valor limiar, sendo que no nível 1, as oscilações estiveram abaixo do threshold. 
Figura 6-30 - $C D_{1}$ gerado pelos dados de velocidade das motos no sentido Leste - Threshold de 146,924

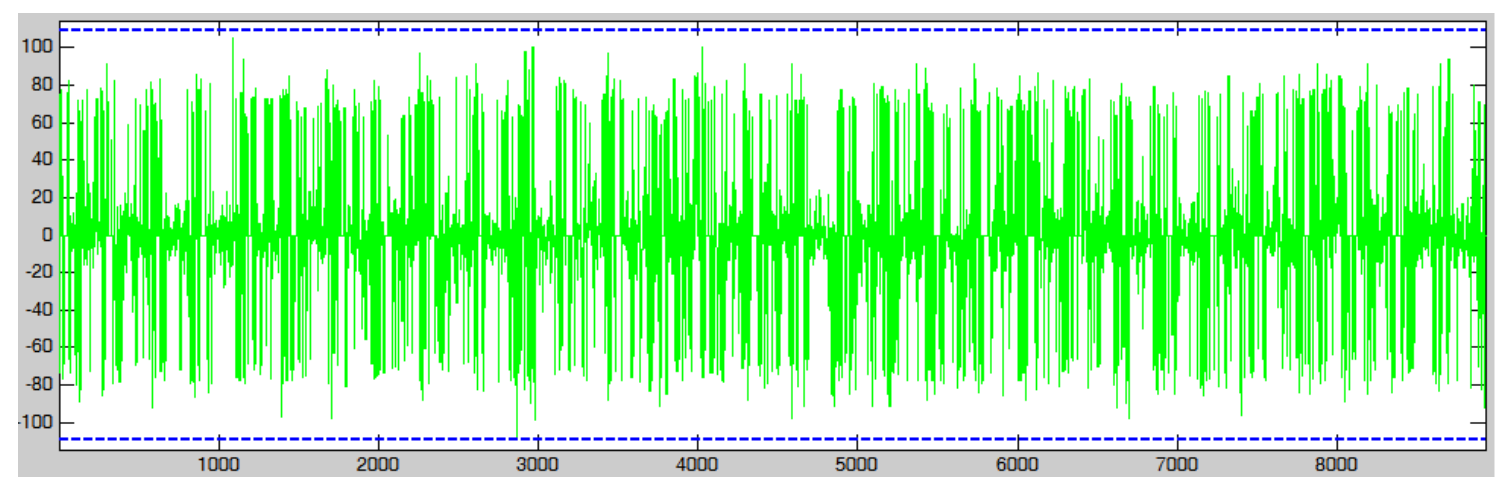

Fonte: Elaborada pelo autor

\subsection{RESOLUÇÃO DO SINAL ORIGINAL}

Conforme apresentado no Capítulo 3, o banco de dados analisado até o momento é formado por dados amostrados em intervalos de 5 minutos, provindos da Concessionária ViaOeste. No entanto, essa configuração pode variar de acordo com o formato da planilha de dados utilizada por cada concessionária. Para analisar os métodos propostos em outra resolução do sinal original foram utilizados os dados da Concessionária AutoBan, dispostos em 6 minutos.

Ao alterar o intervalo do banco de dados, a escala de tempo para cada nível também muda, pois, a resolução de cada componente gerado pela Transformada Wavelet é em função do sinal original. No Capítulo 3 (seção 3.2 - Análise do sinal de entrada) foi demonstrado e discutido detalhadamente como é calculada a janela de tempo e quantos pontos tem cada coeficiente por nível de decomposição. A Tabela 6.29 apresenta a janela de tempo em cada nível gerados pelo sinal de entrada com 5 e 6 minutos de intervalo. 
Tabela 6.29 - Escala da janela em cada nível para os dados com 5 e 6 minutos de intervalo

\begin{tabular}{|c|c|c|c|c|}
\hline Nível (n) & \multicolumn{2}{|c|}{ Janela de Tempo $\left(5 \times 2^{n}\right)$} & \multicolumn{2}{|c|}{ Janela de tempo $\left(6 \times 2^{n}\right)$} \\
\hline 1 & $10 \mathrm{~min}$ & & $12 \mathrm{~min}$ & \\
\hline 2 & $20 \mathrm{~min}$ & & $24 \min$ & \\
\hline 3 & $40 \mathrm{~min}$ & & $48 \mathrm{~min}$ & \\
\hline 4 & $80 \mathrm{~min}$ & (1h 20min) & $96 \min$ & (1h 36min) \\
\hline 5 & $160 \mathrm{~min}$ & (2h 40min) & $192 \mathrm{~min}$ & (3h 12min) \\
\hline 6 & $320 \mathrm{~min}$ & (5h 20min) & $384 \min$ & (6h 24min) \\
\hline 7 & $640 \mathrm{~min}$ & (10h 40min) & $768 \mathrm{~min}$ & (12h 48min) \\
\hline 8 & $1.280 \mathrm{~min}$ & (21h 20min) & 1536 min & (1 dia $1 \mathrm{~h} 36 \mathrm{~min})$ \\
\hline 9 & $2.560 \mathrm{~min}$ & (1 dia $18 \mathrm{~h} 40 \mathrm{~min})$ & $3.072 \mathrm{~min}$ & (2 dias $3 \mathrm{~h} 12 \mathrm{~min})$ \\
\hline 10 & $5.120 \mathrm{~min}$ & (3 dias $13 \mathrm{~h} 20 \mathrm{~min}$ ) & $6.144 \mathrm{~min}$ & (4 dias $6 \mathrm{~h} 24 \mathrm{~min}$ ) \\
\hline 11 & $10.240 \mathrm{~min}$ & (7 dias $2 \mathrm{~h} 40 \mathrm{~min}$ ) & $12.288 \mathrm{~min}$ & ( 8 dias $12 \mathrm{~h} 48 \mathrm{~min}$ ) \\
\hline 12 & $20.480 \mathrm{~min}$ & (14 dias 5 h $20 \mathrm{~min}$ ) & $24.576 \mathrm{~min}$ & (17 dias $1 \mathrm{~h} 36 \mathrm{~min})$ \\
\hline 13 & $40.960 \mathrm{~min}$ & (28 dias $10 \mathrm{~h} 40 \mathrm{~min}$ ) & $49.152 \mathrm{~min}$ & (34 dias $3 \mathrm{~h} 12 \mathrm{~min}$ ) \\
\hline 14 & $81.920 \mathrm{~min}$ & (56 dias $21 \mathrm{~h} 20 \mathrm{~min}$ ) & $98.304 \mathrm{~min}$ & (68 dias $6 \mathrm{~h} 24 \mathrm{~min})$ \\
\hline 15 & $163.840 \mathrm{~min}$ & (113 dias $18 \mathrm{~h} 40 \mathrm{~min}$ ) & $196.608 \mathrm{~min}$ & (136 dias $12 \mathrm{~h} 48 \mathrm{~min}$ ) \\
\hline 16 & $327.680 \mathrm{~min}$ & (227 dias $13 \mathrm{~h} 20 \mathrm{~min})$ & $393.216 \mathrm{~min}$ & (273 dias $1 \mathrm{~h} 36 \mathrm{~min}$ ) \\
\hline
\end{tabular}

Fonte: Elaborada pelo autor

No método proposto para reconhecimento de padrões no Capítulo 4, utilizou-se o Coeficiente de Aproximação do nível 4 por ter a janela correspondente mais próxima a 1 hora. No entanto, como pode ser conferido na Tabela 6.29, o nível mais próximo a 1 hora para o intervalo de 6 minutos é o nível 3, com a escala de 48 minutos. 0 nível 4, para janela de 6 minutos, tem resolução de 96 minutos (1 hora e 36 minutos), o que não é desejado nesta pesquisa pois pretende-se explorar variações horárias.

No método proposto para detectar anomalias, os Coeficientes de Detalhes analisados foram escolhidos de acordo com a resolução do nível. Visto que o objetivo era explorar Coeficientes de Detalhes em diferentes resoluções para analisar as oscilações acima do Threshold e explorar também janelas próximas a um hora, um dia e uma semana, os níveis analisados oriundos do intervalo de 5 minutos foram: 1 (10min), 2 (20min), 3 (40min), 4 (1h $20 \mathrm{~min}$ ), 8 (21h 20min) e 11 (7 dias 2h 40min). Mantendo o mesmo critério para escolher os níveis no intervalo de 6 minutos, define-se os mesmos níveis para detecção de anomalia, porém com a escala de tempo diferente: 1 (12 min), 2 (24 min), 3 (48 min), 4 (1h $36 \mathrm{~min}$ ), 8 (1 dia $1 \mathrm{~h} 36 \mathrm{~min}$ ) e 11 (8 dias $12 \mathrm{~h} 48 \mathrm{~min}$ ).

Após definir os níveis a serem avaliados, foram escolhidos o sensor e o período a serem analisados. Como os dados originados da Concessionária AutoBan apresentaram quantidade significativa de falhas (Apêndice 3.1), escolheu-se o mês de março de 2012 no km 131 da Rodovia Bandeirantes por apresentar um mês completo de dados e ser um mês sem feriados. Os resultados obtidos para os métodos de reconhecimento de padrões e 
detecção de anomalia são apresentados a seguir, para os dois sentidos da rodovia, Norte e Sul.

\section{Norte}

Primeiro foi aplicado e analisado o método proposto para reconhecer padrões no fluxo de tráfego no sentido Norte da Rodovia Bandeirantes. A Figura 6-31 apresenta os grupos formados pelo Coeficiente de Aproximação no nível 3 para o mês de março de 2012.

Figura 6-31 - Resultado das análises de agrupamento para o $C A_{3}$ - Fluxo Norte

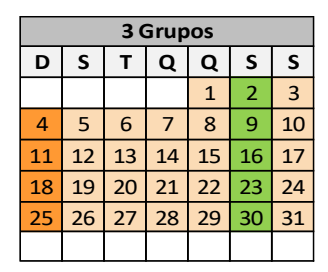

Legenda: \begin{tabular}{l|l|l|}
$\square$ & $\mathbf{G 1} \quad$ \\
\hline & $\mathbf{6 2}$ \\
\hline
\end{tabular}

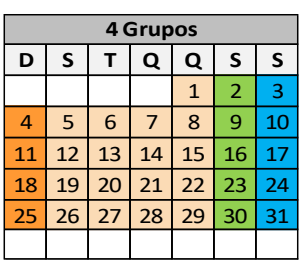

G3
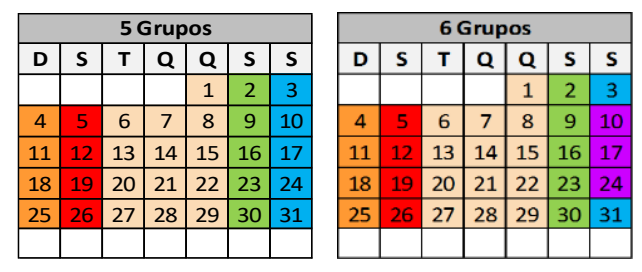

Fonte: Elaborada pelo autor

Nota-se que para 3 grupos, o G1 compreende os dias de segunda a quinta-feira e os sábados, o G2 os domingos e o G3 todas as sextas-feiras. Para 4 agrupamentos os sábados formaram um novo grupo (G4 - 4 grupos). Em seguida, as segundas-feiras formaram um novo grupo (G5 - 5 grupos). Em seis agrupamentos os sábados se dividem em dois grupos (G4 e G6 - 6 agrupamentos) e em sete agrupamentos 3 das 5 quintas-feiras (8, 22 e 29) separam-se do G1 (G7 - 7 grupos).

Analisando os agrupamentos formados, nota-se que os grupos de domingo e sextafeira mantiveram um comportamento de forte similaridade com os sinais que os compõem, mantendo-se em grupos intactos de 3 a 7 agrupamentos. 0 grupo formado por segundas-feiras em 5 agrupamentos (G5 - 5 grupos) também apresentou forte similaridade pois até o cenário de 7 grupos não se separou. A partir de 6 agrupamentos ocorre a tendência de separar grupos típicos em dois, sendo assim, há evidências que cinco grupos sejam a melhor opção para definir os dias típicos de tráfego para a nova rodovia analisada, Rodovia dos Bandeirantes para o Coeficiente de Aproximação 3 (escala de 48 minutos). Sendo assim, a Figura 6-32 ilustra o padrão do tráfego para os cinco grupos formados. 
Figura 6-32 - Grupos formados para 5 agrupamentos com o $C A_{3}$ - Fluxo Norte

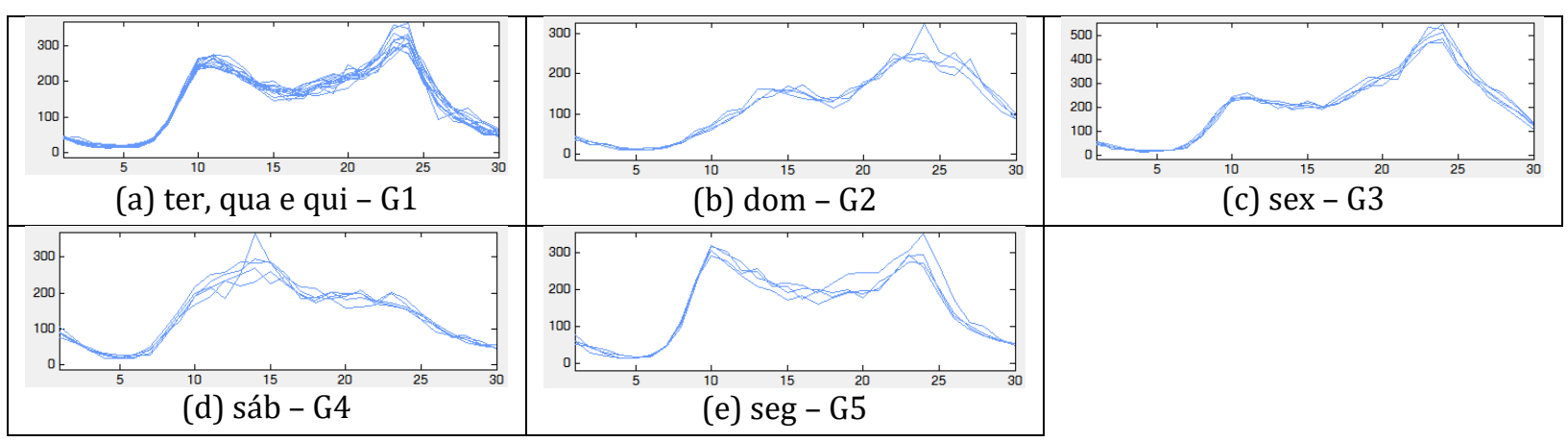

Fonte: Elaborada pelo autor

Observa-se que a quantidade de pontos do $C A_{4}$ no intervalo de 5 minutos para o $C A_{3}$ do intervalo de 6 minutos mudou de 18 para 30 pontos. Isso ocorre devido a nova janela do coeficiente. Como a janela diminui de 80 minutos (1h $20 \mathrm{~min}$ ) para 48 minutos, a quantidade de pontos em 24 horas também muda. Mais detalhes sobre como analisar os coeficientes gerados pela Transformada Wavelet encontram-se no Capítulo 3 (seção 3.2 Análise do sinal de entrada).

Após analisar o reconhecimento de padrões, foi aplicado o método para detectar anomalias na Rodovia dos Bandeirantes no sentido Norte. Os resultados obtidos são apresentados na Tabela 6.30 e Tabela 6.31, que apresentam a porcentagem do total de anomalias para os quatro primeiros níveis em cada tipo de dia para os dados de fluxo de tráfego e velocidade veicular, respectivamente.

Tabela 6.30 - Frequência de anomalias encontradas por dia em cada nível investigado - Fluxo Norte

\begin{tabular}{lrrrrr}
\hline \multicolumn{1}{r}{ Dia } & Nível 1 (\%) & Nível 2 (\%) & Nível 3(\%) & Nível 4 (\%) & Média (\%) \\
\hline Feriado & 0.00 & 0.00 & 0.00 & 0.00 & $\mathbf{0 . 0 0}$ \\
Dom & 0.00 & 0.00 & 0.00 & 0.00 & $\mathbf{0 . 0 0}$ \\
Seg & 0.00 & 0.00 & 0.00 & 0.00 & $\mathbf{0 . 0 0}$ \\
Ter & 0.00 & 0.00 & 0.00 & 0.00 & $\mathbf{0 . 0 0}$ \\
Qua & 0.00 & 0.00 & 0.00 & 0.00 & $\mathbf{0 . 0 0}$ \\
Qui & 25.00 & 33.33 & 0.00 & 0.00 & $\mathbf{1 4 . 5 8}$ \\
Sex & 75.00 & 33.33 & 100.00 & 100.00 & $\mathbf{7 7 . 0 8}$ \\
Sáb & 0.00 & 33.33 & 0.00 & 0.00 & $\mathbf{8 . 3 3}$ \\
\hline
\end{tabular}

Fonte: Elaborada pelo autor 
Tabela 6.31 - Frequência de anomalias encontradas por dia em cada nível investigado - Velocidade Norte

\begin{tabular}{lrrrrr}
\hline \multicolumn{1}{r}{ Dia } & Nível 1 (\%) & Nível 2 (\%) & Nível 3(\%) & Nível 4 (\%) & Média (\%) \\
\hline Feriado & 0.00 & 0.00 & 0.00 & 0.00 & $\mathbf{0 . 0 0}$ \\
Dom & 0.00 & 9.30 & 23.08 & 0.00 & $\mathbf{8 . 0 9}$ \\
Seg & 0.00 & 11.63 & 15.38 & 0.00 & $\mathbf{6 . 7 5}$ \\
Ter & 0.00 & 16.28 & 7.69 & 20.00 & $\mathbf{1 0 . 9 9}$ \\
Qua & 0.00 & 6.98 & 15.38 & 20.00 & $\mathbf{1 0 . 5 9}$ \\
Qui & 0.00 & 20.93 & 7.69 & 0.00 & $\mathbf{7 . 1 6}$ \\
Sex & 0.00 & 16.28 & 15.38 & 20.00 & $\mathbf{1 2 . 9 2}$ \\
Sáb & 0.00 & 18.60 & 15.38 & 40.00 & $\mathbf{1 8 . 5 0}$ \\
\hline
\end{tabular}

Fonte: Elaborada pelo autor

Ao analisar os dados de fluxo de tráfego no sentido Norte da Rodovia dos Bandeirantes (Tabela 6.30) foi notado que as anomalias se concentraram principalmente nas sextas-feiras $(77,08 \%)$, indicando que em relação ao fluxo de tráfego, as oscilações de maior frequência ocorrem nas sextas-feiras. Por sua vez, os dados de velocidade veicular apresentaram as anomalias distribuídas ao longo da semana.

No nível 8, apenas os dados de velocidade veicular apresentaram anomalia: 19/03/2012 às 06:18 e no nível 11, não foi detectada anomalia para ambos os dados.

\section{Sul}

Após analisar o sentido Norte, foi aplicado e analisado o método proposto para reconhecer padrões no fluxo de tráfego no sentido Sul da Rodovia Bandeirantes. A Figura 6-33 apresenta os grupos formados pelo Coeficiente de Aproximação no nível 3 para o mês de março de 2012.

Figura 6-33 - Resultado das análises de agrupamento para o $C A_{3}$ - Fluxo Sul

\begin{tabular}{|c|c|c|c|c|c|c|}
\hline \multicolumn{7}{|c|}{ 3 Grupos } \\
\hline D & S & T & Q & Q & S & S \\
\hline & & & & 1 & 2 & 3 \\
\hline 4 & 5 & 6 & 7 & 8 & 9 & 10 \\
\hline 11 & 12 & 13 & 14 & 15 & 16 & 17 \\
\hline 18 & 19 & 20 & 21 & 22 & 23 & 24 \\
\hline 25 & 26 & 27 & 28 & 29 & 30 & 31 \\
\hline & & & & & & \\
\hline
\end{tabular}

Legenda: \begin{tabular}{l|l|l|l|l}
\hline & $\mathbf{G 1}$ & $\mathbf{G} 2$ \\
\hline
\end{tabular}

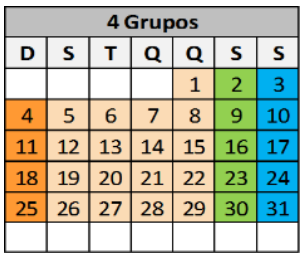

2
G3

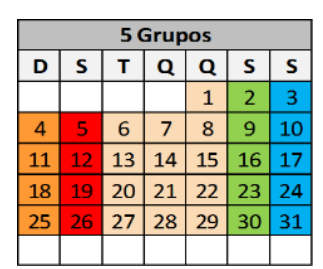

\begin{tabular}{|c|c|c|c|c|c|c|}
\hline \multicolumn{7}{|c|}{ 6 Grupos } \\
\hline D & S & T & Q & Q & S & S \\
\hline & & & & 1 & 2 & 3 \\
\hline 4 & 5 & 6 & 7 & 8 & 9 & 10 \\
\hline 11 & 12 & 13 & 14 & 15 & 16 & 17 \\
\hline 18 & 19 & 20 & 21 & 22 & 23 & 24 \\
\hline 25 & 26 & 27 & 28 & 29 & 30 & 31 \\
\hline & & & & & & \\
\hline
\end{tabular}

\begin{tabular}{|c|c|c|c|c|c|c|}
\hline \multicolumn{7}{|c|}{ 7 Grupos } \\
\hline D & S & T & Q & Q & S & S \\
\hline & & & & 1 & 2 & 3 \\
\hline 4 & 5 & 6 & 7 & 8 & 9 & 10 \\
\hline 11 & 12 & 13 & 14 & 15 & 16 & 17 \\
\hline 18 & 19 & 20 & 21 & 22 & 23 & 24 \\
\hline 25 & 26 & 27 & 28 & 29 & 30 & 31 \\
\hline & & & & & & \\
\hline
\end{tabular}

Analisando os grupos formados para o sentido Sul, observa-se que até 5 agrupamentos, os grupos formados foram iguais ao sentido Norte: No cenário de 3 grupos o G1 compreendeu os dias de segunda a quinta-feira e os sábados, o G2 os domingos e o 
G3 todas as sextas-feiras. No cenário de 4 grupos, os sábados formaram um novo grupo (G4 - 4 grupos). No cenário de 5 grupos, as segundas-feiras formaram um novo grupo (G5 - 5 grupos). Já em seis agrupamentos, as quintas-feiras formaram um novo grupo, com exceção do dia 1 (G6 - 6 grupos) e por fim, em 7 agrupamentos, o dia 17 se isolou em um novo grupo.

Analisando os agrupamentos formados, nota-se que os grupo de domingo manteve um comportamento de forte similaridade com os sinais que os compõe, mantendo-se intacto de 3 a 7 agrupamentos. 0 grupo formado por segundas e quintas-feiras também apresentaram forte similaridade pois desde que foram formados, não sofreram alterações. De forma distinta ao sentido Norte, o sentido Sul, antes dos agrupamentos isolarem alguns dias, formou 6 grupos que definem os dias típicos da semana: (1) domingo, (2) segunda-feira, (3) terça e quarta-feira, (4) quinta-feira, (5) sexta-feira e (6) sábado. Sendo assim, a Figura 6-32 ilustra o padrão do tráfego para seis grupos formados pelos $C A$ z para o sentido Sul da Rodovia Bandeirantes.

Figura 6-34 - Grupos formados para 5 agrupamentos com o $C A_{3}$ - Fluxo Sul

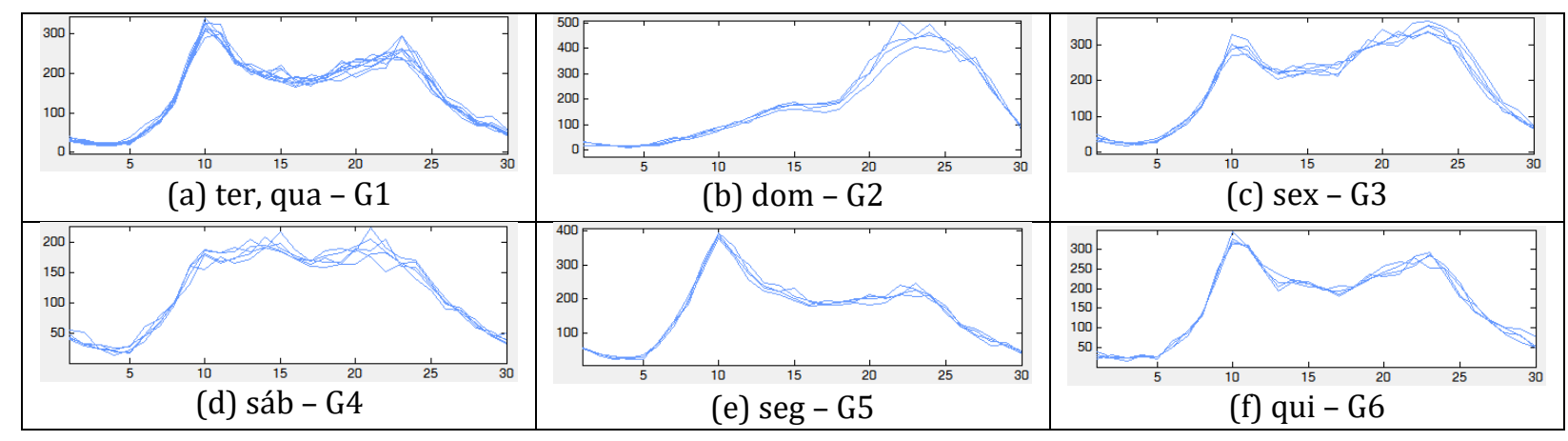

Fonte: Elaborada pelo autor

Após analisar o reconhecimento de padrões para o sentido Norte da Rodovia dos Bandeirantes, foi aplicado o método para detectar anomalias no sentido Sul. Os resultados obtidos são apresentados na Tabela 6.32 e Tabela 6.33, que apresentam a porcentagem do total de anomalias para os quatro primeiros níveis em cada tipo de dia para os dados de fluxo de tráfego e velocidade veicular, respectivamente. 
Tabela 6.32 - Frequência de anomalias encontradas por dia em cada nível investigado - Fluxo Sul

\begin{tabular}{lrrrrr}
\hline \multicolumn{1}{r}{ Dia } & Nível 1 (\%) & Nível 2 (\%) & Nível 3(\%) & Nível 4 (\%) & Média (\%) \\
\hline Feriado & 0.00 & 0.00 & 0.00 & 0.00 & $\mathbf{0 . 0 0}$ \\
Dom & 0.00 & 25.00 & 0.00 & 0.00 & $\mathbf{6 . 2 5}$ \\
Seg & 0.00 & 25.00 & 33.33 & 0.00 & $\mathbf{1 4 . 5 8}$ \\
Ter & 0.00 & 0.00 & 33.33 & 0.00 & $\mathbf{8 . 3 3}$ \\
Qua & 100.00 & 0.00 & 33.33 & 0.00 & $\mathbf{3 3 . 3 3}$ \\
Qui & 0.00 & 0.00 & 0.00 & 0.00 & $\mathbf{0 . 0 0}$ \\
Sex & 0.00 & 50.00 & 0.00 & 0.00 & $\mathbf{1 2 . 5 0}$ \\
Sáb & 0.00 & 0.00 & 0.00 & 0.00 & $\mathbf{0 . 0 0}$ \\
\hline
\end{tabular}

Fonte: Elaborada pelo autor

Tabela 6.33 - Frequência de anomalias encontradas por dia em cada nível investigado - Velocidade Sul

\begin{tabular}{lrrrrr}
\hline \multicolumn{1}{r}{ Dia } & Nível 1 (\%) & Nível 2 (\%) & Nível 3(\%) & Nível 4 (\%) & Média (\%) \\
\hline Feriado & 0.00 & 0.00 & 0.00 & 0.00 & $\mathbf{0 . 0 0}$ \\
Dom & 100.00 & 20.59 & 10.00 & 0.00 & $\mathbf{3 2 . 6 5}$ \\
Seg & 0.00 & 5.88 & 20.00 & 0.00 & $\mathbf{6 . 4 7}$ \\
Ter & 0.00 & 20.59 & 10.00 & 11.11 & $\mathbf{1 0 . 4 2}$ \\
Qua & 0.00 & 23.53 & 20.00 & 33.33 & $\mathbf{1 9 . 2 2}$ \\
Qui & 0.00 & 2.94 & 10.00 & 22.22 & $\mathbf{8 . 7 9}$ \\
Sex & 0.00 & 20.59 & 0.00 & 22.22 & $\mathbf{1 0 . 7 0}$ \\
Sáb & 0.00 & 5.88 & 30.00 & 11.11 & $\mathbf{1 1 . 7 5}$ \\
\hline
\end{tabular}

Fonte: Elaborada pelo autor

Ao analisar os dados de fluxo de tráfego (Tabela 6.32) e velocidade veicular (Tabela 6.33) no sentido Sul da Rodovia dos Bandeirantes notou-se que para ambos os parâmetros, as anomalias estão distribuídas ao longo da semana e não concentradas em apenas um dia da semana. No nível 8 e 11 não foram detectadas nenhuma anomalia.

A análise de resolução de dados tinha como objetivo avaliar se o método proposto para reconhecimento de padrões e detecção de anomalias seria eficiente ainda que o intervalo de tempo do sinal original mudasse. Ao alterar a resolução dos dados, de 5 para 6 minutos, tanto o coeficiente de detalhe quanto o de aproximação foram remodelados, alterando a escala e a quantidade de pontos em todos os níveis entre um sinal e outro. Os resultados obtidos para o sentido Norte e Sul indicaram que mesmo com essa diferença entre os coeficientes foi possível definir os dias típicos e avaliar as anomalias para a rodovia investigada.

\subsection{CONSIDERAÇÕES FINAIS}

Este capítulo apresentou a investigação dos métodos propostos para 
reconhecimento de padrões e detecção de anomalias em dados de tráfego veicular. Para isso, foram aplicados os métodos em outras condições de tráfego, investigando três características distintas: dados de tráfego veicular em diferentes situações, composição do tráfego para diferentes tipos de veículos e resolução dos dados de entrada. Cada seção apresentou uma característica investigada.

$\mathrm{Na}$ análise dos dados de tráfego veicular, a primeira situação a ser avaliada considerou o mesmo local em épocas diferentes. Os resultados obtidos indicaram que assim como no Capítulo 4, os perfis de dias típicos também foram formados por cinco grupos e a distribuição das anomalias foram similares às obtidas no período utilizado no Capítulo 5. Na segunda situação, mesma época para rodovias diferentes, os resultados desta análise indicaram que apesar da Rodovia Raposo Tavares apresentar um comportamento distinto ao da Rodovia Presidente Castelo Branco em um mesmo período, os dias que compuseram cada perfil formado apresentaram forte similaridade entre si, comprovando a validade do método para rodovias distintas. Ainda na segunda situação, os resultados também revelaram a influência do fluxo direcional de forma diferente para cada rodovia. Enquanto na Rodovia Presidente Castelo Branco o fluxo direcional apresentou variações diárias no decorrer da semana, na Rodovia Raposo Tavares o fluxo direcional apresentou variações horárias ao longo do dia. Na última análise investigada para diferentes dados de tráfego veicular, foi avaliada a mesma rodovia e a mesma época para vias distintas: marginal e expressa. Os resultados obtidos indicaram que o comportamento do tráfego para as duas vias não foi similar, tanto na configuração e no perfil de cada agrupamento quanto na distribuição de anomalias nas duas vias.

As análises investigadas de acordo com a classificação do veículo, abordaram três tipos: automóvel, caminhão e moto. Os resultados para os automóveis indicaram que esse tipo de composição apresentou um padrão bem definido para cada perfil de dia típico e as anomalias foram distribuídas ao longo da semana. Com isso, foi possível verificar que os métodos de reconhecimento de padrões e de detecção de anomalias são complementares. No segundo tipo de veículo investigado (caminhão), os resultados indicaram maior dificuldade para formar grupos de dias típicos em relação à composição de automóvel ou do tráfego como um todo. No entanto, foram obtidos alguns padrões e as anomalias indicaram oscilações concentradas no domingo. Por fim, na terceira investigação o comportamento das motos apresentou baixa similaridade entre os dias que 
compuseram os agrupamentos de dias típicos e na detecção de anomalia, apesar de ter muitas oscilações, as mesmas não ultrapassaram o threshold, portanto não foram classificadas como anomalia.

Por último foi investigada a influência da resolução dos dados nos métodos propostos. Os resultados obtidos tanto para o sentido Norte quanto para o sentido Sul da Rodovia dos Bandeirantes indicaram que mesmo com intervalo diferente de entrada, 5 e 6 minutos, a aplicação do método não foi prejudicada.

Em linhas gerais, a aplicação do método em outras condições de tráfego comprovou que os métodos propostos podem ser aplicados para diferentes situações, seja mudando os dados de tráfego veicular, os tipos de veículos ou a resolução dos dados de entrada. Demonstrou também que ao aplicar os dois métodos propostos em conjunto, os resultados do comportamento do tráfego e da detecção de anomalia se complementaram, pois um indicou os comportamentos típicos e o outro, os atípicos. 


\section{CONCLUSÕES E RECOMENDAÇÕES}

A meta desta pesquisa foi realizar uma análise exploratória da aplicação da Transformada Wavelet em dados históricos de tráfego veicular a fim de identificar e representar automaticamente as variações do comportamento da corrente de tráfego. Para tanto, foram propostos os seguintes objetivos específicos:

a) Definir a família Wavelet e a escala de tempo a ser usada nos dados da corrente de tráfego;

b) Reconhecer padrões no comportamento do tráfego veicular em rodovias;

c) Detectar anomalias do tráfego veicular em rodovias

A meta e os objetivos específicos propostos para essa pesquisa foram completamente realizados, visto que todos os objetivos determinados foram cumpridos. Na sequência são apresentadas as conclusões para cada objetivo proposto.

\subsection{CONCLUSÕES}

Para alcançar o primeiro objetivo específico foi necessário compreender os coeficientes gerados pela Transformada Wavelet. Dessa forma, foram especificados procedimentos para fornecer o sinal de entrada, com a obtenção, tratamento e estruturação do banco de dados. Com o sinal original definido, foram abordadas as especificações necessárias para aplicação da TWD e só assim, foram caracterizados os Componentes Detalhe e Aproximação gerados a partir de dados de tráfego veicular. Este objetivo foi de suma importância, pois além de constituir os sinais analisados pelos métodos complementares, serviu como base para análise dos mesmos.

Os dados de tráfego, fluxo e velocidade foram obtidos por laços indutivos agregados em intervalos de cinco ou seis minutos, compostos por dados de automóveis, veículos pesados e motos. Devido as falhas que os sensores estão sujeitos, foi feito o tratamento dos dados em busca de dados faltantes e dados de tráfego repetidos erroneamente. Após 
o tratamento, o banco de dados foi estruturado buscando a sua padronização para não haver propagação de erros no sinal de entrada gerados a partir desses dados.

Com os sinais discretos originados dos dados de fluxo e velocidade, foi aplicada a Transformada Wavelet Discreta de Haar e foram gerados os Coeficientes de Aproximação e Detalhe para cada nível de decomposição. Em seguida, foram determinados os níveis de decomposição que seriam avaliados. Como os coeficientes gerados a cada nível dependiam do intervalo de tempo do sinal original, os mesmos foram definidos de acordo com a janela de tempo resultante. Para analisar a janela próxima a uma hora foi utilizado o nível 4 nos dados com intervalo de 5 minutos e o nível 3 nos dados de intervalo de 6 minutos. Para a janela próxima a um dia, foi avaliado o nível 8 em ambos os intervalos e para a janela próxima a uma semana, o nível 11, também para ambos os dados. No entanto, cada intervalo de tempo gerou janelas diferentes a cada nível de decomposição da Transformada Wavelet. Diante do exposto, conclui-se que para definir o nível de decomposição, independentemente do tipo de Wavelet, é necessário analisar o intervalo do sinal original, pois os coeficientes gerados a cada nível, dependem do sinal original.

Cumprido o primeiro objetivo específico, foi trabalhado o segundo: reconhecer padrões no comportamento do tráfego. Para isso, foi proposto um método dividido em três etapas: escolha do coeficiente, análise de agrupamento e aplicação nos dados por período. Com base na revisão bibliográfica e nos resultados obtidos, foi determinado que os Coeficientes de Aproximação fossem utilizados para as análises de reconhecimento de padrões e os Coeficientes de Detalhe, para detecção de anomalias. Já o método de agrupamento definido foi o procedimento hierárquico de Ward utilizando a distância euclidiana quadrática, pois tende a produzir agrupamentos com tamanhos aproximados, minimizando a variação interna dos grupos. Por fim, foram analisados períodos distintos: anual e mensal.

A partir dos resultados obtidos para o reconhecimento de padrões, diversas conclusões podem ser tecidas pois foram avaliadas diferentes situações. As principais conclusões são: (1) existe grande tendência em classificar terças, quartas e quintas-feiras como dias úteis típicos, (2) o período mensal é melhor para definir os grupos de dias típicos do que o anual, (3) os feriados influenciam a quantidade de agrupamentos que formam os grupos típicos, (4) existe diferentes efeitos para cada feriado e (5) o feriado influência de forma distinta cada sentido da rodovia. 
Por fim, o terceiro objetivo foi detectar anomalias no tráfego veicular. Para cumprir o último objetivo específico foi definido o conceito anomalia nesta dissertação e como as mesmas seriam avaliadas. Para tal, foram utilizados os coeficientes de detalhe e determinado um threshold em função do desvio padrão a cada coeficiente avaliado.

Assim como para o reconhecimento de padrões, os resultados obtidos para detecção de anomalias levaram a várias conclusões, entre elas: (1) os primeiros níveis de decomposição apresentaram maior número de anomalias, (2) as análises em sinais de período mensal concentraram mais anomalias do que a análise em um sinal de período anual, (3) a concentração de anomalias por tipo de dia esteve diretamente relacionada com o fluxo direcional e (4) além de anomalias relacionadas ao comportamento do tráfego, foi possível identificar falhas no sensor.

Como forma de validar os métodos propostos para cumprir os objetivos específicos, os mesmos foram aplicados em outras condições de tráfego, investigando três características distintas: dados de tráfego veicular em diferentes situações, composição do tráfego para diferentes tipos de veículos e resolução dos dados de entrada.

Com os resultados obtidos na aplicação do método de reconhecimento de padrões e detecção de anomalias em diferentes condições de tráfego, concluiu-se que os métodos propostos podem ser aplicados para diferentes situações, seja mudando os dados de tráfego veicular, os tipos de veículos ou a resolução dos dados de entrada. Demonstrou também que ao aplicar os dois métodos propostos em conjunto, os resultados do comportamento do tráfego e da detecção de anomalia se complementaram, pois, enquanto um indicou os comportamentos típicos, o outro indicou os comportamentos atípicos.

\subsection{SUGESTÕES PARA TRABALHOS FUTUROS}

A partir das avaliações feitas durante a pesquisa, é possível indicar algumas recomendações para futuras investigações acadêmicas. A primeira delas é em relação a Wavelet utilizada. Nesta pesquisa foi utilizada a TWD de Haar, no entanto cada família Wavelet apresenta uma forma e característica distintas, portanto sugere-se a investigação de outra que melhor decomponha dados de tráfego veicular. 
Nesta pesquisa foram exploradas as anomalias acima do valor de threshold, no entanto a literatura apresenta a Transformada Wavelet Inversa, que permite reconstruir um sinal que tenha sido decomposto. Essa propriedade pode ser útil para reconstruir o sinal original do tráfego veicular, livre do que foi considerado nesta pesquisa como anomalia. Essa técnica é constantemente empregada na área de processamento de sinais digitais, um exemplo é a sua aplicação em imagens, sendo a mesma decomposta e filtrada para em seguida ser reconstruída, livre de ruídos.

Os resultados obtidos indicaram que o comportamento do tráfego é influenciado por diversos fatores e que o método proposto é capaz de identificar características importantes. Com base nisto, sugere-se o desenvolvimento de um software, que ao fornecer os dados de entrada, exprima todas as características avaliadas e discutidas nesta pesquisa de forma automática.

Por fim, além da sugestão do software, indica-se também desenvolver o método para aplicação direta de modelagem e previsão de tráfego, assim como em detecção de incidentes e outros distúrbios presentes no tráfego veicular, tanto em análises macroscópicas quanto microscópicas. 


\section{APÊNDICES}

APÊNDICE 3.1 - Tabela com a localização do sensor e a quantidade de dados faltantes em cada mês de coleta em escala de cor.

\begin{tabular}{|c|c|c|c|c|c|c|c|c|c|c|c|c|}
\hline RODOVIA & KM & FAIXA & set/11 & out/11 & nov/11 & $\operatorname{dez} / 11$ & jan/12 & fev/12 & $\mathrm{mar} / 12$ & $a b r / 12$ & $\mathrm{mai} / 12$ & jun/12 \\
\hline \multirow{13}{*}{$\begin{array}{c}\text { Presidente } \\
\text { Castelo } \\
\text { Branco }\end{array}$} & 15.9 & OM & 0 & 0 & 0 & 0 & 194 & 12 & 11 & 323 & 445 & 3306 \\
\hline & \multirow{2}{*}{16.0} & L/OE & 0 & 12 & 0 & 0 & 65 & 828 & 0 & 23 & 0 & 41 \\
\hline & & LM & 293 & 1830 & 0 & 0 & 0 & 1429 & 333 & 201 & 0 & 2221 \\
\hline & 18.4 & LM & 0 & 25 & 0 & 430 & 528 & 830 & 0 & 0 & 0 & 0 \\
\hline & \multirow{3}{*}{22.3} & L/OE & 0 & 12 & 0 & 0 & 39 & 1116 & 1567 & 384 & 618 & 0 \\
\hline & & LM & 0 & 12 & 0 & 0 & 0 & 1150 & 0 & 0 & 0 & 0 \\
\hline & & $\mathrm{OM}$ & 0 & 12 & 0 & 0 & 0 & 1176 & 788 & 0 & 0 & 130 \\
\hline & 26.9 & L/OE & 1095 & 8916 & 8500 & 8500 & 8500 & 8500 & 8500 & 8500 & 933 & 3160 \\
\hline & 29.5 & L/OE & 0 & 12 & 0 & 0 & 33 & 12 & 0 & 0 & 0 & 0 \\
\hline & 37.0 & L/OE & 3 & 12 & 26 & 35 & 0 & 12 & 59 & 314 & 39 & 139 \\
\hline & 51.9 & L/OE & 0 & 12 & 0 & 0 & 0 & 12 & 0 & 0 & 0 & 0 \\
\hline & 59.6 & L/OE & 0 & 295 & 0 & 0 & 18 & 1182 & 1099 & 4707 & 5451 & 7854 \\
\hline & 75.0 & L/OE & 0 & 1177 & 2660 & 0 & 0 & 1421 & 0 & 282 & 5 & 2259 \\
\hline \multirow{2}{*}{$\begin{array}{l}\text { Raposo } \\
\text { Tavares }\end{array}$} & 34.0 & L/OE & 8500 & 8500 & 8500 & 8500 & 1248 & 80 & 39 & 0 & 0 & 0 \\
\hline & 39.9 & L/OE & 0 & 22 & 10 & 908 & 1731 & 423 & 94 & 42 & 30 & 0 \\
\hline \multirow{3}{*}{$\begin{array}{l}\text { Rodoanel } \\
\text { Mário Covas }\end{array}$} & 18,3 & $E / I P$ & 8500 & 2217 & 1722 & 2808 & 258 & 0 & 2182 & 250 & 949 & 40 \\
\hline & \multirow{2}{*}{22,3} & EP & 8500 & 8500 & 8500 & 8500 & 8500 & 8500 & 8500 & 8500 & 8500 & 8500 \\
\hline & & IP & 42 & 13 & 0 & 226 & 1101 & 15 & 30 & 1872 & 8500 & 3393 \\
\hline \multirow{12}{*}{ AutoBan } & \multirow{2}{*}{32.0} & $\mathrm{~N}$ & 1700 & 110 & 1660 & 320 & 8500 & 103 & 37 & 1220 & 51 & 50 \\
\hline & & $S$ & 0 & 1090 & 1660 & 320 & 8500 & 103 & 37 & 90 & 51 & 50 \\
\hline & \multirow{2}{*}{50.0} & $\mathrm{~N}$ & 3890 & 10 & 8500 & 4420 & 890 & 312 & 105 & 470 & 590 & 780 \\
\hline & & $S$ & 0 & 10 & 8500 & 3020 & 926 & 312 & 105 & 470 & 590 & 780 \\
\hline & \multirow{2}{*}{65.0} & $\mathrm{~N}$ & 0 & 10 & 2530 & 4500 & 0 & 10 & 567 & 2140 & 0 & 0 \\
\hline & & $S$ & 5200 & 600 & 2530 & 300 & 0 & 10 & 567 & 280 & 0 & 0 \\
\hline & \multirow{2}{*}{92.0} & $\mathrm{~N}$ & 2830 & 830 & 730 & 4810 & 30 & 15 & 6010 & 8500 & 2210 & 0 \\
\hline & & $S$ & 2830 & 830 & 730 & 2970 & 30 & 15 & 0 & 170 & 0 & 0 \\
\hline & \multirow{2}{*}{131.0} & $\mathrm{~N}$ & 0 & 300 & 1581 & 70 & 1616 & 14 & 0 & 60 & 0 & 0 \\
\hline & & $S$ & 0 & 300 & 1581 & 1180 & 1616 & 14 & 0 & 60 & 0 & 0 \\
\hline & \multirow{2}{*}{149.0} & $\mathrm{~N}$ & 1840 & 10 & 0 & 480 & 410 & 631 & 522 & 10 & 0 & 0 \\
\hline & & S & 1840 & 10 & 0 & 480 & 410 & 631 & 522 & 10 & 0 & 0 \\
\hline
\end{tabular}




\begin{tabular}{|c|c|c|c|c|c|c|c|c|c|c|c|c|}
\hline RODOVIA & KM & FAIXA & jul/12 & ago/12 & set/12 & out/12 & nov/12 & dez/12 & jan/13 & fev/13 & $\mathrm{mar} / 13$ & $a b r / 13$ \\
\hline \multirow{13}{*}{$\begin{array}{c}\text { Presidente } \\
\text { Castelo } \\
\text { Branco }\end{array}$} & 15.9 & OM & 0 & 0 & 0 & 0 & 0 & 12 & 562 & 221 & 0 & 0 \\
\hline & \multirow{2}{*}{16.0} & L/OE & 0 & 0 & 0 & 12 & 0 & 3538 & 1119 & 1105 & 594 & 594 \\
\hline & & LM & 0 & 0 & 0 & 0 & 0 & 217 & 0 & 0 & 0 & 0 \\
\hline & 18.4 & LM & 12 & 0 & 0 & 12 & 0 & 659 & 2650 & 0 & 0 & 0 \\
\hline & \multirow{3}{*}{22.3} & L/OE & 0 & 0 & 0 & 12 & 0 & 0 & 0 & 0 & 0 & 1829 \\
\hline & & LM & 0 & 0 & 28 & 17 & 19 & 18 & 0 & 0 & 0 & 0 \\
\hline & & OM & 1151 & 130 & 0 & 0 & 25 & 21 & 0 & 0 & 0 & 0 \\
\hline & 26.9 & L/OE & 0 & 40 & 0 & 12 & 1425 & 0 & 4 & 7 & 0 & 0 \\
\hline & 29.5 & L/OE & 0 & 0 & 0 & 12 & 51 & 0 & 8 & 0 & 0 & 20 \\
\hline & 37.0 & L/OE & 0 & 0 & 0 & 235 & 131 & 147 & 319 & 160 & 186 & 0 \\
\hline & 51.9 & L/OE & 0 & 0 & 3 & 17 & 593 & 1936 & 8500 & 7963 (8500) & 2560 & 0 \\
\hline & 59.6 & L/OE & 4069 & 372 & 754 & 14 & 25 & 11 & 8153 & 6257 & 0 & 0 \\
\hline & 75.0 & L/OE & 5582 & 3056 & 0 & 12 & 0 & 0 & 7219 & 8076 & 8500 & 8500 \\
\hline \multirow{2}{*}{$\begin{array}{l}\text { Raposo } \\
\text { Tavares }\end{array}$} & 34.0 & L/OE & 0 & 0 & 0 & 79 & 1326 & 51 & 37 & 1498 & 2995 & 40 \\
\hline & 39.9 & L/OE & 0 & 75 & 0 & 1522 & 1577 & 0 & 44 & 510 & 211 & 6198 \\
\hline \multirow{3}{*}{$\begin{array}{l}\text { Rodoanel } \\
\text { Mário Covas }\end{array}$} & 18,3 & E/IP & 0 & 26 & 85 & 4062 & 8500 & 8500 & 8500 & 8500 & 8500 & 8500 \\
\hline & \multirow{2}{*}{22,3} & EP & 8500 & 8500 & 8500 & 8500 & 8500 & 8500 & 8500 & 8500 & 7065 & 108 \\
\hline & & IP & 1447 & 838 & 154 & 14 & 9 & 4784 & 8500 & 8500 & 7048 & 10 \\
\hline \multirow{12}{*}{ AutoBan } & \multirow{2}{*}{32.0} & $\mathbf{N}$ & 70 & 50 & 0 & 390 & 23 & 1720 & 2509 & 300 & 3560 & 0 \\
\hline & & $S$ & 70 & 46 & 0 & 390 & 14 & 590 & 2509 & 300 & 3560 & 0 \\
\hline & \multirow{2}{*}{50.0} & $\mathbf{N}$ & 0 & 10 & 0 & 0 & 4480 & 0 & 0 & 552 & 196 & 0 \\
\hline & & $S$ & 0 & 10 & 0 & 0 & 4480 & 0 & 0 & 552 & 196 & 0 \\
\hline & \multirow{2}{*}{65.0} & $\mathbf{N}$ & 280 & 120 & 490 & 0 & 0 & 20 & 606 & 1936 & 1865 & 179 \\
\hline & & $S$ & 280 & 120 & 490 & 0 & 0 & 20 & 606 & 1936 & 1865 & 179 \\
\hline & \multirow{2}{*}{92.0} & $N$ & 36 & 0 & 0 & 10 & 30 & 330 & 0 & 6 & 1293 & 448 \\
\hline & & $S$ & 36 & 0 & 0 & 4831 & 4010 & 330 & 0 & 6 & 1293 & 448 \\
\hline & \multirow{2}{*}{131.0} & $\mathrm{~N}$ & 0 & 0 & 0 & 0 & 2870 & 8500 & 689 & 1183 & 4191 & 0 \\
\hline & & $S$ & 0 & 0 & 0 & 0 & 2870 & 8500 & 689 & 1183 & 4191 & 0 \\
\hline & \multirow{2}{*}{149.0} & $\mathrm{~N}$ & 0 & 380 & 0 & 611 & 6 & 8500 & 2089 & 4 & 136 & 0 \\
\hline & & $S$ & 0 & 380 & 0 & 611 & 6 & 8500 & 2087 & 4 & 136 & 0 \\
\hline
\end{tabular}




\begin{tabular}{|c|c|c|c|c|c|c|c|c|c|c|c|c|}
\hline RODOVIA & KM & FAIXA & mai/13 & jun/13 & $\mathrm{jul} / 13$ & ago/13 & set/13 & out/13 & nov/13 & dez/13 & jan/14 & fev/14 \\
\hline \multirow{13}{*}{$\begin{array}{c}\text { Presidente } \\
\text { Castelo } \\
\text { Branco }\end{array}$} & 15.9 & OM & 0 & 24 & 0 & 0 & 0 & 0 & 77 & 86 & 0 & 7 \\
\hline & \multirow{2}{*}{16.0} & L/OE & 195 & 52 & 152 & 0 & 5 & 0 & 78 & 867 & 61 & 43 \\
\hline & & LM & 0 & 16 & 17 & 0 & 0 & 0 & 82 & 64 & 0 & 7 \\
\hline & 18.4 & LM & 6814 & 1882 & 519 & 3620 & 0 & 0 & 1135 & 274 & 2094 & 8076 \\
\hline & \multirow{3}{*}{22.3} & L/OE & 8500 & 8500 & 8500 & 8500 & 8500 & 8500 & 8500 & 8500 & 8500 & 8500 \\
\hline & & LM & 0 & 55 & 0 & 0 & 0 & 0 & 93 & 234 & 856 & 40 \\
\hline & & OM & 0 & 0 & 0 & 0 & 0 & 0 & 4096 & 1103 & 526 & 10 \\
\hline & 26.9 & L/OE & 0 & 436 & 29 & 0 & 0 & 21 & 5887 & 1985 & 101 & 2681 \\
\hline & 29.5 & L/OE & 0 & 20 & 30 & 0 & 17 & 4 & 98 & 7686 & 8500 & 8500 \\
\hline & 37.0 & L/OE & 0 & 0 & 1699 & 0 & 0 & 0 & 82 & 4155 & 2636 & 329 \\
\hline & 51.9 & L/OE & 0 & 0 & 55 & 3411 & 4 & 18 & 75 & 1964 & 9 & 14 \\
\hline & 59.6 & L/OE & 0 & 84 & 0 & 0 & 27 & 909 & 4057 & 840 & 590 & 77 \\
\hline & 75.0 & L/OE & 4196 & 0 & 211 & 2573 & 1090 & 2575 & 8500 & 8500 & 8500 & 8500 \\
\hline \multirow{2}{*}{$\begin{array}{l}\text { Raposo } \\
\text { Tavares }\end{array}$} & 34.0 & L/OE & 16 & 1396 & 193 & 23 & 66 & 1482 & 3717 & 2703 & 411 & 21 \\
\hline & 39.9 & L/OE & 4225 & 4877 & 4240 & 16 & 0 & 0 & 74 & 108 & 6 & 149 \\
\hline \multirow{3}{*}{$\begin{array}{l}\text { Rodoanel } \\
\text { Mário Covas }\end{array}$} & 18,3 & E/IP & 8500 & 8500 & 8500 & 8500 & 8500 & 8500 & 8500 & 8500 & 8500 & 4181 \\
\hline & \multirow{2}{*}{22,3} & EP & 0 & 400 & 74 & 36 & 142 & 74 & 8500 & 247 & 4000 & 42 \\
\hline & & IP & 0 & 10 & 25 & 0 & 76 & 20 & 8500 & 146 & 4000 & 6 \\
\hline \multirow{12}{*}{ AutoBan } & \multirow{2}{*}{32.0} & $\mathbf{N}$ & 0 & 2175 & 0 & 0 & 0 & 0 & 0 & 0 & 0 & 0 \\
\hline & & $S$ & 0 & 2175 & 0 & 0 & 0 & 0 & 0 & 0 & 0 & 0 \\
\hline & \multirow{2}{*}{50.0} & $\mathbf{N}$ & 0 & 566 & 0 & 0 & 203 & 0 & 5 & 10 & 59 & 103 \\
\hline & & $S$ & 0 & 566 & 0 & 0 & 203 & 0 & 5 & 10 & 59 & 103 \\
\hline & \multirow{2}{*}{65.0} & $\mathbf{N}$ & 0 & 19 & 943 & 0 & 17 & 0 & 0 & 0 & 0 & 0 \\
\hline & & $S$ & 0 & 19 & 943 & 0 & 17 & 0 & 0 & 0 & 0 & 0 \\
\hline & \multirow{2}{*}{92.0} & $\mathbf{N}$ & 1543 & 0 & 0 & 0 & 17 & 0 & 1727 & 0 & 0 & 10 \\
\hline & & $S$ & 1543 & 0 & 0 & 0 & 17 & 0 & 1727 & 0 & 0 & 10 \\
\hline & \multirow{2}{*}{131.0} & $\mathbf{N}$ & 45 & 0 & 9 & 0 & 18 & 0 & 45 & 9 & 0 & 4 \\
\hline & & $S$ & 45 & 0 & 9 & 0 & 18 & 0 & 45 & 9 & 0 & 4 \\
\hline & \multirow{2}{*}{149.0} & $\mathbf{N}$ & 6 & 45 & 14 & 0 & 17 & 11 & 68 & 0 & 0 & 65 \\
\hline & & $S$ & 6 & 45 & 14 & 0 & 17 & 11 & 68 & 0 & 0 & 65 \\
\hline
\end{tabular}




\begin{tabular}{|c|c|c|c|c|c|}
\hline RODOVIA & KM & FAIXA & mar/14 & $a b r / 14$ & mai/14 \\
\hline \multirow{13}{*}{$\begin{array}{c}\text { Presidente } \\
\text { Castelo } \\
\text { Branco }\end{array}$} & 15.9 & OM & 129 & 979 & 0 \\
\hline & \multirow{2}{*}{16.0} & L/OE & 145 & 501 & 8 \\
\hline & & LM & 1669 & 0 & 0 \\
\hline & 18.4 & LM & 8928 & 1523 & 0 \\
\hline & \multirow{3}{*}{22.3} & L/OE & 8500 & 8500 & 8500 \\
\hline & & LM & 47 & 356 & 1222 \\
\hline & & OM & 32 & 159 & 35 \\
\hline & 26.9 & L/OE & 146 & 11 & 132 \\
\hline & 29.5 & L/OE & 8500 & 8500 & 8500 \\
\hline & 37.0 & L/OE & 1716 & 50 & 190 \\
\hline & 51.9 & L/OE & 15 & 24 & 50 \\
\hline & 59.6 & L/OE & 0 & 2646 & 0 \\
\hline & 75.0 & L/OE & 15 & 0 & 0 \\
\hline \multirow{2}{*}{$\begin{array}{l}\text { Raposo } \\
\text { Tavares }\end{array}$} & 34.0 & L/OE & 2784 & 2401 & 1026 \\
\hline & 39.9 & L/OE & 0 & 0 & 0 \\
\hline \multirow{3}{*}{$\begin{array}{l}\text { Rodoanel } \\
\text { Mário Covas }\end{array}$} & 18,3 & E/IP & 4807 & 0 & 3141 \\
\hline & \multirow{2}{*}{22,3} & EP & 4335 & 188 & 2270 \\
\hline & & IP & 4335 & 108 & 2270 \\
\hline \multirow{12}{*}{ AutoBan } & \multirow{2}{*}{32.0} & $N$ & 0 & 8500 & 3411 \\
\hline & & $S$ & 0 & 0 & 3411 \\
\hline & \multirow{2}{*}{50.0} & $\mathbf{N}$ & 176 & 0 & 0 \\
\hline & & $S$ & 176 & 0 & 0 \\
\hline & \multirow{2}{*}{65.0} & $\mathbf{N}$ & 0 & 59 & 0 \\
\hline & & $S$ & 0 & 59 & 0 \\
\hline & \multirow{2}{*}{92.0} & $\mathbf{N}$ & 0 & 0 & 0 \\
\hline & & $S$ & 0 & 0 & 0 \\
\hline & \multirow{2}{*}{131.0} & $\mathbf{N}$ & 20 & 53 & 51 \\
\hline & & $S$ & 20 & 53 & 51 \\
\hline & \multirow{2}{*}{149.0} & $\mathrm{~N}$ & 25 & 6 & 0 \\
\hline & & $S$ & 25 & 6 & 0 \\
\hline
\end{tabular}

\begin{tabular}{|c|c|c|c|}
\hline RODOVIA & PERÍODO & $\begin{array}{c}\text { DADOS } \\
\text { FALTANTES }\end{array}$ & $\begin{array}{c}\text { ESCALA DE } \\
\text { COR }\end{array}$ \\
\hline \multirow{4}{*}{$\begin{array}{c}\text { Presidente Castelo Branco, } \\
\text { Raposo Tavares e Rodoanel } \\
\text { Mário Covas }\end{array}$} & Até 1 hora & 0 à 12 & \\
\hline & De 1 hora à 1 dia & 13 à 288 & \\
\hline & De 1 dia à 1 semana & 289 à 2016 & \\
\hline & $>1$ semana & $>2016$ & \\
\hline \multirow{4}{*}{ AutoBan } & Até 1 hora & 0 à 10 & \\
\hline & De 1 hora à 1 dia & 11 a 240 & \\
\hline & De 1 dia à 1 semana & 241 a 1680 & \\
\hline & $>1$ semana & $>1680$ & \\
\hline
\end{tabular}


APÊNDICE 3.2 - Dados faltantes no período de um ano para todos os sensores analisados (destacado em amarelo até 1 dia faltante).

\begin{tabular}{|c|c|c|c|c|c|c|c|c|c|c|c|c|}
\hline RODOVIA & KM & FAIXA & $\begin{array}{l}\text { Set/2011 - } \\
\text { Ago/2012 }\end{array}$ & $\begin{array}{c}\text { Out/2011 - } \\
\text { Set/2012 }\end{array}$ & $\begin{array}{c}\text { Nov/2011 - } \\
\text { Out/212 }\end{array}$ & $\begin{array}{l}\text { Dez/2011 - } \\
\text { Nov/2012 }\end{array}$ & $\begin{array}{l}\text { Jan/2012 - } \\
\text { Dez/2012 }\end{array}$ & $\begin{array}{c}\text { Fev/2012 - } \\
\text { Jan/2013 }\end{array}$ & $\begin{array}{c}\text { Mar/2012 - } \\
\text { Fev/2013 }\end{array}$ & $\begin{array}{l}\text { Abr/2012 - } \\
\text { Mar/2013 }\end{array}$ & $\begin{array}{c}\text { Mai/2012 - } \\
\text { Abr/2013 } \\
\end{array}$ & $\begin{array}{l}\text { Jun/2012 - } \\
\text { Mai/2013 }\end{array}$ \\
\hline \multirow{13}{*}{$\begin{array}{c}\text { Presidente } \\
\text { Castelo } \\
\text { Branco }\end{array}$} & 15.9 & OM & 4291 & 4291 & 4291 & 4291 & 4303 & 4671 & 4880 & 4869 & 4546 & 4101 \\
\hline & \multirow{2}{*}{16.0} & L/OE & 969 & 969 & 969 & 969 & 4507 & 5561 & 5838 & 6432 & 7003 & 7198 \\
\hline & & LM & 6307 & 6014 & 4184 & 4184 & 4401 & 4401 & 2972 & 2639 & 2438 & 2438 \\
\hline & 18.4 & LM & 1825 & 1825 & 1812 & 1812 & 2041 & 4163 & 3333 & 3333 & 3333 & 10147 \\
\hline & \multirow{3}{*}{22.3} & L/OE & 3736 & 3736 & 3736 & 3736 & 3736 & 3697 & 2581 & 1014 & 2459 & 10341 \\
\hline & & LM & 1162 & 1190 & 1195 & 1214 & 1232 & 1232 & 82 & 82 & 82 & 82 \\
\hline & & OM & 3387 & 3387 & 3375 & 3400 & 3421 & 3421 & 2245 & 1457 & 1457 & 1457 \\
\hline & 26.9 & L/OE & 65144 & 64049 & 55145 & 48070 & 39570 & 31074 & 22581 & 14081 & 5581 & 4648 \\
\hline & 29.5 & L/OE & 57 & 57 & 57 & 108 & 108 & 83 & 71 & 71 & 91 & 91 \\
\hline & 37.0 & L/OE & 639 & 636 & 859 & 964 & 1076 & 1395 & 1543 & 1670 & 1356 & 1317 \\
\hline & 51.9 & L/OE & 24 & 27 & 32 & 625 & 2561 & 11061 & 11049 & 13609 & 13609 & 13609 \\
\hline & 59.6 & L/OE & 25047 & 25801 & 25520 & 25545 & 25556 & 33691 & 38766 & 37667 & 32960 & 27509 \\
\hline & 75.0 & L/OE & 16442 & 16442 & 15277 & 12617 & 12617 & 19836 & 26491 & 34991 & 43209 & 47400 \\
\hline \multirow{2}{*}{$\begin{array}{l}\text { Raposo } \\
\text { Tavares }\end{array}$} & 34.0 & L/OE & 35367 & 26867 & 18446 & 11272 & 2823 & 1612 & 3030 & 5986 & 6026 & 6042 \\
\hline & 39.9 & L/OE & 3335 & 3335 & 4835 & 6402 & 5494 & 3807 & 3894 & 4011 & 10167 & 14362 \\
\hline \multirow{3}{*}{$\begin{array}{c}\text { Rodoanel } \\
\text { Mário Covas }\end{array}$} & 18,3 & E/IP & 18952 & 10537 & 12382 & 19160 & 24852 & 33094 & 41594 & 47912 & 56162 & 63713 \\
\hline & \multirow{2}{*}{22,3} & EP & 102000 & 102000 & 102000 & 102000 & 102000 & 102000 & 102000 & 100565 & 92173 & 83673 \\
\hline & & IP & 17477 & 17589 & 17590 & 17599 & 22157 & 29556 & 38041 & 45059 & 43197 & 34697 \\
\hline \multirow{12}{*}{ AutoBan } & \multirow{2}{*}{32.0} & $\mathbf{N}$ & 13871 & 12171 & 12451 & 10814 & 12214 & 6223 & 6420 & 9943 & 8723 & 8672 \\
\hline & & $S$ & 12017 & 12017 & 11317 & 9671 & 9941 & 3950 & 4147 & 7670 & 7580 & 7529 \\
\hline & \multirow{2}{*}{50.0} & $N$ & 19977 & 16087 & 16077 & 12057 & 7637 & 6747 & 6987 & 7078 & 6608 & 6018 \\
\hline & & $S$ & 14723 & 14723 & 14713 & 10693 & 7673 & 6747 & 6987 & 7078 & 6608 & 6018 \\
\hline & \multirow{2}{*}{65.0} & $\mathrm{~N}$ & 10157 & 10647 & 10637 & 8107 & 3627 & 4233 & 6159 & 7457 & 5496 & 5496 \\
\hline & & $S$ & 9887 & 5177 & 4577 & 2047 & 1767 & 2373 & 4299 & 5597 & 5496 & 5496 \\
\hline & \multirow{2}{*}{92.0} & $\mathbf{N}$ & 26001 & 23171 & 22351 & 21651 & 17171 & 17141 & 17132 & 12415 & 4363 & 3696 \\
\hline & & $S$ & 7611 & 4781 & 8782 & 12062 & 9422 & 9392 & 9383 & 10676 & 10954 & 12497 \\
\hline & \multirow{2}{*}{131.0} & $N$ & 3641 & 3641 & 3341 & 4630 & 13060 & 12133 & 13302 & 17493 & 17433 & 17478 \\
\hline & & $S$ & 4751 & 4751 & 4451 & 5740 & 13060 & 12133 & 13302 & 17493 & 17433 & 17478 \\
\hline & \multirow{2}{*}{149.0} & $N$ & 4283 & 2443 & 3044 & 3050 & 11070 & 12749 & 12122 & 11736 & 11726 & 11732 \\
\hline & & $S$ & 4283 & 2443 & 3044 & 3050 & 11070 & 12747 & 12120 & 11734 & 11724 & 11730 \\
\hline
\end{tabular}




\begin{tabular}{|c|c|c|c|c|c|c|c|c|c|c|c|c|c|}
\hline RODOVIA & KM & FAIXA & $\begin{array}{l}\text { Jul/2012 - } \\
\text { Jun/2013 }\end{array}$ & $\begin{array}{c}\text { Ago/2012 - } \\
\text { Jul/2013 }\end{array}$ & $\begin{array}{l}\text { Set/2012 - } \\
\text { Ago/2013 }\end{array}$ & $\begin{array}{c}\text { Out/2012 - } \\
\text { Set/2013 }\end{array}$ & $\begin{array}{c}\text { Nov/2012 - } \\
\text { Out/2013 }\end{array}$ & $\begin{array}{c}\text { Dez/2012 - } \\
\text { Nov/2013 }\end{array}$ & $\begin{array}{c}\text { Jan/2013 - } \\
\text { Dez/2013 }\end{array}$ & $\begin{array}{c}\text { Fev/2013 - } \\
\text { Jan/2014 }\end{array}$ & $\begin{array}{c}\text { Mar/2013 - } \\
\text { Fev/2014 }\end{array}$ & $\begin{array}{c}\text { Abr/2013 - } \\
\text { Mar/2014 }\end{array}$ & $\begin{array}{c}\text { Mai/2013 - } \\
\text { Abr/2014 }\end{array}$ \\
\hline \multirow{13}{*}{$\begin{array}{c}\text { Presidente } \\
\text { Castelo } \\
\text { Branco }\end{array}$} & 15.9 & OM & 819 & 819 & 819 & 819 & 819 & 896 & 970 & 408 & 194 & 323 & 1302 \\
\hline & \multirow{2}{*}{16.0} & L/OE & 7209 & 7361 & 7361 & 7366 & 7354 & 7432 & 4761 & 3703 & 2641 & 2192 & 2099 \\
\hline & & LM & 233 & 250 & 250 & 250 & 250 & 332 & 179 & 179 & 186 & 1855 & 1855 \\
\hline & 18.4 & LM & 12029 & 12536 & 16156 & 16156 & 16144 & 17279 & 16894 & 16338 & 24414 & 33342 & 34865 \\
\hline & \multirow{3}{*}{22.3} & L/OE & 18841 & 27341 & 35841 & 44341 & 52829 & 61329 & 69829 & 78329 & 86829 & 95329 & 102000 \\
\hline & & LM & 137 & 137 & 137 & 109 & 92 & 166 & 382 & 1238 & 1278 & 1325 & 1681 \\
\hline & & OM & 1327 & 176 & 46 & 46 & 46 & 4117 & 5199 & 5725 & 5735 & 5767 & 5926 \\
\hline & 26.9 & L/OE & 1924 & 1953 & 1913 & 1913 & 1922 & 6384 & 8369 & 8466 & 11140 & 11286 & 11297 \\
\hline & 29.5 & L/OE & 111 & 141 & 141 & 158 & 150 & 197 & 7883 & 16375 & 24875 & 33375 & 41855 \\
\hline & 37.0 & L/OE & 1178 & 2877 & 2877 & 2877 & 2642 & 2593 & 6601 & 8918 & 9087 & 10617 & 10667 \\
\hline & 51.9 & L/OE & 13609 & 13664 & 17075 & 17076 & 17077 & 16559 & 16587 & 8096 & 8110 & 5565 & 5589 \\
\hline & 59.6 & L/OE & 19739 & 15670 & 15298 & 14571 & 15466 & 19498 & 20327 & 12764 & 6584 & 6584 & 9230 \\
\hline & 75.0 & L/OE & 45141 & 39770 & 39287 & 40377 & 42940 & 51440 & 59940 & 61221 & 61645 & 53160 & 44660 \\
\hline \multirow{2}{*}{$\begin{array}{l}\text { Raposo } \\
\text { Tavares }\end{array}$} & 34.0 & L/OE & 7438 & 7631 & 7654 & 7720 & 9123 & 11514 & 14166 & 14540 & 13063 & 12852 & 15213 \\
\hline & 39.9 & L/OE & 19239 & 23479 & 23420 & 23420 & 21898 & 20395 & 20503 & 20465 & 20104 & 19893 & 13695 \\
\hline \multirow{3}{*}{$\begin{array}{c}\text { Rodoanel } \\
\text { Mário Covas }\end{array}$} & 18,3 & E/IP & 72173 & 80673 & 89147 & 97562 & 102000 & 102000 & 102000 & 102000 & 97681 & 93988 & 85488 \\
\hline & \multirow{2}{*}{22,3} & EP & 75573 & 67147 & 58683 & 50325 & 41899 & 41899 & 33646 & 29146 & 20688 & 17958 & 18038 \\
\hline & & IP & 31314 & 29892 & 29054 & 28976 & 28982 & \begin{tabular}{|l|l|}
37473 \\
\end{tabular} & 32835 & 28335 & 19841 & 17128 & 17226 \\
\hline \multirow{12}{*}{ AutoBan } & \multirow{2}{*}{32.0} & $\mathbf{N}$ & 10797 & 10727 & 10677 & 10677 & 10287 & 10264 & 8544 & 6035 & 5735 & 2175 & 10675 \\
\hline & & $S$ & 9654 & 9584 & 9538 & 9538 & 9148 & 9134 & 8544 & 6035 & 5735 & 2175 & 2175 \\
\hline & \multirow{2}{*}{50.0} & $\mathrm{~N}$ & 5804 & 5804 & 5794 & 5997 & 5997 & 1522 & 1532 & 1591 & 1142 & 1122 & 1122 \\
\hline & & $S$ & 5804 & 5804 & 5794 & 5997 & 5997 & 1522 & 1532 & 1591 & 1142 & 1122 & 1122 \\
\hline & \multirow{2}{*}{65.0} & $\mathrm{~N}$ & 5515 & 6178 & 6058 & 5585 & 5585 & 5585 & 5565 & 4959 & 3023 & 1158 & 1038 \\
\hline & & $S$ & 5515 & 6178 & 6058 & 5585 & 5585 & 5585 & 5565 & 4959 & 3023 & 1158 & 1038 \\
\hline & \multirow{2}{*}{92.0} & $\mathbf{N}$ & 3696 & 3660 & 3660 & 3677 & 3667 & 5364 & 5034 & 5034 & 5038 & 3745 & 3297 \\
\hline & & $S$ & 12497 & 12461 & 12461 & 12478 & 7647 & 5364 & 5034 & 5034 & 5038 & 3745 & 3297 \\
\hline & \multirow{2}{*}{131.0} & $\mathrm{~N}$ & 17478 & 17487 & 17487 & 17505 & 17505 & 14680 & 6189 & 5500 & 4321 & 150 & 203 \\
\hline & & $S$ & 17478 & 17487 & 17487 & 17505 & 17505 & 14680 & 6189 & 5500 & 4321 & 150 & 203 \\
\hline & \multirow{2}{*}{149.0} & $\mathbf{N}$ & 11777 & 11791 & 11411 & 11428 & 10828 & 10890 & 2390 & 301 & 362 & 251 & 257 \\
\hline & & $S$ & 11775 & 11789 & 11409 & 11426 & 10826 & 10888 & 2388 & 301 & 362 & 251 & 257 \\
\hline
\end{tabular}


APÊNDICE 4.1 - Resultado da análise de agrupamento a cada mês com 7 cluster para o período de um ano

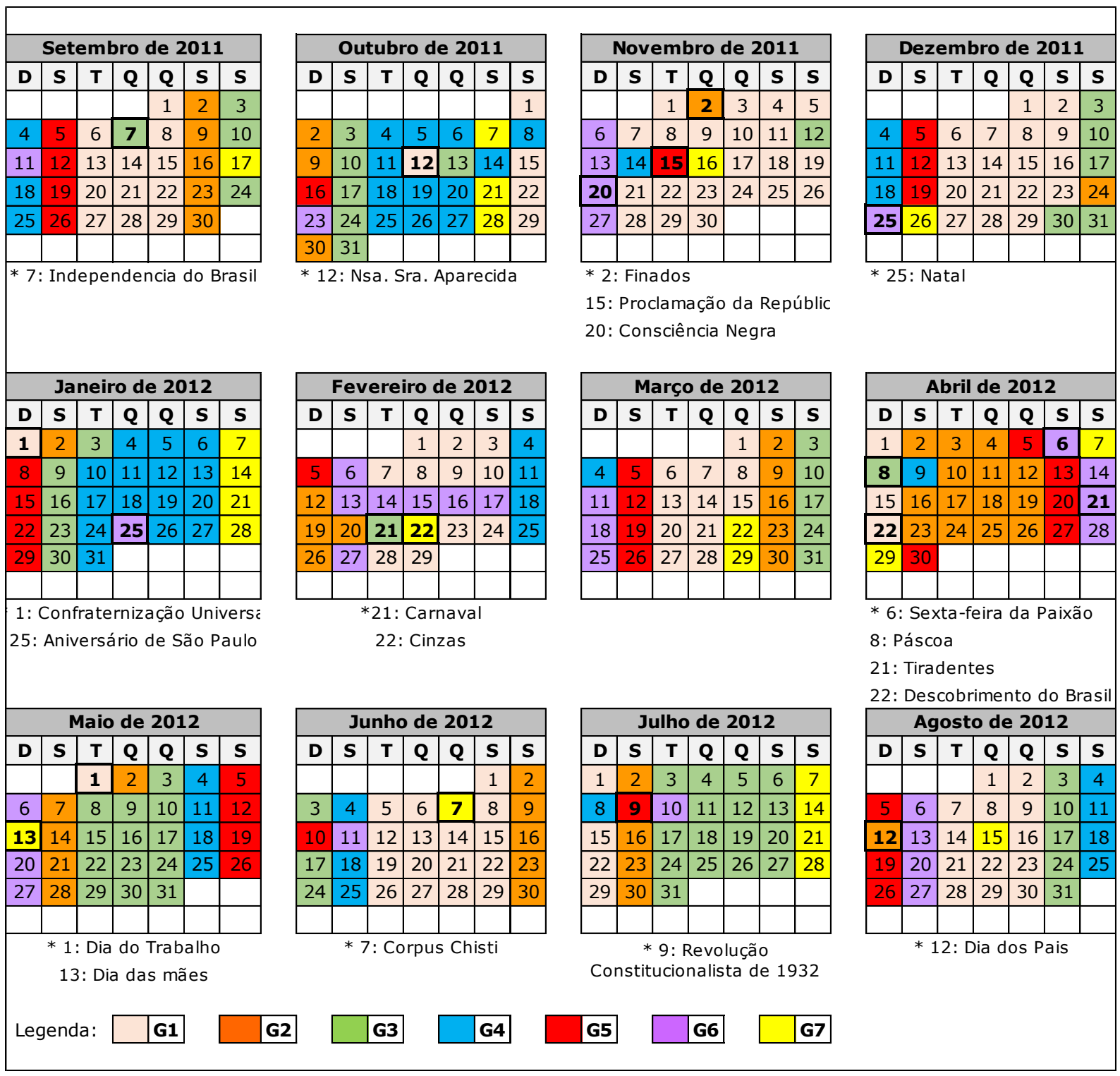


APÊNDICE 5.1 - Anomalias nos dados de fluxo de tráfego no sentido Leste no período anual

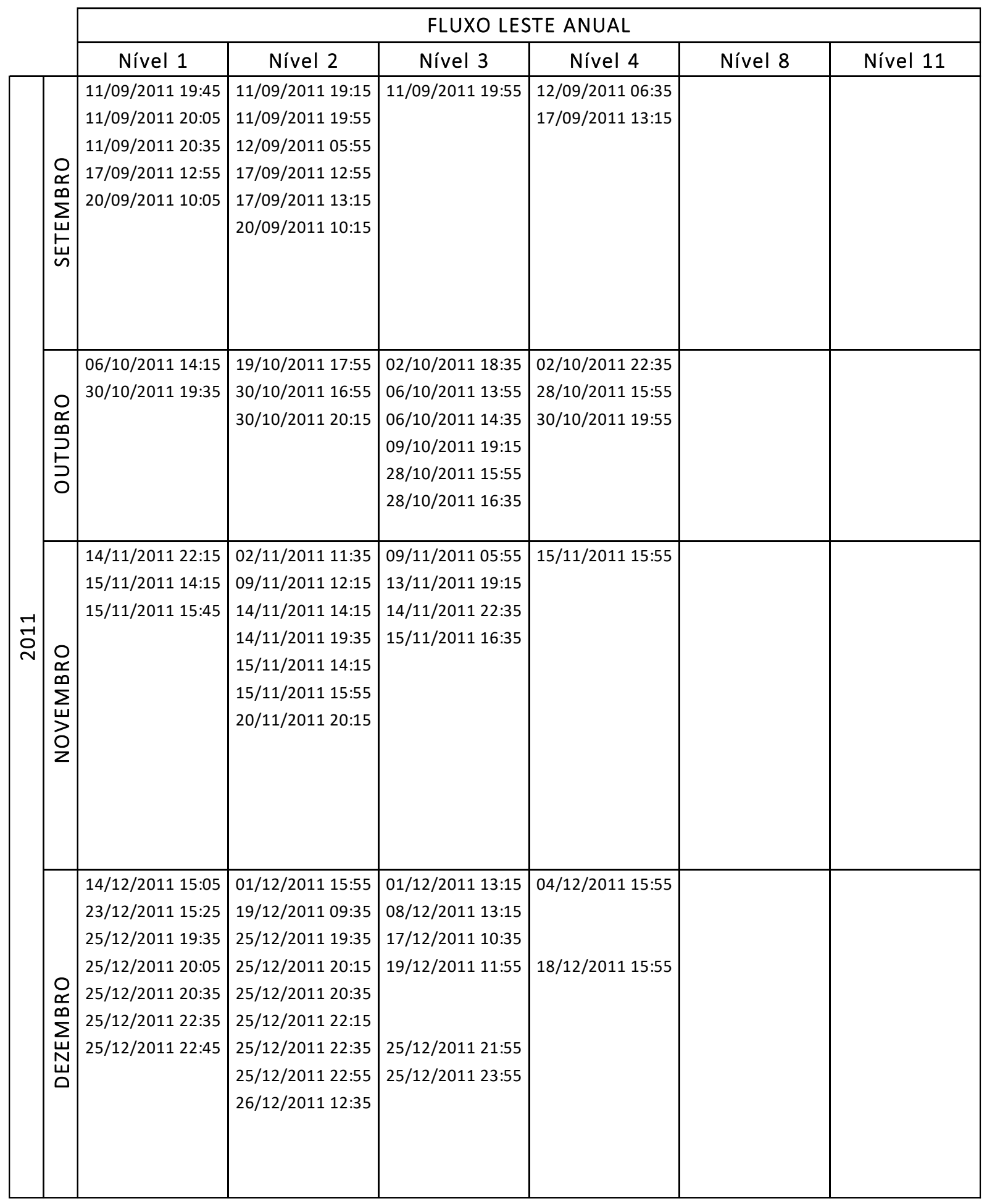




\begin{tabular}{|c|c|c|c|c|c|c|c|}
\hline & \multicolumn{6}{|c|}{ FLUXO LESTE ANUAL } \\
\hline & & Nível 1 & Nível 2 & Nível 3 & Nível 4 & Nível 8 & Nível 11 \\
\hline & & 02/01/2012 10:35 & 02/01/2012 17:35 & 01/01/2012 23:55 & \multirow[t]{8}{*}{ 02/01/2012 01:15 } & & \\
\hline & & 02/01/2012 11:25 & 07/01/2012 09:15 & 02/01/2012 00:35 & & & \\
\hline & & 02/01/2012 11:45 & 07/01/2012 09:35 & 02/01/2012 13:55 & & & \\
\hline & & 02/01/2012 14:35 & $12 / 01 / 201200: 55$ & 15/01/2012 16:35 & & & \\
\hline & & 02/01/2012 17:55 & $15 / 01 / 201215: 35$ & $15 / 01 / 201218: 35$ & & & \\
\hline & 이 & $12 / 01 / 201200: 55$ & $15 / 01 / 201218: 35$ & & & & \\
\hline & $\overline{\mathrm{w}}$ & 15/01/2012 21:15 & $21 / 01 / 201217: 55$ & & & & \\
\hline & $\leq$ & 29/01/2012 18:05 & & & & & \\
\hline \multirow{7}{*}{\multicolumn{2}{|c|}{ 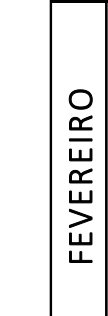 }} & 05/02/2012 18:35 & 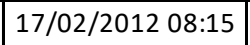 & 05/02/2012 19:15 & 05/02/2012 19:55 & & \\
\hline & & 05/02/2012 23:05 & 17/02/2012 09:15 & 05/02/2012 23:15 & 05/02/2012 23:55 & & \\
\hline & & $17 / 02 / 201208: 15$ & $21 / 02 / 201211: 35$ & $17 / 02 / 201208: 35$ & 20/02/2012 21:15 & & \\
\hline & & $17 / 02 / 201209: 15$ & 21/02/2012 13:15 & 20/02/2012 22:35 & $21 / 02 / 2012$ 10:35 & & \\
\hline & & 20/02/2012 20:45 & & & & & \\
\hline & & 20/02/2012 22:05 & & & & & \\
\hline & & $21 / 02 / 201214: 05$ & & & & & \\
\hline \multirow{4}{*}{$\begin{array}{l}\underset{\sim}{0} \\
\stackrel{N}{ }\end{array}$} & \multirow{4}{*}{ 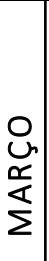 } & 04/03/2012 20:15 & \begin{tabular}{|l|}
$11 / 03 / 2012 ~ 19: 15$ \\
\end{tabular} & \begin{tabular}{|l|}
$11 / 03 / 2012 ~ 19: 55$ \\
\end{tabular} & & & \\
\hline & & $18 / 03 / 201217: 25$ & $11 / 03 / 201220: 15$ & $11 / 03 / 201220: 35$ & & & \\
\hline & & 18/03/2012 19:15 & & & & & \\
\hline & & 30/03/2012 15:25 & & & & & \\
\hline \multirow{6}{*}{\multicolumn{2}{|c|}{$\begin{array}{l}\overrightarrow{\bar{\alpha}} \\
\frac{\alpha}{\alpha}\end{array}$}} & 08/04/2012 13:15 & 08/04/2012 10:35 & & \multirow{6}{*}{$\begin{array}{|ll|}\text { 08/04/2012 } 10: 35 \\
\text { 08/04/2012 18:35 } \\
\text { 09/04/2012 02:35 }\end{array}$} & & \multirow{6}{*}{$15 / 04 / 2012$ 13:15 } \\
\hline & & 08/04/2012 18:25 & 08/04/2012 17:55 & & & & \\
\hline & & 08/04/2012 20:35 & 08/04/2012 18:15 & & & & \\
\hline & & 08/04/2012 20:45 & 08/04/2012 18:35 & & & & \\
\hline & & $15 / 04 / 201218: 35$ & 08/04/2012 20:35 & & & & \\
\hline & & 22/04/2012 18:05 & & & & & \\
\hline \multirow{4}{*}{\multicolumn{2}{|c|}{$\frac{c}{s}$}} & 09/05/2012 07:35 & 26/05/2012 20:55 & 27/05/2012 20:35 & 20/05/2012 19:55 & & \\
\hline & & & & & $27 / 05 / 201219: 55$ & & \\
\hline & & & & & & & \\
\hline & & & & & & & \\
\hline
\end{tabular}




\begin{tabular}{|c|c|c|c|c|c|c|c|}
\hline & \multicolumn{6}{|c|}{ FLUXO LESTE ANUAL } \\
\hline & & Nível 1 & Nível 2 & Nível 3 & Nível 4 & Nível 8 & Nível 11 \\
\hline & & 10/06/2012 13:35 & 10/06/2012 15:35 & 10/06/2012 17:55 & \multirow[t]{6}{*}{ 03/06/2012 19:55 } & & \\
\hline & & 10/06/2012 16:15 & $10 / 06 / 201220: 15$ & $10 / 06 / 2012$ 22:35 & & & \\
\hline & & 10/06/2012 18:35 & 24/06/2012 19:55 & |24/06/2012 19:55 & & & \\
\hline & & $10 / 06 / 201220: 55$ & 24/06/2012 21:35 & $24 / 06 / 2012$ 21:55 & & & \\
\hline & 이 & $24 / 06 / 2012$ 18:15 & & & & & \\
\hline & 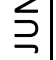 & 24/06/2012 18:35 & & & & & \\
\hline \multirow{26}{*}{ 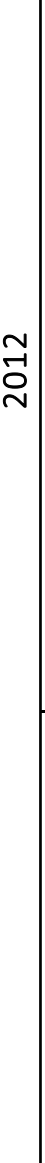 } & \multirow{16}{*}{ 울 } & |06/07/2012 09:25 & 01/07/2012 19:55 & |03/07/2012 20:35 & \multirow{16}{*}{$\begin{array}{l}08 / 07 / 201218: 35 \\
08 / 07 / 201219: 55 \\
15 / 07 / 2012 ~ 21: 15 \\
22 / 07 / 2012 \text { 19:55 }\end{array}$} & & \\
\hline & & 15/07/2012 18:45 & 03/07/2012 19:55 & 08/07/2012 18:35 & & & \\
\hline & & 15/07/2012 20:25 & 03/07/2012 20:15 & 09/07/2012 20:35 & & & \\
\hline & & 22/07/2012 16:05 & 06/07/2012 09:35 & 13/07/2012 09:55 & & & \\
\hline & & 22/07/2012 19:05 & 08/07/2012 19:15 & |15/07/2012 20:35 & & & \\
\hline & & 22/07/2012 19:15 & 09/07/2012 20:35 & 22/07/2012 19:55 & & & \\
\hline & & 22/07/2012 19:35 & 13/07/2012 09:55 & 29/07/2012 19:15 & & & \\
\hline & & 29/07/2012 18:45 & $15 / 07 / 201218: 55$ & 29/07/2012 19:55 & & & \\
\hline & & 29/07/2012 19:55 & 15/07/2012 19:15 & & & & \\
\hline & & 30/07/2012 15:35 & $15 / 07 / 201219: 35$ & & & & \\
\hline & & & 15/07/2012 19:55 & & & & \\
\hline & & & $15 / 07 / 201220: 35$ & & & & \\
\hline & & & $22 / 07 / 2012$ 19:35 & & & & \\
\hline & & & 29/07/2012 18:55 & & & & \\
\hline & & & 29/07/2012 19:55 & & & & \\
\hline & & & 29/07/2012 21:15 & & & & \\
\hline & \multirow{10}{*}{\begin{tabular}{l}
0 \\
兵 \\
0 \\
0 \\
\multirow{4}{4}{}
\end{tabular}} & 06/08/2012 14:35 & 06/08/2012 14:35 & 05/08/2012 19:15 & \multirow{10}{*}{$\begin{array}{l}12 / 08 / 201215: 55 \\
12 / 08 / 201219: 55\end{array}$} & & \\
\hline & & 12/08/2012 19:05 & $11 / 08 / 2012$ 15:15 & |13/08/2012 09:15 & & & \\
\hline & & 12/08/2012 19:15 & $12 / 08 / 2012$ 19:35 & |19/08/2012 19:55 & & & \\
\hline & & 12/08/2012 19:55 & 12/08/2012 19:55 & |19/08/2012 20:35 & & & \\
\hline & & 13/08/2012 08:55 & $12 / 08 / 201220: 55$ & & & & \\
\hline & & 19/08/2012 19:15 & 13/08/2012 08:55 & & & & \\
\hline & & & 13/08/2012 09:15 & & & & \\
\hline & & & 19/08/2012 19:55 & & & & \\
\hline & & & 26/08/2012 18:55 & & & & \\
\hline & & & 26/08/2012 18:55 & & & & \\
\hline
\end{tabular}


APÊNDICE 5.2 - Anomalias nos dados de fluxo de tráfego no sentido Leste no período mensal

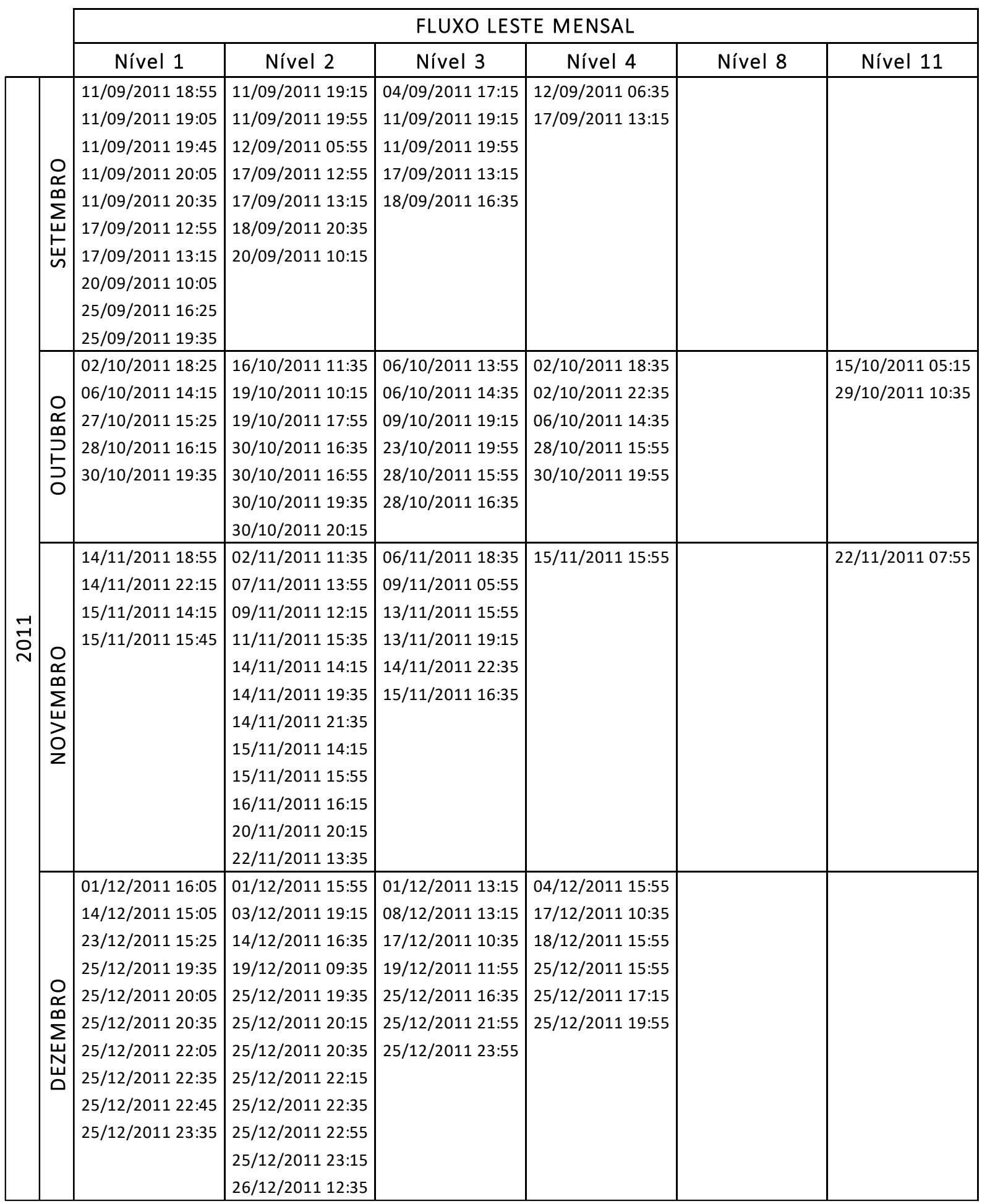




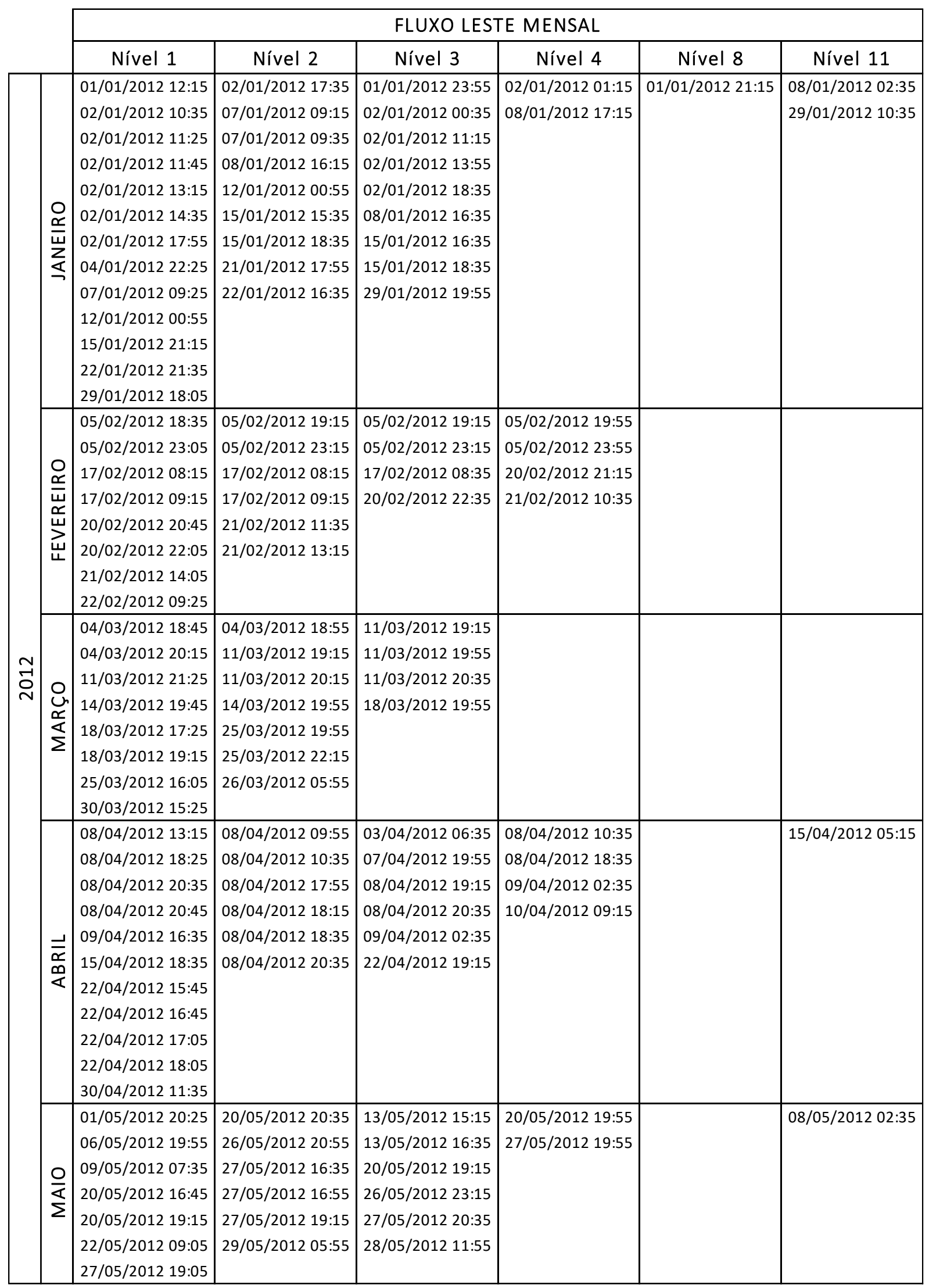




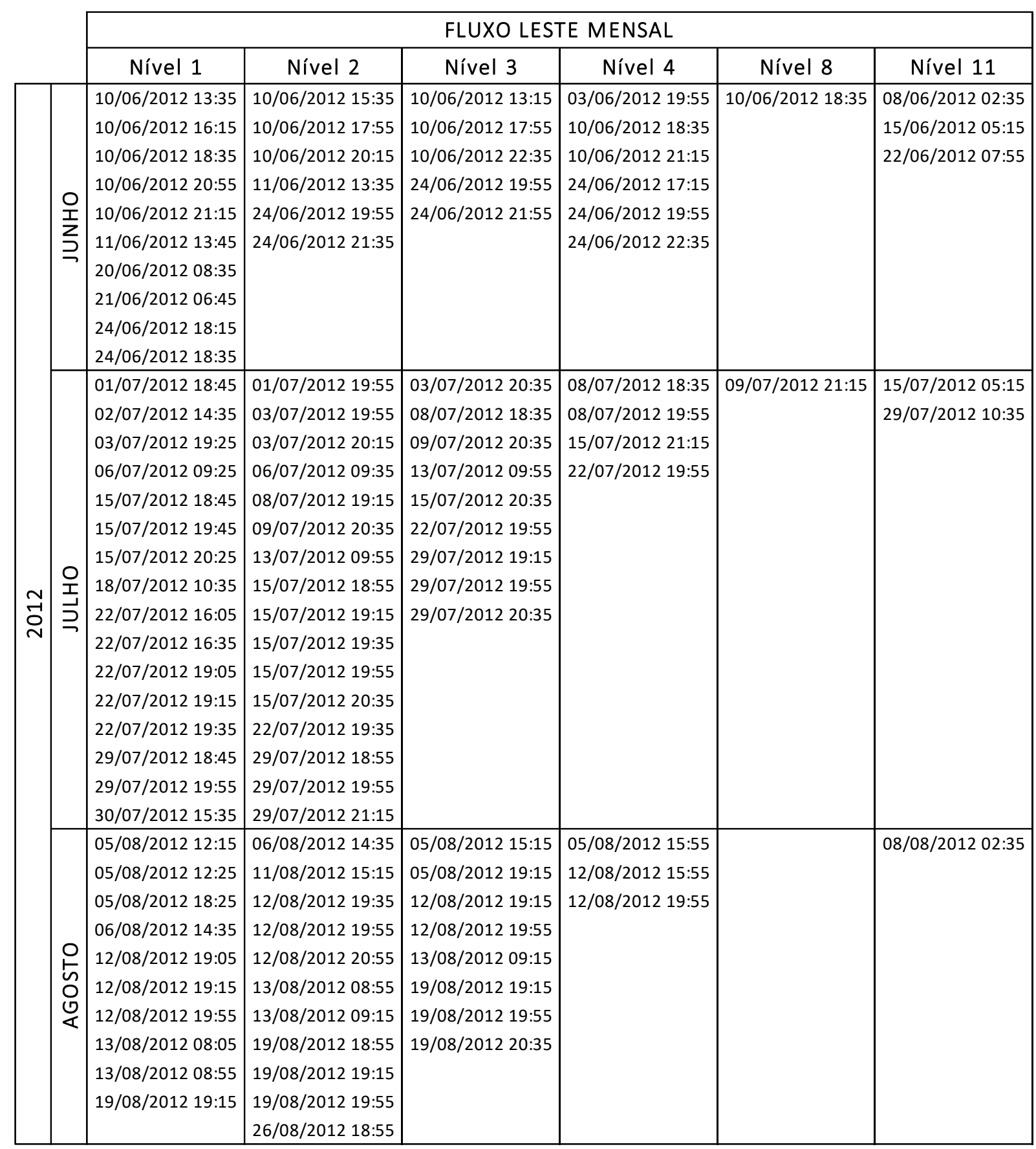


APÊNDICE 5.3 - Anomalias nos dados de fluxo de tráfego no sentido Oeste no período mensal

\begin{tabular}{|c|c|c|c|c|c|c|c|}
\hline & \multicolumn{6}{|c|}{ FLUXO OESTE MENSAL } \\
\hline & & Nível 1 & Nível 2 & Nível 3 & Nível 4 & Nível 8 & Nível 11 \\
\hline & \multirow{13}{*}{ 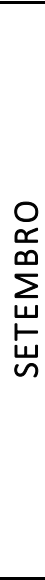 } & 03/09/2011 10:55 & 02/09/2011 21:55 & 06/09/2011 23:55 & 05/09/2011 06:35 & & $15 / 09 / 2011$ 05:15 \\
\hline & & 03/09/2011 11:45 & 03/09/2011 10:55 & 16/09/2011 18:35 & 16/09/2011 18:35 & & 22/09/2011 07:55 \\
\hline & & 09/09/2011 17:25 & 09/09/2011 18:15 & 24/09/2011 12:35 & 16/09/2011 22:35 & & 29/09/2011 10:35 \\
\hline & & 09/09/2011 20:05 & 10/09/2011 14:35 & & 19/09/2011 06:35 & & \\
\hline & & 13/09/2011 17:05 & $16 / 09 / 201114: 35$ & & 26/09/2011 06:35 & & \\
\hline & & 16/09/2011 21:25 & 16/09/2011 22:15 & & & & \\
\hline & & 17/09/2011 11:25 & 20/09/2011 10:15 & & & & \\
\hline & & 17/09/2011 11:35 & 24/09/2011 12:15 & & & & \\
\hline & & 20/09/2011 10:05 & 25/09/2011 07:55 & & & & \\
\hline & & 22/09/2011 14:15 & & & & & \\
\hline & & 24/09/2011 11:55 & & & & & \\
\hline & & 25/09/2011 07:55 & & & & & \\
\hline & & 27/09/2011 14:05 & & & & & \\
\hline & \multirow{10}{*}{ 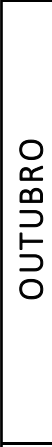 } & 01/10/2011 11:55 & 08/10/2011 10:35 & 03/10/2011 14:35 & 03/10/2011 15:55 & & 08/10/2011 02:35 \\
\hline & & 08/10/2011 12:35 & 08/10/2011 11:15 & 08/10/2011 10:35 & 08/10/2011 09:15 & & $22 / 10 / 201107: 55$ \\
\hline & & 09/10/2011 15:25 & 08/10/2011 13:35 & 17/10/2011 17:15 & $17 / 10 / 201106: 35$ & & \\
\hline & & 13/10/2011 16:35 & $13 / 10 / 2011$ 18:15 & & $21 / 10 / 201121: 15$ & & \\
\hline & & $14 / 10 / 201118: 55$ & $15 / 10 / 201116: 15$ & & & & \\
\hline & & 15/10/2011 16:05 & $21 / 10 / 201122: 35$ & & & & \\
\hline & & 29/10/2011 13:15 & 22/10/2011 09:35 & & & & \\
\hline & & & 22/10/2011 11:35 & & & & \\
\hline & & & $22 / 10 / 201112: 15$ & & & & \\
\hline & & & 22/10/2011 12:35 & & & & \\
\hline & \multirow{15}{*}{ 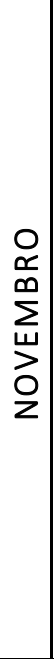 } & 04/11/2011 16:15 & 05/11/2011 12:35 & 01/11/2011 16:35 & 05/11/2011 13:15 & & \\
\hline & & $10 / 11 / 2011$ 14:25 & $11 / 11 / 201123: 35$ & $12 / 11 / 201106: 35$ & 05/11/2011 17:15 & & \\
\hline & & 11/11/2011 11:35 & $12 / 11 / 201106: 15$ & $12 / 11 / 201107: 15$ & $12 / 11 / 201106: 35$ & & \\
\hline & & 11/11/2011 12:05 & $12 / 11 / 201107: 15$ & $12 / 11 / 201107: 55$ & $12 / 11 / 201107: 55$ & & \\
\hline & & $11 / 11 / 2011$ 16:55 & $26 / 11 / 201116: 55$ & $21 / 11 / 201106: 35$ & & & \\
\hline & & 11/11/2011 21:35 & & 29/11/2011 15:15 & & & \\
\hline & & 11/11/2011 23:55 & & & & & \\
\hline & & $12 / 11 / 2011$ 10:35 & & & & & \\
\hline & & 12/11/2011 11:35 & & & & & \\
\hline & & 12/11/2011 11:55 & & & & & \\
\hline & & 12/11/2011 15:05 & & & & & \\
\hline & & $12 / 11 / 2011$ 16:35 & & & & & \\
\hline & & 12/11/2011 17:05 & & & & & \\
\hline & & 25/11/2011 18:35 & & & & & \\
\hline & & 26/11/2011 11:15 & & & & & \\
\hline & \multirow{9}{*}{ 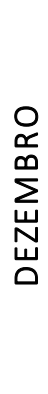 } & 01/12/2011 15:25 & 01/12/2011 06:35 & 01/12/2011 06:35 & \multirow[t]{9}{*}{$20 / 12 / 201115: 55$} & & \multirow[t]{9}{*}{$29 / 12 / 2011$ 10:35 } \\
\hline & & 02/12/2011 18:15 & 02/12/2011 14:35 & 06/12/2011 17:55 & & & \\
\hline & & 02/12/2011 18:35 & $10 / 12 / 2011$ 14:15 & 20/12/2011 14:35 & & & \\
\hline & & 06/12/2011 11:05 & $17 / 12 / 2011$ 11:35 & $23 / 12 / 2011$ 19:55 & & & \\
\hline & & 09/12/2011 07:15 & $17 / 12 / 201112: 15$ & & & & \\
\hline & & 09/12/2011 07:25 & $23 / 12 / 2011$ 17:15 & & & & \\
\hline & & 09/12/2011 14:45 & 23/12/2011 18:55 & & & & \\
\hline & & 10/12/2011 10:45 & & & & & \\
\hline & & 17/12/2011 09:25 & & & & & \\
\hline
\end{tabular}




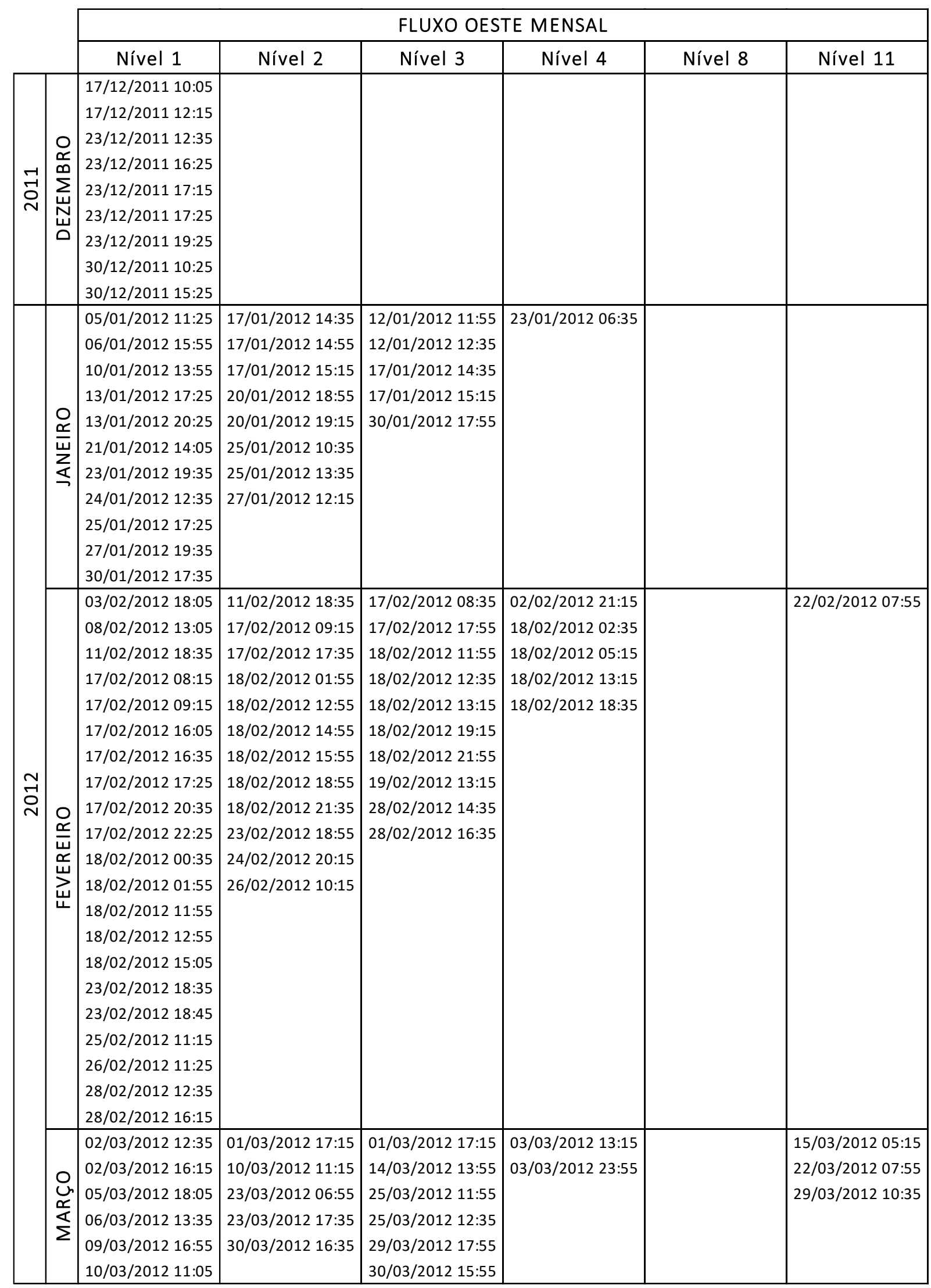




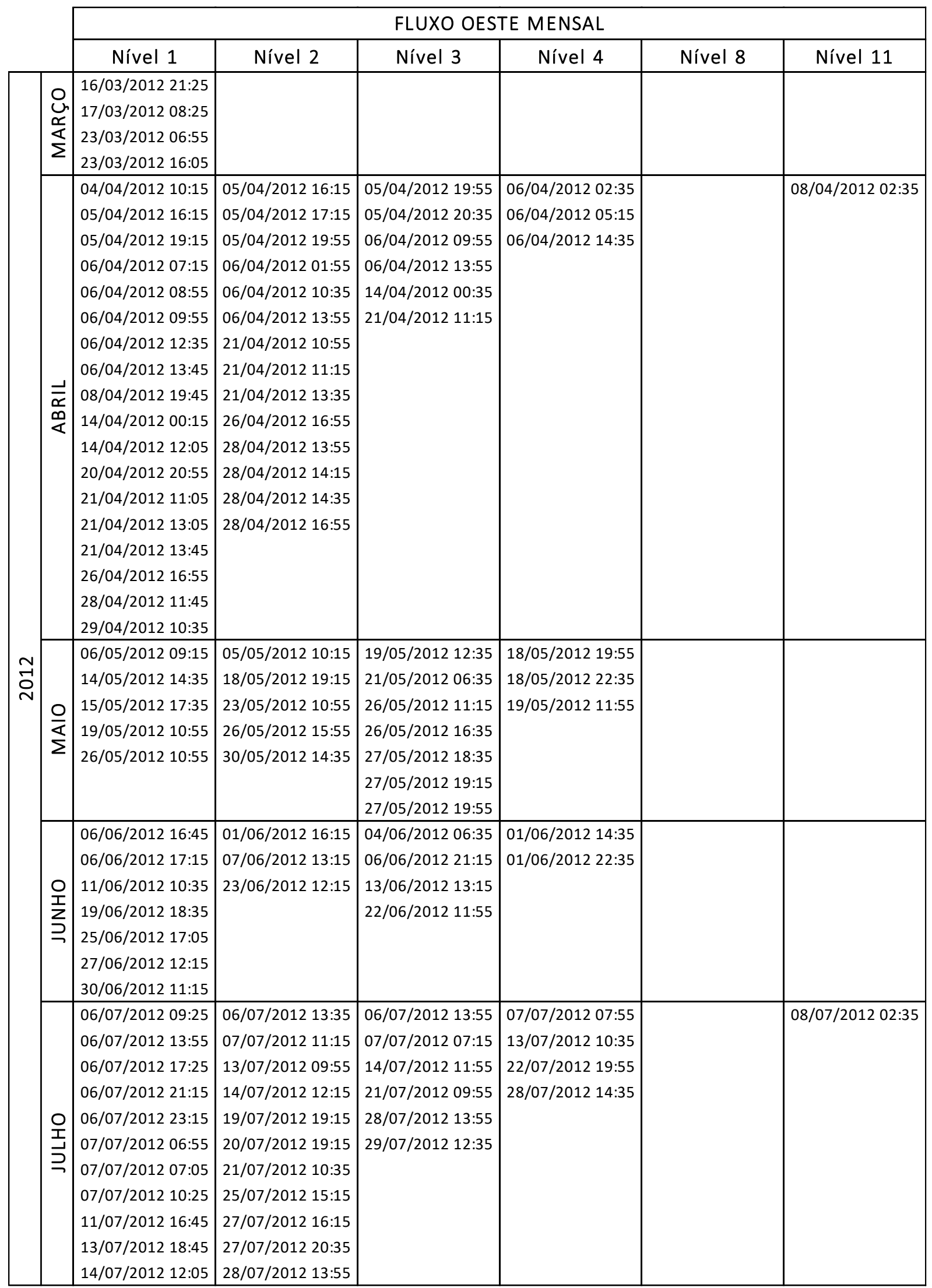




\begin{tabular}{|c|c|c|c|c|c|c|c|}
\hline & \multicolumn{6}{|c|}{ FLUXO OESTE MENSAL } \\
\hline & & Nível 1 & Nível 2 & Nível 3 & Nível 4 & Nível 8 & Nível 11 \\
\hline \multirow{22}{*}{$\begin{array}{l}\underset{N}{0} \\
\text { I }\end{array}$} & & $18 / 07 / 201210: 35$ & 28/07/2012 14:15 & & & & \\
\hline & & 19/07/2012 19:15 & |29/07/2012 11:15 & & & & \\
\hline & & 19/07/2012 19:25 & 29/07/2012 12:15 & & & & \\
\hline & & 21/07/2012 09:55 & & & & & \\
\hline & 0 & 27/07/2012 15:55 & & & & & \\
\hline & $\stackrel{I}{=}$ & 28/07/2012 10:45 & & & & & \\
\hline & & $28 / 07 / 201214: 05$ & & & & & \\
\hline & & 29/07/2012 11:05 & & & & & \\
\hline & & 29/07/2012 12:05 & & & & & \\
\hline & & 29/07/2012 12:25 & & & & & \\
\hline & & 41119.52431 & & & & & \\
\hline & \multirow{11}{*}{ 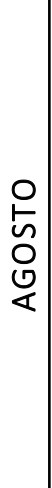 } & 03/08/2012 10:45 & 04/08/2012 08:35 & 03/08/2012 12:35 & 17/08/2012 11:55 & & \\
\hline & & 03/08/2012 13:55 & 06/08/2012 14:35 & 04/08/2012 10:35 & 17/08/2012 22:35 & & \\
\hline & & 03/08/2012 19:05 & 17/08/2012 21:15 & 10/08/2012 19:15 & 41139.44097 & & \\
\hline & & 04/08/2012 12:45 & |17/08/2012 22:15 & 11/08/2012 11:55 & 41146.49653 & & \\
\hline & & 06/08/2012 14:35 & $17 / 08 / 201222: 35$ & 41136.49653 & 41152.94097 & & \\
\hline & & 10/08/2012 15:05 & $18 / 08 / 201210: 55$ & 41138.94097 & & & \\
\hline & & 41131.83681 & $18 / 08 / 201212: 35$ & 41139.44097 & & & \\
\hline & & 41131.87847 & 20/08/2012 10:55 & 41141.46875 & & & \\
\hline & & 41138.60764 & 22/08/2012 17:35 & 41146.44097 & & & \\
\hline & & 41138.73264 & $25 / 08 / 2012$ 10:35 & 41146.46875 & & & \\
\hline & & 41145.66319 & & & & & \\
\hline
\end{tabular}


APÊNDICE 5.4 - Anomalias nos dados de fluxo de velocidade veicular no sentido Leste mensal

\begin{tabular}{|c|c|c|c|c|c|c|c|}
\hline & \multicolumn{6}{|c|}{ VELOCIDADE LESTE MENSAL } \\
\hline & & Nível 1 & Nível 2 & Nível 3 & Nível 4 & Nível 8 & Nível 11 \\
\hline & & 01/09/2011 02:25 & $11 / 09 / 201117: 15$ & 05/09/2011 01:15 & 04/09/2011 19:55 & & $15 / 09 / 201105: 15$ \\
\hline & & 03/09/2011 01:55 & 11/09/2011 19:15 & 11/09/2011 03:15 & $11 / 09 / 201117: 15$ & & \\
\hline & & 03/09/2011 02:05 & 11/09/2011 19:55 & 11/09/2011 17:15 & $18 / 09 / 201118: 35$ & & \\
\hline & & 06/09/2011 00:35 & $11 / 09 / 201121: 35$ & 11/09/2011 19:15 & & & \\
\hline & & 06/09/2011 02:05 & 18/09/2011 17:55 & 11/09/2011 21:15 & & & \\
\hline & & 11/09/2011 02:45 & 18/09/2011 19:15 & 18/09/2011 17:55 & & & \\
\hline & & 11/09/2011 17:05 & $21 / 09 / 201100: 55$ & 18/09/2011 18:35 & & & \\
\hline & $\begin{array}{l}0 \\
\Upsilon\end{array}$ & 11/09/2011 18:45 & 28/09/2011 00:15 & & & & \\
\hline & $\sum^{\infty}$ & $11 / 09 / 201118: 55$ & 29/09/2011 02:15 & & & & \\
\hline & 㟧 & 11/09/2011 19:45 & & & & & \\
\hline & $\dot{w}$ & 11/09/2011 20:05 & & & & & \\
\hline & & $11 / 09 / 201120: 25$ & & & & & \\
\hline & & $11 / 09 / 201120: 35$ & & & & & \\
\hline & & $11 / 09 / 201120: 55$ & & & & & \\
\hline & & 11/09/2011 21:25 & & & & & \\
\hline & & 18/09/2011 17:45 & & & & & \\
\hline & & 18/09/2011 18:25 & & & & & \\
\hline & & 18/09/2011 19:05 & & & & & \\
\hline & \multirow{15}{*}{$\begin{array}{c}0 \\
\propto \\
0 \\
9 \\
己 \\
5 \\
0\end{array}$} & 02/10/2011 21:55 & 02/10/2011 15:55 & 02/10/2011 15:55 & 06/10/2011 11:55 & & \\
\hline & & 04/10/2011 17:45 & 04/10/2011 17:55 & 02/10/2011 18:35 & $06 / 10 / 2011$ 13:15 & & \\
\hline & & 06/10/2011 12:55 & 06/10/2011 12:55 & 06/10/2011 13:15 & 06/10/2011 14:35 & & \\
\hline & & 06/10/2011 13:55 & 06/10/2011 13:55 & 06/10/2011 13:55 & $16 / 10 / 201101: 15$ & & \\
\hline & & 09/10/2011 15:45 & 16/10/2011 01:55 & 16/10/2011 01:15 & $16 / 10 / 201102: 35$ & & \\
\hline & & 16/10/2011 01:55 & $16 / 10 / 201102: 55$ & $16 / 10 / 201101: 55$ & $16 / 10 / 201103: 55$ & & \\
\hline & & 16/10/2011 02:55 & 23/10/2011 19:55 & 16/10/2011 03:15 & $23 / 10 / 2011$ 18:35 & & \\
\hline & & 16/10/2011 03:05 & 24/10/2011 01:15 & 23/10/2011 19:55 & $30 / 10 / 2011$ 17:15 & & \\
\hline & & 21/10/2011 01:15 & $30 / 10 / 2011$ 16:35 & $30 / 10 / 2011$ 16:35 & & & \\
\hline & & 23/10/2011 17:55 & $30 / 10 / 2011$ 16:55 & & & & \\
\hline & & $30 / 10 / 201104: 25$ & $30 / 10 / 201120: 15$ & & & & \\
\hline & & $30 / 10 / 2011$ 16:15 & $31 / 10 / 201101: 55$ & & & & \\
\hline & & 30/10/2011 16:35 & & & & & \\
\hline & & 30/10/2011 19:35 & & & & & \\
\hline & & $31 / 10 / 201101: 55$ & & & & & \\
\hline & \multirow{14}{*}{ 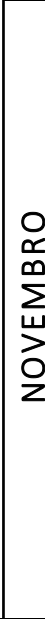 } & 03/11/2011 00:15 & 06/11/2011 17:35 & 06/11/2011 17:55 & 09/11/2011 02:35 & \multirow[t]{14}{*}{ 09/11/2011 21:15 } & \multirow{14}{*}{$\begin{array}{l}15 / 11 / 201105: 15 \\
22 / 11 / 201107: 55\end{array}$} \\
\hline & & 06/11/2011 01:15 & 09/11/2011 00:55 & 09/11/2011 03:55 & 09/11/2011 05:15 & & \\
\hline & & 09/11/2011 00:45 & 09/11/2011 06:35 & 09/11/2011 06:35 & 09/11/2011 06:35 & & \\
\hline & & 09/11/2011 01:45 & 14/11/2011 19:35 & 14/11/2011 19:55 & $14 / 11 / 2011$ 19:55 & & \\
\hline & & 09/11/2011 02:55 & 14/11/2011 21:15 & 14/11/2011 21:15 & $14 / 11 / 201122: 35$ & & \\
\hline & & 09/11/2011 03:05 & $14 / 11 / 201122: 15$ & 14/11/2011 22:35 & $15 / 11 / 2011$ 14:35 & & \\
\hline & & 09/11/2011 03:25 & $15 / 11 / 2011$ 14:15 & 16/11/2011 01:55 & $15 / 11 / 2011$ 17:15 & & \\
\hline & & 09/11/2011 03:35 & $15 / 11 / 2011$ 15:55 & 16/11/2011 02:35 & & & \\
\hline & & 09/11/2011 06:25 & $15 / 11 / 2011$ 16:15 & & & & \\
\hline & & 14/11/2011 21:15 & 15/11/2011 16:35 & & & & \\
\hline & & 14/11/2011 22:15 & $16 / 11 / 201101: 35$ & & & & \\
\hline & & 15/11/2011 14:15 & $16 / 11 / 201102: 35$ & & & & \\
\hline & & $15 / 11 / 2011$ 14:25 & 28/11/2011 15:35 & & & & \\
\hline & & 15/11/2011 15:35 & & & & & \\
\hline
\end{tabular}




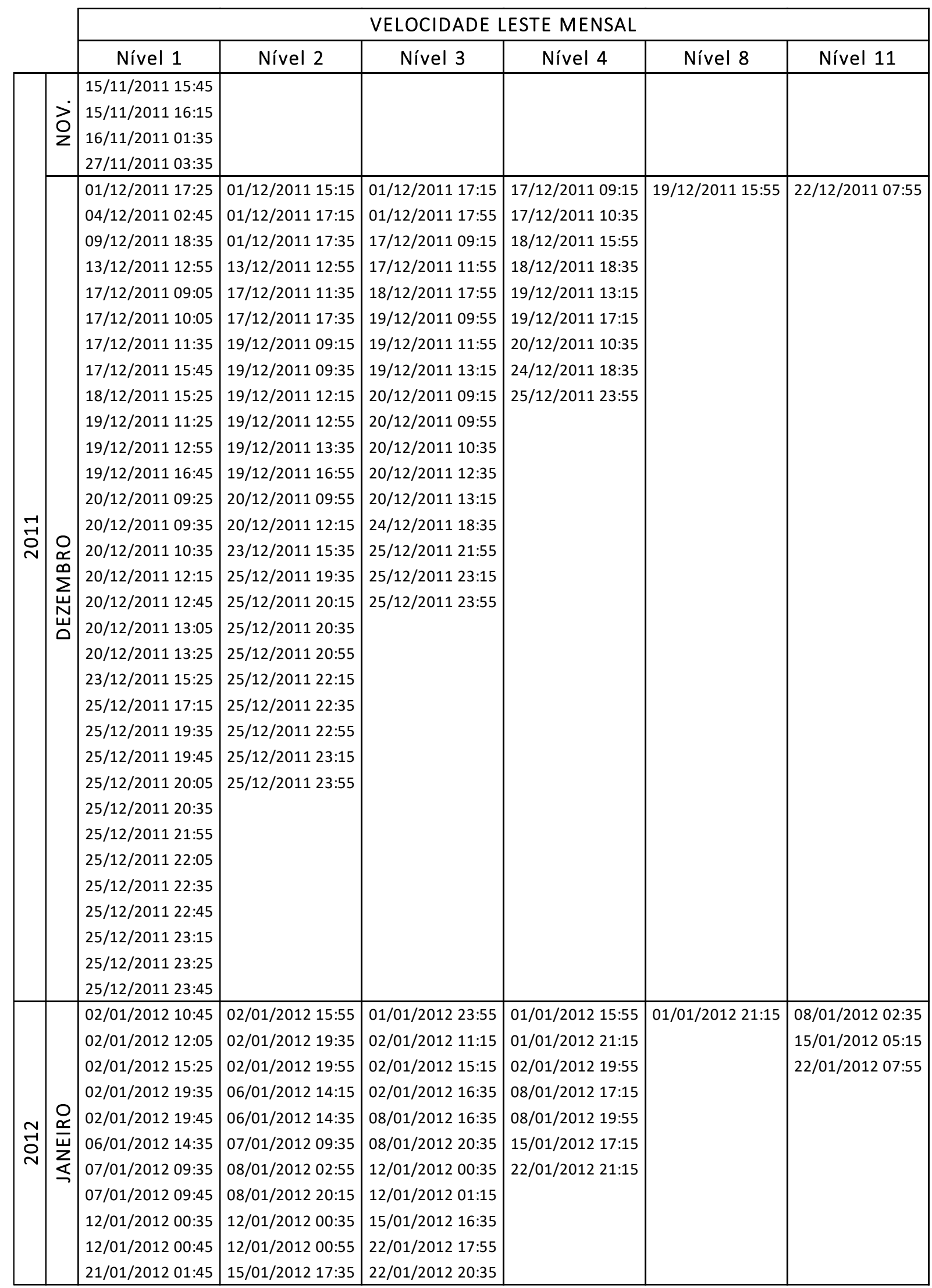




\begin{tabular}{|c|c|c|c|c|c|c|}
\hline & \multicolumn{6}{|c|}{ VELOCIDADE LESTE MENSAL } \\
\hline & Nível 1 & Nível 2 & Nível 3 & Nível 4 & Nível 8 & Nível 11 \\
\hline \multirow{5}{*}{ 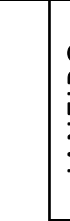 } & 22/01/2012 17:25 & 15/01/2012 18:15 & & & & \\
\hline & $25 / 01 / 201200: 45$ & $15 / 01 / 2012$ 18:35 & & & & \\
\hline & $29 / 01 / 2012$ 02:45 & 22/01/2012 20:35 & & & & \\
\hline & $31 / 01 / 201215: 45$ & 29/01/2012 03:35 & & & & \\
\hline & & $31 / 01 / 201215: 55$ & & & & \\
\hline \multirow{15}{*}{ 出 } & 09/02/2012 04:35 & 09/02/2012 04:35 & 05/02/2012 23:15 & 17/02/2012 09:15 & $22 / 02 / 201207: 55$ & \\
\hline & 09/02/2012 04:45 & 09/02/2012 04:55 & 09/02/2012 05:15 & 20/02/2012 18:35 & & \\
\hline & $12 / 02 / 201216: 15$ & 10/02/2012 16:35 & 10/02/2012 16:35 & 20/02/2012 21:15 & & \\
\hline & 17/02/2012 08:15 & 17/02/2012 08:15 & $17 / 02 / 201208: 35$ & 20/02/2012 22:35 & & \\
\hline & 17/02/2012 09:15 & 17/02/2012 09:15 & 17/02/2012 09:15 & 21/02/2012 10:35 & & \\
\hline & 20/02/2012 18:05 & 19/02/2012 02:55 & 20/02/2012 20:35 & 21/02/2012 18:35 & & \\
\hline & 20/02/2012 20:35 & 20/02/2012 20:35 & 20/02/2012 22:35 & & & \\
\hline & 20/02/2012 20:45 & 20/02/2012 22:15 & $21 / 02 / 201213: 15$ & & & \\
\hline & 20/02/2012 22:05 & 21/02/2012 11:35 & $21 / 02 / 201213: 55$ & & & \\
\hline & $21 / 02 / 201214: 05$ & 21/02/2012 12:15 & $21 / 02 / 201214: 35$ & & & \\
\hline & $21 / 02 / 201214: 15$ & 21/02/2012 12:55 & $21 / 02 / 201219: 55$ & & & \\
\hline & $21 / 02 / 201219: 35$ & 21/02/2012 13:15 & & & & \\
\hline & $22 / 02 / 201210: 45$ & $21 / 02 / 201213: 35$ & & & & \\
\hline & 26/02/2012 02:45 & $21 / 02 / 2012$ 18:35 & & & & \\
\hline & & $22 / 02 / 201210: 55$ & & & & \\
\hline \multirow{16}{*}{ O) } & 04/03/2012 01:15 & $02 / 03 / 2012$ 18:15 & 04/03/2012 19:55 & \multirow{16}{*}{$\begin{array}{l}04 / 03 / 201219: 55 \\
11 / 03 / 2012 \text { 19:55 } \\
11 / 03 / 2012 \text { 21:15 } \\
18 / 03 / 201218: 35 \\
18 / 03 / 201219: 55\end{array}$} & & \multirow{16}{*}{$\begin{array}{l}\text { 15/03/2012 05:15 } \\
29 / 03 / 2012 \text { 10:35 }\end{array}$} \\
\hline & 04/03/2012 18:45 & 04/03/2012 18:55 & 11/03/2012 19:15 & & & \\
\hline & |04/03/2012 19:05 & |04/03/2012 19:15 & $11 / 03 / 201219: 55$ & & & \\
\hline & 04/03/2012 19:35 & 04/03/2012 19:35 & $11 / 03 / 201220: 35$ & & & \\
\hline & $11 / 03 / 201201: 45$ & $11 / 03 / 201218: 35$ & $11 / 03 / 201221: 15$ & & & \\
\hline & $11 / 03 / 201202: 45$ & 11/03/2012 19:15 & $11 / 03 / 201221: 55$ & & & \\
\hline & 11/03/2012 18:35 & 11/03/2012 20:15 & 15/03/2012 19:15 & & & \\
\hline & $11 / 03 / 201220: 15$ & $11 / 03 / 201220: 35$ & $18 / 03 / 201218: 35$ & & & \\
\hline & $11 / 03 / 201220: 55$ & 11/03/2012 20:55 & 18/03/2012 19:15 & & & \\
\hline & $11 / 03 / 201221: 25$ & $11 / 03 / 201221: 15$ & 22/03/2012 21:55 & & & \\
\hline & $15 / 03 / 201218: 55$ & $11 / 03 / 201221: 35$ & 24/03/2012 20:35 & & & \\
\hline & 18/03/2012 17:25 & 18/03/2012 19:15 & & & & \\
\hline & 18/03/2012 19:15 & \multirow[t]{4}{*}{ 25/03/2012 18:55 } & & & & \\
\hline & 23/03/2012 00:25 & & & & & \\
\hline & 25/03/2012 02:55 & & & & & \\
\hline & 29/03/2012 01:25 & & & & & \\
\hline \multirow{11}{*}{$\begin{array}{l}\vec{\alpha} \\
\stackrel{c}{\alpha} \\
\frac{\alpha}{\alpha}\end{array}$} & 01/04/2012 02:05 & 08/04/2012 10:35 & 02/04/2012 01:15 & 08/04/2012 14:35 & \multirow[t]{11}{*}{ 08/04/2012 23:55 } & \multirow[t]{11}{*}{$15 / 04 / 201205: 15$} \\
\hline & 01/04/2012 03:45 & 08/04/2012 17:55 & 08/04/2012 10:35 & 08/04/2012 18:35 & & \\
\hline & 08/04/2012 10:45 & 08/04/2012 18:15 & 08/04/2012 12:35 & 08/04/2012 19:55 & & \\
\hline & 08/04/2012 18:05 & 08/04/2012 18:35 & 08/04/2012 13:15 & 08/04/2012 21:15 & & \\
\hline & 08/04/2012 18:25 & 08/04/2012 20:35 & 08/04/2012 14:35 & 10/04/2012 18:35 & & \\
\hline & 08/04/2012 19:35 & 08/04/2012 23:55 & 08/04/2012 19:55 & 21/04/2012 02:35 & & \\
\hline & |08/04/2012 20:35 & 10/04/2012 17:35 & 08/04/2012 20:35 & & & \\
\hline & |08/04/2012 20:45 & 13/04/2012 20:35 & 21/04/2012 02:35 & & & \\
\hline & 13/04/2012 20:35 & 19/04/2012 00:15 & 24/04/2012 03:55 & & & \\
\hline & 15/04/2012 01:35 & 21/04/2012 08:35 & & & & \\
\hline & 15/04/2012 03:55 & $22 / 04 / 2012$ 17:15 & & & & \\
\hline
\end{tabular}




\begin{tabular}{|c|c|c|c|c|c|c|c|}
\hline & \multicolumn{6}{|c|}{ VELOCIDADE LESTE MENSAL } \\
\hline & & Nível 1 & Nível 2 & Nível 3 & Nível 4 & Nível 8 & Nível 11 \\
\hline & & $17 / 04 / 201202: 05$ & 24/04/2012 03:35 & & & & \\
\hline & $\overrightarrow{\bar{\alpha}}$ & $22 / 04 / 2012$ 17:05 & & & & & \\
\hline & 足 & $24 / 04 / 201203: 35$ & & & & & \\
\hline & & 29/04/2012 03:15 & & & & & \\
\hline \multirow{19}{*}{\multicolumn{2}{|c|}{$\frac{0}{\frac{1}{\Sigma}}$}} & 03/05/2012 01:35 & \begin{tabular}{|l|l|}
$05 / 201201: 15$ \\
\end{tabular} & \begin{tabular}{|l|}
$20 / 05 / 2012 ~ 17: 55$ \\
\end{tabular} & \multirow{19}{*}{$\begin{array}{l}20 / 05 / 201218: 35 \\
20 / 05 / 201219: 55 \\
27 / 05 / 201218: 35 \\
28 / 05 / 201213: 15 \\
28 / 05 / 201214: 35\end{array}$} & \multirow[t]{19}{*}{ 28/05/2012 13:15 } & \multirow[t]{19}{*}{$22 / 05 / 201207: 55$} \\
\hline & & $10 / 05 / 201223: 45$ & 20/05/2012 17:15 & $27 / 05 / 201201: 55$ & & & \\
\hline & & $13 / 05 / 201201: 35$ & 20/05/2012 19:15 & 27/05/2012 19:15 & & & \\
\hline & & $14 / 05 / 201214: 45$ & 27/05/2012 04:15 & $28 / 05 / 201210: 35$ & & & \\
\hline & & 20/05/2012 16:45 & 27/05/2012 17:55 & 28/05/2012 11:15 & & & \\
\hline & & 20/05/2012 16:55 & 27/05/2012 19:15 & 28/05/2012 11:55 & & & \\
\hline & & 20/05/2012 17:25 & 27/05/2012 19:35 & 28/05/2012 13:15 & & & \\
\hline & & 20/05/2012 17:35 & 27/05/2012 19:55 & $28 / 05 / 201213: 55$ & & & \\
\hline & & 20/05/2012 19:15 & 28/05/2012 10:35 & $28 / 05 / 201214: 35$ & & & \\
\hline & & $27 / 05 / 201217: 15$ & 28/05/2012 10:55 & & & & \\
\hline & & $27 / 05 / 201219: 15$ & 28/05/2012 11:35 & & & & \\
\hline & & $27 / 05 / 201219: 25$ & 28/05/2012 13:15 & & & & \\
\hline & & $27 / 05 / 201219: 35$ & 28/05/2012 13:35 & & & & \\
\hline & & $27 / 05 / 201219: 55$ & 28/05/2012 14:15 & & & & \\
\hline & & 28/05/2012 10:35 & & & & & \\
\hline & & 28/05/2012 10:55 & & & & & \\
\hline & & 28/05/2012 11:35 & & & & & \\
\hline & & 28/05/2012 13:25 & & & & & \\
\hline & & 28/05/2012 14:05 & & & & & \\
\hline \multirow{24}{*}{ 궁 } & \multirow{18}{*}{ 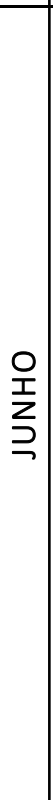 } & 03/06/2012 03:25 & 05/06/2012 07:55 & \multirow{18}{*}{$\begin{array}{l}10 / 06 / 201213: 15 \\
10 / 06 / 2012 ~ 16: 35 \\
10 / 06 / 2012 ~ 17: 55 \\
10 / 06 / 2012 ~ 19: 15 \\
11 / 06 / 201209: 55 \\
14 / 06 / 201212: 35\end{array}$} & \multirow{18}{*}{$\begin{array}{ll}10 / 06 / 2012 & 17: 15 \\
10 / 06 / 2012 & 19: 55 \\
14 / 06 / 2012 & 13: 15 \\
14 / 06 / 2012 & 14: 35\end{array}$} & & \multirow[t]{18}{*}{$22 / 06 / 2012$ 07:55 } \\
\hline & & $10 / 06 / 201203: 05$ & 06/06/2012 01:35 & & & & \\
\hline & & $10 / 06 / 201205: 35$ & 09/06/2012 02:55 & & & & \\
\hline & & $10 / 06 / 201215: 15$ & $11 / 06 / 201209: 55$ & & & & \\
\hline & & $14 / 06 / 201212: 05$ & $14 / 06 / 201213: 35$ & & & & \\
\hline & & $14 / 06 / 201212: 15$ & $14 / 06 / 201214: 15$ & & & & \\
\hline & & $14 / 06 / 201213: 25$ & $15 / 06 / 2012$ 03:35 & & & & \\
\hline & & 14/06/2012 13:55 & $16 / 06 / 201202: 15$ & & & & \\
\hline & & $15 / 06 / 2012$ 03:35 & 19/06/2012 00:15 & & & & \\
\hline & & $17 / 06 / 201203: 05$ & 20/06/2012 01:55 & & & & \\
\hline & & 20/06/2012 03:15 & 21/06/2012 06:55 & & & & \\
\hline & & 20/06/2012 03:25 & 24/06/2012 16:15 & & & & \\
\hline & & 21/06/2012 06:45 & & & & & \\
\hline & & $22 / 06 / 201202: 25$ & & & & & \\
\hline & & $24 / 06 / 201216: 15$ & & & & & \\
\hline & & $24 / 06 / 201217: 15$ & & & & & \\
\hline & & $24 / 06 / 201217: 25$ & & & & & \\
\hline & & 28/06/2012 23:25 & & & & & \\
\hline & \multirow{6}{*}{ 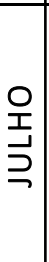 } & 01/07/2012 04:05 & \begin{tabular}{|l|l|}
$01 / 2012 ~ 17: 35$ \\
\end{tabular} & \begin{tabular}{|l|}
$01 / 07 / 2012 ~ 17: 55$ \\
\end{tabular} & \begin{tabular}{|l|}
$01 / 07 / 2012 ~ 19: 55$ \\
\end{tabular} & \multirow[t]{6}{*}{$16 / 07 / 201202: 35$} & \multirow[t]{6}{*}{$22 / 07 / 2012$ 07:55 } \\
\hline & & 01/07/2012 17:15 & 01/07/2012 18:35 & 01/07/2012 19:55 & $15 / 07 / 201221: 15$ & & \\
\hline & & 01/07/2012 19:25 & 01/07/2012 19:55 & 09/07/2012 18:35 & $21 / 07 / 2012$ 02:35 & & \\
\hline & & 01/07/2012 19:55 & 08/07/2012 03:15 & $13 / 07 / 2012$ 09:55 & $22 / 07 / 2012$ 19:55 & & \\
\hline & & $13 / 07 / 201209: 45$ & 09/07/2012 18:35 & $15 / 07 / 201220: 35$ & $29 / 07 / 201217: 15$ & & \\
\hline & & $15 / 07 / 201217: 25$ & 13/07/2012 09:55 & $22 / 07 / 201217: 55$ & & & \\
\hline
\end{tabular}




\begin{tabular}{|c|c|c|c|c|c|c|}
\hline & \multicolumn{6}{|c|}{ VELOCIDADE LESTE MENSAL } \\
\hline & Nível 1 & Nível 2 & Nível 3 & Nível 4 & Nível 8 & Nível 11 \\
\hline \multirow{34}{*}{$\begin{array}{l}\text { 足 } \\
\text { 至 }\end{array}$} & 15/07/2012 18:45 & 15/07/2012 18:55 & 22/07/2012 19:15 & & & \\
\hline & |15/07/2012 19:55 & 15/07/2012 19:15 & 22/07/2012 19:55 & & & \\
\hline & 15/07/2012 20:25 & 15/07/2012 19:55 & 22/07/2012 21:15 & & & \\
\hline & 17/07/2012 01:05 & 15/07/2012 20:35 & |23/07/2012 01:15 & & & \\
\hline & 17/07/2012 23:55 & 21/07/2012 17:35 & |29/07/2012 17:55 & & & \\
\hline & |21/07/2012 02:25 & 22/07/2012 17:35 & |29/07/2012 20:35 & & & \\
\hline & 22/07/2012 18:35 & 22/07/2012 18:55 & & & & \\
\hline & 22/07/2012 18:45 & 22/07/2012 19:15 & & & & \\
\hline & 22/07/2012 19:15 & 22/07/2012 19:35 & & & & \\
\hline & 22/07/2012 19:35 & 22/07/2012 21:35 & & & & \\
\hline & 22/07/2012 21:25 & 29/07/2012 17:35 & & & & \\
\hline & |29/07/2012 18:05 & 29/07/2012 21:15 & & & & \\
\hline & |29/07/2012 20:15 & & & & & \\
\hline & |29/07/2012 21:25 & & & & & \\
\hline & $31 / 07 / 201201: 25$ & & & & & \\
\hline & 05/08/2012 03:25 & 05/08/2012 12:15 & 06/08/2012 14:35 & 05/08/2012 13:15 & & \\
\hline & 05/08/2012 12:15 & 05/08/2012 12:35 & 12/08/2012 17:15 & 06/08/2012 01:15 & & \\
\hline & 05/08/2012 12:25 & 06/08/2012 14:35 & $12 / 08 / 201219: 15$ & 06/08/2012 14:35 & & \\
\hline & 06/08/2012 14:35 & 12/08/2012 17:15 & $12 / 08 / 201219: 55$ & $12 / 08 / 201217: 15$ & & \\
\hline & $12 / 08 / 201202: 05$ & $12 / 08 / 201218: 35$ & $12 / 08 / 201221: 15$ & $12 / 08 / 201219: 55$ & & \\
\hline & $12 / 08 / 201218: 35$ & $12 / 08 / 201219: 35$ & 19/08/2012 17:55 & 19/08/2012 19:55 & & \\
\hline & $12 / 08 / 201218: 45$ & $12 / 08 / 201220: 55$ & 19/08/2012 19:15 & 19/08/2012 21:15 & & \\
\hline & $12 / 08 / 201219: 05$ & 19/08/2012 16:35 & 19/08/2012 19:55 & & & \\
\hline & 12/08/2012 19:15 & 19/08/2012 17:35 & $19 / 08 / 201220: 35$ & & & \\
\hline & 19/08/2012 02:15 & 19/08/2012 19:55 & $20 / 08 / 201201: 15$ & & & \\
\hline & 19/08/2012 03:05 & 19/08/2012 20:15 & & & & \\
\hline & 19/08/2012 04:15 & & & & & \\
\hline & |19/08/2012 17:25 & & & & & \\
\hline & 19/08/2012 18:55 & & & & & \\
\hline & |19/08/2012 19:15 & & & & & \\
\hline & |19/08/2012 20:15 & & & & & \\
\hline & 23/08/2012 01:35 & & & & & \\
\hline & $25 / 08 / 201215: 25$ & & & & & \\
\hline & 26/08/2012 04:05 & & & & & \\
\hline
\end{tabular}


APÊNDICE 5.5 - Anomalias nos dados de fluxo de velocidade veicular no sentido Oeste mensal

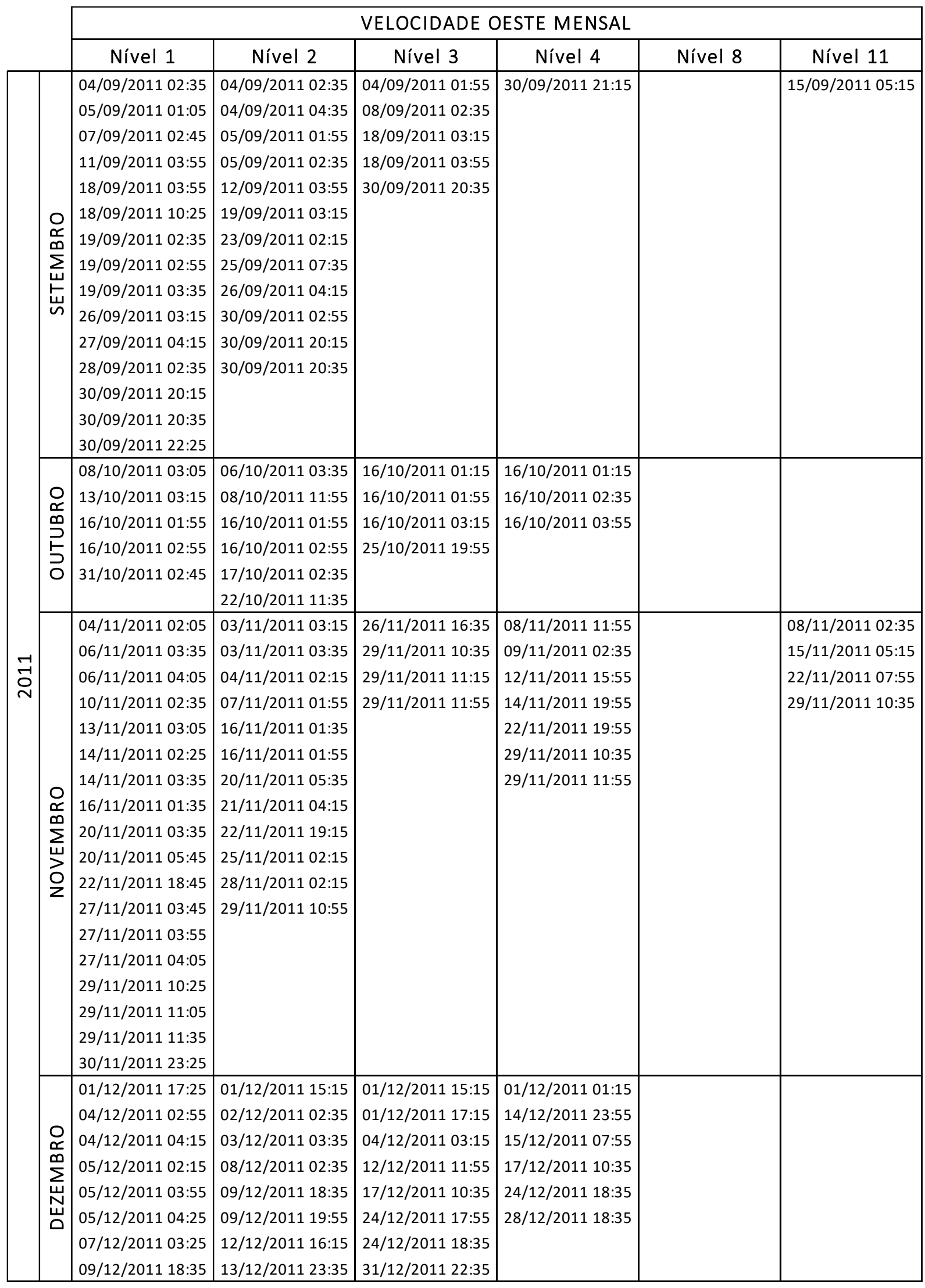




\begin{tabular}{|c|c|c|c|c|c|c|c|}
\hline & \multicolumn{6}{|c|}{ VELOCIDADE OESTE MENSAL } \\
\hline & & Nível 1 & Nível 2 & Nível 3 & Nível 4 & Nível 8 & Nível 11 \\
\hline \multirow{14}{*}{ 离 } & \multirow{14}{*}{ 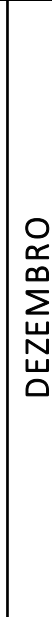 } & \begin{tabular}{|l|}
$10 / 12 / 201103: 45$ \\
\end{tabular} & 15/12/2011 06:35 & & & & \\
\hline & & 15/12/2011 00:15 & $17 / 12 / 2011$ 10:15 & & & & \\
\hline & & 15/12/2011 02:05 & $17 / 12 / 201112: 55$ & & & & \\
\hline & & 15/12/2011 06:35 & 19/12/2011 02:55 & & & & \\
\hline & & 17/12/2011 02:15 & 19/12/2011 03:15 & & & & \\
\hline & & $17 / 12 / 201110: 05$ & 19/12/2011 04:55 & & & & \\
\hline & & $17 / 12 / 201110: 15$ & $25 / 12 / 201105: 15$ & & & & \\
\hline & & 18/12/2011 03:55 & & & & & \\
\hline & & 26/12/2011 02:15 & & & & & \\
\hline & & 26/12/2011 02:35 & & & & & \\
\hline & & 26/12/2011 03:15 & & & & & \\
\hline & & 26/12/2011 03:55 & & & & & \\
\hline & & 27/12/2011 02:55 & & & & & \\
\hline & & 27/12/2011 03:05 & & & & & \\
\hline \multirow{33}{*}{\begin{tabular}{c}
\multirow{2}{*}{} \\
$\stackrel{\sim}{2}$
\end{tabular}} & \multirow{16}{*}{ 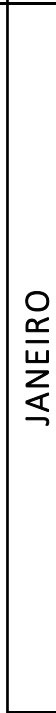 } & 05/01/2012 03:05 & 12/01/2012 01:15 & 02/01/2012 15:55 & 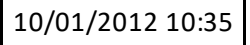 & & \\
\hline & & 06/01/2012 02:15 & $12 / 01 / 201212: 15$ & 08/01/2012 16:35 & $12 / 01 / 2012$ 13:15 & & \\
\hline & & 10/01/2012 02:35 & 14/01/2012 21:35 & $12 / 01 / 201201: 15$ & $12 / 01 / 201214: 35$ & & \\
\hline & & $12 / 01 / 201201: 05$ & $22 / 01 / 2012$ 17:35 & $12 / 01 / 201211: 55$ & $14 / 01 / 201222: 35$ & & \\
\hline & & $13 / 01 / 201202: 35$ & 24/01/2012 19:55 & $12 / 01 / 201212: 35$ & 22/01/2012 18:35 & & \\
\hline & & $14 / 01 / 201221: 25$ & 27/01/2012 17:55 & $15 / 01 / 201211: 15$ & 23/01/2012 17:15 & & \\
\hline & & 15/01/2012 03:35 & $27 / 01 / 201218: 15$ & $24 / 01 / 2012$ 19:55 & 24/01/2012 15:55 & & \\
\hline & & 15/01/2012 03:55 & 29/01/2012 04:15 & $27 / 01 / 201217: 55$ & & & \\
\hline & & 16/01/2012 04:35 & 31/01/2012 03:15 & $27 / 01 / 201218: 35$ & & & \\
\hline & & $18 / 01 / 201202: 45$ & & & & & \\
\hline & & 20/01/2012 03:45 & & & & & \\
\hline & & 22/01/2012 02:25 & & & & & \\
\hline & & 22/01/2012 04:15 & & & & & \\
\hline & & $22 / 01 / 201217: 25$ & & & & & \\
\hline & & $27 / 01 / 201218: 05$ & & & & & \\
\hline & & 30/01/2012 03:45 & & & & & \\
\hline & \multirow{12}{*}{ 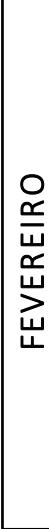 } & 17/02/2012 08:15 & 10/02/2012 00:55 & 10/02/2012 16:35 & 10/02/2012 01:15 & \multirow[t]{12}{*}{$18 / 02 / 201218: 35$} & \multirow[t]{12}{*}{$22 / 02 / 201207: 55$} \\
\hline & & 17/02/2012 09:15 & 10/02/2012 16:35 & $17 / 02 / 201208: 35$ & 17/02/2012 09:15 & & \\
\hline & & 18/02/2012 08:55 & 17/02/2012 08:15 & 17/02/2012 09:15 & |18/02/2012 09:15 & & \\
\hline & & 18/02/2012 09:35 & 17/02/2012 09:15 & 18/02/2012 09:15 & 18/02/2012 10:35 & & \\
\hline & & 18/02/2012 11:45 & 18/02/2012 08:55 & 18/02/2012 09:55 & 18/02/2012 11:55 & & \\
\hline & & 18/02/2012 11:55 & 18/02/2012 09:35 & 18/02/2012 11:55 & 18/02/2012 13:15 & & \\
\hline & & $18 / 02 / 201212: 55$ & 18/02/2012 11:15 & 18/02/2012 13:15 & & & \\
\hline & & $18 / 02 / 201213: 25$ & 18/02/2012 12:55 & $18 / 02 / 201214: 35$ & & & \\
\hline & & 20/02/2012 03:35 & 18/02/2012 14:15 & & & & \\
\hline & & 26/02/2012 03:25 & 26/02/2012 03:35 & & & & \\
\hline & & 26/02/2012 03:45 & & & & & \\
\hline & & 27/02/2012 03:05 & & & & & \\
\hline & \multirow{5}{*}{$\begin{array}{l}\stackrel{O}{u} \\
\text { úc } \\
\sum\end{array}$} & 05/03/2012 02:15 & 02/03/2012 18:15 & 13/03/2012 14:35 & $13 / 03 / 201215: 55$ & \multirow[t]{5}{*}{$26 / 03 / 201218: 35$} & \multirow[t]{5}{*}{ 08/03/2012 02:35 } \\
\hline & & $11 / 03 / 201202: 55$ & 06/03/2012 16:35 & $13 / 03 / 201215: 15$ & 23/03/2012 18:35 & & \\
\hline & & $13 / 03 / 201214: 35$ & $13 / 03 / 201214: 35$ & $13 / 03 / 201215: 55$ & 24/03/2012 10:35 & & \\
\hline & & $13 / 03 / 201215: 15$ & $13 / 03 / 201215: 15$ & $15 / 03 / 201219: 15$ & 24/03/2012 11:55 & & \\
\hline & & $13 / 03 / 201215: 45$ & $13 / 03 / 201215: 55$ & 22/03/2012 21:55 & 26/03/2012 11:55 & & \\
\hline
\end{tabular}




\begin{tabular}{|c|c|c|c|c|c|c|}
\hline & \multicolumn{6}{|c|}{ VELOCIDADE OESTE MENSAL } \\
\hline & Nível 1 & Nível 2 & Nível 3 & Nível 4 & Nível 8 & Nível 11 \\
\hline & 13/03/2012 15:55 & $15 / 03 / 201218: 55$ & 23/03/2012 13:55 & 26/03/2012 15:55 & & \\
\hline & 15/03/2012 18:55 & 23/03/2012 13:35 & 23/03/2012 17:15 & & & \\
\hline & 23/03/2012 13:45 & 23/03/2012 16:15 & 23/03/2012 17:55 & & & \\
\hline & 23/03/2012 13:55 & 23/03/2012 16:35 & 24/03/2012 10:35 & & & \\
\hline & 23/03/2012 16:05 & 23/03/2012 17:35 & 24/03/2012 11:15 & & & \\
\hline & 23/03/2012 16:25 & 24/03/2012 10:35 & 24/03/2012 20:35 & & & \\
\hline & 24/03/2012 10:15 & 24/03/2012 11:15 & 26/03/2012 11:15 & & & \\
\hline & 24/03/2012 11:15 & 26/03/2012 11:15 & 26/03/2012 12:35 & & & \\
\hline$\underline{u}$ & 24/03/2012 12:35 & 26/03/2012 11:35 & 26/03/2012 15:15 & & & \\
\hline 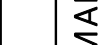 & 24/03/2012 12:45 & 26/03/2012 12:35 & 30/03/2012 11:55 & & & \\
\hline & 26/03/2012 11:15 & 26/03/2012 13:55 & & & & \\
\hline & 26/03/2012 11:25 & 26/03/2012 15:15 & & & & \\
\hline & 26/03/2012 11:45 & & & & & \\
\hline & 26/03/2012 12:15 & & & & & \\
\hline & 26/03/2012 12:25 & & & & & \\
\hline & 26/03/2012 12:55 & & & & & \\
\hline & 26/03/2012 15:05 & & & & & \\
\hline & 30/03/2012 03:05 & & & & & \\
\hline & 01/04/2012 01:05 & |05/04/2012 19:55 & 05/04/2012 19:55 & 05/04/2012 19:55 & 30/04/2012 07:55 & \\
\hline & 01/04/2012 02:35 & 05/04/2012 20:35 & 05/04/2012 20:35 & 05/04/2012 21:15 & & \\
\hline & 03/04/2012 14:25 & 07/04/2012 04:15 & 15/04/2012 00:35 & 06/04/2012 02:35 & & \\
\hline & 05/04/2012 20:25 & 10/04/2012 17:35 & 15/04/2012 02:35 & 10/04/2012 18:35 & & \\
\hline & 10/04/2012 17:35 & 10/04/2012 17:55 & 21/04/2012 02:35 & 15/04/2012 02:35 & & \\
\hline$\underset{7}{\mathfrak{H}}$ & 10/04/2012 17:45 & 13/04/2012 20:35 & 21/04/2012 11:15 & 21/04/2012 02:35 & & \\
\hline i & $11 / 04 / 201202: 35$ & 15/04/2012 01:35 & 21/04/2012 11:55 & 26/04/2012 19:55 & & \\
\hline$=$ & 13/04/2012 20:35 & 21/04/2012 08:35 & & 29/04/2012 21:15 & & \\
\hline$\stackrel{\circ}{\infty}$ & 15/04/2012 00:15 & 21/04/2012 10:55 & & & & \\
\hline & 15/04/2012 04:15 & 21/04/2012 11:15 & & & & \\
\hline & 16/04/2012 03:25 & 22/04/2012 04:15 & & & & \\
\hline & 21/04/2012 10:35 & 22/04/2012 04:55 & & & & \\
\hline & $22 / 04 / 201201: 35$ & 26/04/2012 19:35 & & & & \\
\hline & 24/04/2012 02:45 & & & & & \\
\hline & $26 / 04 / 201216: 55$ & & & & & \\
\hline & 28/04/2012 11:45 & & & & & \\
\hline & 29/04/2012 03:55 & & & & & \\
\hline & 02/05/2012 02:05 & 01/05/2012 04:35 & 02/05/2012 10:35 & 02/05/2012 10:35 & & 15/05/2012 05:15 \\
\hline & 07/05/2012 03:15 & 02/05/2012 10:35 & 24/05/2012 13:15 & 02/05/2012 11:55 & & 29/05/2012 10:35 \\
\hline & 14/05/2012 14:35 & 02/05/2012 11:15 & 24/05/2012 16:35 & 24/05/2012 17:15 & & \\
\hline & 16/05/2012 03:55 & 13/05/2012 03:15 & 28/05/2012 16:35 & 27/05/2012 03:55 & & \\
\hline & 21/05/2012 02:15 & 14/05/2012 02:55 & 28/05/2012 17:15 & 28/05/2012 17:15 & & \\
\hline 으 & 23/05/2012 02:05 & $14 / 05 / 201214: 35$ & & & & \\
\hline $\bar{\S}$ & $25 / 05 / 201203: 35$ & $17 / 05 / 201204: 35$ & & & & \\
\hline & 27/05/2012 02:35 & 20/05/2012 02:55 & & & & \\
\hline & 27/05/2012 03:05 & 24/05/2012 16:15 & & & & \\
\hline & 27/05/2012 03:25 & 28/05/2012 16:35 & & & & \\
\hline & $27 / 05 / 201204: 25$ & & & & & \\
\hline & 28/05/2012 02:35 & & & & & \\
\hline & /05/2012 1 & & & & & \\
\hline
\end{tabular}




\begin{tabular}{|c|c|c|c|c|c|c|}
\hline & \multicolumn{6}{|c|}{ VELOCIDADE OESTE MENSAL } \\
\hline & Nível 1 & Nível 2 & Nível 3 & Nível 4 & Nível 8 & Nível 11 \\
\hline \multirow{43}{*}{ 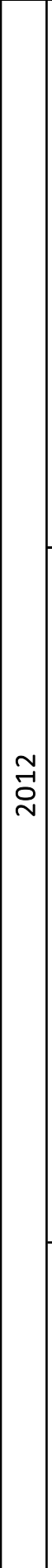 } & 04/06/2012 02:35 & 03/06/2012 01:35 & 03/06/2012 05:55 & 05/06/2012 21:15 & & \multirow{15}{*}{\begin{tabular}{|l} 
08/06/2012 02:35 \\
22/06/2012 07:55
\end{tabular}} \\
\hline & 05/06/2012 01:35 & 03/06/2012 02:35 & |05/06/2012 19:55 & 06/06/2012 15:55 & & \\
\hline & 06/06/2012 02:35 & 04/06/2012 02:15 & 07/06/2012 05:15 & 07/06/2012 05:15 & & \\
\hline & 08/06/2012 02:35 & 04/06/2012 02:55 & 07/06/2012 05:55 & \multirow[t]{12}{*}{ 18/06/2012 11:55 } & & \\
\hline & 09/06/2012 01:05 & 04/06/2012 21:35 & 11/06/2012 09:55 & & & \\
\hline & 10/06/2012 02:45 & 05/06/2012 02:55 & 26/06/2012 06:35 & & & \\
\hline & |16/06/2012 02:45 & 07/06/2012 05:55 & 28/06/2012 09:55 & & & \\
\hline & 17/06/2012 03:45 & 08/06/2012 02:15 & \multirow[t]{8}{*}{ 28/06/2012 11:15 } & & & \\
\hline & 17/06/2012 04:35 & 08/06/2012 04:15 & & & & \\
\hline & 20/06/2012 04:05 & |10/06/2012 03:15 & & & & \\
\hline & 25/06/2012 03:25 & 11/06/2012 09:55 & & & & \\
\hline & 27/06/2012 03:15 & 12/06/2012 03:15 & & & & \\
\hline & & $15 / 06 / 201204: 15$ & & & & \\
\hline & & 24/06/2012 02:55 & & & & \\
\hline & & 26/06/2012 06:35 & & & & \\
\hline & 06/07/2012 13:45 & 02/07/2012 03:15 & 06/07/2012 13:55 & 06/07/2012 14:35 & \multirow{19}{*}{\begin{tabular}{|l|} 
15/07/2012 05:15 \\
$28 / 07 / 2012 ~ 13: 15$
\end{tabular}} & \\
\hline & 06/07/2012 13:55 & 06/07/2012 14:15 & 13/07/2012 09:55 & 14/07/2012 10:35 & & \\
\hline & 06/07/2012 14:05 & 07/07/2012 10:15 & 14/07/2012 10:35 & 28/07/2012 10:35 & & \\
\hline & 07/07/2012 10:15 & 13/07/2012 09:55 & 14/07/2012 11:55 & 28/07/2012 14:35 & & \\
\hline & |09/07/2012 03:45 & 14/07/2012 12:15 & 14/07/2012 12:35 & \multirow[t]{15}{*}{ 29/07/2012 19:55 } & & \\
\hline & |13/07/2012 09:45 & 28/07/2012 09:35 & 28/07/2012 11:15 & & & \\
\hline & 14/07/2012 12:05 & 28/07/2012 09:55 & 28/07/2012 13:55 & & & \\
\hline & |16/07/2012 02:15 & 28/07/2012 10:35 & 29/07/2012 01:15 & & & \\
\hline & 23/07/2012 02:25 & 28/07/2012 10:55 & \multirow[t]{11}{*}{ 29/07/2012 19:55 } & & & \\
\hline & 28/07/2012 09:35 & 28/07/2012 13:55 & & & & \\
\hline & 28/07/2012 09:45 & 29/07/2012 01:15 & & & & \\
\hline & 28/07/2012 10:15 & 29/07/2012 19:15 & & & & \\
\hline & 28/07/2012 10:25 & 29/07/2012 19:35 & & & & \\
\hline & 28/07/2012 13:45 & \multirow[t]{6}{*}{ 29/07/2012 19:55 } & & & & \\
\hline & 28/07/2012 14:05 & & & & & \\
\hline & 29/07/2012 01:15 & & & & & \\
\hline & |29/07/2012 03:15 & & & & & \\
\hline & 29/07/2012 19:35 & & & & & \\
\hline & 29/07/2012 19:45 & & & & & \\
\hline & 06/08/2012 14:35 & 06/08/2012 14:35 & 05/08/2012 06:35 & 06/08/2012 14:35 & \multirow[t]{9}{*}{$20 / 08 / 201213: 15$} & \multirow[t]{9}{*}{ 08/08/2012 02:35 } \\
\hline & |12/08/2012 04:15 & 12/08/2012 04:15 & 06/08/2012 14:35 & 14/08/2012 01:15 & & \\
\hline & |13/08/2012 01:35 & 13/08/2012 02:15 & 20/08/2012 09:55 & 20/08/2012 10:35 & & \\
\hline & 14/08/2012 00:55 & 14/08/2012 00:15 & 20/08/2012 11:15 & 20/08/2012 11:55 & & \\
\hline & 14/08/2012 01:05 & $14 / 08 / 201200: 55$ & \multirow[t]{5}{*}{ |25/08/2012 11:15 } & & & \\
\hline & 19/08/2012 02:55 & 14/08/2012 01:15 & & & & \\
\hline & |20/08/2012 09:45 & 20/08/2012 10:55 & & & & \\
\hline & 20/08/2012 09:55 & 20/08/2012 11:15 & & & & \\
\hline & $20 / 08 / 201210: 55$ & $25 / 08 / 201210: 35$ & & & & \\
\hline
\end{tabular}




\section{REFERÊNCIAS BIBLIOGRÁFICAS}

ADELI, H.; GHOSH-DASTIDAR, S. (2004). Mesoscopic-Wavelet freeway work zone flow and congestion feature extraction model. Journal of Transportation Engineering, v.130, n. 1, 94-103, 2004. Disponível em: <https://trid.trb.org/view.aspx?id=686686>.

ADELI, H.; SAMANT, A. (2000). An adaptive conjugate gradient neural network-Wavelet model for traffic incident detection. Computer-Aided Civil and Infrastructure Engineering, v. 15, n. 4, p. 251-260, 2000. DOI: 10.1111/0885-9507.00189.

ARKIAN, H. R.; ATANI, R. E., POURKHALILI, A.; Kamali, S. (2014). Cluster-based traffic information generalization in Vehicular Ad-hoc Networks. Vehicular communications, v. 1, n. 4, p. 197-207, 2014. DOI: 10.1016/j.vehcom.2014.08.003.

ARTESP (2014). Anexo 05 - Serviços correspondentes a funções operacionais. Agência Reguladora de Serviços Públicos de Transporte do Estado de São Paulo. 51 p., 2015. Disponível em: <http://www.artesp.sp.gov.br/Media/Default/Rodovias/ppp Tamoios/05-Servi\%C3\%A7os\%20Correspondentes\%20a\%20Fun\%C3\%A7\%C3\% B5es\%200peracionais\%20 Final .pdf>. Acesso em: 16 fev. 2017.

AUNET, B. (2000). Wisconsin's Approach to Variation in Traffic Data. Report, Wisconsin Departament of Transportation, Madison, Wisconsin, EUA. Disponível em: <https://ntl.bts.gov/lib/10000/10900/10982/051ppr.pdf>. Acesso em: 29 out. 2016.

BARBOSA, A. C. B.; BLITZKOW, D. (2008). Ondaletas: Histórico e Aplicação. 39p. Apostila. Instituto de Astronomia, Geofísica e Ciências Atmosféricas. Universidade de São Paulo, SP. Disponível em: <http://sites.poli.usp.br/ptr/ltg/FTP/Apostila Ondaletas \%20MSc.Augusto Barbosa\&Dr.Denizar Blitzkow.pdf>. Acesso em: 2 fev. 2015.

BETHONICO, F. C. (2016). Calibração de simuladores microscópicos de tráfego através de medidas macroscópicas. Dissertação (Mestrado) - Escola de Engenharia de São Carlos, Universidade de São Paulo, São Carlos. Disponível em: <http://www.teses.usp.br/teses/disponiveis/18/18144/tde-18072016-135825/ pt-br.php>.

BONNESON, J. A. (1987). Traffic Volume Adjustments for Impact Analysis. ITE Journal, abril/1987, p. 43-46. Disponível em: <http://citeseerx.ist.psu.edu/viewdoc/down

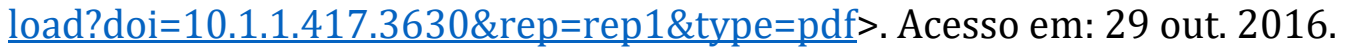

BOTO-GIRALDA, D.; DÍAS-PERNAS, F. J.; GONZÁLEZ-ORTEGA, D.; DÍEZ-HIGUERA, J. F.; ANTÓN-RODRÍGUEZ, M.; MARTÍNEZ-ZARZUELA, M.; TORRE-DÍEZ, I. (2010). Wavelet-Based Denoising for Traffic Volume Time Series Forecasting with Self- 
Organizing Neural Networks. Computer-Aided Civil and Infrastructure Engineering, v. 25, n. 7, p. 530-545, 2010. DOI: 10.1111/j.1467-8667.2010.00668.x.

CASTRO-NETO, M.; JEONG, Y. S.; JEONG, M. K.; HAN, L. D. (2009) Online-SVR for short-term traffic flow prediction under typical and atypical traffic conditions. Expert systems with applications, v. 36, n. 3, p. 6164-6173, 2009. DOI: 10.1016/j.eswa.2008.07.069.

CET (1982). Pesquisa e Levantamentos de Tráfego. Boletim Técnico 31. Org. Eduardo Alcântara Vasconcelos. Companhia de Engenharia de Tráfego de São Paulo. São Paulo. Disponível em: <http://www.cetsp.com.br/media/65280/bt31$\% 20$ pesquisa $\% 20 \mathrm{e} \% 20$ levantamento $\% 20 \mathrm{de} \% 20$ trafego-parte 01 .pdf $>$. Acesso em: 29 out. 2016.

CHUNG, E. (2003). Classification of traffic pattern. Proc. of the $11^{\text {th }}$ World Congress on ITS, p. 687-694, 2003. Disponível em: <https://www.researchgate.net/profile/Edward Chung/publication/229015078 Classification of traffic pattern/links/0c960529e459049c62000000.pdf>.

CUNHA, A. L. B. N. (2007). Avaliação do Impacto da Medida de Desempenho no Equivalente Veicular de Caminhões. Dissertação (Mestrado) - Escola de Engenharia de São Carlos, Universidade de São Paulo, São Carlos. Disponível em: $<$ http://www.teses.usp.br/teses/disponiveis/18/18144/tde-27112007094400/pt-br.php>.

CUNHA, A. L. B. N.; SETTI, J. R. A. (2008). Classificação de caminhões através de agrupamento por análise de cluster. XXII Congresso de Pesquisa e ensino em Transportes ANPET Fortaleza, CE, p. 1447-1459.

CUNHA, A. L. B. N. (2013) Sistema automático para obtenção de parâmetros de tráfego veicular a partir de imagens de vídeo usando OpenCV. Tese (Doutorado) - Escola de Engenharia de São Carlos, Universidade de São Paulo, São Carlos. Disponível em: $<$ http://www.teses.usp.br/teses/disponiveis/18/18144/tde-1911201365611/pt-br.php>.

DAUBECHIES, I. (1992). Ten Lectures on Wavelets. Philadelphia, PA, EUA: Society for Industrial and Applied Mathematics, 1992. ISBN 0-89871-274-2.

DEMARCHI, S. H. (2000). Influência dos veículos pesados na capacidade e nível de serviço de rodovias de pista dupla. 166 p. Tese (Doutorado) - Escola de Engenharia de São Carlos, Universidade de São Paulo, São Carlos, SP.

DIAS, M. H. C. (2003) Estimação das respostas do canal real de propagação rádio-móvel nos domínios espacial e temporal. Tese (Doutorado) - Pontifícia Universidade Católica do Rio de Janeiro, Rio de Janeiro.

DICIONÁRIO PRIBERAM DA LÍNGUA PORTUGUESA (2017). “anomalia”, 2008-2017. Disponível em: <https://www.priberam.pt/dlpo/anomalia>. Acesso em: $13 \mathrm{fev}$. 2017. 
DNIT (2006). Manual de Estudos de Tráfego. Departamento Nacional de Infraestrutura de Transportes. Instituto de Pesquisas Rodoviárias. Rio de Janeiro, RJ. Disponível em: Disponível em: <http://www1.dnit.gov.br/arquivos internet/ipr/ipr new/ manuais/manual estudos trafego.pdf>. Acesso em: 15 jan. 2015.

DONOHO, D. L.; JOHNSTONE, I. M. (1994). Ideal spatial adaptation by Wavelet shrinkage. Biometrika, v. 81, n. 3, p. 425-455, 1994. D0I: 10.2307/2337118.

DONOHO, D. L.; JOHNSTONE, I. M. (1995). Adapting to unknown smoothness via Wavelet shrinkage. Journal of the American Statistical Association, v. 90, n. 432, p. 1200-1224, 1995. DOI: $10.2307 / 2291512$.

FARIA, R. R. A. (1997) Aplicação de Wavelets na análise de gestos musicais em timbres de instrumentos acústicos tradicionais. Dissertação (Mestrado) - Escola Politécnica, Universidade de São Paulo, São Paulo. Disponível em: <http://www.teses.usp.br/teses/disponiveis/3/3142/tde-18072013-104904/ptbr.php>. Acesso em 7 out. 2015.

FUGAL, D. L. (2009). Conceptual Wavelets in digital signal processing: an in-depth, practical approach for the non-mathematician. Space \& Signals Technical Pub., 2009.

GABOR, D. (1946) Theory of communication. Journal of the Instituion of Electrical Engineers, v. 93, n 26, p. 429-4414, 1946. Disponível em: <http://genesis.eecg.toronto.edu/gabor1946.pdf>. Acesso em: 18 dez. 2016.

GHOSH, B.; BASU, B.; O'MAHONY, M. (2006). Analysis of trend in vehicular traffic flow data by Wavelets. IEE Irish Signals and Systems Conference, Dublin, p. 415-419, 2006. Disponível em: < http://ieeexplore.ieee.org/document/4123937/>.

GHOSH, B.; BASU, B.; O’MAHONY, M. (2010). Random Process Model for Urban Traffic Flow Using a Wavelet-Bayesian Hierarchical Technique. Computer-Aided Civil and Infrastructure Engineering, v. 25, n. 8, p. 613-624, 2010. DOI: 10.1111/j.14678667.2010.00681.x.

GHOSH-DASTIDAR, S.; ADELI, H. (2003). Wavelet-clustering-neural network model for freeway incident detection. Computer-Aided Civil and Infrastructure Engineering, v.18, n. 5, 325-338, 2003. DOI: 10.1111/1467-8667.t01-1-00311.

GHOSH-DASTIDAR, S.; ADELI, H. (2006) Neural network-Wavelet microsimulation model for delay and queue length estimation at freeway work zones. Journal of Transportation Engineering, v. 132, n. 4, 331-341, 2006. DOI: 10.1061/(ASCE)0733947X(2006)132:4(331).

GUIDO, R. C. (2011). A note on practical relationship between filter coefficients and scaling and Wavelet functions of Discrete Wavelet Transforms. Applied Mathematics Letters, v 24, n. 7, p. 1257-1259. DOI: 10.1016/j.aml.2011.02.018. 
GUIDO, R. C.; SLAETS, J. F. W.; ALMEIDA, L. O. (2012). Processamento Digital de Sinais: Wavelets x Fourier. Revista Saber Eletrônica, n466, 20-24, Novembro/Dezembro 2012.

HAIR, J. F.; ANDERSON; R. E.; TATHAM, R. L.; BLACK, W. C. (2005). Análise Multivariada de Dados. 5aㅡ ed. Bookman Companhia Editora. Porto Alegre, Rio Grande do Sul, 593 p.

HOMBURGER, W. S.; HALL, J. S.; LOUTZENHEISER, R. C.; REILLY, W. R. (1996). Fundamentals of Traffic Engineering. Institute of Transportation Studies, University of California. Berkley, EUA.

IVAN, J. N.; ELDESSOUKI, W. M.; ZHAO, M.; GUO, F. (2002). Estimating Link Traffic Volumes by Month, Day of Week and Time of Day. Report JHR 02-287, Connecticut Departament of Transportation. University of Connecticut, EUA. Disponível em: http://trrjournalonline.trb.org/doi/10.3141/1522-01>. Acesso em: 13 fev. 2017.

JEONG, Y. S.; CASTRO-NETO; M.; JEONG, M. K.; HAN, L. D. (2011). A Wavelet-based freeway incident detection algorithm with adapting threshold parameters. Transportation Research Part C: Emerging Technologies, v. 19, n. 1, p. 1-19, 2011. DOI: 10.1016/j.trc.2009.10.005.

JIANG, X.; ADELI, H. (2004). Wavelet Packet-Autocorrelation Function Method for Traffic Flow Pattern Analysis. Computer-Aided Civil and Infrastructure Engineering, v. 19, n. 5, p. 324-337, 2004. DOI: 10.1111/j.1467-8667.2004.00360.x.

JIANG, X.; ADELI, H. (2005). Dynamic Wavelet neural network model for traffic flow forecasting. Journal of Transportation Engineering, v. 131, n. 10, p. 771- 779, 2005. DOI: 10.1061/(ASCE)0733-947X(2005)131:10(771).

KAPLAN, I. (2001). Applying the Haar Wavelet Transform to Times Series Information. Disponível em: <http://www.bearcave.com/misl/misl tech/Wavelets/haar.html\# NoiseFilters >. Acesso em: 12 jan. 2015.

KAUFMAN, L.; ROUSSEUW, P. J. (1990). Finding Groups in Data: An Introduction to Cluster Analysis. John Wiley \& Sons, Hoboken.

KARIM, A.; ADELI, H. (2002). Incident detection algorithm using Wavelet energy representation of traffic patterns. Journal of Transportation Engineering, v. 128, n. 3, p. 232-242, 2002. DOI: 10.1061/(ASCE)0733-947X(2002)128:3(232).

KARIM, A.; ADELI, H. (2003). Fast automatic incident detection on urban and rural freeways using Wavelet energy algorithm. Journal of Transportation Engineering, v. 129, n. 1, p. 57-68, 2003. Disponível em: <https://trid.trb.org/view.aspx?id=732331>.

KLEIN, L. (2001). Sensor Technologies and Data Requirements for ITS. Boston, Massachusetts, EUA. Artech House (Artech House ITS library). ISBN 9781580530774. 
KUMAR, I.; ZHALNIN, A.; KIM, A., BEAULIEU, L. J. (2016). Transportation and logistics cluster competitive advantages in the US regions: A cross-sectional and spatiotemporal analysis. Research in Transportation Economics, 2016. DOI: 10.1016/j.retrec.2016.07.028.

LAROCCA, A. P. C.; NETO, J. O. A.; TRABANCO, J. L. A.; BITTENCOURT, T. N. (2014). Monitoramento dinâmico de uma ponte de concreto com receptores GPS L1 - Etapas iniciais. $56^{\circ}$ Congresso Brasileiro do Concreto CBC 2014, Natal, RN.

MALLAT, S. G. (1989). A theory for multiresolution signal decomposition: The Wavelet representation. IEEE Transactions on Pattern Analysis and Machine Intelligence, $\mathrm{v}$. 11, n. 7, p. 674-693. Disponível em: <https://www.di.ens.fr/ mallat/papiers/ MallatTheory89.pdf>. Acesso em: 13 fev. 2017.

MAY, A. D. (1990). Traffic Flow Fundamentals. Prentice-Hall, Engleood Cliffs, New Jersey, EUA.

MEYER, Y. (1993). Wavelets and applications. SIAM, Journal on Applied Mathematics. Vol. $53, \mathrm{n}^{\circ} 1$, Philadelphia, EUA.

MOEN, B. A.; KOLLBAUM, J. A.; BONNESON, J. A.; MCCOY, P. T. (1993). Traffic data collection using a computerized data acquisition system. Transportation Research Record, n. 1412, 1993. Disponível em: <https://trid.trb.org/view.aspx?id=385050>.

MOHAN, D. M.; ASIF, M. T.; MITROVIC, N.; DAUWELS, J.; JAILLET, P. (2014). Wavelets on graphs with application to transportation networks. Intelligent Transportation Systems (ITSC), 2014 IEEE 17th International Conference on. IEEE, 2014. p. 17071712. Disponível em: <http://web.mit.edu/ jaillet/www/general/ITSC2014Wavelets-final.pdf $>$. Acesso em: 14 ago. 2015.

MORETTIN, P. A. (1999). Ondas e Ondaletas: da análise de Fourier à análise de ondaletas. São Paulo. Editora da Universidade de São Paulo, 272 p., 1999.

NALDI, M.; SALCEDO-SANZ, S.; CARRO-CALVO, L.; LAURA, L.; PORTILLA-FIGUERAS, A.; ITALIANO, G. F. (2013). A traffic-based evolutionary algorithm for network clustering. Applied Soft Computing, v. 13, n. 11, p. 4303-4319, 2013. DOI: doi.org/10.1016/j.asoc.2013.06.022.

OLIVEIRA, H. C. R. (2016) Proposta de redução da dose de radiação na mamografia digital utilizando novos algoritmos de filtragem de ruído Poisson. Dissertação (Mestrado) Escola de Engenharia de São Carlos, Universidade de São Paulo, São Carlos, 2016. Disponível em: <http://www.teses.usp.br/teses/disponiveis/18/18152/tde29032016-160603/pt-br.php>.

OLIVEIRA, M. V. T. (2004). A natureza dos padrões de variação espaço-temporal do volume veicular em ambiente urbano: estudo de caso em Fortaleza. Dissertação (Mestrado) Universidade Federal do Ceará, Fortaleza. Disponível em: <http://repositorio. ufc.br/bitstream/riufc/4903/1/2004 dis mvtoliveira.pdf>. 
OÑA, J.; LÓPEZ, G.; MUJALLI, R.; CALVO, F. J. (2013). Analysis of traffic accidents on rural highways using Latent Class Clustering and Bayesian Networks. Accident Analysis \& Prevention, v. 51, p. 1-10, 2013. DOI: 10.1016/j.aap.2012.10.016.

PIVA, F. J. (2015) Fatores de equivalência de veículos pesados em rodovias de pista dupla. Dissertação (Mestrado) - Escola de Engenharia de São Carlos, Universidade de São Paulo, São Carlos, 2015. Disponível em: < http://www.teses.usp.br/teses/ disponiveis/18/18144/tde-14082015-095803/pt-br.php>.

RAKHA, H.; AERDE, M. V. (1995). Statical Analysis of Day-to-Day Variations in Real-Time Traffic Flow Data. Transportation Research Board. The $75^{\text {th }}$ Annual Meeting, Washington, D.C., EUA. Disponível em: <https://trid.trb.org/view.aspx?id= 453104>. Acesso em: 03 nov. 2016.

ROESS, R. P.; MCSHANE, W. R.; PRASSAS, E. S. (1998). Traffic Engineering. Second Edition, Prentice Hall, New Jersey, EUA.

SÁBLON, V. I. B.; MENDEZ, L. R.; IANO, Y. A Transformada Wavelet no processamento e compressão de imagens. TCP Telecom, Centro Universitário UNISAL, Universidade de Campinas, Campinas, São Paulo.

SAMANT, A.; ADELI, H. (2000). Feature extraction for traffic incident detection using Wavelet transform and linear discriminant analysis. Computer-Aided Civil and Infrastructure Engineering, v. 15, n. 4, 241-250, 2000. DOI: 10.1111/08859507.00188.

SAMANT A.; ADELI, H. (2001). Enhancing neural network traffic incident - detection algorithms using Wavelets. Computer-Aided Civil and Infrastructure Engineering, v. 16, n. 4, 239-245, 2001. DOI: 10.1111/0885-9507.00229.

SECRETARIA DE TRANSPORTES DO ESTADO DE SÃO PAULO (2017). Infraestrutura Rodoviário. Governo do Estado de São Paulo, 2017. Disponível em: <http://www.transportes.sp.gov.br/infraestrutura/rodoviario.asp >. Acesso em: 16 fev. 2017.

SETTI, J. R. A. (2002) Tecnologia de Transportes. Material didático, 214 p. Universidade de São Paulo, Escola de Engenharia de São Carlos

SPINDOLA, R. C. M. R.; GRISALES, J. C. (2007). Ingenieria de Transito: Fundamentos y aplicaciones. 8aed. Alfaomega, Cay y Mayor y Asociados, Universidad del Valle. México, 2007. Disponível em: <https://pt.scribd.com/document/287369051/ Ingenieria-de-Transito-Fundamentos-y-Aplicaciones>. Acesso em: 28 out. 2016.

STATHOPOULOS, A.; KARLAFTIS, M. (2001). Temporal and Spatial Variations of RealTime Traffic Data in Urban Areas. Transportation Research Board, The $80^{\text {th }}$ Annual Meeting, Washington, D.C., EUA. DOI: 10.3141/1768-16. 
TENG, H.; QI, Y. (2003) Application of Wavelet technique to freeway incident detection. Transportation Research Part C: Emerging Technologies, v. 11, n. 3, p. 289-308, 2003. DOI: 10.1016/S0968-090X(03)00021-4.

THOMAS, T.; WEIJERMARS, W.; BERKUM, E. V. (2008). Variotions in urban traffic volumes. EJTJR European Journal of Transport and Infrastructure research, v.8, n.3, pg. 251263. Disponível em: <https://www.researchgate.net/publication/228900183 Variations in urban traffic volumes>. Acesso em: 13 fev. 2017.

TRB (2010). Highway Capacity Manual. Transportation Research Board, National Research Council, Whashington, D. C., EUA.

WEIJERMARS, W.; BERKUM, E. V. (2005). Analyzing highway flow patterns using cluster analysis. $8^{\text {th }}$ IEEE International Conference on Intelligent Transportation Systems, p.831-836, Vienna, Austria. Disponível em: <http://doc.utwente.nl/54970 /1/01520157.pdf>. Acesso em: 8 mar. 2016.

WRIGHT, T.; HU, P.; YOUNG, J.; LU, A. (1997). Variability in Traffic Monitoring Data. Final Sumary Report, Oak Ridge National Laboratory for the US Department of Energy, University of Tennessee-Knoxville, Tennessee, EUA. Disponível: <https://www.fhwa.dot.gov/ohim/flawash.pdf>. Acesso em: 28 out. 2016.

XIE, Y.; ZHANG, Y.; YE, Z. (2007) Short-Term Traffic Volume Forecasting Using Kalman Filter with Discrete Wavelet Decomposition. Computer-Aided 47 Civil and Infrastructure Engineering, v. 22, n. 5, p. 326-334, 2007. DOI: 10.1111/j.14678667.2007.00489.x.

ZHANG, M. (2016) Real-time Traffic Flow Prediction using Augmented Reality. Electronic Theses and Dissertations. Paper 5687. University of Windsor (2016). Disponível em:

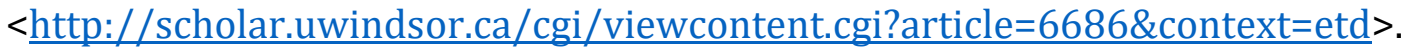
Acesso em: 17 fev. 2017.

ZHENG, Z.; AHNS, S.; CHEND, D.; LAVAL, J. (2011). Applications of Wavelet transform for analysis of freeway traffic: Bottlenecks, transient traffic, and traffic oscillations. Transportation Research Part B: Methodological, v.45, $\mathrm{n}^{\circ} 2$, p. 372-384. DOI: 10.1016/j.trb.2010.08.002.

ZHENG, Z.; WHASHINGTON, S. (2012). On selecting an optimal Wavelet for detecting singularities in traffic and vehicular data. Transportation Research Part C: Emerging Technologies, v. 25, p. 18-33. DOI: 10.1016/j.trc.2012.03.006.

ZHU, Y.; NINGBO, G.; WANG, J.; LIU, C. (2016). Study on traffic flow patterns identification of single intersection intelligent signal control. Procedia Engineering, v. 137, p. 452460, 2016. DOI: 10.1016/j.proeng.2016.01.280. 